
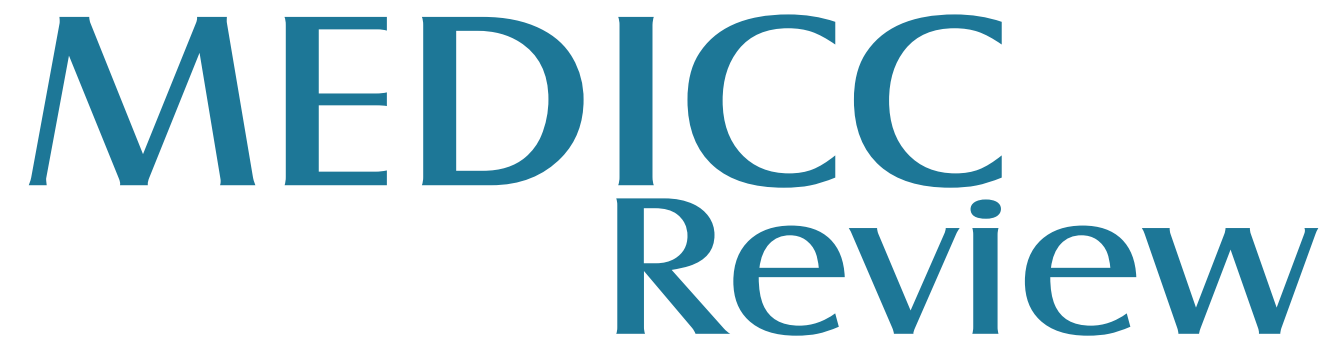

January 2021

Vol 23, No 1

Adverse Events Following
Immunization in Cuba

$\begin{array}{c:c}\text { Cuban Biotech's } & 01 \\ \text { Hepatitis Vaccines } & \end{array}$

Hypothermia for

Oxygen-Deprived Neonates

On COVID-19

Global Review of

Mother-to-Child Transmission

US-Cuba Collaboration

30

Cuban Genetics Studies

72
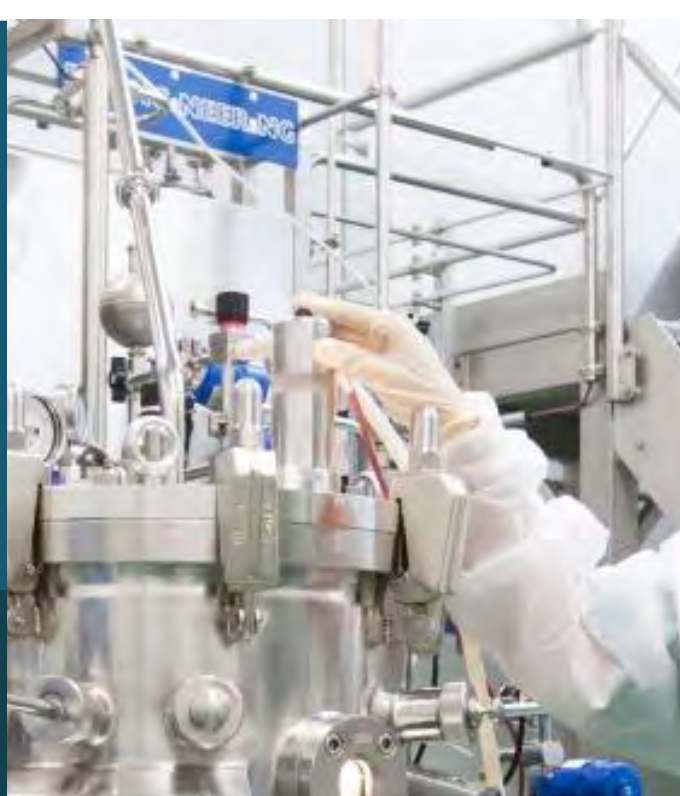

is
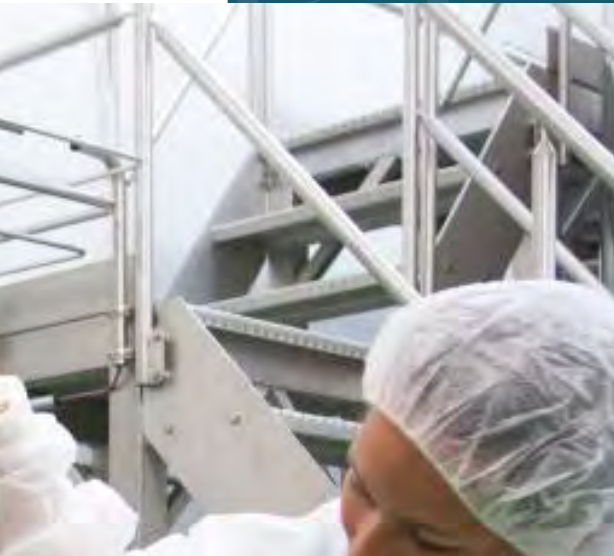


\section{PLANETARY HEALTH ANNUAL MEETING}

(1)

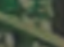

(

\section{APRIL 19-21, 2021}

Universidade de São Paulo, Brazil
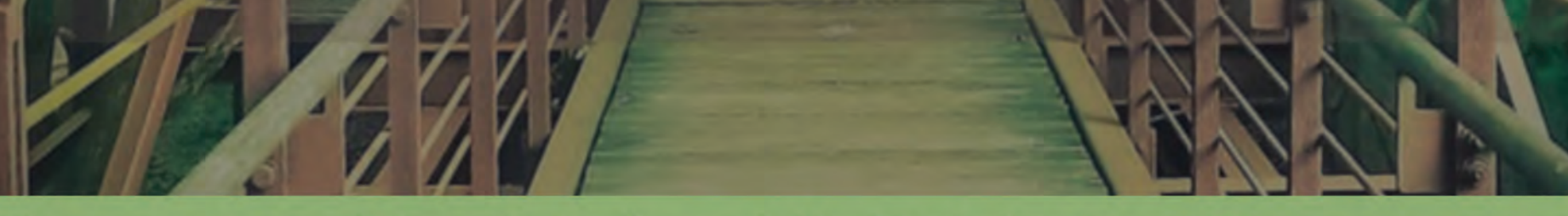

Planetary Health for All: Bridging Communities to Achieve the Great Transition

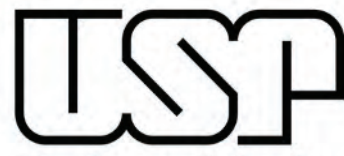
Universidade de São Paulo
P L A N E T A R Y H E A L T H A L L I A N C E planetaryhealthannualmeeting.com

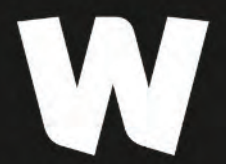

welloome 


\section{MED D}

\section{January 2021, Vol 23, No 1}

\section{EDITORIAL}

4 Build Back Better: Leadership for US-Cuba Health Cooperation

\section{ABOUT THE CONTRIBUTORS}

6

PEER REVIEWERS 2020

9

\section{LETTERS}

10 COVID-19 Control in a Havana Surgical Hospital

Julián F. Ruiz-Torres MD PhD, et al.

Dangers and Management of Obstructive Sleep Apnea Syndrome in COVID-19 Patients

Calixto Machado-Curbelo MD PhD FAAN

\section{CUBA'S WOMEN OF SCIENCE - INTERVIEW}

12 Researchers at Cuba's National Medical Genetics Center:

Pioneering Studies on COVID-19

Gail A. Reed MS

\section{INTERVIEW}

18 Cuba's Medical Team in the European Epicenter of COVID-19:

Carlos R. Pérez-Díaz MD MS PhD

Director, JoaquínAlbarrán Provincial Clinical-Surgical Hospital, Havana

Henry Reeve Medical Contingent Leader, Lombardy, Italy

Gisele Coutin-Marie MD MS and Conner Gorry MA

\section{POLICY \& PRACTICE}

21 Cuban Prophylactic and Therapeutic Vaccines for Controlling Hepatitis B Eduardo Pentón-Arias MD PhD and Julio C. Aguilar-Rubido PhD

\section{ORIGINAL RESEARCH}

$30 \quad$ Hypoxic Ischemic Encephalopathy in Units Reporting

to the Ibero-American Society of Neonatology Network:

Prevalence and Mortality

Fernando Domínguez-Dieppa MD PhD, et al.

Characterization of Adverse Events Following Childhood Immunizations in Pinar del Río, Cuba

Elba Cruz-Rodríguez MD MS, et al.

Urinary Metabolic Disorders Associated with Urolithiasis

in Cuban Pediatric Patients

Raymed A. Bacallao-Méndez MD MS, et al.

49 Short-term Tolerance of Nasally-Administered NeuroEPO in Patients with Parkinson Disease

MaritéGarcía-Llano MD, et al.

Evaluating Cerebral Perfusion in Alzheimer Patients and First-Degree Relatives: Lessons from Artemisa Province, Cuba

Yamilé Peña-Quián MD PhD, et al.
Non-Alcoholic Fatty Liver Disease in Cuba

Marlen I. Castellanos-Fernández MD PhD, et al.
Editor-in-Chief

C. William Keck MD MPH FACPM

Executive Editor

Gail Reed MS

Senior Editor, English Edition Caitlin Baird PhD

Senior Editor

Conner Gorry MA

Primary Issue Coordinator

Jorge Bacallao PhD DSc

Issue Coordinators

Alina Alerm MD MS

Lila Castellanos PhD DSc

Gisele Coutin MD MS

Esther María Fajardo MS

Editorial Associates

Anna Kovac

Annet Sánchez

Copy Editor

Carolyn Gorry

Communications Consultant

Elizabeth Sayre MA

Publishing \& Circulation

Aram Álvarez MFA

Silvia García

Yenny Leal

Translators

Pamela Boyle

Roxane K. Dow MA

Kathleen Vickery MA

MEDICC Review is indexed in:

MEDLINE $^{\circledR} /$ PubMed $^{\circledR}$

1) Clarivate Analytics

redalyc latindex

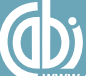

Global Health

Tropical Diseases Bulletin

EBSCO

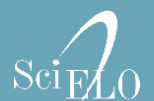

ELSEVIER

\section{MEDICC}

MEDICC Review is a unique open-access platform for Latin American and Caribbean praxis addressing today's critical interactions between human health, development of sustainable societies, and the health of our planet. Drawing upon the contributions of the region in social medicine, social movements, rich diversity and scientific prowess Latin America and Caribbean authors published in the journal can help fill gaps in thinking and evidence sorely needed to build a sustainable future and a hopeful legacy for future generations. We look forward to contributing to increased visibility for their work and to its positive impact on both regional integration and worldwide solutions.

MEDICC Review is published by MEDICC, a US nonprofit organization founded in 1997, based in Oakland, California, USA, and dedicated to US, Cuban and global health cooperation and equity.

MEDICC Review online (ISSN 1527-3172) is an openaccess publication: see our Creative Commons License online for details.

www.mediccreview.org - Copyright $\odot 2021$, MEDICC Review 


\section{MEDICC \\ Review}

\section{January 2021, Vol 23, No 1}

\section{REVIEW ARTICLE}

72 Congenital and Intrapartum SARS-CoV-2 Infection in Neonates:

Hypotheses, Evidence, and Perspectives

Gerardo R. Robaina-Castellanos MD PhD and

Solangel de la CaridadRiesgo- Rodríguez MD MS

\section{PERSPECTIVE}

84 Psychocardiology's Contributions to

Comprehensive Cardiovascular Care in Cuba

Teresa Rodríguez-Rodríguez MS PhD, et al.

\section{VIEWPOINT}

89 Cuba-US Collaboration: The Pandemic Imperative Roberto Cañete MD PhD and Kenneth W. Goodman PhD

90 Can Anti-Ribosomal Antibodies Improve Systemic Lupus Erythematosus Diagnosis? Elena Kokuina MD PhD

Comprehensive Surveillance Needed to Contain COVID-19

Saurabh RamBihariLal Shrivastava MD and

Prateek Saurabh Shrivastava MD

\section{ABSTRACTS \\ (3) Cuban Research in Current International Journals \\ (3) Special Abstracts Section COVID-19}

(3) Available online only

Cover photo: Production plant at the Molecular Immunology Center (CIM), Havana, Cuba. CIM produces the receptor-binding domain (RBD) of the coronavirus's spike protein that is included in the Soberana 01 and Soberana 02 vaccine candidates for COVID-19. Credit: E. Añé 
Neil Arya BASc MD CCFP FCFP

Director, Office of Global Health

Schulich School of Medicine and Dentistry

Western University, Canada

Rifat Atun MBBS MBA FRCGP FFPH FRCP

Professor of Global Health Systems

Director, Health Systems Cluster

Harvard University School of Public Health, USA

Michael Bird MSW MPH

Public Health Consultant, Kewa Pueblo Health Board

Urban Indian Health Commission

Albuquerque, New Mexico, USA

James Boex PhD MBA

Emeritus Professor of Medical Education

Univ. of Cincinnati College of Medicine, USA

Peter Bourne MD MA

Visiting Senior Research Fellow

Green Templeton College, University of Oxford, UK

Alfred Brann MD

Professor of Pediatrics

Emory University School of Medicine, USA

Jaime Breilh MD PhD MSc

Director, Health Department

Universidad Andina Simón Bolívar, Ecuador

Paulo M. Buss MD MPH

Director, FIOCRUZ Center for Global Health

Oswaldo Cruz Foundation, Brazil

Pastor Castell-Florit MD PhD DSc

Director, National School of Public Health, Cuba

José F. Cordero MD MPH

Patel Distinguished Professor of Public Health

Chair, Department of Epidemiology and Biostatistics

College of Public Health, University of Georgia, USA

Yamila de Armas MD

Professor, National School of Public Health, Cuba

Maria Cecilia de Souza Minayo MS PhD

Professor of Sociology

National School of Public Health, Brazil

Timothy De Ver Dye PhD MS MA MPA

Professor, OB-GYN and Pediatrics

Public Health Sciences and Medical Informatics

University of Rochester School of Medicine and

Dentistry, USA

Roger Downer PhD DSc FRSC MRIA

President Emeritus, University of Limerick, Ireland

Leith L. Dunn PhD

Senior Lecturer \& Head, Institute for Gender

\& Development Studies, Mona Unit

University of the West Indies, Jamaica

Paul C. Erwin MD DrPH

Dean, University of Alabama at Birmingham

School of Public Health, USA

Lowell Gerson PhD

Professor Emeritus of Family \& Community Medicine

Northeast Ohio Medical University, USA
Tee L. Guidotti MD, MPH, DABT

Consultant, Occupational \& Environmental Health and Medicine, Toronto, Canada

Jean Handy PhD

Associate Professor of Microbiology \& Immunology

University of North Carolina School of Medicine, USA

Barbara J. Hatcher PhD MPH RN FAAN

Associate Professor, George Mason University

College of Nursing \& Health Sciences, USA

Raúl Herrera MD PhD DSc

Distinguished Professor, Medical University of

Havana; Chair, National Nephrology Group, Cuba

Eve J. Higginbotham SM MD

Vice Dean of Diversity \& Inclusion, University of

Pennsylvania Perelmen School of Medicine, USA

Sharon K. Hull MD MPH

Founder and CEO

Metta Solutions, USA

C. William Keck MD MPH FACPM

Professor Emeritus, Family and Community

Medicine, Northeast Ohio Medical University, USA

Ann Marie Kimball MD MPH FACPM

Senior Consulting Fellow, Chatham House Royal

Institute of Foreign Affairs; Strategic Consultant in

Global Health, Rockefeller Foundation, USA

Barry Kistnasamy MBChB Mmed

Head, Occupational Health, Department of Health South Africa

Patrick Kuma-Aboagye MB-BCH MPH

Deputy Director and Head

Reproductive and Child Health Department

Ghana Health Service, Ghana

Albert Kuperman PhD

Emeritus Associate Dean for Medical Education

Albert Einstein College of Medicine of Yeshiva

University, USA

Margaret Larkins-Pettigrew MD MEd MPPM Assistant Professor, Global Health/OB-GYN and Reproductive Biology, Univ Hospitals, Case Medica Center \& MacDonald Women's Hospital, USA

Linh Cu Le MD MSc PhD

Associate Professor of Public Health

Vinmec International Hospital JSC, Viet Nam

Noni MacDonald MD MSc FRCPC FCAHS

Professor of Pediatrics and Computer Science

Dalhousie University, Canada

\section{Pedro Más MD PhD DSc}

Full Professor, Medical University of Havana Senior Researcher, Pedro Kourí Tropical Medicine Institute, Cuba

Nancy A. Myers, PhD

Vice President, Leadership and System Innovation Center for Health Innovation, American Hospital

Association, USA
Daniel J. Ncayiyana MD FACOG

Emeritus Professor, University of Cape Town South Africa

André-Jacques Neusy MD DTM\&H

Senior Director, Training for Health Equity Network THEnet, USA

F. Javier Nieto MD PhD

Dean, College of Public Health \& Human Sciences

Oregon State University, USA

Peter Orris MD MPH

Professor and Chief, Occupational \& Environmental

Medicine, University of Illinois Hospital and Health

Sciences System, USA

Jorge Pérez MD MS

Adviser to the Director and Full Professor

Pedro Kourí Tropical Medicine Institute, Cuba

Patricia Rodney PhD MPH RN

Partners in Health, Education and Development, USA

María Isabel Rodríguez MD

Health and Education Advisor to the President of the Republic, El Salvador

F. Douglas Scutchfield MD FACPM FAAP Peter P. Bosomworth Professor of Health Services

Research and Policy, University of Kentucky

Colleges of Public Health and Medicine, USA

Stuart G. Shanker DPhil MA

Distinguished Research Professor of Philosophy and Psychology; Director, Milton \& Ethel Harris Research Initiative, York University, Canada

Augusto Sola MD

Neonatologist, St Jude's Hospital and Children's

Hospital, Orange County, California, USA

Ronald St. John MD MPH

President, St. John Public Health Consulting International, Canada

Pedro Urra MS

Full Professor, University of Havana, Cuba

Pedro A. Valdés-Sosa MD PhD

Deputy Director, Neuroscience Center, Cuba

Luis F. Vélez MD MPH PhD

Director, Program Development, Evaluation

and Quality Improvement

DePelchin Children's Center, USA

Howard Waitzkin MD PhD FACP

Distinguished Professor Emeritus

University of New Mexico, USA

Suwit Wibulpolprasert MD

Senior Advisor on Disease Control

Ministry of Public Health, Thailand

Professor Paul Worley

Emeritus Professor of Rural Medical Education

Prideaux Centre for Research in Health Professions

Education, Flinders University, Australia
MEDICC Review (ISSN 1555-7960) is published quarterly by MEDICC (Medical Education Cooperation with Cuba) in January, April, July \& October.

Submissions MEDICC Review publishes original peer-reviewed articles by Cuban and international authors. Send letters to editors@mediccreview.org Guidelines for authors at www.mediccreview.org.

Open Access MEDICC Review online (ISSN 1527-3172) is an Open Access publication; articles may be reproduced with proper attribution under Creative Commons License (www.mediccreview.org).
Advertising at www.mediccreview.org or write admin@mediccreview.org for ad swaps. Acceptance of advertising does not imply endorsement.

Ethics Opinions expressed in articles and letters in MEDICC Review are the views of their authors, and do not necessarily reflect those of the Editors, publishers or Editorial Board. Responsibility for originality of manuscripts, free of plagiarism or fraud, rests with the authors. MEDICC Review will retract any article found to contain plagiarized or fraudulent content.

Reprints Articles in the 'Reprints' section of MEDICC Review print edition may be reproduced or distributed only authorized by the original copyright holder. 


\section{Build Back Better: Leadership for US-Cuba Health Cooperation}

As members of the global public health community, we thought the outgoing Trump administration in Washington could not do much else to shock us. But when President Biden revealed that his predecessor had left him not with a bad plan to tackle the COVID-19 pandemic - but with no plan at all—we were appalled, contemplating the nearly 100 million infected throughout the world, and the over 400,000 dead in the USA alone. It is no wonder that Dr Anthony Fauci, Biden's chief medical advisor and member of the coronavirus task force, told the press that he felt liberated now that science was back in the driver's seat. "Everything we do," he said of the new administration's approach, "is based on science and evidence."

If that is the case, then the US president's coronavirus task force should heed advice on the global cooperation urgently needed to stem the pandemic, which goes beyond staying in $\mathrm{WHO}$, and listen to Dr Fauci's own advice on health cooperation with Cuba. In MEDICC Review's April 2018 issue, he advocated for just that after visiting Havana, writing with colleagues: "(Joint) infectious disease research can provide a model for other US-Cuba scientific cooperation."

The Biden-Harris administration already has a framework for such collaboration in the two Memoranda of Understanding signed during the Obama presidency by US Secretary of Health and Human Services, Silvia Mathews Burwell and Cuban Minister of Public Health Roberto Morales Ojeda. The two documents provide a useful, practical blueprint for initiating cooperation beneficial to people in both countries and, indeed, the world.

The first MOU, signed in June 2016, built on the two governments' commitment to "deepen public health cooperation, focusing on communicable diseases including those caused by arboviruses such as Zika, dengue and chikungunya; as well as on the prevention and treatment of chronic non-communicable diseases, such as cancer."

The agreement intended to strengthen "collaboration in these and other scientific and health areas." It noted that first efforts would be aimed at a health cooperation strategy "to address shared priorities such as: communicable diseases, principally arboviruses, including Zika, dengue, and chikungunya; non-communicable diseases, such as cancer, diabetes, hypertension, mental health and substance abuse disorders, and others; healthcare systems and public health management; quality management and patient safety systems in hospitals and outpatient settings; exchange of health professionals; health security and international health regulations; public health emergency preparedness and response; biomedical research and development, clinical trials, and medical product regulation; health information technology and the flow of health data; human services; and aging." The second MOU, signed in October the same year, proposed collaboration on cancer control, including research, surveillance, monitoring and evaluation.

However, to clear the way to revitalizing these agreements-which were never rescinded in their entirety as far as we know-means stripping away some 200 additional restrictions on Cuba that were added to already onerous sanctions during the Trump-Pompeo era. These include everything from hindering remittances intended for Cuban families to blocking oil and other shipments, torpedoing Cuban small businesses with added banking restrictions and putting all Cuban hotels off-limits to US travelers. In a bizarre turn of events, with just a few days left in his term and facing a second impeachment-this time for inciting a white supremacist mob that overran the US Capitol-Trump, mindless of the irony, named Cuba a "state sponsor of terror," a designation with far-reaching effects. Currently, Cuban health and government authorities are forced to grapple not only with the pandemic itself but also with the economic and social fallout of this draconian move whose roots are imbedded in Florida's rightwing, not in Cuba.

MEDICC Review's publisher, MEDICC, decried the eleventh-hour decision, comparing Cuba's significantly better record of confronting the pandemic with the Trump administration's COVID-19 denialism, and emphasized the "thousands of Cuban health professionals volunteering to fight COVID-19 in 40 countries," while the White House was clinging to 'vaccine nationalism'. The rates of disease and death in the two countries beg comparison. To date, The New York Times tracker shows the United States with 7549 cases per 100,000 population, compared to 182 cases per 100,000 population in Cuba; the USA at 126 deaths per 100,000, compared to just 2 per 100,000 population in Cuba.

Sharing experiences, research and effective strategies to tackle the pandemic is why MEDICC Review is engaging in a series of US-Cuba virtual forums, involving experts in both countries. We held the first on December 16, 2020, co-sponsored by the University of Minnesota and organized jointly with its Schools of Nursing and Public Health. University President Joan Galen and Minnesota Senator Amy Klobuchar participated, as did specialists in epidemiology, clinical care and vaccine research.

"With so much at stake, we need to build on partnerships like this one to ensure that our medical communities are benefiting from the most up-to-date and best practices for treating and preventing coronavirus, especially given the relatively low number of cases and deaths in Cuba." - Sen. Amy Klobuchar of Minnesota closing the MEDICC Review-University of Minnesota virtual forum, December 16, 2020

COVID-19 is highlighted in this issue of MEDICC Review and featured in a Cuba's Women of Science roundtable with investigators at the National Medical Genetics Center. Their preliminary immunogenetics findings on SARS-CoV-2 viral behavior in Cuba also have implications for the four Cuban COVID-19 vaccine candidates now in clinical trials. We provide continuing coverage of Cuban health professionals' experience treating COVID-19 patients abroad in an interview with Dr Carlos R. Pérez, who headed the team that served in Lombardy, Italy at the height of the epidemic there. Robaina's global literature review focuses on COVID-19's potential for mother-to-child transmission; and Ruiz details the response of a Havana surgical hospital to the disease. Drs Saurabh and 
Shrivastava issue an appeal for enhanced disease surveillance worldwide in their Viewpoint.

As COVID-19 vaccine production and distribution are ramped up worldwide-raising added questions of equity and vaccine hesitancy-Cruz takes the long view on vaccine-attributable adverse events in Cuba's childhood immunization program for 13 diseases, carried out in the context of a universal health system.

Cuban biotech products are the subject of two original research papers: one on hepatitis B preventive and therapeutic vaccines, and another on nasally-administered Cuban erythropoietin for patients with Parkinson disease. Additional articles treat issues important for Alzheimer and lupus disease research, as well as non-alcoholic fatty liver disease and urolithiasis in children and adolescents. And a Perspective reviews experience with psychological care for heart patients.

Finally, an important paper looks at an underutilized therapy to save the lives of newborns suffering from hypoxic ischemic encephalopathy in Latin America.

In this issue, we also take the opportunity to thank our peer reviewers for their contribution to the journal in 2020.
We are not yet prepared to surrender to the idea that global scientific collaboration is impossible; that politics will invariably undermine research and development; that selfishness will always prevail over symbiosis.

-Viewpoint by Robert Cañete, Medical University of

Matanzas, Cuba and Kenneth W. Goodman, University of Miami Miller School of Medicine

Moving into 2021-when overarching concerns of climate, planetary health and human survival must command our attention-we are struck by the lessons unlearned and unheeded by those who would lead us. In the case of the United States government and its over 60 years of nearly unbroken hostility towards Cuba, foregoing cooperation, we say enough. Basta. End the sanctions on Cuba. It's not too late to collaborate: COVID-19 has provided the urgency. Now all it takes is leadership. President Biden? - 1/

\section{The Editors}




\section{About the Contributors}

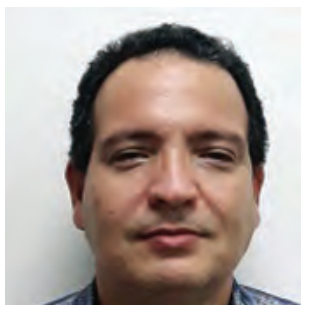

Julio C. Aguilar-Rubido PhD Biochemist with a doctorate in biology. $\mathrm{Dr}$ Aguilar is affiliated with the Hepatitis B Group in the Vaccine Department at the Biomedical Research Division of the Genetic Engineering and Biotechnology Center in Havana, Cuba, where he is the main specialist on the Hepatitis $B$ Vaccine Project. He is the lead author on seven research projects awarded the Cuban Academy of Science's Annual Prize.
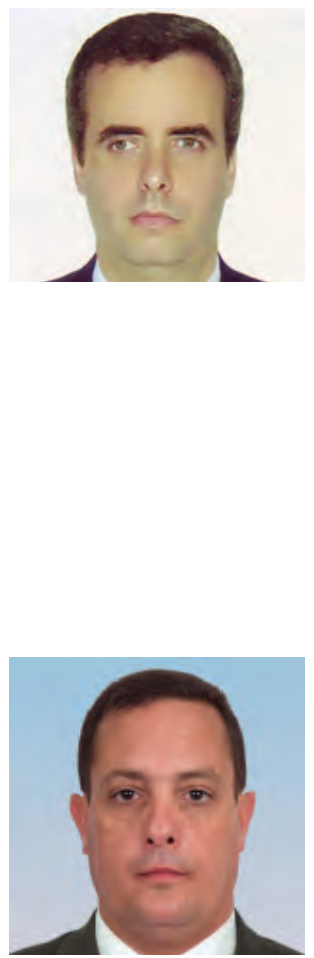

Raymed A. Bacallao-Méndez MD MS Nephrologist with master's degrees in emergency medicine and diagnostic methods. Dr Bacallao heads the Teaching and Research Department at the Dr Abelardo Buch López Nephrology Institute, Havana, Cuba, where he is associate researcher and associate professor. He was twice awarded Cuba's National Health Prize. His current research focuses on the pathology, prevention and treatment of urinary stones; renal disease in Central America; and COVID-19 kidney complications.

\section{Roberto Cañete MD PhD}

Physician specializing in microbiology with a master's degree in parasitology and a doctorate in medical sciences. Dr Cañete is full professor and senior researcher at the Medical University of Matanzas, Cuba, where he also chairs the bioethics committee. He is a member of the American Society of Bioethics and Humanities.

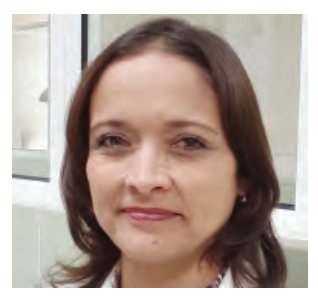

Marlen Ivón Castellanos-Fernández MD PhD Gastroenterologist with a doctorate in medical sciences. Dr Castellanos chairs Cuba's National Gastroenterology Group and is full professor and senior researcher at the Gastroenterology Institute. Her research concentrates on hepatology, particularly fatty liver disease, viral and autoimmune hepatitis, and hepatic cirrhosis. In 2011, she was awarded Cuba's National Health Prize.

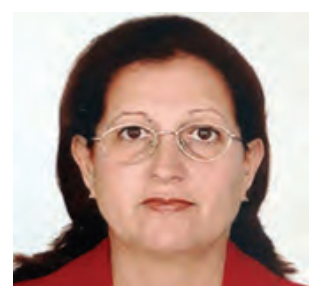

Elba Cruz-Rodríguez MD MS

Physician specializing in family medicine and epidemiology, with a master's degree in epidemiology. Dr Cruz is assistant professor and adjunct researcher in the Epidemiological Surveillance and Research Department at the Pedro Kourí Tropical Medicine Institute, Havana, Cuba. Her research has historically centered on pediatric diarrheal disorders with a change of focus during the COVID-19 pandemic to asymptomatic SARS-CoV-2 infection. In 2020, she was awarded the Cuban Academy of Science's Annual Prize for her work on vaccine safety.

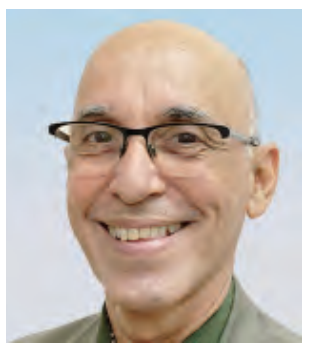

Fernando Domínguez-Dieppa MD PhD Neonatologist with a doctorate in medical sciences. Dr Domínguez is full professor and senior researcher at the Medical University of Havana, Cuba, and head of the neurodevelopment section at the Ramón González Coro Women's Hospital. He is a member of the National Ethics Commission of the Cuban Ministry of Public Health (MINSAP) and has volunteered internationally as a physician in the Democratic Republic of the Congo.

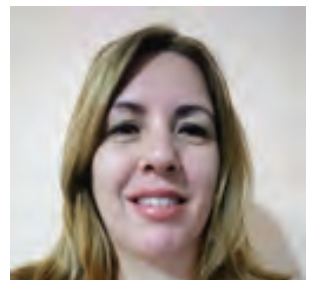

Marité García-Llano MD MS

Physician with dual specialties in family medicine and neurology, and a master's degree in emergency medicine. Dr García heads the Neurology Department at the Abel Santamaría Cuadrado Provincial Clinical-Surgical Hospital in Pinar del Río, Cuba, where her research focuses on Parkinson disease and the neurological impact of arbovirus infections. 


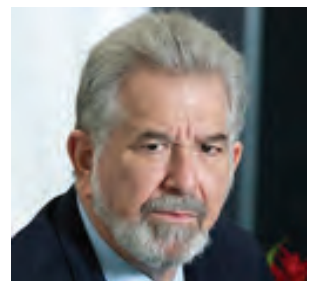

Kenneth W. Goodman PhD

Bioethicist. Dr Goodman is founder and director of the University of Miami Miller School of Medicine's Institute for Bioethics and Health Policy, a $\mathrm{PAHO} / \mathrm{WHO}$ Collaborating Center. $\mathrm{He}$ is also professor of medicine at the University of Miami. His research focuses on the intersection of medical ethics and information technology. $\mathrm{Dr}$ Goodman chairs the Ethics Committee of the American Medical Informatics Association, and was co-founder of its Ethical, Legal and Social Issues Working Group.

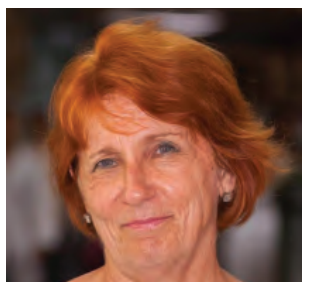

\section{Elena Kokuina MD PhD}

Immunologist. Dr Kokuina is full professor and senior researcher at the Hermanos Ameijeiras ClinicalSurgical Teaching Hospital in Havana, Cuba, and adjunct faculty at the Medical University of Havana. She has published extensively on immunologic diagnosis of autoimmune diseases. With numerous awards for her achievements including recognition from the Cuban Academy of Sciences, her current research addresses the clinical value of autoantibodies in autoimmune disease.

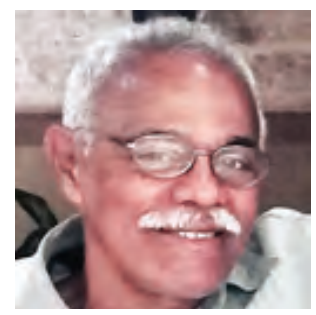

\section{Eduardo Pentón-Arias MD PhD} Physician specializing in clinical biochemistry with a doctorate in biology. Dr Pentón is senior researcher and adjunct professor at the Latin American School of Medicine and the Genetic Engineering and Biotechnology Center (CIGB) in Havana, Cuba. He is a member of CIGB's Experts Committee and Scientific Council. His early work on interferons has earned him the 'Founder of Cuban Biotechnology' distinction, and he currently serves on the Editorial Board of Biotecnología Aplicada.

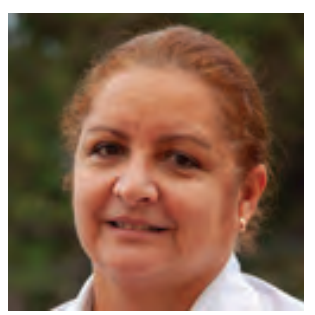

Yamilé Peña-Quián MD PhD

Physician specializing in internal medicine and nuclear medicine, with a doctorate in medical sciences. Dr Peña is senior researcher in the Clinical Research Department at the Isotopes Center in Havana, Cuba. Her research focuses on immunotherapy and immunoscintigraphy and she has been the principal investigator on nine projects on advanced techniques in nuclear medicine since 2001 . She has headed the Clinical Research Department at the Cuban Isotopes Center (CENTIS) since 2003.

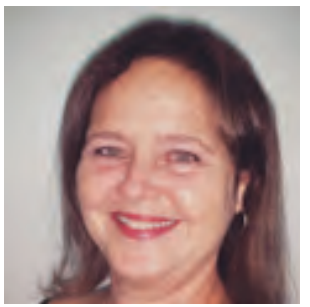

\section{Solangel de la Caridad Riesgo-} Rodríguez MD MS

Physician with dual specialties in pediatrics and family medicine and a master's degree in comprehensive child health. Dr Riesgo is full professor and associate researcher in the Teaching and Research Department at the Medical University of Matanzas, Cuba where she also chairs the Pediatrics Department.

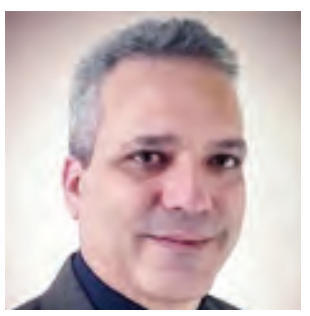

Gerardo R. Robaina-Castellanos MD PhD Neonatologist with a doctorate in medical sciences. Dr Robaina is full professor and senior researcher in the neonatology service at the José Ramón López Tabrane Provincial Women and Children's Hospital, Medical University of Matanzas, Cuba He chairs the province's Scientific Council on Health. His current research focuses on the impact of the COVID-19 pandemic on maternal and child health.

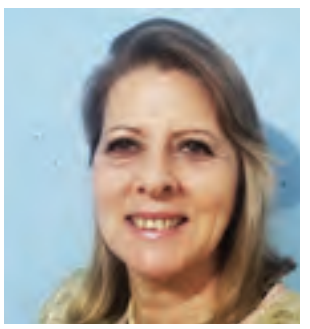

Teresa Rodríguez-Rodríguez MS PhD Psychologist with both a master's degree and a doctorate in the field. Dr Rodríguez heads the Behavioral Medicine Group in Cuba and is full professor and senior researcher at the Dr Gustavo Aldereguía Lima University General Hospital, Cienfuegos, Cuba. Her research focuses on the intersection of chronic disease and psychology, particularly cardiopsychology. In 2019, she was awarded Cuba's Annual Health Prize. 


\section{About the Contributors}

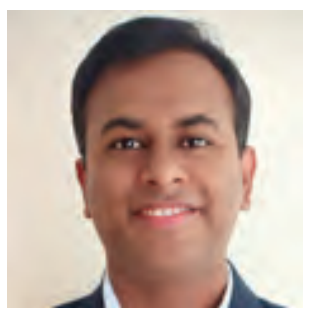

Saurabh RamBihariLal Shrivastava MD MS

Epidemiologist and a public health expert with a master's degree in community medicine; fellow of the Foundation for Advancement of International Medical Education and Research. Dr Saurabh is a distinguished professor and

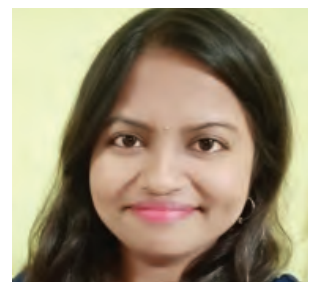

Prateek Saurabh Shrivastava MD MS

Physician specializing in public health with a master's degree in community medicine. Dr Shrivastava is professor at Shri Sathya Sai Medical College and Research Institute, Sri Balaji Vidyapeeth, Puducherry, India. Her research focuses on epidemiology, infectious diseases, nonresearcher with more than 950 communicable diseases and medical research publications at Shri Sathya education.

Institute, Sri Balaji Vidyapeeth,

Puducherry, India. His research focuses on medical education, recent advances in public health and infectious diseases.

The remaining authors in the following pages are members of the journal's editorial team. 
All original scientific articles appearing in MEDICC Review are subject to double-blind international peer review. MEDICC Review is indebted to the following colleagues for their collaboration as peer reviewers in 2020:

Anselmo A. Abdo Cuza MD PhD, Cuba Yamila Adams Villalón MD MS, Cuba Gladys Abreu Suárez MD PhD, Cuba María Oslaida Agüero Martínez MD MS, Cuba Raúl Aguilera Eguía MD MS, Chile Tania Alfaro Morgado MD MPH, Chile Ismarys Alfonso Horta MD PhD, Cuba Daniel F. Alonso PhD, Argentina Patricia Alonso Galbán MD MS, Cuba Mireya Alvarez Tosté MD, Cuba Roberto Alvarez Fumero MD MS, Cuba Daniel Antiporta Penaloza MS MPH, USA Manuel Araña Rosaínz MD PhD, USA Carmen Arocha Mariño MD PhD, Cuba José A. Arronte Villamarín MD, Cuba Enrique Arús Soler MD PhD, Cuba Juan A. Ayala Serrano MD PhD, Spain Ricardo M. Barrera, Argentina Enrique Beldarraín Chaple MD PhD, Cuba José M. Belizán MD PhD, Argentina Jorge Berlanga Acosta DVM MS PhD, Cuba Raúl Bernal Reyes MD, Mexico

Tatiana Blanco MD, Colombia James Boex MBA PhD, USA

Mariano H. Bonet Gorbea MD, Cuba Armando Caballero López MD PhD, Cuba María Cáceres Toledo MD PhD, Cuba Raúl O. Calderín Bouza MD MS, Cuba Rafael Camacho Carranza MD, Mexico Rolando Camacho Rodríguez MD PhD, Cuba Isabel A. Caravia Pubillones MD MS, Cuba Alfonso J. Casado Collado PhD, Spain Ignacio A. Casarini MD, Argentina lleana Castañeda Abascal DDS PhD, Cuba Pastor Castell-Florit Serrate MD PhD DSc, Cuba Marlén I. Castellanos Fernández MD PhD, Cuba Berta Lidia Castro Pacheco MD, Cuba Caridad Chao Pereira MD MS PhD, Cuba Nataniel A. Chaparro Mérida MD, Bolivia Helena J. Chapman MD MPH PhD, USA Ariadna Corral Martín MD PhD, Cuba Andrea Cortegiani MD, Italy

Iván E. Cuevas Valdespino MD MPH, Cuba Lidia de Isaacs MD, Panamá

Deyanira de la Rosa Hernández MD MS, Cuba Jorge de Lázaro Coll Costa PhD, Cuba Elena Delgado Blanco PhD, Spain Carlos A. del Risco Turiño MD MS, Cuba María del Valle Juárez MD, Argentina Alina Díaz Machado MD MS, Cuba Fernando Domínguez Dieppa MD FAAP PhD, Cuba Carlos Duarte Cano PhD, Cuba

Sandalio Durán Álvarez MD, Cuba

Ragaa El-Gazzar MPH PhD, Egypt

Alfredo D. Espinosa Brito MD MS PhD DSc, Cuba Mercedes Esquivel Lauzurique MD PhD, Cuba Justo R. Fabelo Roche PhD, Cuba María Elena Faxas García MD MS PhD, Cuba Ridel J. Febles Sanabria MD MS, Cuba José I. Fernández Montequín MD, Cuba Juan Enrique Fernández Romar PhD, Uruguay Luis Enrique Fernández Molina PhD, Cuba Rodolfo Ferrando Castagnetto MD MS, Uruguay Marlene Ferrer Arrocha MD MS PhD, Cuba José C. Florín Yrabién MD, Cuba

Andrés Fraguela Collar PhD, Mexico
Hermes Fundora Hernández MD MS, Cuba Anai García Fariñas PhD, Cuba

Diana García del Barco Herrera MD PhD, Cuba

Eberto García Silvera MD MPH, Cuba

Ignacio García Doval MD, Spain

Luis F. García Moreno MD PhD, Colombia

Osvaldo García González MD MS PhD, Cuba

Ricardo A. García Hernández MD MS, Cuba

Rigoberto García Gómez MD MS PhD, Cuba

Octavio Gárciga Ortega PhD, Cuba

Lizette Gil del Valle PhD, Cuba

Sergio G. Golombek MD MPH FAAP, USA

Carlos Alberto González Delgado MD MS PhD, Cuba

Javier González de Dios MD, Spain

Julio C. González Aguilera MD MS, Cuba

Manuel A. González González MD MS, Ecuador

Norma L. González Jaimes MS, Mexico

Ricardo A. González Menéndez MD PhD DSc, Cuba

Yolanda González Hernández MD MS PhD, Mexico

Silvia B. Gorban de Lapertosa MD, Argentina

Rosa Mayelín Guerra Bretaña PhD, Cuba

José Eduardo Guerrero-Espinel MD MPH, Colombia

Daniel Gutiérrez Raina RN PhD, Argentina

Damaris Hernández Véliz MD, Cuba

Dulce María Hernández Hernández MD, Mexico

Francisco Hernández Bernal MD MS, Cuba

Mileidys Hernández Pérez MD MS, Cuba

Tays Hernández García PhD, Cuba

Luis Herrera Martínez MD PhD, Cuba

Vivian Huerta Galindo MS PhD, Cuba

Robert Huish MA PhD, Canada

Cristina Irigoyen Laborra MD PhD, Spain

Ashly E. Jordan MS MPH PhD, USA

C. William Keck MD MPH FACPM, USA

Agustín Lage Dávila MD PhD, Cuba

Gloria Lara Calderín MD, Cuba

Roberto Lardoeyt Ferrer MD PhD, Cuba

Nuris Ledón Naranjo PhD, Cuba

Rene Loewenson PhD MScCHDC, Zimbabwe Jazmín López de Méndez MD MS PhD, El Salvador

Liuber Y. Machado Zaldívar MS PhD, Cuba

Mercedes Macías Parra MD MS, Mexico

Gonzalo L. Mariani MD, Argentina

Melba Márquez Fernández MD PhD, Cuba

Antonio Marrero Figueroa MD, Cuba

Vianed Marsán Suárez MD PhD, Cuba

José Luis Martín Romero PhD, Cuba

María del Carmen Martín Alonso PhD, Spain

Silvia Martínez Calvo MD PhD, Cuba

Pedro Más Bermejo MD PhD DSc, Cuba

Pedro R. Matos Gracias MD PhD, Cuba

Zaima Mazorra Herrera PhD, Cuba

Ivis Mendoza Hernández MS, Cuba

Jesús Menéndez Jiménez MD MPH, Cuba

Estela Morales Peralta MD PhD, Cuba

Andrés A. Morrilla Guzmán MD, Cuba

Didier Mugabe MD MPH, Mozambique

Agustín M. Mulet Pérez MD, Cuba

Adrián Naranjo Domínguez MD, Cuba

Rolando Ochoa Azze MD PhD, Cuba

Rosaida Ochoa Soto MD, Cuba

Yarumi Ochoa Gibert MD, Cuba

Joan O'Connell MHSc PhD, USA

Juan P. Oliva González MD PhD, Cuba

Teresa Orosa Fraíz MS, Cuba

S. Deybis Orta Hernández MD MS, Cuba
Alina J. Ortega Bravo MS PhD, Cuba Nuria Pajuelo Díaz MS, Spain

María Amparo Pascual López MD PhD, Cuba

Fernanda M. Pastrana Fundora MD MS, Cuba Amalia T. Peix González MD PhD DSc, Cuba Eduardo Pentón Arias MD PhD, Cuba

Nuvia Pérez Cruz MD MS, Cuba Ana Beatriz Pérez Díaz MD PhD, Cuba D. Raúl Pérez González MD MS, Cuba David J. Pérez Reyes MD MS, Nicaragua Rolando Pérez Rodríguez PhD, Cuba Sonia Pérez Rodríguez MD MS, Cuba Patricia Piedra Sierra MD, Cuba Juan Pablo Pimentel González MD MS, Canada María del Carmen Pría Barros MD MS PhD, Cuba Maida Ramos Suzarte MD PhD, Cuba Raúl E. Real Delor MD PhD, Paraguay Francisca Redondo Moneta MD, Chile Tomás Reinoso Medrano MD PhD, Cuba Victoria Ribot Reyes MD MS PhD, Cuba

Luis M. Ríos Buceta MD, Spain

Humbelina Robles Ortega, Spain

David S. Rodríguez Araujo MD, El Salvador Ingrid Rodríguez Alonso MS, Cuba

Julián Rodríguez Alvarez MS, Cuba Misladys Rodríguez Ortega MD MS, Cuba

Tania Roig Alvarez MD MS PhD, Cuba Martha Ruben MD PhD, Canada Danay Saavedra Hernández MD MS PhD, Cuba Joana G. Salia MD MPH PhD, Mozambique Belinda Sánchez Ramírez PhD, Cuba Jesús E. Sánchez García PhD, Cuba Miguel Román Sarduy Nápoles MD PhD, Cuba Giselle Saurez Martínez MD, Cuba Adele Schwartz Benzakem MD MS PhD, Brazil Anadys B. Segura Fernández MD MS, Cuba Miguel Ángel Serra Valdés MD MS, Cuba Orlando Serrano Barreras MD MS, Cuba Armando H. Seuc Jo MS PhD, Cuba Gisela María Suárez Formigo MD, Cuba Omar Sued MD MS, Argentina

Teddy O. Tamargo Barbeito MD MPH PhD, Cuba Angela D. Tuero Iglesias MS, Cuba

Rafael de Jesús Tuesca Molina MD MPH PhD, Colombia

María Cristina Ugrin MD, Argentina

Alicia Vaglio MD, Uruguay

Carmen Valenti Pérez MD MS, Cuba

Juan Vela Valdés MD PhD, Cuba

Francisco H. Velásquez Forero MD, Mexico

Pedro Velbes Marquetti MD MS, Cuba

Pedro L. Véliz Martínez MD MS PhD, Cuba

Silvia Venero Fernández MD MS PhD, Cuba

Bienvenido Veras Estévez MD MBA MPH

MEC-FETP MSc-CPs (DOR),

Dominican Republic

Denis Verdasquera Corcho MD PhD, Cuba

Eduardo Verde Moreno MD PhD, Spain

Carlos E. Verne Martín MD PhD, Peru

María Vidal Ledo MS PhD, Cuba

Jesús Vila Díaz MD, Ecuador

Haiyang Yu MD, China

Tatiana Zaldívar Vaillant MD MS, Cuba

Yaíma Zúñiga Rosales MD MS, Cuba -1M 


\section{COVID-19 CONTROL IN A HAVANA SURGICAL HOSPITAL}

\section{To the Editors:}

We write to share the experience in COVID-19 transmission control at our hospital, National Center of Minimally Invasive Surgery (CNCMA) in Havana, Cuba. The institution is the national reference center for application, training and research related to minimally invasive surgical procedures.[1]

During the epidemic in Cuba, CNCMA has continued surgeries, following nationally established COVID-19 protocols,[2] implementing actions for prevention, diagnosis and control of the disease in patients and health personnel. These include training health workers on epidemiological and biosafety aspects, in accordance with their potential levels of exposure; application three times daily of $0.5 \%$ sodium hypochlorite solution in areas of the hospital not usually disinfected (office furniture, common areas such as elevators, stair handrails, doors, etc.), as well as $0.5 \%$ sodium hypochlorite solution for shoes and $0.1 \%$ solution for hands upon hospital entrance; active case finding to detect possible cases; and individual PPE for employees. In the April-June 2020 period, we also restricted surgical activity to oncology patients or those requiring urgent care due to digestive hemorrhage,[3] which thus decreased it to $14 \%$ of monthly averages compared to the preepidemic January-March 2020 period, gradually increasing to the 'new normal' phase by October, reaching $66 \%$ of planned surgeries for the month.[2] Access to the institution has also been limited (patient visits suspended, limits on numbers of personnel, telecommuting where possible), and a CNCMA-specific protocol was developed for the pandemic,[4] based on the national Prevention and Control Program for Healthcare-related Infections,[5] and the National COVID-19 Protocol.[2]

From April through October, 2020, 719 surgeries were performed and 3529 patients were seen in CNCMA's outpatient services, completing $47.0 \%$ of annually planned surgeries and $56.2 \%$ of ambulatory consults for the period. Of 410 current employees, $379(92.4 \%)$ have been incorporated on-site. As of this writing (November 7), all services have been re-established as well as part of our academic activities, and no cases of COVID-19 have been reported among patients or staff.

Implementing the institutional protocol for surgical activity during the pandemic[4] has been essential for normalizing our work and providing quality medical care to patients. Its guidelines could be useful for similar institutions as well as to supplement the National Protocol for COVID-19 Prevention and Control with respected to surgical activities. -1 -

1. National Center of Minimally Invasive Surgery (CU) [Internet]. Havana: National Center of Minimally Invasive Surgery (CU); c2020 [updated 2020 Oct 27; cited 2020 Nov 5]. Available at: http://www.cce.sld.cu/. Spanish.

2. Ministry of Public Health (CU). Protocolo de actuación nacional para la COVID-19. Versión 1.5. [Internet]. Havana: Ministry of Public Health (CU); 2020 Aug [cited 2020 Oct 30]. 215 p. Available at: https://files.sld.cu/editorhome/ files/2020/08/VERSION-5-DEL-PROTOCOLO-PARA-PUBLICAR-13-DE -AGOSTO-2020.pdf. Spanish.

3. Ministry of Public Health (CU). Resolución128. Disposiciones sanitarias para la etapa de prevención y control de la propagación de la COVID-19 del MINSAP [Internet]. Havana: Ministry of Public Health (CU); 2020 May 11 [cited 2020 Jun 10]; [about 7 p.]. Available at: http://juriscuba.com/resolucion-no-128-2020/. Spanish.

4. National Center of Minimally Invasive Surgery (CU). Actuación en situación de pandemia de COVID-19 [Internet]. Havana: National Center of Minimally
Invasive Surgery (CU); 2020 [cited 2020 Nov 5]. 22 p. Available at: http://www .cce.sld.cu/pub/pno-covid-19-cncma.pdf . Spanish.

5. Ministry of Public Health (CU), Vice ministry of Hygiene, Epidemiology and Microbiology, National Department of Epidemiology. Programa de prevención y control de las infecciones asociadas a la asistencia sanitaria. Versión 0.5. Havana: Ministry of Public Health (CU); 2011. Spanish.

Julián Francisco Ruiz-Torres MD PhD, Director, National Center of Minimally Invasive Surgery (CNCMA), Havana, Cuba. https://orcid.org/0000 $-0002-0024-6487$

Tania González-León MD PhD (tania@cce.sld.cu), CNCMA, Havana, Cuba. http://orcid.org/0000-0003-3813-9588

Rafael de la Caridad Torres-Peña MD PhD, CNCMA, Havana, Cuba. https://orcid.org/0000-0001-6599-987X

Daimarelis Guerra-del Valle MD MS, CNCMA, Havana, Cuba. https:// orcid.org/0000-0002-8439-4996.

Javier Barrera-González MD PhD, CNCMA, Havana, Cuba. https://orcid .org/0000-0003-3867-0985

Rosalba Roque-González MD PhD, CNCMA, Havana, Cuba. https:// orcid.org/0000-0002-5014-872X.

https://doi.org/10.37757/MR2021.V23.N1.16

\section{DANGERS AND MANAGEMENT OF OBSTRUCTIVE SLEEP APNEA SYNDROME IN COVID-19 PATIENTS}

\section{To The Editors:}

Related to my earlier publications on central nervous system involvement in COVID-19,[1,2] I would like to stress the importance of diagnosing obstructive sleep apnea syndrome (OSAS) in infected patients, prompting early use of continuous positive air pressure (CPAP) to prevent hypoxemia.

OSAS is commonly related to obesity, which is considered an important risk factor for severe COVID-19. Nevertheless, publications about the possible association between OSAS and COVID-19 are relatively scarce.[3]

SARS-CoV-2 uses the angiotensin-converting enzyme 2 (ACE2) receptor for host cell entry. In COVID-19 patients whose OSAS is untreated, augmented ACE2 expression and deregulation of the renin-angiotensin system occur. OSAS leads to repetitive airway collapse with apnea/hypopnea and hypoxia during sleep. Hypoxia/re-oxygenation during each apnea episode in OSAS patients worsens hypoxemia and can stimulate ACE2 synthesis in endothelial cells, inducing higher ACE activity and thus aggravating the cytokine storm typical of severe COVID-19. Thus, OSAS (particularly with concurrent obesity) could contribute to increased hypoxemia, further provoking the cytokine storm that can cause acute respiratory distress syndrome (ARDS), multiorgan failure and death in these patients. $[1,2,4]$

Non-invasive ventilation (NIV) plays a more significant and helpful role than first thought, mainly if used at early stages of COVID-19. CPAP is now the preferred form of NIV to manage hypoxemic COVID-19 patients. In fact, use of improved and enhanced CPAP equipment is providing growing evidence that this NIV method 
may benefit patients early in the disease's progression, preventing ARDS and reducing the need for invasive ventilation.[3,5] Hence, I highly recommend beginning CPAP in COVID-19 patients as soon as the first respiratory symptoms appear-even during care outside of intensive care units-especially for those patients with OSAS.[4] -

1. Machado C. Severe Covid-19 cases: is respiratory distress partially explained by nervous central system involvement? MEDICC Rev. 2020 Apr;22(2):38-9.

2. Machado-Curbelo C. Silent or 'happy' hypoxemia: an urgent dilemma for COVID-19 patient care. MEDICC Rev. 2020 Apr;22(2):85-6.

3. Thorpy M, Figuera-Losada M, Ahmed I, Monderer R, Petrisko M, Martin C, et al. Management of sleep apnea in New York City during the COVID-19 pandemic. Sleep Med. 2020 Oct;74:86-90.

4. Machado C, DeFina PA, Machado Y, Chinchilla M, Cuspineda E, Machado Y. Continuous positive air pressure (CPAP) should be used in all COVID-19 patients when the first and mild respiratory symptoms commence. J Respir Dis Med. 2020;2:1-6. DOI: 10.15761/JRDM.1000124.

5. Cade BE, Dashti HS, Hassan SM, Redline S, Karlson EW. Sleep apnea and COVID-19 mortality and hospitalization. Am J Respir Crit Care Med. 2020 Nov 15;202(10):1462-4. DOI: 10.1164/rccm.202006-2252LE.

Calixto Machado-Curbelo MD PhD FAAN (braind@infomed.sld.cu), Department of Clinical Neurophysiology, Neurology and Neurosurgery Institute, Havana, Cuba. https://orcid.org/0000-0002-0539-5844 


\section{Researchers at Cuba's National Medical Genetics Center: Pioneering Studies on COVID-19}

\section{Gail A. Reed MS}

Three fourths of the 175 staff at Cuba's National Medical Genetics Center (CNGM) are women. And women constitute $90 \%$ of the research team working on the Center's largest current projectunlocking the biological secrets of COVID-19 in the Cuban population. They are identifying particularly vulnerable groups and geographies, reviewing therapies applied and long-term sequelae of the disease, and contributing to ongoing vaccine research and trials. Their results are critical to determining effective preventive and treatment strategies as the country moves into the next phases of epidemic control. The national study is the first and only one of its kind in Latin America.

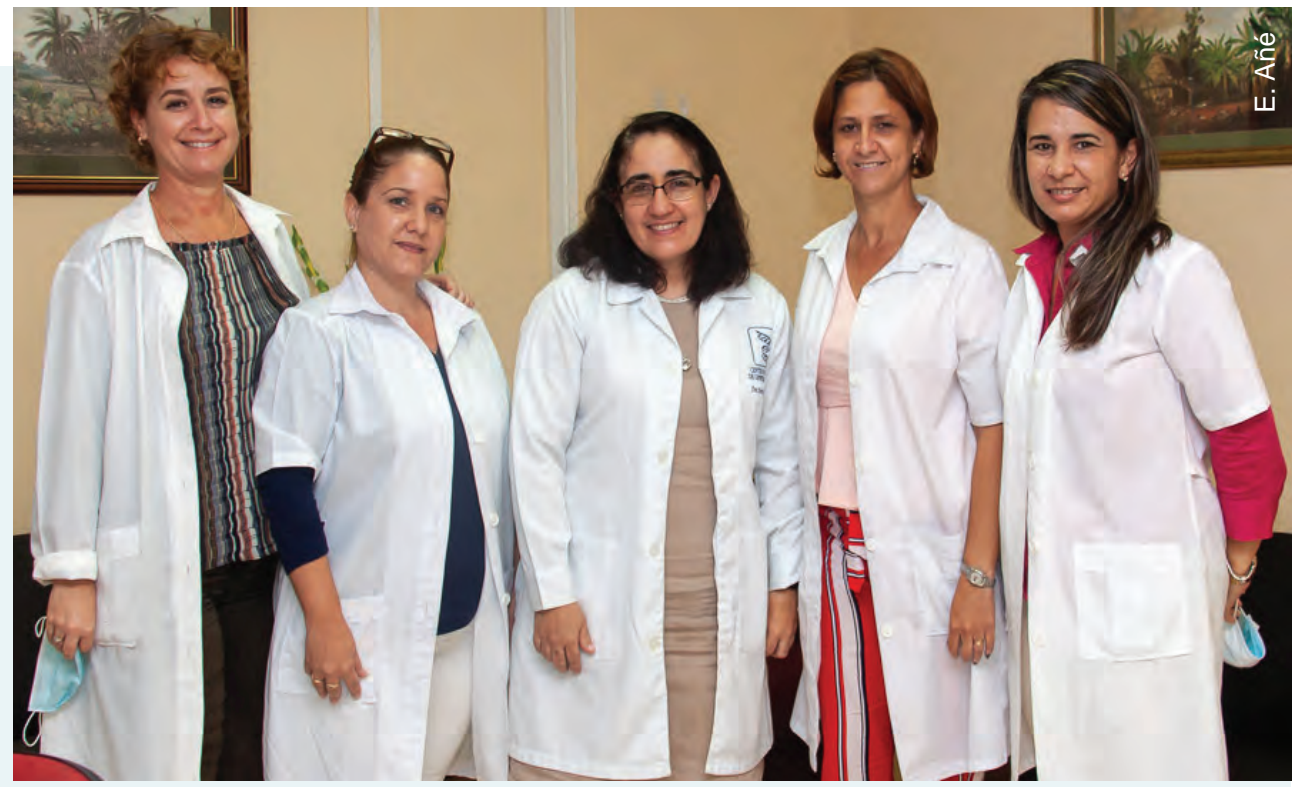

The team (I. to r.): Dr Giselle Monzón, clinical geneticist; Dr Beatriz Suárez, family physician; Dr Beatriz Marcheco, clinical geneticist and CNGM Director; Dr Yaíma Zúñiga, immunologist; and Dr Hilda Roblejo, clinical geneticist.
When the first COVID-19 cases were diagnosed in Cuba on March 11, 2020, the Center's role in epidemiological surveillance was activated, based on its experience with the Zika threat in 2015. This involved mobilizing the National Genetics Network anchored in primary healthcare facilities, comprised of 452 genetics counselors, nurses and clinical geneticists, supported by technicians, epidemiologists and family doctors. The Network's role would become key to the ensuing research.

As the magnitude of the pandemic became clearer, CNGM investigators approached the Ministry of Public Health and government leaders with a broad-ranging proposal to study biological factors that would help explain differences in vulner-

MEDICC Review: Dr Marcheco, can you give us a broad view of what your team is looking for with this national study?

Beatriz Marcheco: The study, although coordinated by our Center, was carried out in primary health care, using all the resources at our disposal from the National Genetics Network. We were already seeing differences in transmission and frequency of the disease in different parts of the country and different population groups. The eastern provinces had fewer cases, for example, while there were more in western Cuba. Why were we seeing such variations? And this was just one of our questions. So we started working with databases from the Ministry of Public Health and genetics departments, then generated guidelines and a participant questionnaire, and began the rollout, which needless to say involved serious logistical planning and attention to PPE and other protection for our team. ability, symptoms, immune response and severity of the disease, as well as its profile in different Cuban subpopulations. After approval, the studies got underway in June, encompassing Cubans who had been infected through June 11, 2020, and were by now convalescing.

The nine main research lines were defined, and principal investigators went to work developing the instruments needed and training personnel across the island on their use. While final results are still being analyzed, CNGM Director Dr Beatriz Marcheco and four lead researchers talked with MEDICC Review about the scope of their work and some of the most intriguing preliminary findings.
The universe of 2233 people who had contracted COVID-19 through June 11 was whittled down to 1182 , our final sample. Eliminated were those who had died, as well as infants under one year old, non-citizens, people who had moved from their area of residence, and 186 who decided not to participate. The final group, from all 15 provinces plus the Isle of Youth Special Municipality, also included health workers.

\section{MEDICC Review: It seems you had a relatively good response. What about those who refused to participate?}

Beatriz Marcheco: We learned a lot about the psychological toll the epidemic has taken on people who contract the disease. Many received us with open arms, anxious that their cases be included. But some just didn't want to hear about COVID-19 again. One man told us that people were closing their doors or crossing the street 
to avoid contact, that he'd become a pariah. Another woman said her downstairs neighbors didn't want her hanging the wash where it might drip on their balcony, for fear of contagion.

This was important to us from a sociological perspective-to see the panic the pandemic had generated. In our meetings with government authorities, we said an effective public messaging campaign was needed, not only to create risk perception, but also to build solidarity... rather than talking about social distancing, to talk about physical distancing and social solidarity. The experience also confirmed our approach: avoiding biological reductionism, and instead taking a comprehensive, integrated look at biological phenomena in social contexts that can either synergize or attenuate their magnitude.

\section{MEDICC Review: Who was involved in the research and how did you proceed?}

Beatriz Marcheco: Some 200 professionals were involved from the National Genetics Network, plus our staff. Upon receiving written informed consent, and before carrying out interviews and clinical exams, our team reviewed all participants' hospital charts. One advantage we had is that all PCR-confirmed cases of COVID-19 in Cuba were hospitalized; none were left at home. So this means researchers could meet with hospital clinicians to get a more precise understanding of individual treatment regimens, since symptoms such as fever could be a result of the disease or secondary to interferon therapy, for example. At the Center, we received the completed interview questionnaires and blood samples for analysis. It was quite a rigorous process, even in the midst of the pandemic.

The study also contemplated a first-degree relative of each patient, one who had cohabitated with the infected person during pre-hospitalization, but who consistently tested negative by PCR. They constituted a control group to compare people who had considerable genetic makeup and living environments in common, but who reacted differently to the virus.

\section{MEDICC Review: What were the main lines of research?}

Beatriz Marcheco: Initially, our priority was an immunogenic analysis of our sample, and we even organized the research at one point around the possibility of carrying out flow cytometry to characterize the cellular subpopulations involved in the body's defenses. Our main aim was a hematological assessment of each individual, including $A B O$ blood group, lymphocyte subpopulations via flow cytometry, and various DNA markers. But flow cytometry requires maintaining the cold chain-impractical given the transport time involved from distant provinces. In the end, we limited this to just under 400 participants.

The main, national study characterized severity of the disease according to several variables. Few investigations have done this, and fewer still have compared convalescing patients to controls who are first-degree relatives. If we look at the lines of research we expect to reflect in scientific papers, I can summarize these, beginning with specific population groups, some of which we can describe in more detail:

- Older adults (persons aged 60 years and older);

- Pregnant women (a case series of 7 women);
- Havana Province, with all the complexities of a national capital; and

- Pediatric patients (137 children, mainly looking at cardiovascular implications, myocarditis in particular).

Then there are the various biological studies, such as:

- The results of flow cytometry, related to lymphocyte subpopulations in both convalescing patients and controls.

- Characterization of molecular markers: tumor necrosis factor alpha (TNF- $\alpha$ ), concerning immune response and related symptoms; vitamin D receptor, which plays an essential role in the body's defenses (in particular, we studied genetic characteristics determining ability to retain and process this vitamin); and interleukin 12, which stimulates interferon gamma production. We also studied the ACE2 receptors, the points of cellular entry for the virus (fewer receptors, fewer points of entry).

- Research on symptoms that persisted after initial infection, an investigation carried out in six Havana municipalities.

- Hematological studies involving 31parameters in over 300 participants, analyses conducted here at the Center, to see how these variables behaved during the convalescent period.

The main study describes results for the whole country, which Dr Yaíma Zúñiga can explain. It also includes several spinoff investigations: one in cooperation with the Immunoassay Center, another with the Molecular Immunology Center (CIM) and a final one with the Finlay Vaccine Institute (IFV). The Immunoassay Center proposed detection of antibodies specific to SARS-CoV-2. CIM proposed an inhibition assay with samples from the flow cytometry group, to more precisely characterize those antibodies and see to what extent they inhibit coupling of the virus with receptors. IFV proposed a neutralization trial, to study not only inhibition but also whether the antibodies had sufficient 'quality' to neutralize the virus in subsequent exposures. The latter has helped researchers there determine the levels of efficiency required for the Cuban vaccine candidates.

MEDICC Review: Dr Zúñiga, can you introduce yourself and give us an overview of the main national study?

Yaíma Zúñiga: Certainly. I'm an immunologist and have been working here at the Center since 2011. For the main study, our principal aim was to identify immunogenic risk factors related to severity of COVID-19, that is, why some people are asymptomatic while others develop mild or severe forms. One strength of our research was its national character, involving convalescing patients from all 15 provinces and the Isle of Youth Special Municipality, thanks to the National Genetics Network. As Dr Marcheco mentioned, we included as controls first-degree cohabitating family members who remained healthy.

Confirmation of all COVID-19 cases in Cuba is done by PCR. This uniformity of diagnosis constitutes another strength, one not always seen in other studies. And application of a national treatment protocol also made for more standardized therapies.

One challenge was correctly classifying patients according to WHO diagnostic criteria: for example, determining whether those who were asymptomatic at diagnosis actually remained asymptomatic, or whether their diagnosis was simply made in a presymptomatic phase of their illness. This was accomplished by 
NATIONAL MEDICAL GENETICS CENTER STUDIES ON COVID-19 VULNERABILITY, RATES, SYMPTOMS, SEVERE FORMS AND DEATH: CONVALESCING PATIENTS AND CONTROLS, CUBA (MARCH 11, 2020-JUNE 11, 2020)

\begin{tabular}{|c|c|c|c|}
\hline No. & $\begin{array}{l}\text { Study participants/subjects and specific } \\
\text { parameters }\end{array}$ & Number & Comments \\
\hline \multirow[t]{5}{*}{1} & $\begin{array}{l}\text { All convalescing COVID-19 patients in Cuba } \\
\text { ( }>1 \text { year old, Cuban citizen, informed consent } \\
\text { of patient or guardian), plus one first-degree } \\
\text { cohabitating relatives (as controls) }\end{array}$ & $\begin{array}{l}\text { Patients: } 1182 \\
\text { Controls: } 500 \\
\text { Total: } 1682 \\
\text { Plus: } 84 \text { deceased }\end{array}$ & $\begin{array}{l}\text { Carried out in all } 15 \text { Cuban provinces and the Isle of } \\
\text { Youth Special Municipality; includes } \pm 200 \text { health workers; } \\
\text { demographic and biological characteristics related to risk of } \\
\text { disease onset, symptoms, severity and death }\end{array}$ \\
\hline & Persistent symptoms & 67 & $\begin{array}{l}\text { Convalescent patients studied in six municipalities of } \\
\text { Havana Province }\end{array}$ \\
\hline & Hematological profile & 344 & $\begin{array}{l}\text { Includes } 31 \text { parameters (complete blood count, ABO blood } \\
\text { group, etc.) }\end{array}$ \\
\hline & Molecular markers & $\begin{array}{l}\text { TNF- } \alpha: 1028 \\
\text { Vitamin D receptor: } 133 \\
\text { ILK12: } 128 \\
\text { ACE2 receptor gene: } 400\end{array}$ & $\begin{array}{l}\text { Tumor necrosis factor alpha (TNF- } \alpha \text { ); vitamin D receptor; } \\
\text { interleukin 12, ILK12 (stimulates interferon gamma produc- } \\
\text { tion); and ACE2 receptor gene }\end{array}$ \\
\hline & Immunological status via flow cytometry & 389 & \\
\hline 2 & Subpopulation: older adults ( $\geq 60$ years old) & Living: 241 & $\begin{array}{l}\text { Patients from all except Granma Province; includes } 14 \\
\text { health workers }\end{array}$ \\
\hline 3 & Subpopulation: pregnant women & 7 & Extended to their newborns \\
\hline 4 & Subpopulation: Havana Province & 431 & $\begin{array}{l}\text { All } 15 \text { municipalities (In Cuba, Havana Province is also the } \\
\text { capital city.) }\end{array}$ \\
\hline 5 & Subpopulation: pediatric patients & 137 & Emphasis on cardiovascular sequelae, myocarditis \\
\hline
\end{tabular}

NOTES: All confirmed COVID-19 patients in Cuba are hospitalized. Convalescing patients included in the study were those who were RT-PCRpositive from March 11, 2020 through June 11, 2020, and had received at least two negative PCRs (first at hospital and second 15 days after discharge). Controls were RT-PCR-negative fist-degree relatives cohabitating with sick individuals during the pre-hospitalization phase of infection. Postmortem analysis included 84 deceased from COVID-19, for whom demographics (age, sex, etc.) and comorbidities were considered.

reviewing patients' hospital charts and through interviews. Interestingly, although $60 \%$ to $70 \%$ had originally been classified as asymptomatic, this portion dropped considerably through reclassification, since they developed symptoms later. We also found that adults fell ill more often than children, but that children were more often asymptomatic, making them silent carriers.

As far as genetic factors, we analyzed such things as skin color, which is difficult in Cuba where there is so much mestizaje, which means less relation between skin color and actual genetic ancestry. Some US and European literature had reported higher rates as well as greater severity and higher mortality among minorities-Black, Asian, Hispanic. However, we found that disease distribution mirrored fairly well the proportion of people of different skin colors in the Cuban population as a whole (according to census data). We did find differences when it came to severity and mortality, which we are still analyzing. It may be that being mestizo is a protective factor.

MEDICC Review: Have you accounted for other confounding variables, having to do with environment, socioeconomic status, etc.?

Beatriz Marcheco: We didn't carry out a detailed sociological study. We did include employment, educational level and where participants lived-whether in urban or rural areas. Once a person becomes sick, various factors begin to influence outcomes: age, comorbidities, blood group and also skin color. Who are the people who have become seriously ill, at least in Cuba? Most often, these are older people. Which leads us to a number of

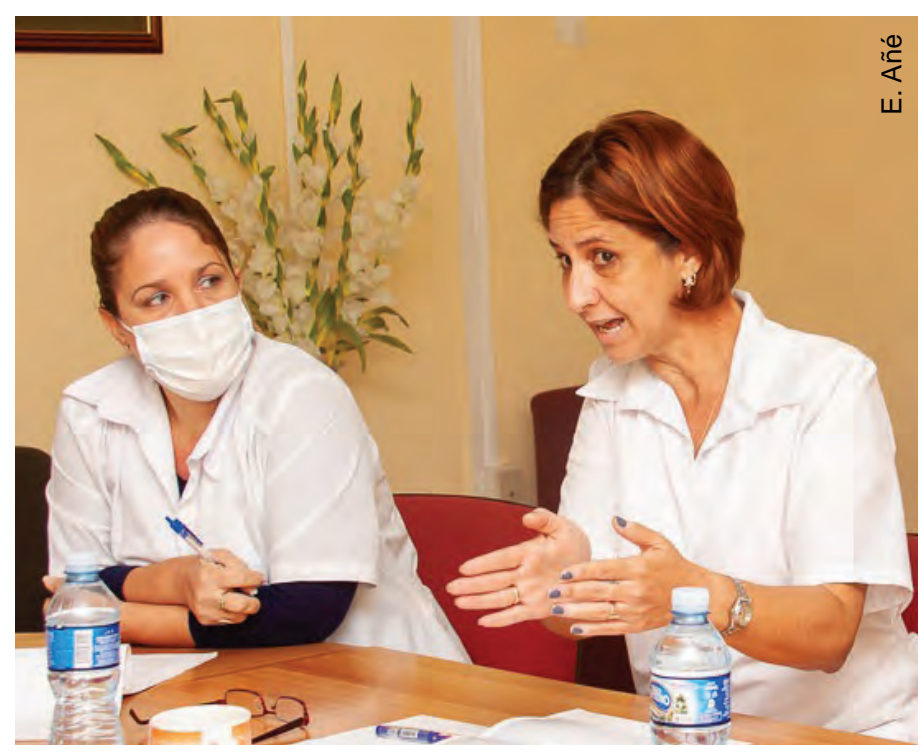

"One strength of the study was its national character, involving convalescing patients from all 15 provinces," Dr. Yaíma Zúñiga.

social and historical variables. In the case of skin color, you would have to look into the nutritional levels and socioeconomic conditions that prevailed for darker-skinned people some 60 years ago, when they were growing up and the basis of their health status was being determined. Those conditions were certainly more precarious than for lighter-skinned people. No matter that Cuba has moved the needle towards equity, that past is important. 
Yaíma Zúñiga: We confirmed what other international studies are showing: that advanced age is indeed a risk factor for developing severe COVID-19 and for death. Our aim was to quantify this risk by comparing different age groups, as ages climbed. The educational level in our study was high, with more university graduates than in the general population. The fact that some 200 health workers, primarily doctors and nurses, were included may have influenced this (thankfully, with no deaths in that subpopulation).

We also looked at blood types. We didn't find any important association of infection risk with Rh factor. However, when we analyzed ABO blood groups, we found persons in blood group A were more apt to progress to severe forms of the disease. Concerning comorbidities in the Cuban population, it is clear that diabetes mellitus and cancer present the most risk, particularly for severe COVID-19 and death. And our results coincided with others that indicate greater risk of death for men.

\section{MEDICC Review: You also analyzed post-mortem cases?}

Yaíma Zúñiga: Yes, 84, determined by death certificates, the total number of deaths from COVID-19 during the period. We analyzed them on the basis of data from the Ministry of Public Health's Statistics Division and the records of the national group that monitors serious and critical cases. For patients who survived, we also looked at antibody response to SARS-CoV-2: in particular, the quantity and quality of antibodies during convalescence, important for predicting re-infection. And also if these antibodies are capable of neutralizing the virus if a person is re-exposed. This is still a big question. Our convalescents were for the most part PCR negative for at least 60 days when studied, and what we began to see was a relation between antibody response and disease severity: the more severe the form, the greater the antibody response. As Dr Marcheco mentioned, this is important for determining what characteristics a vaccine must have to be effective.

\section{MEDICC Review: Turning to Havana, where over two million Cubans live, and which has been the epicenter of the island's COVID-19 epidemic...Dr Roblejo?}

Hilda Roblejo: I've been a clinical geneticist here at the Center since 2009. The cases we studied here in Havana were more than a third of all those in our sample, 431 convalescing patients. Like all capitals, Havana presented its own complexities. The disease was disseminated in all municipalities, unlike some other provinces. So our research team interviewed people in virtually all neighborhoods.

Many aspects of the Havana sample mirrored that of the country as a whole. Most of our patients did develop symptoms; the average age was in the 40s (nationally it was 45 years old). An earlier study looked at advancing age as a risk factor, and identified Plaza as a high-risk municipality, since it is the 'oldest' in the country. On the map, Plaza, Playa, Central Havana...these areas contain some of the most aged populations in the country. In Central Havana, you also have the added risk factor of overcrowding, and the same goes for 10 de Octubre Municipality, with high population density.

In terms of blood group, our results were slightly different from the national findings: we found blood group $\mathrm{O}$ to represent a greater protective factor than we saw nationally.
MEDICC Review: In addition to blood group, were there any other findings that separated Havana from the rest of the sample?

Hilda Roblejo: We found that being asthmatic was actually a protective factor against the severe forms of COVID-19. We think asthmatics fared better due to the therapies most often prescribed, which include immunomodulators, medications that modulate ACE2 receptor production.

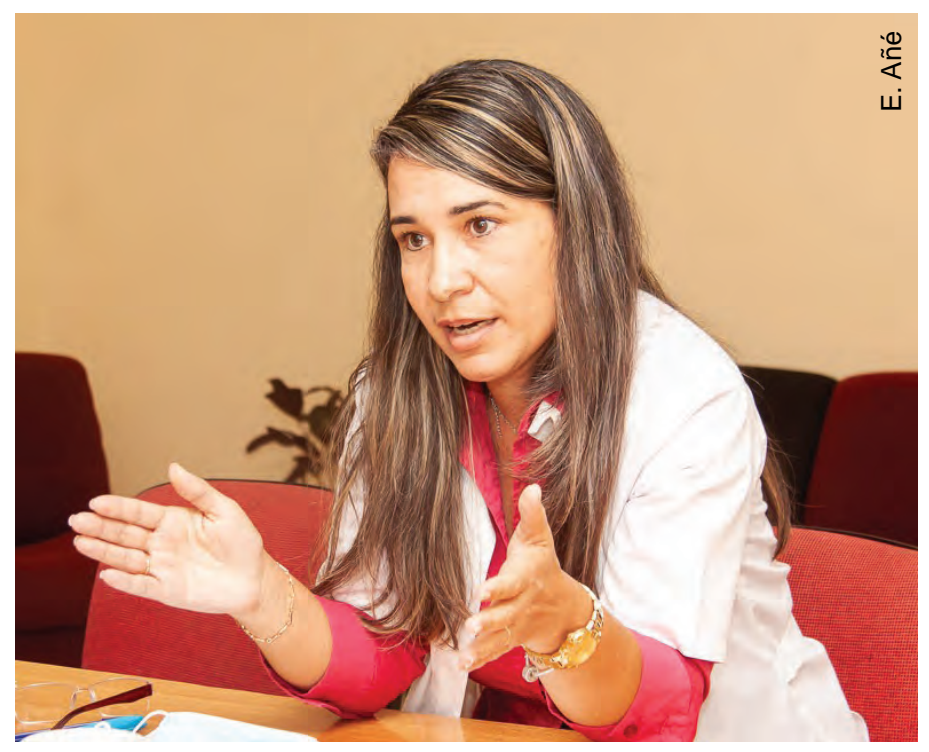

In Havana, "we found that being asthmatic was actually a protective factor against the severe forms of COVID-19," Dr Hilda Roblejo.

MEDICC Review: Dr Suárez, can you introduce yourself and talk about the research facets that concentrated on older convalescent patients?

Beatriz Suárez: I'm a specialist in family medicine with a master's degree in medical genetics. I've worked here at the Center since 2009. My main responsibility is to coordinate the services of the National Genetics Network across the country.

In Latin America, Cuba's is one of the most rapidly aging populations. So for this part of the study, we concentrated on persons 60 years and older, which corresponded to $22 \%$ of those infected during the study period, a good share of whom had either developed severe forms or died from the disease.

The highest concentrations of convalescing patients and also older patients were in Villa Clara, Havana and Matanzas Provinces. Villa Clara, the 'oldest' province, also experienced an outbreak at a nursing home. In Matanzas, cases were concentrated in Cárdenas Municipality, close to the resort town of Varadero, which made it particularly vulnerable given that the first COVID-19 wave in Cuba was determined mainly by imported cases. And Dr Roblejo already spoke about Havana's characteristics.

We studied 241 patients in all, and found slight increases in severe forms according to advancing age. Fourteen of these patients were health workers, and although most had already retired, $22 \%$ were still working. 
As in the international literature, we saw greater risk of infection as the number of comorbidities increased. Among the comorbidities, hypertension was the most frequent, found in half these older adults. Most of these patients contracted COVID-19 with mild or moderate symptoms, and we described the more common ones.

\section{MEDICC Review: What are some of the most important risk factors leading to death?}

Yaíma Zúñiga: More men die than women. Worldwide, we see that men have more risk of developing severe forms of COVID-19 and of dying. We didn't find this correlation with severity of disease in Cuba. However, Cuban men were more at risk of dying. And another interesting thing is that the women who died were older than the men who died. We know that women in general have a better immune response, due to various factors. As an aside, I should also note that more women agreed to participate in our study than men...something we've experienced in other research.

\section{MEDICC Review: What did you find with the group of wom- en who were pregnant when they contracted COVID-19? Dr Monzón?}

Giselle Monzón: I'm originally from Camagüey Province, but have been at the Center since 1998, when I specialized in medical genetics here.

Pregnant women have constituted a vulnerable group in past respiratory disease epidemics, where we have seen them at greater risk of developing serious complications requiring ICU care, and of dying. So this is of grave concern to us as we confront COVID-19.

Through September 2020, PAHO reported over 60,000 pregnant women infected in 14 countries of the Americas, with a mortality of $1 \%$. The highest mortality was reported in Mexico, Brazil and the United States. In Cuba through July 31, 2020, 23 cases had been confirmed among pregnant women, including 16 during the period of our study. Seven women participated in our research, about $44 \%$ of the total sample. In their case, our aim was to identify genetic risk factors associated with more serious disease.

In addition to the interview, we were able to follow the outcome of each pregnancy. All this was possible thanks to the National Genetics Network and the National Maternal-Child Program. This program, based in primary health care, leads to early monitoring of pregnant women in medical services, well before their third trimester, different from what happens in many other countries. And COVID-19 cases in this population were also identified mainly in the community, as a result of active case finding and contact tracing. This enabled early diagnosis by PCR and immediate hospitalization. Pregnant women, according to our national protocols, received antiviral therapy, including interferon alfa- $2 b$, which appears to help explain why none developed serious complications or died.

They did develop mild to moderate symptoms. Interestingly, fever was not one of the main ones most frequently described.

While this was a small sample, we didn't see secondary effects of medications reported by some other patients, either for their own health or for the healthy development of the fetus or newborn. We also carried out a genetic assessment of the neonates.

MEDICC Review: Do you have any evidence of vertical transmission of the SARS-CoV-2 virus?

Giselle Monzón: No, no evidence of vertical transmission, either in the study, or in Cuba up to now. Any transmission has been associated with inadequate management via maternal aerosols and so on.

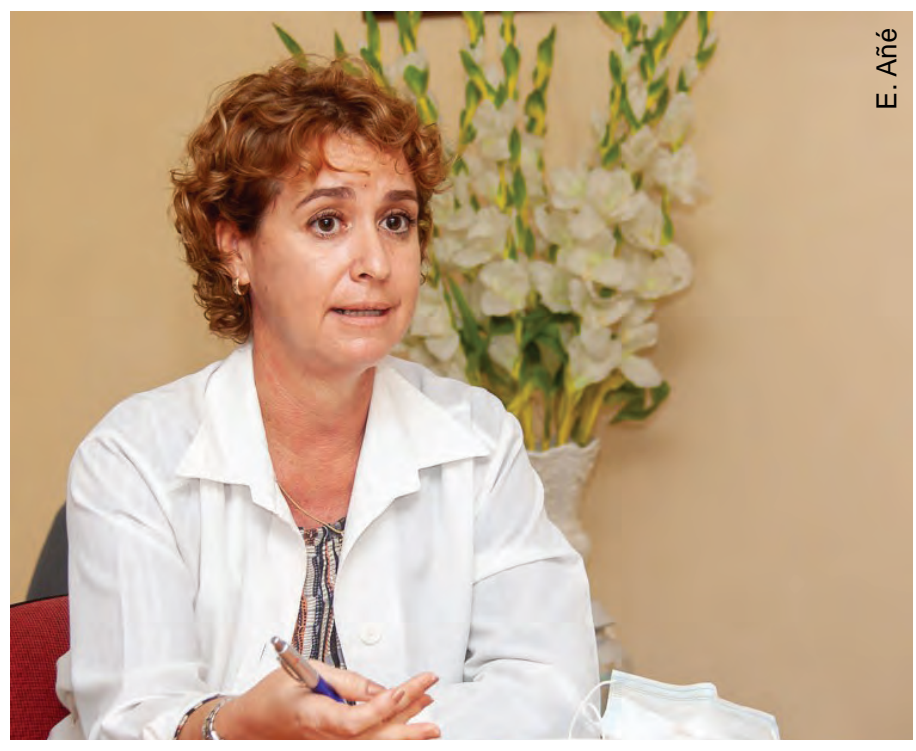

"No evidence of vertical transmission, either in the study, or in Cuba up to now," Dr Giselle Monzón.

MEDICC Review: What are the implications of your findings thus far for Cuban treatment protocols and for the vaccines being developed by Cuban biotech?

Yaíma Zúñiga: In terms of the vaccines, we are determining the antibody titers and the capacity of these antibodies to neutralize the virus, that is, what level of immunogenicity is required-establishing that threshold. To date, the FDA has said that titers must be equal or greater than $1 / 160$ to guarantee neutralization, the level considered by the current vaccine candidates. But when you design a vaccine, you have a given population as a reference, since populations may respond differently. So studying this in our own population is important, a first approximation.

Hilda Roblejo: Our research didn't go as far as to include pharmacogenetic markers that would permit analysis of interferons and other therapies in our treatment protocol, to determine a relation between patient response and these markers. But we have stored DNA samples of all participants for further study of these aspects, especially because this will help design more personalized treatments.

Thus far, what we have been able to do is stratify risk and vulnerabilities, and as a function of this, personalize interventions. On this basis, once Cuba has a vaccine, we can make recommendations on who should be vaccinated first....groups such as older adults, health workers in Havana, people in blood group A, and so forth. 
Beatriz Marcheco: That's what I would emphasize: this research contributes results to the health system for decision-making on priority actions, based on a better stratification of vulnerabilities.

Yaíma Zúñiga: Not only therapeutic management but also for preventive approaches, what to do epidemiologically, what kinds of measures to adopt for different populations. Because I think a strength we have is that we now have DNA and sera from these patients, representing the first group in Cuba that was infected with SARS-CoV-2.

\section{MEDICC Review: We're seeing new variants of the virus emerge through mutations.}

Beatriz Marcheco: The Pedro Kourí Tropical Medicine Institute (IPK) is sequencing genes of cases that have entered from countries in Europe where one new variant has been reported, to see if it is circulating in the country. I expect so. They are also sequencing variants from outbreaks in Ciego de Ávila Province, to see if they are different from others circulating in Cuba. In the case of Ciego de Ávila, this is an important question, since the frequency of cases there, the transmissibility, severity and mortality have been greater than in other regions of Cuba.

We have some observations...we know, for example, that there have been more asymptomatic cases in Ciego de Ávila than elsewhere, which could facilitate greater transmission. And there are genetic markers that also indicate different disease behavior in

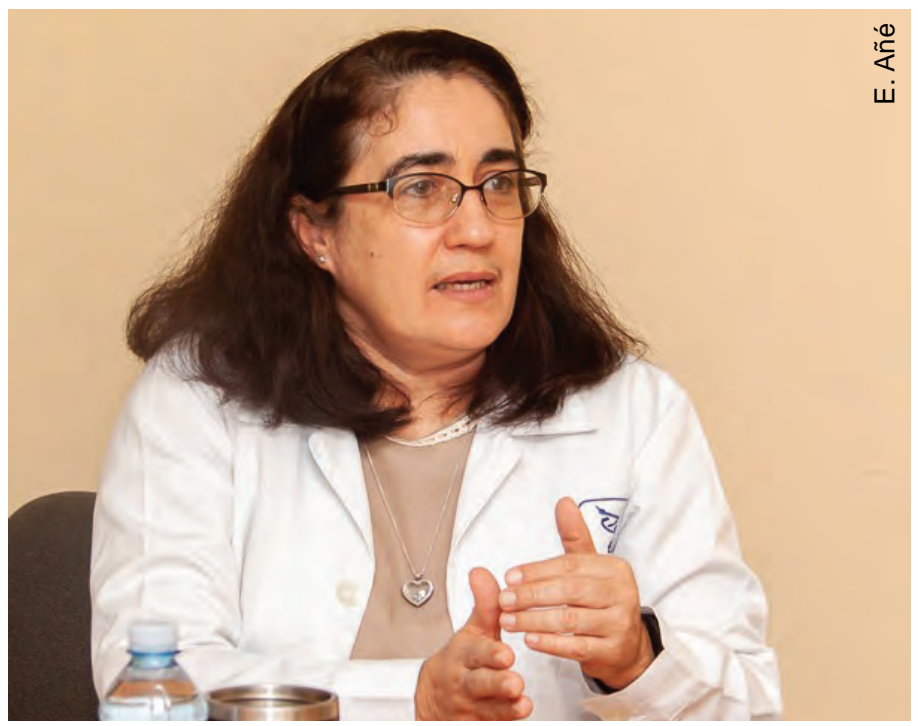

“...the most far-reaching population-based study (on COVID-19) reported in Latin America," Dr Beatriz Marcheco. that province: antibody levels are lower, protection against new exposure is less, and so on.

MEDICC Review: Is that due to the patients themselves or to a different viral strain?

Beatriz Marcheco: That's the question. We don't know. That's what we need to find out.

MEDICC Review: And there is speculation on whether the vaccines being developed will be effective against new mutations.

Beatriz Marcheco: And that's my question, too.

Yaíma Zúñiga: Generally, vaccine designs take into account the immunogen capable of the best neutralizing response. As long as the changes implied by mutations don't involve that specific immunogen, then there should be no problem. But that's the key factor.

MEDICC Review: Returning to your research: are there findings that are particularly important or novel for Cuba or for the world?

Beatriz Marcheco: I think this is the most far-ranging populationbased study that has been reported in Latin America, contemplating the entire country. In terms of particular aspects: we described distribution of symptoms in children and adults, the patterns of symptom presentation, and the relation of these to the risk of developing severe forms of the disease, which we haven't seen in other research.

Characterization of blood groups in such a large number of convalescing patients has only been published in Spain and Italy, not for Latin American populations where the frequency composition of blood groups is different. In Cuba, it's even different by provinces, depending on genetic ancestry. That is, those with more African genetic ancestry are more frequently blood group $\mathrm{O}$, which in some populations appears to be a protective factor against infection, although not against developing severe forms.

And the other important thing is that all these findings contribute to a national strategy for confronting COVID-19, particularly ongoing prevention efforts. Because we now have results that not only consider research from other countries, but most importantly detail quite precisely how the disease is behaving right here in our own population. And thankfully, through the Ministry of Public Health and the experts working on COVID-19, we have a direct line to the decision-makers. $-1 /$ - 


\title{
Cuba's Medical Team in the European Epicenter of COVID-19: Carlos R. Pérez-Díaz MD MS PhD Director, Joaquín Albarrán Provincial Clinical-Surgical Hospital, Havana Henry Reeve Medical Contingent Leader, Lombardy, Italy
}

\author{
Gisele Coutin MD MS and Conner Gorry MA
}

On March 23, 2020, Cuba's Henry Reeve Emergency Medical Contingent began treating COVID-19 patients at Maggiore Hospital in Crema, Lombardy. Within days, the 52-member contingent comprised of 36 doctors and 15 nurses (plus 1 logistics specialist), together with Italian colleagues, were receiving patients in an adjacent field hospital established and equipped for this purpose. At the time, Lombardy was the epicenter of COVID-19 transmission in Europe.

Many of the Cubans in Lombardy were Contingent veterans, having served in postdisaster and epidemic scenarios in Chile, Pakistan, Haiti and elsewhere since the founding of the emergency medical team in 2005.

Importantly, some had worked fighting the 2014 Ebola epidemic in West Africa. Even

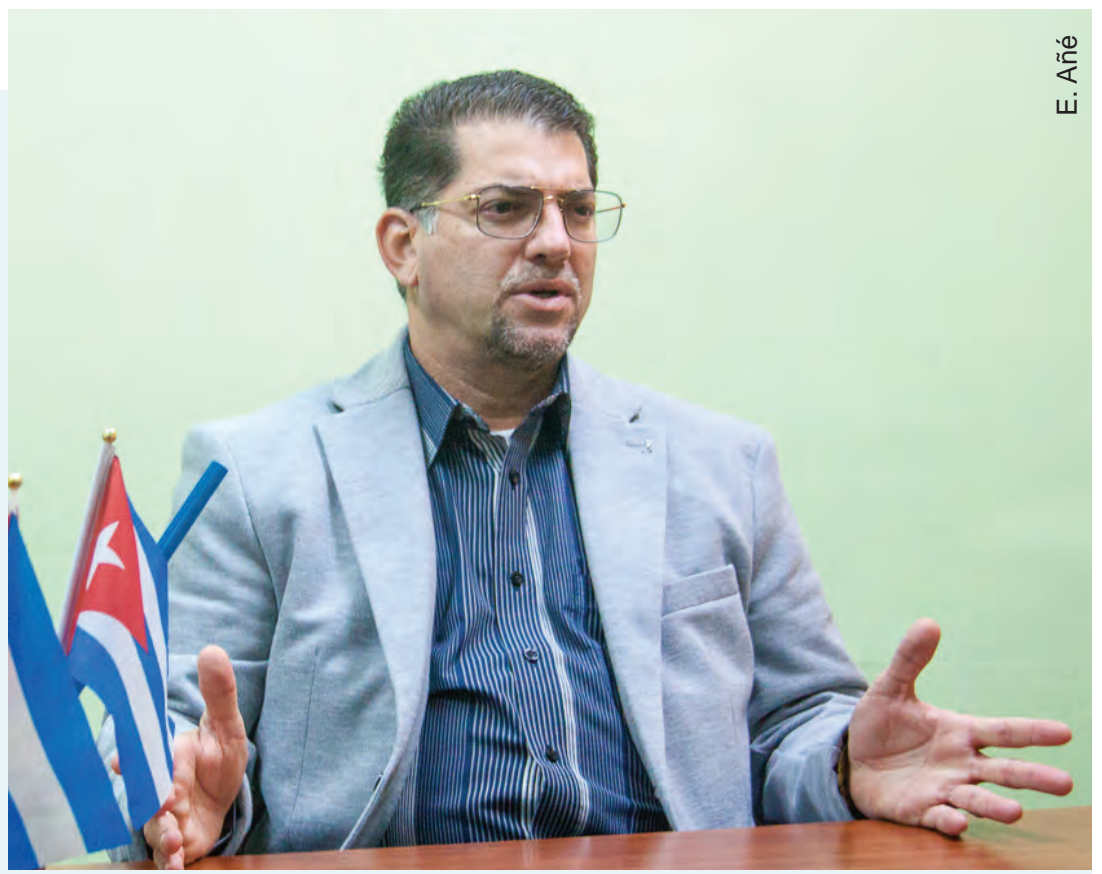
so, providing medical care during COVID-19 is a unique challenge, the likes of which had never before been seen by the Cuban team.

Dr Carlos R. Pérez-Díaz, one of the Contingent's founding members, headed the team during its 60-day rotation in Lombardy, drawing on a wide array of professional experience. From 2006 to 2009, Dr Pérez-Díaz led the Cuban team posted at the Peltier Hospital in Djibouti, where he worked in the infectious disease department; in 2008, this team helped control a cholera outbreak that had spread to three countries. Following the 2010 earthquake in Chile, Dr Pérez-Díaz headed the team of Henry Reeve volunteers that provided free health services for 10 months in a tent hospital established to treat victims; he returned to Chile in 2015, again as head of the Henry Reeve Contingent, after severe flooding struck the Atacama region.

Dr Pérez-Díaz has dual specialties in family and internal medicine and a doctorate in medical education. Additionally,

MEDICC Review: You-and the team you headed-have extensive overseas experience, but Cuban medical professionals had never before served in Europe, nor during a pandemic of this magnitude. Can you describe how the Lombardy COVID-19 effort differed from other overseas postings?

Carlos R. Pérez: Everyone on the team knew we'd be facing a huge challenge in Lombardy. Although the scientific and medical standards there are high, COVID-19 was new, it was ravaging

in 2014 he was accredited as a medical expert to treat victims of chemical warfare and dangerous chemical substances by the Organization for the Prohibition of Chemical Weapons (OPCW); in 2019 he began imparting classes for the OPCW. Dr Pérez-Díaz is currently the director of the Joaquín Albarrán Provincial Clinical-Surgical Hospital in Havana, a post he has held since 2015. He is a member of the expert panel formed in January 2020 by Cuba's Ministry of Public Health (MINSAP) to confront COVID-19. Since returning from Lombardy, Dr Pérez-Díaz has worked in hospitals, multi-service community polyclinics and isolation centers in various provinces helping contain the pandemic at home, and participates in training future Henry Reeve teams at Cuba's Central Medical Cooperation Unit (UCCM). MEDICC Review had the opportunity to interview Dr Pérez-Díaz as he juggled various responsibilities_including the possibility of heading overseas again as subsequent waves of COVID-19 strike around the world.

the region and we had to apply our knowledge and incorporate emerging evidence within this difficult context. We began treating patients in late March; our Italian colleagues had been battling COVID-19 for some time before we arrived and had developed protocols based on autopsy studies.

Fortunately, 31 of the Contingent's 52 members in Lombardy had also served in West Africa during the Ebola epidemic. This previous epidemic-control experience helped; we understood the need 
for strict biosafety protocols, for example, and were able to share firsthand experiences with others. I think this was particularly useful for the younger members of our team.

MEDICC Review: Given the factors particular to providing medical services during COVID-19, did volunteer recruitment differ for this Henry Reeve team?

We learned a lot from our
Italian colleagues and were
confident that working
together we could save lives

Carlos R. Pérez: Recruitment principles for the Lombardy team were the same as in previous efforts over the past 15 years: everyone was a volunteer; local health authorities indicated which specialists they most needed; selection was based on availability; and only those who would not affect services in Cuba were eligible. Nevertheless, given the risk entailed, priority was given to experienced Henry Reeve veterans-especially those who had worked in West Africa fighting Ebola.

By this point, several countries had requested Cuba's help to address COVID-19, and mixed brigades-with a combination of veterans from the Ebola outbreak and other volunteers-became the norm. In this way, the intense work in Africa and the valuable lessons learned could be shared across different teams now facing COVID-19.

MEDICC Review: What preparation did you receive before leaving for Italy? The biosafety protocols for COVID-19 plus working in a tent hospital must have warranted special consideration...

Carlos R. Pérez: First, it's worth pointing out that in February 2020, MINSAP provided countrywide, province-by-province training for all our health professionals on prevention and control of the novel coronavirus. So we had a jump-start. Once the members for the Lombardy team were selected, we received a specialized course from professors of the Pedro Kourí Tropical Medicine Institute (IPK) in Havana. This covered all the latest COVID-19 protocols and biosafety measures, plus step-by-step training on working in wards for confirmed cases, also known as 'red zones'. (IPK, Cuba's national reference center for infectious diseases is where Henry Reeve members received biosecurity training before departing for West Africa. The institute has provided COVID-19 testing, research and patient care since the first cases in Cuba were diagnosed on March 11, 2020, Eds).

Personally, the OPCW courses I took related to injuries sustained from chemical weapons and dangerous substances helped immensely in my preparation. This included biosafety measures of course, but also disaster modeling scenarios where I gained invaluable organizational, planning and resource allocation experience.

\section{MEDICC Review: How was the work organized in Crema?}

Carlos R. Pérez: As soon as we arrived our shifts were organized and distributed between the Cuban team and our Italian colleagues. We received supplementary training on proper use of personal protective equipment (PPE), plus learned local protocols for case classification, and patient management and treatment regimens for each case based on their clinical evolution and imaging studies. During this process, various recommendations from our epidemiologists were adopted to assure maximum protection for personnel working with red zone patients. Next we familiarized ourselves with nursing procedures and how to perform arterial blood gas analysis adapted to the technology used in Italy-some of which was new to us. We also updated emergency fire safety and protection protocols while we were at it.

MEDICC Review: Working with professionals from a different culture, in a different language, in an extraordinarily difficult context-medical and personal. Can you talk about the collaborative aspect of your work?

Carlos R. Pérez: The language barrier was challenging at first when we all defaulted to English, but since Spanish and Italian are both romance languages with similar vocabulary and phrases, we quickly adapted. Another factor that facilitated our cooperation despite these differences was the fact that it had been established from the outset that the Cuban team would be subordinate to the needs of the region and would adhere strictly to local case management and treatment protocols. As a result, we developed great relationships with our Italian colleagues during our two-month rotation. It was a very positive work atmosphere marked by cooperation and scientific exchange. Every day we-Italians and Cubans alikelearned more about the physiopathology of COVID-19, the evolution of the disease and how to apply this knowledge to patient care. Emerging evidence from autopsies; the negative effects of invasive mechanical ventilation and the benefits of regular prone position ventilation; and the importance of early, comprehensive and individualized treatment meant we were constantly incorporating new knowledge and developing ideas together about how to better treat patients.

\section{Successful cooperation of this type depends on mutual respect}

The learning process was a two-way street. We came to appreciate on a deeper level that successful cooperation of this type depends on mutual respect-between and among colleagues and patients. This includes respecting each other's customs, culture and religious beliefs. Fundamental as well is support from local government, religious leaders, civil society and support groups, police and the armed forces. The Italian army proved vital during our collaboration, resolving complex logistical problems quickly.

Once they got to know us and our work ethic, I think our Italian counterparts learned from us as well. Our humane and affectionate manner with patients and our diagnostic capabilities-using our skills and whatever tools are available-are things Cuban doctors are known for. But it wasn't only our clinical methods and economic use of resources-it was also our adaptability to new, advanced technologies that they came to value.

MEDICC Review: And the local population, the patients? How did they respond to your presence and work?

Carlos R. Pérez: The care and affection we showed our patients was reciprocated by them and their families. We were shown tremendous hospitality and after a few weeks, Cuban flags and banners with messages of gratitude for our coopera- 
tion began appearing on balconies throughout Crema. Solidarity abounded and it was inspiring to see all these messages of hope, a ray of light in this very dark time, with so many people dying.

MEDICC Review: Indeed, this pandemic has filled the world with so much pain and loss. How did you and the team confront this-especially given the risky work you were doing and the possibility of getting infected yourselves?

Carlos R. Pérez: To be honest, it was Dantesque, especially at the beginning. The fear of infection and death was always there and the context in which we were working was difficult, to say the least. All of us were thinking of our families, our chilldren and the possibility that we might not return...But we knew the best way to overcome this fear was through discipline, by adhering strictly to biosafety protocols and maintaining a positive attitude-individually and collectively. Before leaving Cuba, we were conscious of the commitment we were making and that it wouldn't be an easy undertaking. Every day before heading to the hospital, we reminded ourselves of this commitment, underscoring the importance of observing all biosafety measures-even though they were a pain. Persistence and determination became our mantra.

It helped that we were in constant contact with our families. This kept our spirits up and allowed us to face each day with the good humor for which Cubans are known. It's ingrained in us-you could say it's in our blood-and accompanies us wherever we go.

MEDICC Review: How about results? What would you consider the main outcomes of your work in Lombardy?

Carlos R. Pérez: Our 60-day rotation was intense, and virtually all of it in red zones, with highly complex patients. The bulk of the work was conducting consultations (5526), and performing nursing procedures (3676). Members of our team also worked in the coronary ICU attending critical patients, where we carried out 228 interventions. In the internal medicine department, we attended 1800 serious patients, and in the pulmonology department, we managed another 854 serious patients. Our records show that 219 seriously ill patients in our care were saved, while 10 lost their lives to the disease.

Beyond the statistics, the experience itself was an important result-reinforcing our biosafety knowledge on control and management of serious epidemics in a field hospital is an invaluable takeaway; this will serve us well in future collaborations, wherever they may take us.
Cuba's Henry Reeve Medical Contingent was awarded the Dr Lee Jong-wook Memorial Prize for Public Health by $\mathrm{WHO}$ in 2017. The Contingent has been nominated for the 2021 Nobel Peace Prize.

MEDICC Review: Given the high-risk work you were doing, what steps were taken to protect you, your families and the local community when you returned from Italy?

Carlos R. Pérez: Upon returning, the entire team underwent a ten-day quarantine in La Pradera (located in Havana, La Pradera is an international health facility offering a variety of specialized medical and health services; a wing was equipped as a quarantine center for the Henry Reeve team, Eds). Once there, we continued observing strict national COVID-19 protocols and were each tested by RT-PCR; on the ninth day of quarantine the test was repeated. The entire team tested negative for COVID-19 in the first and second tests. Each member also received immunoglobulin antibody tests (both IgG and IgM) to determine whether we had been exposed to the virus at any point, all of us testing negative again. After these results were in, we received the okay to return to our homes and communities-again, following the protocols established nationally for COVID-19 control.

MEDICC Review: Have this and other postings made a difference in your work back in Cuba?

Carlos R. Pérez: These experiences are enriching both professionally and personally. Helping save lives, far from home, makes you look at life differently. Of course, we gain knowledge-medical, scientific, cultural-working with colleagues from around the world. But international postings go beyond that, helping us broaden our horizons and develop into more well-rounded individuals and doctors, as we interact with patients and families from differing backgrounds, social classes, belief systems and languages.

\section{MEDICC Review: Would you do it again? Volunteer overseas?}

Carlos R. Pérez: Absolutely. Saving lives and helping mitigate the impact of natural disasters or epidemics is something I will always be ready to do-no matter where in the world. The indelible lessons and experiences, especially the gratitude shown us by our patients, their families and the local population, are the greatest reward imaginable. -1 . 


\title{
Cuban Prophylactic and Therapeutic Vaccines for Controlling Hepatitis B
}

\author{
Eduardo Pentón-Arias MD PhD and Julio C. Aguilar-Rubido PhD
}

\begin{abstract}
Hepatitis B causes liver failure, cirrhosis and cancer. It has an estimated global prevalence of $6 \%$, and 700,000 to 1 million persons die every year of hepatitis B-related causes. In 1989, hepatitis B incidence in Cuba was 14.9 per 100,000 population. To control infection, the Genetic Engineering and Biotechnology Center and the Ministry of Public Health, both in Havana, collaborated on a joint project that first produced natural interferon and recombinant interferon alpha-2b, and later a polyethylene glycolconjugated interferon. As part of the Cuban biotechnology development strategy, the project produced a vaccine against hepatitis B in 1985. At that time, hepatitis $B$ vaccines available elsewhere in the world were costly and inaccessible to Cubans due to the US economic and trade embargo. The Heberbiovac HB preventive vaccine was approved by the Cuban regulatory authority and added to the Cuban newborn vaccination program in 1992 after phase 1-3 clinical trials demonstrated its safety and immunogenicity. From 2001 to 2003, PAHO/WHO qualified and requalified the vaccine four times. When associated with other antigens or molecules, Heberbiovac HB provides a common platform of virus-like particles that can be used in different ways, such as in the pentavalent vaccine containing Bordetella pertussis and Haemophilus influenzae type $\mathrm{b}$ antigens and tetanus and diptheria toxoids.
\end{abstract}

\section{INTRODUCTION}

This paper discusses the Cuban preventive recombinant vaccine for hepatitis $B(\mathrm{HB})$, Heberbiovac $\mathrm{HB}$, which eliminated acute hepatitis $B(A H B)$ from among the nation's health problems. We also discuss a new version, which contains two antigens (rHB$\mathrm{sAg} / \mathrm{rHBcAg}$ ). This version is the precursor to a therapeutic vaccine, HeberNasvac, now supported by four published clinical trials completed in Cuba and Bangladesh.[1-4]

The hepatitis B virus (HBV) causes acute and chronic hepatitis, as well as liver failure, cirrhosis and cancer. Global HB prevalence is estimated at $6 \%$. Every year, more than 4 million persons are infected, and 700,000 to 1 million die. There are reportedly $>350$ million HBV carriers worldwide, of whom approximately $25 \%$ are expected to die of chronic liver disease, cirrhosis or primary hepatocellular carcinoma. In its 2017 Global Hepatitis Report, WHO set a goal to eradicate hepatitis B and C by 2030.[5]

In 1989, HB incidence in Cuba was 14.9 per 100,000 population, and prevalence of chronic hepatitis was $1 \%-5 \%$, according to research on infection detection. Chronically infected patients become reservoirs for virus spread, and it is estimated that at

\section{IMPORTANCE}

This article summarizes 30 years of work by Cuba's Genetic Engineering and Biotechnology Center (CIGB) in controlling hepatitis $B$, the impact of its recombinant preventive vaccine and promising results for a related therapeutic vaccine.
Thanks to this vaccine, annual incidence of acute hepatitis in Cuba has dropped from more than 2000 cases to fewer than 100, and no infections in children aged 0-15 years have been reported since 2007. It is now used in more than 30 countries, providing protective, long-lasting antibody levels with no reports of serious adverse events.

Yet, hepatitis B cannot be eliminated until there are no chronic patients. The comprehensive hepatitis $\mathrm{B}$ control project therefore included development of a therapeutic vaccine based on Heberbiovac HB. Using its platform, researchers designed an innovative version of the vaccine that was the precursor of a therapeutic nasal/subcutaneous vaccine for chronic hepatitis $B$, HeberNasvac. This precursor vaccine, which combines Heberbiovac $\mathrm{HB}$ with a recombinant antigen from the virus nucleocapsid ( $\mathrm{rHBcAg}$ ), was patented and licensed in 2015 by the Cuban regulatory authority. This article provides an overview of the progress-to-date on the development of this therapeutic vaccine, including clinical trials (some completed and others ongoing) to determine safety, efficacy and therapeutic benefits.

KEYWORDS Hepatitis B, vaccines, recombinant DNA, clinical trials, Cuba

least $10 \%$ of new infections become chronic.[6] In the 1980 s, $\mathrm{HB}$ vaccines were costly (US\$239 per dose),[7] and the only one was manufactured in the United States, thus off limits to Cuban patients due to the US embargo on Cuba. Thus, as part of its domestic biotechnology development strategy, in 1985, Cuba conducted clinical trials to evaluate the safety, immunogenicity and efficacy of its own prophylactic vaccine (PV) which was then licensed and included in the Cuban vaccination program.[7]

Using prophylactic vaccination, Cuba has reduced HB morbidity and mortality by more than $95 \%$ since $2003,[8]$ but control and elimination cannot be achieved until there are no more patients with chronic $\mathrm{HB}(\mathrm{CHB})$. Cuba has therefore designed and produced a therapeutic vaccine (TV), HeberNasvac, for CHB.

The scientific community has received limited reports on the results of Cuba's development and use of preventive recombinant vaccines for $\mathrm{HB}$, especially on the impact of preventing infection through universal prophylactic vaccination of newborns. This information is important for countries with limited resources because the immunogen used in the prophylactic vaccine, the HBV surface antigen obtained using recombinant DNA technology (rHBsAg), is autochthonous. The PV's rHBsAg is also a component of the TV, which gives the TV the safety and effectiveness demonstrated in prophylactic vaccination over the last 28 years in Cuba and more than 30 countries, with no reports of serious adverse events following immunization (AEFI).[9]

Any biopharmaceutical to be used in the Cuban health system must prove that it can solve or ameliorate a major health problem, and its development and production must be financially self-sustaining.[10] It must also meet the needs of the domestic market 
and create exportable surplus to support continued research and development, as well as the health system, a "closed loop."

Preventive strategies, such as vaccines for $\mathrm{HB}$ and therapies to cure or improve $\mathrm{CHB}$, aim at disease eradication, but immunotherapies such as interferon (IFN), monoclonal antibodies and therapeutic vaccines have received special attention because they link different generations of biotech products. While the Cuban $\mathrm{PV}$ has been shown effective in decreasing $\mathrm{HB}$ incidence and mortality, like other countries, Cuba has not been able to reduce prevalence of chronic infection due to poor results from conventional treatments. Therefore, as part of its HB control project and biotechnology development strategy, Cuba decided to develop a TV that would stimulate the immune system to eliminate the virus in $\mathrm{CHB}$ patients.

Our main purpose is not to describe clinical trials of the recombinant PV and TV before their approval, but rather the principles, properties and development of these vaccines. This brief survey of TV clinical trials may also indicate how these vaccines perform in different scenarios, since the TV contains the PV's main component. The PV Heberbiovac HB was licensed 30 years ago and has been used in Cuba and abroad, but what is most impressive is its impact during decades of use in Cuba and elsewhere. The results show that it has controlled and eliminated HBV in Cuban children aged 0-15, with no major adverse effects and only mild transient effects.[7]

\section{DISCUSSION}

Characteristics and composition of hepatitis $B$ vaccines The Cuban PV and TV for hepatitis B were designed and produced at the Genetic Engineering and Biotechnology Center (CIGB). The Cuban recombinant $\mathrm{PV}$ for hepatitis $\mathrm{B}$ was licensed as Heberbiovac HB in Cuba in 1990,[11] and by PAHO/WHO in 2003.[7] Each $1 \mathrm{~mL}$ dose of PV for intramuscular administration contains $20 \mu \mathrm{g}$ of the hepatitis B surface antigen " $\mathrm{s}$ " produced using recombinant DNA technology (rHBsAg) in $\mathrm{Al}^{3+}$ hydroxide, sodium chloride $(\mathrm{NaCl})$, sodium phosphate dibasic anhydrous or sodium phosphate monobasic dihydrate, and $0.05 \mathrm{mg}$ of thiomersal.[11]

Heberbiovac HB differs from similar vaccines on the global market in three main ways:

1) The recombinant antigen is obtained in a strain of Picchia pastoris yeast transformed by genomic DNA insertion that codes rHBsAg expression, while other vaccines are usually derived from plasmid constructions expressed in Saccharomyces cerevisiae.

2) The process, which involves original chromatographic purification using adsorption and desorption in diatomaceous earth, and industrial columns with immunoaffinity with a suitable, specific and selective monoclonal antibody developed at CIGB, preserves the molecular integrity of the rHBsAg.[12,13]

3) As a result of this process, rHBsAg is obtained as virus-like particles (VLPS) that form aggregates. Within these, a wide variety of epitopes are protected from proteolysis and form highimmunogenicity clusters that preserve antigen diversity, thus favoring a multispecific immune response.

Heberbiovac HB provides a common platform of VLPs with different use options, such as the pentavalent vaccine, included in the
Cuban immunization program after licensing in 2006,[14] which includes antigens for HBV, Bordetella pertussis, and Haemophilus influenzae type b, as well as tetanus and diphtheria toxoids. But the newest example is the HeberNasvac nasal/subcutaneous therapeutic $\mathrm{HBC}$ vaccine, which integrates Heberbiovac $\mathrm{HB}$ with the recombinant HBV nucleocapsid antigen (rHBcAg).

The TV formulation licensed as HeberNasvac [15] contains two recombinant $\mathrm{HBV}$ antigens, and is a mixture of equal parts of rHBsAg produced in P. pastoris with recombinant HBV nucleocapsid antigen (rHBcAg) produced in Escherichia coli. Each $1 \mathrm{~mL}$ dose for intranasal (IN) or subcutaneous (SC) administration contains $100 \mathrm{mg} \mathrm{rHBsAg}+100 \mathrm{mg}$ rHBcAg, suspended in a solution of disodium hydrogen phosphate, disodium phosphate dihydrate, ethylene-diamine-tetra-acetic acid (EDTA) disodium salt, $\mathrm{NaCl}$ and water for injection, without adjuvant.[15] Like Heberbiovac HB, it can provide a common immune-potentiating platform for other antigens.[16,17]

Heberbiovac HB prophylactic vaccine CIGB and the Ministry of Public Health (MINSAP) developed an HBV control program for hospitals and community polyclinics to test and administer natural, recombinant and polyethylene glycol-conjugated IFN (PEGIFN), as well as the Heberbiovac HB vaccine.

Phase 1, 2 and 3 clinical trials with a $20 \mu \mathrm{g} / \mathrm{mL}$ dose of Heberbiovac $\mathrm{HB}$ in adults, children and newborns demonstrated its safety, immunogenicity and protective efficacy. The national regulatory authority, the Center for State Control of Medicines and Medical Devices (CECMED), supervised and approved clinical trials performed from 1989 to 1991.[7] This entity licensed the PV[11] and authorized its use in the Cuban immunization program starting in 1992, with a first dose at birth for all newborns and in groups considered at high risk for HBV.[8] Vaccination was organized by MINSAP in collaboration with CIGB, under the supervision of CECMED.

The Cuban vaccine controlled transmission of HBV in vaccinated groups and reduced the annual HBV infection rate in the general population from more than 2000 to fewer than 100 per year (Figure 1). By 2006, HBV incidence had been reduced by $99 \%$ compared to the 1992 rate, before universal vaccination of newborns. Since 2007, no cases of AHB have been reported in children from birth to

Figure 1: Annual acute Hepatitis B cases in children and the general population, Cuba 1992-2018

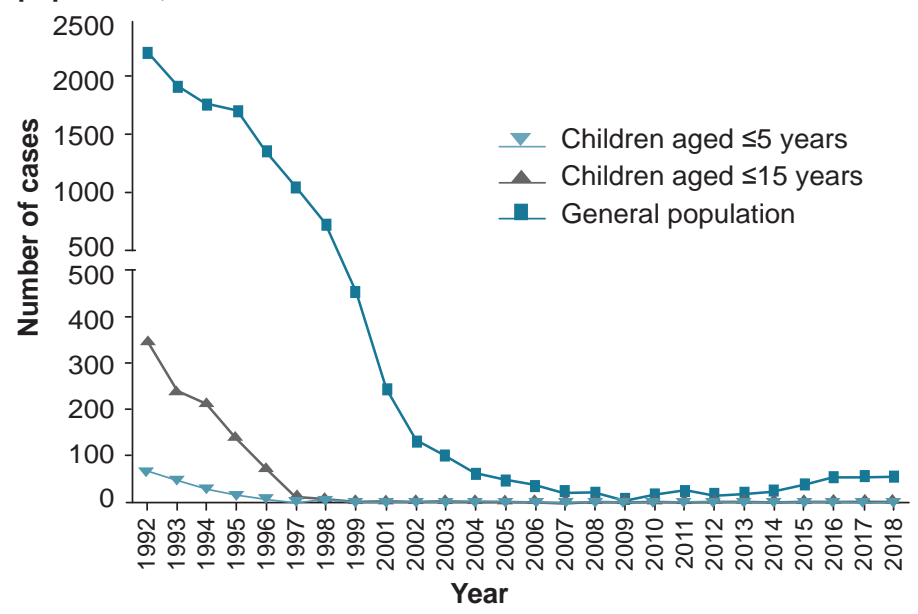


age 15 years.[6] HBV vaccination coverage has been maintained above 98\% since 1994.[6,7] This broad coverage, along with the vaccine's immunogenicity, explains the decreased incidence of $\mathrm{AHB}$ and the absence of new cases in persons aged $<15$ years.

A study published in 2006 reported a perinatal transmission of $3.8 \%$ in children of seropositive mothers $(\mathrm{HBsAg}+)$, proving that the vaccine protects infants born to $\mathrm{HbsAg}+$ mothers, since these children are at high risk of infection.[18]

Since 1992, 80 postmarketing clinical trials of the PV have been conducted in Cuba and other countries in more than 35,000 patients, both adults and children. These trials confirmed its safety, immunogenicity and protective efficacy.[7] Three phase 4 studies conducted in Cuba in infants aged under one year under routine use conditions demonstrated safety similar to that in phase 1-3 clinical trials, and the vaccine's ability to provoke a protective response against HBV in children aged less than five years. This was a long-term response showing antibody titers above $10 \mathrm{IU} / \mathrm{L}$ (protective) 5 years after vaccination in $95.4 \%$ of children.[19]

Additional postmarketing studies involving adult and childhood vaccination were performed in 35 countries on 3 continents. Mild local AEFIs were reported. At 75 days post-vaccination, seroconversion with seroprotection (anti-HB concentrations above $10 \mathrm{IU} / \mathrm{L}$ ) was reported in $92 \%$ of adults and $100 \%$ of children. At two years, the studies confirmed that $100 \%$ of those vaccinated had protective antibody levels.[20] Based on the duration results obtained in different studies and the estimated 3-year half-life of anti-HBs, it was predicted that protective antibody levels would still be present at 15 years post-vaccination.[21]

Despite reduced HB incidence in Cuba and the fact that no AHB cases in children aged $0-15$ years have been reported since 2007, MINSAP continues monitoring children born to $\mathrm{HBsAg}+$ mothers after Heberbiovac HB became part of the national vaccination schedule, because a possibility of hidden infection exists even in the presence of antibodies against the vaccine antigen. A study published in 2016 reported that $2.1 \%$ of children aged 7 months to 5 years, born from 2002 to 2012, had hidden HB infection with positive viral DNA, although they had developed antibodies in response to vaccination.[22] However, later studies found high protection levels in children of seropositive mothers (93.8\%) when they were studied from age 3 to 18 years, and only 1 of 32 children showed hidden infection.[23]

WHO first accepted Heberbiovac HB in 2001 and certified it for compliance with its good manufacturing practices guidelines,[7] thus ensuring that exportable surplus product could be marketed within a closed-loop system.

Immunopathology and immunotherapy in chronic hepatitis B In those who recover from a primary HBV infection (produced by a noncytopathic but immunopathogenic virus) is associated with a strong polyclonal, multispecific and cytotoxic T-cell response against viral nucleocapsid (core) proteins, viral polymerase and the viral envelope antigen.[24,25] However, in patients who develop a persistent necroinflammatory infection, these cell responses are weak or even undetectable. Thus, the predominant immunotherapy trend for $\mathrm{CHB}$ is to promote activation and expansion of a sustained, effective antiviral T-cell immune response. The purpose of the HeberNasvac TV for CHB was to improve the responses elicited by other TV candidates, which failed to resolve the infection.

To eradicate HBV, it must be eliminated in chronic patients, who are disease reservoirs. Various CHB therapies are being explored, which has turned it into a "proving ground" where only IFNs, nucleoside or nucleotide analogues, anti-HB intravenous immunoglobulin, and liver and bone marrow transplants have met US Food and Drug Administration (FDA) requirements and received approval. However, transplants are used only when HBV coexists with other diseases for which transplant is indicated, such as terminal liver failure, leukemias and lymphomas.[26]

Antiviral therapies reported effective in treating $\mathrm{CHB}$ include interferon alpha (IFN-alpha) and PEG-IFN, of which CIGB produces a biosimilar,[27] and nucleoside or nucleotide analogues (NAs). IFN-alpha achieves 10\%-20\% sustained viral suppression 24-48 weeks post-treatment, and PEG-IFN shows 30\% effectiveness. $[28,29]$ PEG-IFN has antiviral and immunomodulatory properties, but limited effectiveness because it does not clear infected cells, fails to fully inhibit viral replication since it leaves remaining pockets of virus, and does not effectively reverse weak antiviral T-cell response. NAs are highly effective in controlling HBV and work by inhibiting viral reverse transcriptase,[29] but require lengthy treatment and cause major adverse events (AEs), thereby reducing expected benefits in clinical practice. Although alternative treatments with simple preparations of IFN or PEG-IFN are given for limited periods, they usually cause AEs that sometimes reduce treatment compliance.[30]

Since HB can be eradicated only by preventing new cases and curing chronic patients, in addition to manufacturing the PV and TV, Cuba's strategy for controlling and eradicating HB through prophylactic and therapeutic vaccination was based on developing technologies that allowed it to:

1) Produce and purify polyclonal antibodies against viral antigens. 2) Obtain HBs monoclonal antibodies (McA) to purify rHBsAg and develop analytical and diagnostic methods.

3) Standardize and validate qualitative and quantitative ELISA for viral antigens (HBsAg, anti-HBs, HBcAg, anti-HBc).

4) Develop methods for quantitative determination of viral load $(\mathrm{VL})$ by polymerase chain reaction (qPCR) for HBV DNA. To treat $\mathrm{CHB}$, the natural IFN, recombinant IFN and PEG-IFN therapeutic biomolecules were produced. PEG-IFN prolongs IFN activity by extending its half-life in blood and improving its effectiveness.

Therapeutic vaccine Although no TV in the world has been approved for clinical use, TVs have gained ground among products proposed for treating $\mathrm{CHB}$ in an attempt to eradicate the disease.[21] Cuba has produced the HeberNasvac vaccine candidate, and its safety and efficacy shown in clinical trials reveal its potential to treat patients with chronic disease. This vaccine has been patented[31-33] and was registered in Cuba in 2015.[15]

Its efficacy seems to be related to the presence of trace amounts of nucleic acids from $E$. coli bound to the C-terminal region of the rHBcAg molecule. According to mass spectrometry studies, these nucleic acids make up a nucleoprotein within the VLP that could contribute to the strong immunogenicity of rHBcAg, as well as its adjuvant effect on rHBsAg,[34] which has been proven for other antigens.[16,17] 
This TV's first clinical trials in Cuba involved healthy volunteers and a small number of patients with $\mathrm{CHB}$, and other trials were conducted in Bangladesh (ClinicalTrials.gov NCT 01374308). All were completed and their results published.[1-4] Additional trials are now underway (in Japan and Bangladesh) or in the planning and design stage in other countries. If new trials confirm the results of completed and published studies, HeberNasvac could be recognized as the first effective TV for chronic HBV that contains two antigens originating from the virus. Insertion of $\mathrm{rHBsAg}$ into a TV formulation is also being used as an immune-stimulating carrier and modulator of a synthetic HIV antigen in a TV candidate for treating HIV $[16,17]$ now being used in a clinical trial.

Previous attempts used TVs based solely on rHBsAg that contained potent adjuvants, but failed to control viral replication, although they did show some ability to subvert tolerance to the viral antigen.[25] This effect was attributed to the lack of response against $\mathrm{HBcAg}$, an important $\mathrm{CHB}$ immune marker[35] and to the fact that adoptive transfer of $\mathrm{HBcAg}$-specific T-cells controls HBV and induces anti-HBs seroconversion.[36] This evidence suggested that HBcAg could be used as an immunogen along with rHBsAg to increase the number and variety of epitopes required for an effective antiviral response.[37]

Preclinical experiments in animal models of $\mathrm{CHB}$, including HBV and HBsAg transgenic mice, have demonstrated the immunogenicity of intranasal and subcutaneous HeberNasvac. Pharmacologic, preclinical and toxicologic animal studies have confirmed its safety and efficacy, including experiments with DNA, Dane particles, HBsAg and HBeAg. These studies showed that HBsAg tolerance ended, and strong humoral and cell responses against HBsAg and HBcAg began, with a predominantly T helper cell 1 (Th1) immune response. The studies also demonstrated the vaccine's immunogenicity and its ability to induce a response in mucosal and systemic compartments. [38-43] Acute toxicity, repeat-dose and safety studies using intranasal and subcutaneous inoculation showed no local or systemic toxic or adverse effects, or macro- or microscopic changes in organs. $[44,45]$

HeberNasvac can be given as a preventive vaccine in populations with little or no response to conventional prophylactic vaccines, and to healthy persons at risk for HBV. It has shown greater effectiveness and/or fewer AEFIs compared to other treatments. The standard of care for $\mathrm{CHB}$ includes antiviral treatments that effectively suppress the chronic virus but require lifelong antiviral treatment.[46]

HeberNasvac is the first product with activity against $\mathrm{CHB}$ that contains both surface antigens (HBsAg) and nucleocapsid antigens $(\mathrm{HBcAg})$ in the form of VLPS, that can be administered intravenously and/or subcutaneously. Figure 2 outlines the general schedule for patients with $\mathrm{CHB}$ (HBsAg+ for $\geq 6$ months).

Clinical trials with HeberNasvac in healthy volunteers and CHB patients The phase 1 (two trials), phase $1 / 2$ and phase 3 trials were conducted in Cuba, in the Abel Santamaría Cuadrado Provincial Clinical-Surgical Hospital in Pinar del Río Province, Cuba, and in the Bangabandhu Sheikh Mujib Medical University and Farabi Hospitals in Dhaka, Bangladesh, in strict compliance with Good Clinical Practice guidelines, and following the Declaration of Helsinki[47] with certification by CECMED.
Figure 2: HeberNasvac immunization and followup schedules

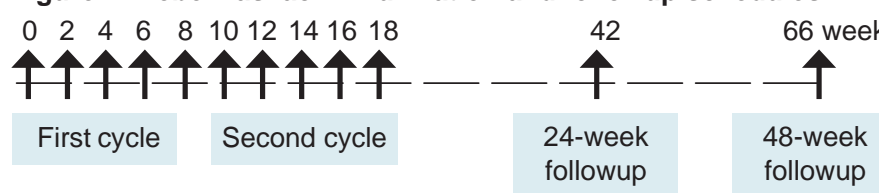

Nasal vaccine: $100 \mu \mathrm{g} \mathrm{HBsAg}$ and $100 \mu \mathrm{g} \mathrm{HBCAg}$

Subcutaneous vaccine: $100 \mu \mathrm{g} \mathrm{HBsAg}$ and $100 \mu \mathrm{g} \mathrm{HBcAg}$

After receiving a detailed explanation of the study's risks and benefits, each participant provided written consent. Investigators selected laboratory methods according to principles of maximum possible benefits and minimal possible harm, following good laboratory practices. Each of these clinical trials received approval from the relevant institutional ethics committee and was completed and published.[1-4]

Phase 1 clinical trial in healthy persons A phase 1 (code: IG/VHN/ $\mathrm{HB} / 0201$ ) placebo-controlled, randomized, double-blind trial was conducted in 19 healthy adults (9 vaccinated and 10 who received placebo) to evaluate the preliminary safety and immunogenicity of intranasal immunization with HeberNasvac, following a schedule of 5 doses containing $50 \mu \mathrm{g}$ of each antigen per dose $(0.5 \mathrm{~mL})$, at 14-day intervals.[1]

In this trial, HeberNasvac showed a safety profile comparable to that of the saline solution used as placebo (Table 1).

The vaccine showed high safety and minimal reactogenicity. There were no unexpected or serious AEFIs, and no volunteers left the study due to them. Basic hematology and clinical chemistry parameters showed no abnormalities. The AEFIs noted were mild and few; local AEFIs most often seen were sneezing, rhinorrhea, nasal obstruction and laryngeal itching, all occurring in $<35 \%$ of patients. Among systemic AEFIs, most common were headache and general malaise, both in $<10 \%$ of cases.

This clinical trial demonstrated the immunogenicity of HeberNasvac, since $100 \%$ of vaccinated subjects responded to $\mathrm{HBcAg}$ with anti-HBc titers $>1: 10$. A high percentage of subjects generated an anti-HBs protective response (concentrations $\geq 10 \mathrm{IU} / \mathrm{L}$ ), and of these, more than half were good responders (anti-HBs $\geq 100 \mathrm{IU} / \mathrm{L}$ ). The volunteers in the placebo group remained negative for both antibodies throughout the study.

The licensed therapeutic HBV vaccines produce a seroprotective response of up to $20 \%$ after the first dose and $71 \%$ one month after the second dose in healthy young adults.[48,49] These were encouraging results, considering that these were the first humans immunized intranasally with HBsAg, and that the TV was not yet optimized for dose and vaccination schedules. Subsequent studies focused on testing higher concentrations of the antigen by dose and number of inoculations.

Phase 1 clinical trial in CHB patients A phase 1 clinical trial evaluated the safety of an active immunotherapy schedule with HeberNasvac administered intranasally in six patients with $\mathrm{CHB}$ refractory to treatment with recombinant interferon alfa-2b, the standard of antiviral care for $\mathrm{CHB}$ in Cuba. Average patient age 
Table 1: Summary of clinical trials to evaluate HeberNasvac

\begin{tabular}{|c|c|c|c|c|}
\hline & $\begin{array}{c}\text { Phase } 1 \mathrm{CT} \text { in healthy } \\
\text { volunteers[1] }\end{array}$ & $\begin{array}{c}\text { Phase } 2 \mathrm{CT} \text { in } \mathrm{CHB} \\
\text { patients[2] }\end{array}$ & $\begin{array}{c}\text { Phase } 2 / 3 \mathrm{CT} \text { in CHB } \\
\text { patients [3] }\end{array}$ & $\begin{array}{c}\text { Phase } 3 \mathrm{CT} \text { in } \mathrm{CHB} \\
\text { patients }[4]\end{array}$ \\
\hline Country & Cuba & Cuba & Bangladesh & Bangladesh \\
\hline Design & $\begin{array}{l}\text { Placebo-controlled, } \\
\text { randomized, double-blind trial }\end{array}$ & Open single-arm trial & Open two-arm trial & $\begin{array}{l}\text { Open, randomized, two-arm trial } \\
\text { with control treatment (PEG-IFN) }\end{array}$ \\
\hline Objective & $\begin{array}{l}\text { Preliminary safety and } \\
\text { inmunogenicity }\end{array}$ & $\begin{array}{l}\text { Preliminary safety and } \\
\text { immunogenicity }\end{array}$ & Safety and immunogenicity & $\begin{array}{l}\text { Efficacy, inmunogenicity and } \\
\text { safety }\end{array}$ \\
\hline $\begin{array}{l}\text { General } \\
\text { demographics }\end{array}$ & $\begin{array}{l}\mathrm{N}=19, \text { healthy volunteers } \\
\text { Healthy young men (18-45 } \\
\text { years) } \\
9 \text { with TV and } 10 \text { with } \\
\text { placebo }\end{array}$ & $\begin{array}{l}\mathrm{N}=6,18-65 \text { years, failed } \\
\text { alfa-2b IFN treatment } \\
3 \mathrm{HBeAg}+ \\
3 \mathrm{HBeAg-}\end{array}$ & $\begin{array}{l}\mathrm{N}=20,19-65 \text { years, no } \\
\text { prior treatment. } \\
13 \mathrm{HBeAg}+ \\
7 \mathrm{HBeAg}-\end{array}$ & $\begin{array}{l}\mathrm{N}=160,18-65 \text { years, }>80 \% \\
\text { without prior treatment } \\
\sim 80 \% \mathrm{HBeAg}- \\
80 \text { with TV and } 80 \text { with PEG-IFN }\end{array}$ \\
\hline $\begin{array}{l}\text { Treatment, schedule, } \\
\text { routes and dose }\end{array}$ & $\begin{array}{l}0,1,2,4,6 \text { weeks } \\
\text { IN }(50 \mu g / A g / d o s e) \\
\text { vs placebo, same schedule }\end{array}$ & $\begin{array}{l}0,2,4,6,8,10,12,14,16 \\
18 \text { weeks } \\
\text { IN }(100 \mu g / A g / d o s e)\end{array}$ & $\begin{array}{l}2 \text { cycles } \\
1 \text { st: } 0,2,4,6,8 \text { weeks } \\
\text { IN }(100 \mu g / A g / d o s e+100 \\
\mu g \text { HBcAg) } \\
2 \text { nd: } 12,14,16,18,20 \\
\text { weeks } \\
\text { IN }(100 \mu g / A g / d o s e+100 \\
\mu g \text { HBcAg) } \\
\text { SC }(100 \mu g / A g / \text { dose })\end{array}$ & $\begin{array}{l}2 \text { cycles } \\
\text { 1st: } 0,2,4,6,8 \text { weeks } \\
\text { IN }(100 \mu g / A g / d o s e+100 \mu g \\
\text { HBcAg) } \\
2 \text { nd: } 12,14,16,18,20 \text { weeks } \\
\text { IN }(100 \mu g / A g / d o s e+100 \mu g \\
\text { HBcAg+100 } \mu g \text { HBcAg) } \\
\text { SC }(100 \mu g / A g / \text { dose }) \\
\text { vs PEG-IFN } 48 \text { weeks }\end{array}$ \\
\hline $\begin{array}{l}\text { Main results with } \\
\text { focus on safety }\end{array}$ & $\begin{array}{l}\text { Demonstrated safety and } \\
\text { immunogenicity when given } \\
\text { via IN route, } 100 \% \text { anti- } \\
\text { HBcAg response and sero- } \\
\text { protection in } 77.7 \%(7 / 9) \text { of } \\
\text { immunized patients }\end{array}$ & $\begin{array}{l}\text { Demonstrated safety } \\
\text { in } \mathrm{CHB} \text { patients and } \\
\text { initial evidence of antiviral } \\
\text { response in } 2 \text { of } 3 \text { patients } \\
\text { with HBeAg+. Long-term } \\
\text { followup of viral load } \\
\text { detected virus in } 1 \text { of } 6 \\
\text { subjects in last followup } \\
\text { blood draw. Generalized } \\
\text { normalization of transami- } \\
\text { nases. }\end{array}$ & $\begin{array}{l}\text { Demonstrated safety and } \\
\text { immunogenicity based } \\
\text { on in vitro detection of } \\
\text { proinflammatory cytokines. } \\
\text { Evidence of efficacy, such } \\
\text { as decreased viral load in } \\
\text { most patients; } 50 \% \text { had } \\
\text { undetectable levels at end } \\
\text { of followup. Sustained } \\
\text { antiviral response and } \\
\text { generalized normalization } \\
\text { of transaminases. }\end{array}$ & $\begin{array}{l}\text { Fewer adverse events related } \\
\text { to HeberNasvac compared to } \\
\text { PEG-IFN. } \\
\text { Similar antiviral efficacy during } \\
\text { treatment. Sustained response } \\
\text { of HeberNasvac favored signifi- } \\
\text { cantly superior antiviral effect at } \\
24 \text { and } 48 \text { weeks post-treatment. } \\
\text { Generalized normalization of } \\
\text { transaminases observed. }\end{array}$ \\
\hline
\end{tabular}

CHB: Chronic hepatitis B CT: Clinical trial IN: Intranasal HBeAg: Marker of an actively replicating hepatitis B virus infection PEG-IFN: Polyethylene glycol-conjugated interferon SC: Subcutaneous TV: Therapeutic vaccine

was 43 years, and average time since diagnosis was 13.5 years (Table 1). All were serum HBsAg+ for more than six months and had transaminase levels (ALAT and/or ASAT) above the upper limit of normal, detected at least once within six months prior to trial inclusion.

Subjects received ten $100 \mu \mathrm{g}$ doses of HeberNasvac $(1 \mathrm{~mL})$ intranasally every two weeks (Table 1), using a nasal actuator (VP7D, Valois, France) calibrated to release $125 \mu \mathrm{L}$ of the formula with each plunger depression. The vaccine was safe, showed low reactogenicity, and was well tolerated by all patients. The vaccination did not cause liver, kidney or bone marrow dysfunction. These patients had documented histories of over 12 years with $\mathrm{CHB}$ that had been refractory or not fully responsive to IFN-alpha for 10 years, and had various comorbidities (alcohol consumption and advanced age).

HBsAg became undetectable in 1 of 6 patients, and 2 of 6 seroconverted to anti-HBs, one in week 24 , with no reversion after 5 years of followup (Figure 3). Alanine aminotransferase (ALAT) elevations were transient, and no patients developed cirrhosis during followup, which suggests that ALAT elevations were benign.[2] Results of vibration-controlled transient elastography (FibroScan, Echosens, France) showed slow progression and low fibrosis levels.
The improvement in virologic and serologic variables associated with HBV and mild fibrosis after five years of followup suggest that in addition to the therapeutic benefits of the TV, it may protect the liver. With regard to clinical practice guidelines for HB infection,[46] none of the patients required additional treatment.

HeberNasvac produced no serious AEFIs. There were no deaths, or any onset of chronic disease during followup (52 weeks). Most AEFIs noted were mild and resolved without medical intervention. The most common AEFIs (more than $10 \%$ of total) were: sneezing, general malaise, headache and asthenia. Other local AEFIs were noted, such as nasal secretions, mild localized burning sensation at the inoculation site, and nasal pruritus. After completion of the study, which demonstrated safety and an antiviral effect, $\mathrm{SC}$ administration was adopted to complement IN, for improved clinical benefits.[2]

Phase 1/2 clinical trial in previously untreated CHB HeberNasvac was evaluated in a 2009 phase $1 / 2$ clinical trial in 20 treatmentnaïve patients with an average age of 28 years residing in Dha$\mathrm{ka}$, Bangladesh (Table 1). All had HBsAg+ lasting more than 6 months, detectable viral load, ( $\geq 1000$ copies of HBV DNA/mL), and elevated transaminases within 6 months of inclusion. Patients with $\mathrm{HBeAg}+$ and $\mathrm{HBeAg}-$ were included. 
Figure 3: Copies of HBV DNA and concentration of HBsAg (qHBsAg) in sera of 6 patients 5 years after HeberNasvac administration
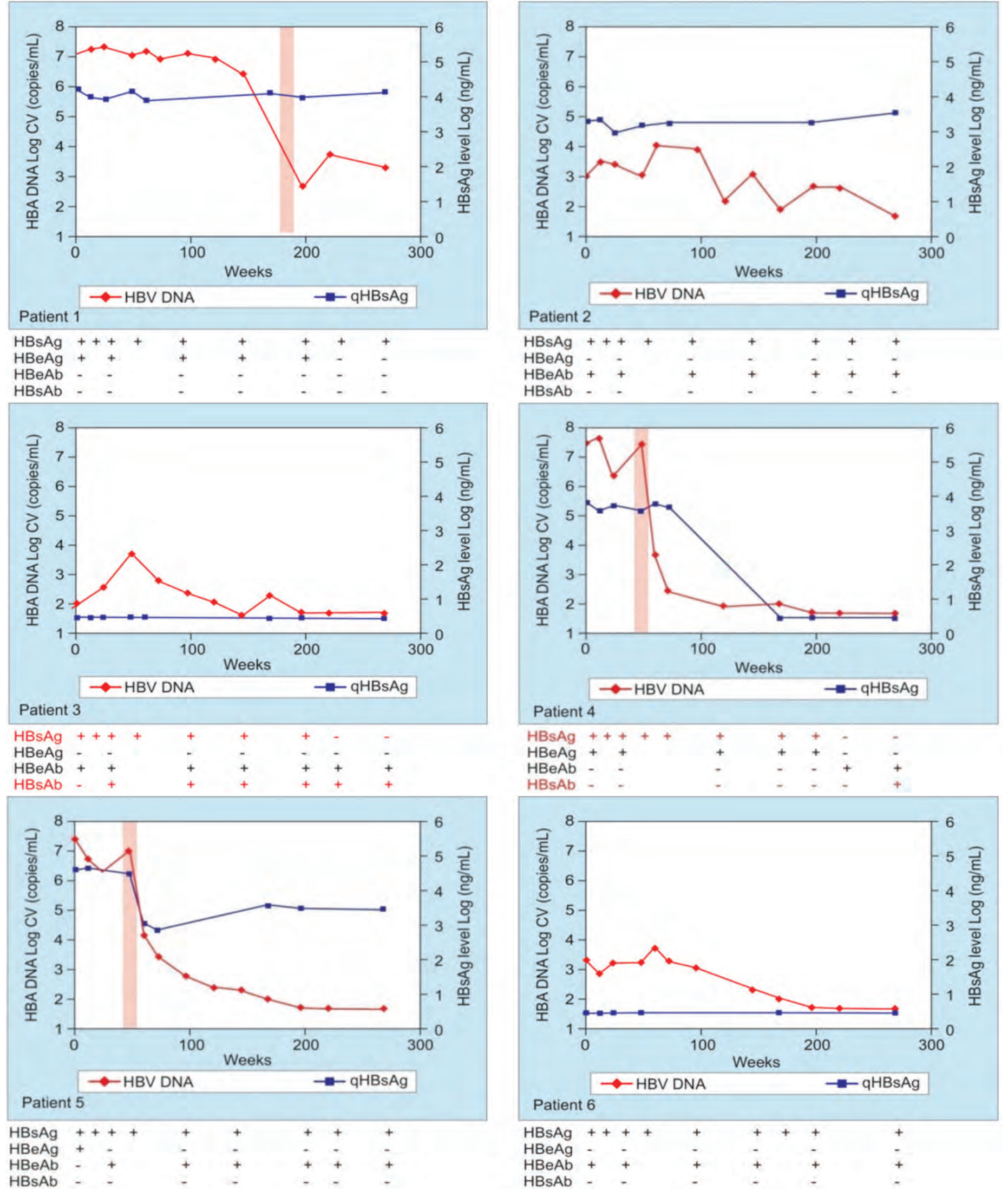

The results of the serological tests are shown below each graph for each patient (patients 1 to 6 ). The time frame of ALAT elevations are represented by a pink shaded bar. Figure taken from ref [2]; with publisher's permission. HBV DNA: Hepatitis B virus DNA 
The TV was given intranasally in the first 5-dose treatment cycle (each $1 \mathrm{~mL}$ dose contained $100 \mu \mathrm{g} \mathrm{HBsAg}+100 \mu \mathrm{g} \mathrm{HBcAg}$ ); in the second cycle, the 5 doses were given intranasally and subcutaneously at the same time. The study measured virologic response using quantitative PCR (250 copies/mL detection limit) after 5 and 10 doses. After 48 weeks, a high percentage of patients who were $\mathrm{HBeAg}$ - had eliminated HBV, and ALAT normalized in all patients. Of those who joined the study with $\mathrm{HBeAg}+$, six cleared the virus from circulation, eight seroconverted to anti-HBe (HBeAg became negative and antibodies against it appeared), and ALAT levels became normal for sustained periods.

That viral load reduction was maintained during followup is of interest because in a high percentage of patients treated with current antivirals, the virus reappears once treatment ends. SC and IN administration of HeberNasvac was safe and well tolerated in all subjects. No serious or moderate AEFIs were recorded. All AEFIs noted during the second treatment cycle were associated with SC administration; $100 \%$ of these were mild, including pain at injection site (27.8\%), fever (22.2\%) and general malaise (11.1\%).

Because the vaccine was given both IN and SC in this clinical trial, it provided the first safety and efficacy profiles of the HeberNasvac regimen for both routes. Vaccination with $\mathrm{rHBs} / \mathrm{rHBcAg}$ via both routes induced production of proinflammatory cytokines and activation of antigen-presenting dendritic cells in the peripheral blood of CHB patients and demonstrated the TV's immunomodulatory effect after the first five intranasal doses.[3]

The investigators in this trial recommended that HeberNasvac manufacturers use the regimen in a phase 3 clinical trial to assess effectiveness and offer a more in-depth perspective on its safety and efficacy.

Phase 3 clinical trial in untreated CHB patients This phase 3 trial was conducted in Bangladesh and was approved by the ethics committees of the participating hospitals and the Bangladesh General Office of Medication Administration. It was registered on ClinicalTrials.gov (NCT01374308). This trial used the same schedule and dose as the phase 1/2 trial and compared TV to PEG-IFN treatment (Table 1). General results indicate that over the short and long term, HeberNasvac was safer than PEG-IFN as an immunotherapy agent in $\mathrm{CHB}$ patients. In patients treated with PEG-IFN, AEs were significantly more common, intense, prolonged and associated with the treatment, mostly consisting of fever, weakness, headache and localized pain.[11]

During the trial, investigators detected transient ALAT elevations twice the upper limit of normal in week 12 after 5 nasal vaccinations. This was seen in a higher percentage of patients treated with HeberNasvac than in patients who received PEG-IFN, and occurred regardless of patient HBeAG status, sex, age, or initial viral load. As was seen in the phase 1 trial in $\mathrm{CHB}$ patients, ALAT elevations were transient in the group receiving HeberNasvac. In every case, they occurred in week 12, and were 5 to 10 times greater than the upper limit of normal.[4] ALAT increases in patients treated with PEG-IFN had a similar range of intensity (up to $300 \mathrm{U} / \mathrm{L}$ ) but occurred in fewer patients and not in week 12.

Increased ALAT levels in nearly all patients receiving HeberNasvac suggests that these were the result of beneficial immune activation to eliminate the virus after five IN doses, and that this route supports HeberNasvac's mechanism of action. Results in a model of HBV transgenic mice showed that the IN (not parenteral) route was associated with a higher proportion of multifunctional T CD4+ cells that migrated to the liver. CD8+ cells were present in lower proportions.[38]

At end of treatment, the antiviral effect was similar in both groups, but HeberNasvac showed better sustained control of HBV DNA during followup. At 24 weeks post-treatment, a higher proportion of HBV DNA (<250 copies $/ \mathrm{mL}$ ) had been cleared in subjects who received HeberNasvac than in those who received PEG-IFN. This was seen as lower levels of viral DNA. Patients treated with HeberNasvac had less progression in their hepatic fibrosis. Compared to patients who received PEG-IFN, HBeAg disappeared in a higher proportion of patients treated with HeberNasvac, and more patients treated with HeberNasvac seroconverted to anti-HBe.

The hypothesis of this trial was tested at 24 weeks post-treatment. Intention-to-treat analysis showed a significantly higher proportion of patients with a viral load $<250$ copies/mL (HBV DNA undetectable) in the group immunized with HeberNasvac. Protocol analysis showed a similar difference. A rebound in viremia, more pronounced in the PEG-IFN group, occurred after treatment, with a significant reduction in the proportion of patients with controlled viral load (<250 copies $/ \mathrm{mL}$ ) at 24 week followup compared to end of treatment.[4]

The results for the Cuban PV and TV discussed here show their impact on prevention of acute hepatitis in different age groups and on treatment of chronic forms of the disease. For the TV, better results will depend on the antigens selected or designed for formulations, adjuvant adsorption strategies, the most useful immunization route and possible receptors, for which appropriate biomarkers must be selected. Other studies are also needed to confirm the relevance of mucosal immunization and its mechanisms of action in the field of therapeutic vaccination.

The marketing registration granted to HeberNasvac in Cuba and the first international collaboration using this TV in Japan and other Asian countries[50,51] are encouraging signs for patients with $\mathrm{CHB}$. To find a permanent cure and eradicate HB, however, we will need strategies that combine TV with conventional therapies and others still being tested, since single treatments have not succeeded thus far in eliminating the virus and curing chronic patients.

\section{CONCLUSIONS}

Acute hepatitis B has ceased to be a health problem in Cuba after universal vaccination of newborns with the Cuban prophylactic vaccine Heberbiovac HB. Because Cuba has systematically administered the vaccine in a broad-ranging national program, it has maintained low annual incidence in the general population, and no cases have been reported in children since 2007. Compared to PEG-IFN, therapeutic vaccination with HeberNasvac via both routes has fewer adverse events, reduces long-term viral load without reversion in a higher proportion of patients, and decreases transaminase and rigidity values. Transient ALAT elevations are associated with immune activation, not development of hepatic fibrosis. HeberNasvac is a safe alternative as monotherapy for short-term treatment of CHB. The HeberNasvac TV is a practical example of biotech product innovation in Cuba. $1 /$ - 


\section{REFERENCES}

1. Betancourt AA, González Delgado CA, Estévez ZC, Martínez JC, Ríos GV, Moreno AureolesRoselló SR, et al. Phase I in healthy adults of a nasal vaccine candidate containing recombinant hepatitis B surface and core antigens. Int J Infect Dis. 2007 Sep;11(5):394-401.

2. Fernández G, Sánchez AL, Jerez E, Anillo LE, Freyre F, AguiarJA, et al. Five-year follow-up of chronic hepatitis $B$ patients immunized by nasal route with the therapeutic vaccine HeberNasvac. Euroasian J Hepato-Gastroenterol. 2018 Jul -Dec;8(2):133-9.

3. Al-Mahtab M, Akbar SMF, Aguilar JC, Uddin MH, Khan MSI, Rahman S. Therapeutic potential of a combined hepatitis B virus surface and core antigen vaccine in patients with chronic hepatitis $B$. Hepatol Int. 2013 Oct;7(4):981-9.

4. Al Mahtab M, Akbar SMF, Aguilar JC, Guillén G, Pentón E, Tuero A, et al. Treatment of chronic hepatitis $B$ naïve patients with a therapeutic vaccine containing $\mathrm{HBs}$ and $\mathrm{HBc}$ antigens (a ran domized, open and treatment controlled phase III). PLoS One. 2018 Aug 22;13(8):e0201236.

5. Global Hepatitis Report 2017 [Internet]. Geneva: World Health Organization; 2017 Apr [cited 2020 Nov 2]. 83 p. Available at: https://www .who.int/hepatitis/publications/global-hepatitis -report2017/en/

6. Torres Vidal RM, Galindo Sardiña MA, Valcárcel Sánchez M. Enfermedades prevenibles por vacunas. Morbilidad y mortalidad. In: Rojas Ochoa F, editor. Vacunas. Cuba.1959-2008 [Internet]. Havana: ECIMED; 2011 [cited 2020 Nov 2]. p. 43. Available at: http://www.bvscuba.sld.cu/libro/ vacunas-cuba-1959-2008/. Spanish.

7. Muzio V, Quiñones Y, Quintana M. Vacuna cubana contra la hepatitis B. Impacto de un producto biotecnológico en la salud pública. In: Rojas Ochoa F. Vacunas. Cuba.1959-2008 [Internet]. Havana: ECIMED; 2011 [cited 2020 Nov 27]. p. 134. Available at: http://www.bvscuba.sld.cu/ libro/vacunas-cuba-1959-2008/. Spanish.

8. Reed G, Galindo MA. Cuba's National Immunization Program. MEDICC Rev. 2007 Oct;9(1):5-7.

9. López Ambrón L, Egües Torres LI, Pérez Carreras A, Galindo Santana BM, Galindo Sardiña MA, Resik Aguirre S, et al. Experiencia cubana en inmunización, 1962-2016. Rev Panam Salud Pública. 2018 Apr 24;42:e34. DOI: 10.26633/ RPSP.2018.34. Spanish.

10. Cuba's biotech boom. Nature. 2009 Jan 8;457(7226):130. DOI: https://doi.org/10.1038/45 $7130 \mathrm{a}$

11. Center for State Control of Medicines and Medical Devices (CECMED) [Internet]. Havana: Ministry of Public Health (CU); c2020. Registro. RCP. HEBERBIOVAC HB® . (VACUNAANTIHEP ATITIS B RECOMBINANTE); 2017 [cited 2020 Nov 27]. 5 p. Available at: https://www.cecmed.cu/re gistro/rcp/heberpentar-I-vacuna-pentavalente-liqui da-difteria-tetanos-tos-ferina-hepatitis-b. Spanish.

12. Hardy E, Martínez E, Diago D, Díaz R, González $D$, Herrera L. Large-scale production of recombinant hepatitis $B$ surface antigen from Pichia pastoris. J Biotechnol. 2000 Feb 17;77(2-3):157-67.

13. Agraz A, Quiñones $Y$, Expósito N, Breña $F$, Madruga J, Pentón E. Adsorption-desorption of recombinant hepatitis B surface antigen ( $r-\mathrm{HBsAg}$ ) from P. pastoris on a diatomaceous earth matrix: Optimization of parameters for purification. Biotechnol Bioeng. 1993 Nov 20;42(10):1238-44.

14. Center for State Control of Medicines and Medical Devices (CECMED) [Internet]. Havana: Ministry of Public Health (CU); c2020. Registro. RCP. Heberpenta ${ }^{\circledR}-L$ (Vacuna pentavalente líquida contra la difteria, tétanos, tos ferina, hepatitis B y Haemophilus influenzae tipo b); [cited 2020 Nov 27]. 6 p. Available at: https://www.cecmed.cu/
registro/rcp/heberpentar-I-vacuna-pentavalente -liquida-difteria-tetanos-tos-ferina-hepatitis-b. Spanish.

15. Center for State Control Medicines and Medical Devices (CECMED) [Internet]. Havana: Ministry of Public Health (CU); c2020. Registro. RCP. HeberNasvac $®$ (Vacuna terapéutica recombinante contra la hepatitis B); [cited 2020 Nov 27]. 6 p. Available at: https://www.cecmed.cu/registro/ rcp/hebernasvacr-vacuna-terapeutica-recomb inante-hepatitis-b. Spanish.

16. Iglesias E, García D, Carrazana Y, Aguilar JC, Sánchez A, Gorobaya L, et al. Anti-HIV-1 and anti-HBV immune responses in mice after parenteral and nasal co-administration of a multiantigenic formulation. Curr HIV Res. 2008 Sep;6(5):452-60.

17. Iglesias $E$, Thompson $R$, Carrazana $Y$, Lobaina Y, García D, Sánchez J, et al. Co-inoculation with hepatitis B surface and core antigen promotes a Th1 immune response to a multiepitopic protein of HIV-1. Immunol Cell Biol. 2006 Apr;84(2):174-83.

18. Bello Corredor M, Díaz González M, Heng Hung Ricardo L, Delgado González G, Montalvo Villalba $\mathrm{MC}$, et al. Marcadores serológicos en lactantes de alto y bajo riesgo de infección por el virus de la hepatitis $B$ inmunizados con una vacuna recombinante cubana. Paediatrica. 2006;8(1):7-14. Spanish.

19. Muzio González V, Cinza Estévez Z, Ortega Tápanes A, Véliz Ríos G, Galindo MA, Delgado $\mathrm{G}$, et al. Estudios postlicenciamiento de la vacuna cubana contra la hepatitis B, Heberbiovac HB. Biotecnol Aplic. 2001 Apr;18(2):103-4. Spanish.

20. Ramírez Albajéz V, González Griego A, Alerm González A, Vega García I, Pentón Arias E, González Griego M. Seguridad e inmunogenicidad de la vacuna cubana Heberbiovac HB en poblaciones de América, Europa, Africa y Asia. Rev Cubana Invest Bioméd. 2000 JanApr;19(1):28-33. Spanish.

21. Zumaeta E, González Griego A, Ferrandiz J, Villanueva A, Soto V, Almeida R, et al. Pronóstico de duración de títulos protectores anti-HBs ag en trabajadores de la salud del Perú luego de 6 años de vacunados. Rev Gastroenterol Perú [Internet]. 2001 Oct-Dec [cited 2020 Nov 29];21(4):276-81. Available at: http://www.scielo .org.pe/scielo.php?script=sci_arttext\&pid=S1022 $-51292001000400004 \& \operatorname{lng}=e s$. Spanish.

22. Bello Corredor M, Rodríguez Lay LA, Rodríguez Argueta D, Montalvo Villalba MC, Pedroso Flaquet $P$, Sariego Frómeta $S$, et al. Infección oculta por el virus de la hepatitis $B$ en hijos de madres positivas al HBsAg. VacciMonitor. 2016 Jan -Apr;25(1):1-6. Spanish.

23. Rodríguez Lay LA, Bello Corredor M, Montalvo Villalba MC, Chibás Ojeda AG, Sariego Frómeta S, Díaz González M, et al. Hepatitis B virus infection assessed 3 to 18 years after vaccination in Cuban children and adolescents born to HBsAg-positive mothers. Arch Virol. 2017 Aug;162(8):2393-6.

24. Jung MC, Pape GR. Immunology of hepatitis B infection. Lancet Infect Dis. 2002 Jan;2(1):43-50.

25. Michel ML, Deng Q, Mancini-Bourgine M. Therapeutic vaccines and immune-based therapies for the treatment of chronic hepatitis B: perspectives and challenges. J Hepatol. 2011 Jun;54(6):1286 -96 .

26. Verna EC. Updated Hepatitis B guidance: implications for liver transplant patients. Liver Transpl. 2018 Apr;24(4):465-9.

27. Center for State Control Medicines and Medical Devices (CECMED) [Internet]. Havana: Ministry of Public Health (CU); c2020. Registro. RCP. PEG-Heberon $\AA$ (Interferón alfa $2 b$ hu-rec conjugado a polietilenglicol); [cited 2020 Nov 30]. 8 p.
Available at: https://www.cecmed.cu/registro/rcp/ peg-heberonr-interferon-alfa-2b-hu-rec-conjuga do-polietilenglicol. Spanish

28. Shamliyan TA, MacDonald R, Shaukat A, Taylor BC, Yuan JM, Johnson JR, et al. Antiviral therapy for adults with chronic hepatitis B: a systematic review for a National Institutes of Health Consensus Development Conference. Ann Intern Med. 2009 Jan 20;150(2):111-24.

29. Lin $\mathrm{CL}, \mathrm{Kao} \mathrm{JH}$. Recent advances in the treatment of chronic hepatitis B. Expert Opin Pharmacother. 2011 Sep;12(13):2025-40.

30. Scaglione SJ, Lok ASF. Effectiveness of hepatitis $B$ treatment in clinical practice. Gastroenterology. 2012 May;142(6):1360-8.

31. Aguilar Rubido JC, Palenzuela Gardón DO, Muzio González VL, Guillén Nieto GE, Pentón Arias E, Pichardo Díaz D, et al, inventors; Center for Genetic Engineering and Biotechnology (CIGB), assignee. WO2000032229 A1 Preparations containing virus-like particles as immunopotentiators administered through the mucosa. Cuba patent CU PCT/CU1999/000006. 2008 Jun 6.

32. Aguilar Rubido JC, Pentón Arias E, Tleugabulova D, Sewer Mensies M, Muzio González VL, Guillén Nieto GE, et al, inventors; Center for Genetic Engineering and Biotechnology (CIGB), assignee. WO2002043756 A2 Method for obtaining antigenic aggregates and the use thereof in formulations. Cuba patent CU PCT/ CU2001/000009. 2002 Jun 6

33. Aguilar Rubido JC, Lobaina Mato $Y$, Iglesias Pérez E, Pentón Arias E, Guillén Nieto GE, Aguiar Santiago JA, et al, inventors; Center for Genetic Engineering and Biotechnology (CIGB), assignee. WO2017167317 A1 Pharmaceutical composition that includes the surface and nucleocapsid antigens of the hepatitis B virus. Cuba patent CU PCT/CU2017/050001. 2017 Oct 5.

34. Aguilar JC, Lobaina Y, Muzio V, García D, Pentón E, Iglesias E, et al. Development of a nasal vaccine for chronic hepatitis $B$ infection that uses the ability of hepatitis B core antigen to stimulate a strong Th1 response against hepatitis B surface antigen. Immunol Cell Biol. 2004 Oct;82(5):539-46.

35. Vandepapelière $P$, Lau GKK, Leroux-Roels G, Horsmans Y, Gane E, Tawandee T, et al. Therapeutic HBV Vaccine Group of Investigators. Therapeutic vaccination of chronic hepatitis $B$ patients with virus suppression by antiviral therapy: a randomized, controlled study of co-administration of $\mathrm{HBsAg/ASO2}$ candidate vaccine and lamivudine. Vaccine. 2007 Dec 12;25(51):8585-97.

36. Lau GK, Suri D, Liang R, Rigopoulou El, Thomas MG, Mullerova I, et al. Resolution of chronic hepatitis B and anti-HBs seroconversion in humans by adoptive transfer of immunity to hepatitis B core antigen. Gastroenterology. 2002 Mar;122(3):614-24.

37. Aguilar JC, Lobaina Y. Immunotherapy for chronic hepatitis B using HBsAg-based vaccine formulations: from preventive commercial vaccines to therapeutic approach. Euroasian J Hepatogastroenterol. 2014 Jul-Dec;4(2):92-7.

38. Bourgine M, Crabe S, Lobaina Y, Guillén G, Aguilar JC, Michel ML. Nasal route favors the induction of $\mathrm{CD} 4(+) \mathrm{T}$ cell responses in the liver of HBV-carrier mice immunized with a recombinant hepatitis B surface- and core-based therapeutic vaccine. Antiviral Res. 2018 May;153:23-32.

39. Mancini-Bourgine $M$, Guillén $G$, Michel $M L$, Aguilar JC. Impact of the immunogen nature on the immune response against the major HBV antigens in an HBsAg and HLA-humanized transgenic mouse model. Euroasian J Hepatogastroenterol. 2014 Jan-Jun;4(1):36-44.

40. Bourgine M, Dion S, Godon O, Guillén G, Michel $\mathrm{ML}$, Aguilar JC. Optimization of immune respons- 
es induced by therapeutic vaccination with crossreactive antigens in a humanized hepatitis $B$ surface antigen transgenic mouse model. Virology. 2012 Aug 15;430(1):10-9.

41. Trujillo H, Blanco A, García D, Freyre F, Agu iar J, Lobaina $\mathrm{Y}$, et al. Optimization of a therapeutic vaccine candidate by studying routes, immunization schedules and antigen doses in HBsAg-positive transgenic mice. Euroasian $\mathrm{J}$ Hepatogastroenterol. 2014 Jul-Dec:4(2):70-8.

42. Akbar SMF, Yoshida O, Chen S, Aguilar JC, Abe $M$, Matsuura $B$, et al. Immune modulator and antiviral potential of dendritic cells pulsed with both hepatitis B surface antigen and core antigen for treating chronic HBV infection. Antivir Ther. 2010;15(6):887-95.

43. Akbar SMF, Chen S, Al-Mahtab M, Abe M, Hiasa $Y$, Onji M. Strong and multi-antigen specific immunity by hepatitis B core antigen ( $\mathrm{HBcAg}$ )based vaccines in a murine model of chronic hepatitis $\mathrm{B}$ : HBcAg is a candidate for a therapeutic vaccine against hepatitis $B$ virus. Antiviral Res 2012 Oct;96(1):59-64.

44. Porras DN, Cosme K, Aldana L, Bacardí D, Merino $N$, Milá L, et al. Determination and assess ment of the irritant potential of a nasal vaccine candidate, which combines Hepatitis B surface antigen and Hepatitis B core antigen. Biotecnol Aplic. 2004 Jan;21(3):143-7.

45. Lobaina Mato Y, Aguilar Rubido JC, Guillén Nieto $G$. ABX203, a novel therapeutic vaccine fo chronic hepatitis B patients. Almanac Clin Med 2016 Sep;44(6):713-8.
46. Terrault NA, Bzowej NH, Chang KM, Hwang JP, Jonas MM, Murad $\mathrm{MH}$, et al. AASLD guidelines for treatment of chronic hepatitis B. Hepatology. 2016 Jan;63(1):261-83.

47. World Medical Association. Declaration of Helsinki: ethical principles for medical research involving human subjects. JAMA [Internet]. 2013 Nov 27 [cited 2018 Jun 13];310(20):2191-4. Available at: https://jamanetwork.com/journals/jama/fullar ticle/10.1001/jama.2013.281053

48. Jilg $W$, Schmidt $M$, Deinhardt F. Vaccination against hepatitis $B$ : comparison of three different vaccination schedules. J Infect Dis. 1989 Nov;160(5):766-9.

49. Cassidy WM, Watson B, Ioli VA, Williams K, Bird S, West DJ. A randomized trial of alternative two- and three-dose hepatitis $B$ vaccination regimens in adolescents: antibody responses, safety, and immunological memory. Pediatrics. 2001 Apr:107(4):626-31.

50. Yoshida O, Imai Y, Akbar SMF, Kohara M, Kohara K, Miyazak T, et al. A nasal administrative therapeutic vaccine (NASVAC) with modified treatment strategy reduces and eliminates HBs antigen in HBV infected patients with or without nucleos(t)ide analogs therapy. AASLD Abstracts. Hepatology. 2018;68(1).

51. Wedemeyer H, Hui AJ, Sukeepaisarnjaroen W, Tangkijvanich P, Guillén G, Gineste P, et al. Therapeutic vaccination of chronic hepatitis $B$ patients with ABX203 (NASVAC) to prevent relapse after stopping NAs: contrasting timing rebound between tenofovir and entecavir. J Hepatol. 2017 Dec; 66:S101.

\section{THE AUTHORS}

Eduardo Pentón-Arias (Corresponding author: eduardo.penton@cigb.edu.cu) physician specializing in clinical biochemistry with a doctorate in biological sciences. Senior researcher, Latin American School of Medicine (ELAM) and Genetic Engineering and Biotechnology Center (CIGB). Hepatitis B Group, Vaccine Department, Biomedical Research Division, CIGB, Havana, Cuba. https://orcid.org/0000-0002-0574-7942

Julio César Aguilar-Rubido, biologist, Hepatitis B Group, Vaccine Department, Biomedical Research Division, CIGB, Havana, Cuba. https://orcid.org/0000-0003-0166-4784

Submitted: January 14, 2020

Approved for publication: January 9, 2021

Disclosures: Eduardo Pentón-Arias belongs to the group that developed the Cuban recombinant hepatitis vaccine Heberbiovac $H B$ at CIGB and Julio César Aguilar-Rubido is a researcher at CIGB. Both Heberbiovac $H B$ and HeberNasvac are produced by CIGB. 


\title{
Hypoxic Ischemic Encephalopathy in Units Reporting to the Ibero-American Society of Neonatology Network: Prevalence and Mortality
}

\author{
Fernando Domínguez-Dieppa MD PhD, Marcelo Cardetti MD, Susana Rodríguez MD, Alfredo García-Alix MD, Augusto Sola MD
}

\begin{abstract}
INTRODUCTION Hypoxic ischemic encephalopathy is a neurological condition occurring immediately after birth following a perinatal asphytic episode. Therapeutic hypothermia is a safe and effective intervention to reduce mortality and major disability in survivors. In Latin America, perinatal asphyxia is a major problem, but no data are available characterizing its current situation in the region or the impact of hypoxic ischemic encephalopathy on its management.
\end{abstract}

OBJECTIVE Understand the prevalence, mortality and use of therapeutic hypothermia in newborns at $\geq 36$ weeks gestational age with hypoxic ischemic encephalopathy admitted to neonatal units reporting to the Ibero-American Society of Neonatology Network.

METHODS The Ibero-American Society of Neonatology Network groups various neonatology centers in Latin America that share information and collaborate on research and medical care. We evaluated data on newborns with $\geq 36$ weeks gestational age reported during 2019. Each unit received a guide with definitions and questions based on the Society's 7th Clinical Consensus. Evaluated were encephalopathy frequency and severity, Apgar score, need for resuscitation

\section{INTRODUCTION}

Hypoxic ischemic encephalopathy (HIE) is a neurological syndrome that presents immediately after birth after a perinatal asphytic episode. It is characterized by alterations in alertness, with decreased ability to awaken and maintain muscle tone, decreased motor responses and reactivity. It occurs as a consequence of oxygen deprivation in the brain, from arterial hypoxemia or cerebral ischemia, or both.[1,2]

Therapeutic hypothermia $(\mathrm{TH})$ is the reduction of body temperature by $3-4{ }^{\circ} \mathrm{C}$ in the first 6 hours of life, maintained for 72 hours. It is a safe and effective intervention for reducing mortality and major disability in survivors.[3-5] It is currently the only standard therapy specific to HIE.[1,6-10] The Ibero-American Society of Neonatology (SIBEN) published a guide establishing standards and recommendations for HIE management in Latin America aimed at promoting a comprehensive therapeutic approach, including recommendation of $\mathrm{TH} .[1]$

\section{IMPORTANCE}

This study, the first of its kind, provides data from healthcare institutions in Latin America related to hypoxic ischemic encephalopathy in neonates and can be used as a basis for determining mortality and improving access to therapeutic hypothermia in the region. at birth, use of therapeutic hypothermia and clinical evolution at discharge. Our analysis includes descriptive statistics and comparisons made using the chi-square test.

RESULTS We examined reports of 2876 newborns from 33 units and 6 countries. In 2849 newborns with available data, hypoxic encephalopathy prevalence was 5.1\% (146 newborns): 27 (19\%) mild, 36 $(25 \%)$ moderate, $43(29 \%)$ severe, and $40(27 \%)$ of unknown intensity. In those with moderate and severe encephalopathy, frequencies of Apgar scores $\leq 3$ at the first minute $(p=0.001)$, Apgar scores $\leq 3$ at the fifth minute $(p<0.001)$ and advanced resuscitation $(p=0.007)$ were higher. Therapeutic hypothermia was performed in only $13 \%$ of newborns (19). Neonatal mortality from encephalopathy was $42 \%$ (61).

CONCLUSION Hypoxic ischemic encephalopathy is a neonatal condition that results in high mortality and severe neurological sequelae. In this study, the overall prevalence was $5.1 \%$ with a mortality rate of $42 \%$. Although encephalopathy was moderate or severe in $54 \%$ of reported cases, treatment with hypothermia was not performed in $87 \%$ of newborns. These data reflect a regional situation that requires urgent action.

KEYWORDS Hypoxia ischemia, brain; encephalopathy, neonatal; mortality; hypothermia, induced; neonatology; Latin America

According to $\mathrm{WHO}$, in 2017 some 2.5 million children died in their first month of life. This is approximately 7000 newborns each day, 1 million in the first day of life and nearly 1 million in the following 6 days.[11] Globally, the leading direct causes of neonatal death are preterm birth (28\%), severe infections (26\%) and asphyxia (23\%). [12] These three causes account for three quarters of neonatal mortality worldwide.[13]

HIE is one of the leading causes of neonatal death and permanent disability, and its contribution to the health burden is high, in terms of years of life lost and years lived with disability. In addition to the important contribution of asphyxia to perinatal mortality, it is estimated that more than one million newborns who survive it annually develop cerebral palsy, epilepsy, learning disabilities and other developmental problems.[6-8] The risk of major disability in those who survive is high. Without $\mathrm{TH}$, the risk of death or major disability with moderate HIE is $52 \%$ and with severe HIE approximately $78 \%$.[10]

In the 20th century, no specific therapeutic interventions were performed to prevent or ameliorate brain damage associated with HIE perinatal aggression. Neonates with moderate and severe HIE constitute a therapeutic challenge due to the associated risk of death or neurological sequelae. The medical, social and legal implications associated with this devastating condition are of consequence and represent an important social and health problem.[14] In Latin America, composed of low- and middleincome countries, perinatal asphyxia is a major problem, and 
it can be assumed that thousands of newborns do not receive adequate care. While precise information is available regarding the extent of this problem and its impact in Europe, Canada and the United States, reliable information is not available for Latin American countries; with the exception of Cuba, where there are recent reports.[15]

The scarce published data for Latin America describe singlecenter experiences in large cities, with small patient numbers.[1] These data estimate HIE incidence at $4 \%-6.2 \%$ of live newborns and risk of death at $10 \%-20 \%$ in neonates with moderate HIE, and $>60 \%$ in those with severe HIE.[1] However, these data almost assuredly underestimate the reality of the current situation.

The SIBEN Network brings together various Latin American neonatology units for information sharing and collaboration in research and patient care. The units maintain their autonomy while participating in a joint effort aimed at a common objective: promote continuous improvements in the quality of care offered by each. The Network thus facilitates comparative evaluation among participating units and centers, collaborating to implement good clinical practices that may influence care throughout the region. Network participation is free for SIBEN members. Currently, 45 neonatal intensive care units (NICUs) in 9 Latin American countries belong.

It is essential and urgent to improve the quality and accessibility of information on HIE's magnitude in Latin America in order to: 1) characterize perinatal care in the region; 2) obtain objective data that allow for monitoring changes over time; 3) understand healthcare needs generally and for specific geographic areas, to develop plans for improvement and to correct inequalities in the care of newborns with perinatal asphyxia-HIE; and 4) systematize and rationalize efforts aimed at improving care for asphytic neonates who develop HIE.

The objective of this study was to determine the prevalence of HIE in neonates at $\geq 36$ weeks of gestational age (GA) admitted to NICUs that participated in the SIBEN Network registry in 2019 , and to understand related mortality rates and the use of therapeutic hypothermia.

\section{METHODS}

The 45 units comprising the SIBEN Network are in the public sector. All were invited to participate in this study. However, since only 33 units in 6 countries (Argentina, Brazil, Ecuador, Peru, the Dominican Republic and Venezuela) report data on newborns at $\geq 36$ weeks GA, we used data exclusively from these units. There were great disparities in numbers of centers reporting (and thus the numbers of newborns included per country): 18 from Argentina, 11 from the Dominican Republic, and 1 each from Ecuador, Peru, Brazil and Venezuela. Newborns with major congenital malformations were excluded from our research. The study population thus included 2876 newborns (at $\geq 36$ weeks GA) admitted to 33 neonatal intensive care units from January 1, 2019 through December 31, 2019.

A clinical care guide was distributed to each of the participating units, accompanied by a list of requested data, both based on the therapeutic recommendations from the 7th SIBEN Clinical Consensus for Neonatal HIE.[1] Accordingly, HIE severity was classified in three grades: mild, moderate and severe. In addition to neurological dysfunction after delivery, HIE diagnosis was established when the newborn had a history of potential hypoxic ischemic aggression during delivery (e.g., a sentinel event or alteration of the fetal cardio-topographic record) and/or alteration of status at birth (Apgar $<5$ at 10 minutes, $\mathrm{pH}$ in the first hour $\leq 7.0$, or the need for advanced cardiopulmonary resuscitation).[1]

\section{Study variables We collected the following:}

- Apgar score at 1 minute and 5 minutes

- HIE severity by grade

- use of advanced cardiopulmonary resuscitation (CPR) when the newborn required endotracheal intubation

- fraction of inspired oxygen $\left(\mathrm{FiO}_{2}\right)$ during resuscitation

- presence of seizures

- use of TH (body or brain)

- mortality during hospitalization (death of the newborn before discharge and death of the newborn attributable to HIE)

We analyzed the data using descriptive statistics, summary measures, frequency tables and graphs.

This study complies with the internationally accepted ethical recommendations established by the Declaration of Helsinki, in its current version.[16]

\section{RESULTS}

2876 newborns admitted to neonatal intensive care units in 33 healthcare institutions in 6 countries were reported to the SIBEN Network from January 1, 2019 through December 31, 2019 (Table 1). Due to the large differences in the number of reports by geographic location, the newborns were analyzed as a group, without making comparisons among NICUs or countries.

Frequency and severity of HIE reported to the SIBEN Network Data was not reported on HIE for 27 of the 2876 newborns. Among the remaining 2849 newborns with available data, 146 cases of HIE (5.1\%) were reported, classified according to severity (Table 2). Severity was not reported for 40 (27.4\%), and thus these are not included in Table 2, although they are added for the total count. The absolute frequencies and percentages corresponding to the Apgar categories at one minute and five minutes, clinical seizures, advanced resuscitation, $\mathrm{TH}$ use and mortality are also reported.

Apgar score Out of the cohort of 2876 newborns, 275 (9.6\%) with an Apgar score $\leq 3$ in the first minute of life and 258 (8.6\%)

Table 1: Case data supplied to SIBEN Network

\begin{tabular}{|l|r|r|}
\hline Country & $\begin{array}{c}\text { Number of NICUs } \\
\text { reporting }\end{array}$ & $\begin{array}{c}\text { Number of newborns } \\
\text { reported }\end{array}$ \\
\hline Dominican Republic & 11 & 1839 \\
\hline Argentina & 18 & 1002 \\
\hline Ecuador & 1 & 14 \\
Peru & 1 & 10 \\
\hline Brazil & 1 & 7 \\
Venezuela & 1 & 4 \\
\hline Total & 33 & 2876
\end{tabular}

NICU: neonatal intensive care unit 
Table 2: Apgar score, advanced resuscitation, seizures, therapeutic hypothermia use, and mortality by HIE severity

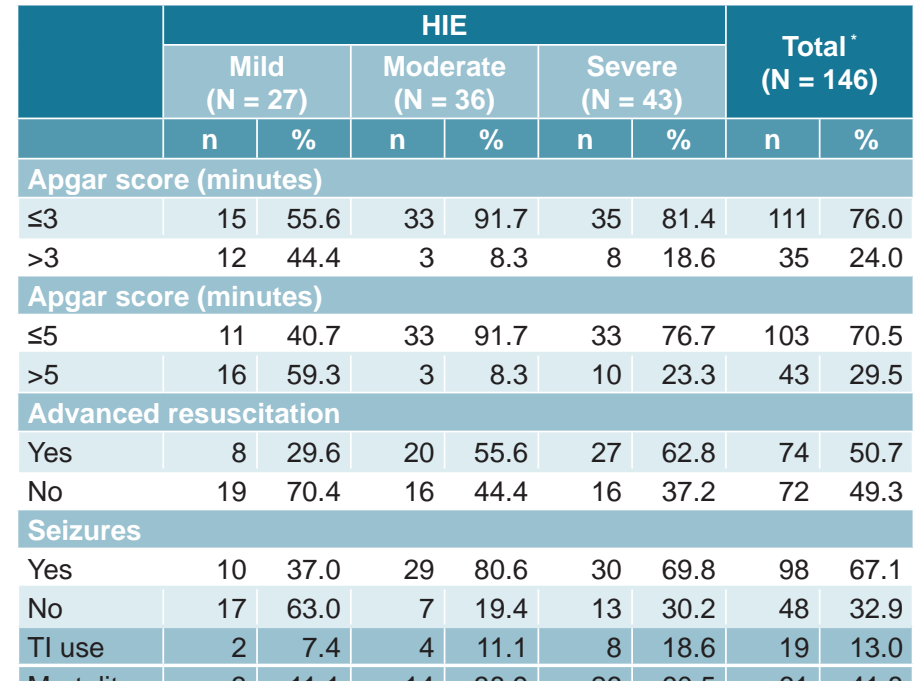

* Includes cases in which HIE severity was not reported during hospitalization.

$\mathrm{n}$ : number of cases \%: percentage with respect to total cases

HIE: hypoxic ischemic encephalopathy $\mathrm{TH}$ : therapeutic hypothermia

with a score $\leq 5$ at 5 minutes were reported. Of the 146 newborns who presented with HIE, $111(76 \%)$ had an Apgar score of $\leq 3$ at 1 minute of life and $103(70.5 \%) \leq 5$ at 5 minutes of life. Low Apgar scores were much more common in the moderate and severe forms of HIE (Table 2).

Seizures Of the 146 newborns with HIE, 98 (67.1\%) experienced seizures. Seizures were also much more common in moderate and severe forms of HIE (Table 2).

Resuscitation according to HIE severity Advanced resuscitation was necessary in 74 newborns with HIE (51\%) (Table 2). The likelihood of advanced resuscitation obviously increased with HIE severity. Of the 20 newborns with moderate HIE who received advanced CPR, 9 (45\%) required cardiac massage and $4(20 \%)$ required vasoactive medication. Of the neonates with severe HIE, 27 (63\%) required advanced CPR, of which $22(81 \%)$ required cardiac massage and 11 (41\%) required medication. Only $11 \%$ of newborns were resuscitated with $21 \% \mathrm{FiO}_{2}$ and $40 \%$ were resuscitated with $100 \%$ oxygen. $\mathrm{FiO}_{2}$ data was not reported for the remaining $49 \%$.

Therapeutic hypothermia Only 19 of the 146 newborns with HIE (13\%) were treated with TH (mild HIE: 2, moderate HIE: 4, severe HIE: 8, with unknown severity: 5) (Table 2). Of those treated with $\mathrm{TH}, 75 \%$ received body cooling and $25 \%$ received selective brain cooling. It is obvious that, regardless of the severity of HIE, TH use is infrequent.

Mortality Among the 2876 newborns, mortality reported was $11 \%$ (310 newborns) while mortality in the 146 newborns with HIE was $42 \%$ (61/146), which is positively correlated with HIE severity. Of the 61 newborns with HIE who died, 37 cases $(60.7 \%)$ were directly attributable to $\mathrm{HIE}$, regardless of severity. In the remaining 24 (39.3\%), death was attributed to sepsis, meningitis, respiratory failure, hypoxemia, kernicterus and other causes.

\section{DISCUSSION}

HIE is a neonatal condition that results in high mortality and severe neurological sequelae.[1-3] In this study, HIE prevalence in newborns at $\geq 36$ weeks GA admitted to SIBEN Network centers was $5.1 \%$ with a mortality rate of $42 \%$, almost four times that of non-HIE newborns at the same GA reported to the Network. Although HIE severity was not reported for all newborns, in $54 \%$ of reported cases it was either moderate or severe. These data do not represent all of Latin America nor the reality of each country, as our sample corresponds to voluntary reporting made by only some of the neonatal units within the region. However, even with the aforementioned limitations of our sample, these data reflect a situation demanding urgent action.

TH has proven benefits for newborns with HIE,[10,15,17-23], among which the reduction in mortality or neurodevelopmental alterations at 18 months stands out with a relative risk (RR) of $0.75,95 \% \mathrm{Cl}(0.68-0.83)$.[17] $\mathrm{TH}$ has few side effects and its implementation is relatively simple. However, TH was only used in a small number of newborns with HIE in this sample, and it remains unavailable in many centers throughout the region. In the SIBEN Network during the study period, $87 \%$ of neonates who presented with $\mathrm{HIE}$ did not receive $\mathrm{TH}$, and of the 79 reported with moderate or severe HIE, only $12(15 \%)$ had access to $\mathrm{TH}$. It is highly probable that the mortality rate in these newborns would have been lower if $\mathrm{TH}$ had been available and applied. Even though we do not know the neurological evolution of these newborns after discharge, evidence shows that $\mathrm{TH}$ leads to reduced rates of major disability associated with HIE and therefore better long-term neurological outcomes.[17]

As is the case with other health indicators, no Latin American countries present national data on prevalence and clinical evolution of newborns with HIE, with the exception of Cuba, where HIE frequency in 2017 and 2018 was comparable to rates in high-income countries. HIE mortality rates in Cuba of $12 \%$ and $17 \%$ (for 2017 and 2018, respectively) cannot be stratified by HIE severity since, as of this writing, the Cuban national registry has not yet recorded this data for later analysis. Unlike Latin America, other regions have working groups that track information related to HIE incidence, its severity, conditions available for comprehensive care and the TH implementation. [24,25] In a cross-sectional study conducted in 57 Spanish hospitals, $95 \%$ of those surveyed used servo-controlled total body cooling and had established protocols specific to HIE patient care.[26]

This study does not include an analysis of the use of oxygen in advanced resuscitation procedures. The universal recommendation is to use ambient air $\left(21 \% \mathrm{FiO}_{2}\right)$. However, this was the case in only $11 \%$ of newborns resuscitated in this sample. Some $40 \%$ were resuscitated with $100 \%$ oxygen, despite ample evidence advising against this practice and the damage the hypoxia-reperfusion-hyperoxia cycle can have on the brain. [27-31]

Any process aimed at improving quality of care for newborns with HIE must be based on reliable information. This is the first study involving Latin American countries that provides data on this important problem. Comprehensive care of newborns affected by HIE is multi-faceted and must include the 
availability of adequate resuscitation with trained personnel in the delivery room, avoiding inappropriate use of oxygen; rapid clinical diagnoses; the ability to assess HIE severity, and use of previously validated care protocols. Timely care for families is essential, as is $\mathrm{TH}$ provision in the $\mathrm{NICU}$ or potential for patient referral to a center capable of providing $\mathrm{TH}$ within the first six hours of life. Finally, given the consequences HIE has for neurodevelopment and quality of life for both children and their families, specialized followup programs should be established to identify and treat neurodevelopmental issues in a timely manner, and offer support and guidance to families.[32]

\section{CONCLUSIONS}

Hypoxic ischemic encephalopathy is a neonatal condition responsible for high mortality rates and severe neurological sequelae. HIE prevalence in this study was $5.1 \%$, with an overall mortality rate of $42 \%$. Despite the fact that HIE was graded as either moderate or severe in $54 \%$ of cases, therapeutic hypothermia was not performed on $87 \%$ of neonates presenting with HIE. This is the first study published containing multicenter data on HIE in Latin America, and it demonstrates an urgent need for the implementation of programs to improve the quality of care available for newborns with neonatal encephalopathy. - 1 -

\section{REFERENCES}

1. Lemus Varela ML, Sola A, Golombek SG, Baquero H, Dávila CR, Fariña D, et al. Recomendaciones terapéuticas del VII Consenso Clínico de SIBEN para la encefalopatía hipóxico-isquémica neonatal. NeoReviews. 2016;17(9):e554-67. Spanish.

2. García Alix A, Martínez-Biarge M, Arnaez J, Valverde E, Quero J. Asfixia Intraparto y encefalopatía hipóxico isquémica. In: Protocolos Diagnóstico Terapéuticos [Internet]. Madrid: Asociación Española de Pediatría AEP: Neonatología; 2008 [cited 2020 Mar 27]. 11 p. Available at: https://www.aeped.es/sites/default/files/docu mentos/26.pdf. Spanish.

3. García Alix A, Martínez-Biarge M, Diez J, Gayá $F$, Quero J. Incidencia y prevalencia de la encefalopatía hipóxico-isquémica en la primera década del siglo XXI. An Pediatr (Barc). 2009 Oct;71(4):319-26. Spanish.

4. Ruiz Peláez JG, Romero-Pradilla R, BuitragoLópez A. Guía práctica clínica del recién nacido con asfixia perinatal [Internet]. Bogotá: Ministry of Health and Social Protection of Colombia; 2013 Apr [cited 2020 Mar 27]. p. 1-38. Available at: https://www.minsalud.gov.co/sites/rid/Lists/Bi bliotecaDigital/RIDE/INEC/IETS/GPC_Completa Asfix.pdf. Spanish

5. Novoa J, Milad M, Fabres J, Fasce J, Toso $\mathrm{P}$, Arriaga $\mathrm{M}$, et al. Consenso sobre el manejo integral del neonato con encefalopatía hipóxico isquémica. Rev Chilena Pediatría. 2012;83(5):492-501. Spanish.

6. Rizzotti A, Bas J, Cuestas E. Meta análisis sobre la eficacia y seguridad de la hipotermia en el tratamiento de la encefalopatía hipóxico isquémica. Rev Facultad Cienc Méd. 2010;67(1):15-23. Spanish.

7. Medina Alva MP, Rivera Abbiati F, Tri Murgueytio AA, Montiel Blanco J, Guillén Pinto RD. Frecuencia, características y mortalidad asociada a la enfermedad neurológica en la unidad de cuidados intensivos neonatales del Hospital Cayetano Heredia. Rev Perú Pediatr. 2007 JanApr;60(1):11-9. Spanish.

8. Booth D, Evans DJ. Anticonvulsants for neonates with seizures. Cochrane Database Syst Rev. 2004 Oct 18;4:CD004218.

9. Thompson CM, Puterman AS, Linley LL, Hann $\mathrm{FM}$, van der Elst CW, Molteno CD, et al. The value of a scoring system for hypoxic ischaemic encephalopathy in predicting neurodevelopmental outcome. Acta Paediatr. 1997:86(7):757-61.

10. Tagin MA, Woolcott CG, Vincer MJ, Whyte RK, Stinson DA. Hypothermia for neonatal hypoxic ischemic encephalopathy: an updated systematic review and meta-analysis. Arch Pediatr Adolesc Med. 2012 Jun 1;166(6):558-66.

11. World Health Organization [Internet]. Geneva: World Health Organization; c2020. Centro de prensa. Reducir la mortalidad de los recién nacidos; 2019 Dec 19 [cited 2020 Aug 1]; [about 4 p.].
Available at: https://www.who.int/es/news-room/ fact-sheets/detail/newboRN-reducing-mortality. Spanish.

12. Lawn JE, Cousens S, Zupan J; Lancet Neonatal Survival Steering Team. 4 million neonatal deaths: when? Where? Why? Lancet. 2005 Mar 5-11;365(9462):891-900.

13. Disminuye la mortalidad neonatal, pero aumenta su proporción en la mortalidad en la niñez a escala mundial. Geneva: World Health Organization; 2011 [cited 2020 Aug 8]. Available at: https:// www.who.int/mediacentre/news/releases/2011/ newborn deaths 20110830/es/\#:. Spanish.

14. Grupo de Trabajo Hipotermia Terapéutica, Comité de Estudios Feto-Neonatales (CEFEN). Recomendación para el tratamiento con hipotermia en recién nacidos con encefalopatía hipóxicoisquémica. Arch Argent Pediatr. 2017;115 Suppl 3:S38-52. Spanish.

15. Franco AO, Coca ÁG, Domínguez DF, Andrés $A D$, Andino AD. La encefalopatía hipóxico isquémica en una unidad de cuidados intensivos. Rev Cubana Pediatr. 2017;89(4). Spanish.

16. WMA Declaration of Helsinki - Ethical Principles for Medical Research Involving Human Subjects 64th WMA General Assembly, Fortaleza, Brazil, October 2013 [Internet]. Ferney-Voltaire (FR): World Medical Association; 2013 Oct [cited 2020 Aug 8]. Available at: https://www.wma .net/policies-post/wma-declaration-of-helsinki -ethical-principles-for-medical-research-involving -human-subjects/

17. Shah PS. Hypothermia: a systematic review and meta-analysis of clinical trials. Semin Fetal Neonatal Med. 2010;15(5):238-46.

18. Jacobs SE, Berg M, Hunt $R$, Tarnow-Mordi WO, Inder TE, Davis PG. Cooling for newborns with hypoxic ischaemic encephalopathy. Cochrane Database of Syst Rev. 2013 Jan 31;2013(1):CD003311.

19. Saliba E, Debillon T. [Hypothermia for hypoxicischemic encephalopathy in full term newborns]. Arch Pediatr. 2010 Sep;17 Suppl 3:S67-77. French.

20. National Institute for Health and Care Excellence. NICE interventional procedure guidance [IPG347]: Therapeutic hypothermia with intracorporeal temperature monitoring for hypoxic perinatal brain injury [Internet]. [cited 2016 Jun 16]. Available at: http://www.nice.org.uk/guidance/ ipg347.

21. Blanco D, García-Alix A, Valverde E, Tenorio V, Vento M, Cabañas F; Comisión de Estándares de la Sociedad Española de Neonatología. [Neuroprotection with hypothermia in the newborn with hypoxic-ischaemic encephalopathy. Standard guidelines for its clinical application]. An Pediatr (Barc). 2011 Nov;75(5):341.e1-20. Spanish.

22. Peliowski-Davidovich A; Canadian Paediatric Society, Fetus and Newborn Committee. Hypothermia for newborns with hypoxic ischemic encephalopathy. Paediatr Child Health. 2012 Jan;17(1):41-6. English, French.

23. Takenouchi $T$, Iwata $O$, Nabetani M, Tamura M. Therapeutic hypothermia for neonatal encephalopathy: JSPNM \& MHLW Japan Working Group Practice Guidelines Consensus Statement from the Working Group on Therapeutic Hypothermia for Neonatal Encephalopathy, Ministry of Health, Labor and Welfare (MHLW), Japan, and Japan Society for Perinatal and Neonatal Medicine (JSPNM). Brain Dev. 2012 Feb;34(2):165-70.

24. Guía de Práctica Clínica sobre Encefalopatía Hipóxico-Isquémica Perinatal en el recién nacido. Catalunya: Ministerio de Sanidad, Servicios Sociales e Igualdad Agencia de Qualitat i Avaluacio Sanitaries de Catalunya (AQuAS); 2015. 271 p. Spanish.

25. Arnaez J, García Alix A, Arca G, Valverde E, Caserío S, Moral TM, et al. Incidencia de la encefalopatía hipóxico-isquémica e implementación de la hipotermia terapéutica por regiones en España. An Pediatr (Barc). 2018 Jul;89(1):1223. Spanish.

26. Arnaez J, Herranz Rubia N, García Alix A; Grupo de Trabajo EHI-ESP. Atención integral del neonato con encefalopatía hipóxico-isquémica en España. An Pediatr (Barc) [Internet]. 2020 May 1;92(5):286-96. Available at: https://doi .org/10.1016/j.anpedi.2019.05.013. Spanish.

27. Sola A, Rogido MR, Deulofeut R. Oxygen as a neonatal health hazard: call for détente in clinical practice. Acta Paediatr. 2007 Jun;96(6):801-12.

28. Sola A. Oxygen saturation in the newborn and the importance of avoiding hyperoxia-induced damage. Neo Reviews. 2015 Jul;16(7):e393-405.

29. Rabi Y, Rabi D, Yee W. Room air resuscitation of the depressed newborn: a systematic review and meta-analysis. Resuscitation. 2007 Mar;72(3):353-63.

30. Perlman JM, Wyllie J, Kattwinkel J, Wyckoff MH, Aziz K, Guinsburg R, et al. Part 7: Neonatal resuscitation: 2015 international consensus on cardiopulmonary resuscitation and emergency cardiovascular care science with treatment recommendations. Circulation. 2015 Oct 20;132(16 Suppl 1):S204-41.

31. Soll RF. The use of oxygen in the delivery room. Pediatrics. 2019 Jan;143(1):e20183365. DOI: https://doi.org/10.1542/peds.2018-3365

32. Martínez-Biarge M, Blanco D, García-Alix A, Salas S; Grupo de Trabajo de Hipotermia de la Sociedad Española de Neonatología. Seguimiento de los recién nacidos con encefalopatía hipóxico-isquémica. An Pediatr (Barc). 2014 Jul;81(1):52.e1-14. DOI: 10.1016/j.anpedi.2013 .06.015. Spanish.

\section{ACKNOWLEDGMENTS}

We are grateful to the following specialists for collecting and reporting data to the SIBEN Net- 
work: Maria Rosa Frias, Diego Depietro, Ignacio Sosa, Belen Falco, Maiara Celiz, Segundo Jaime Sánchez, Anabell Pereira, María Elisa Villoldo, Carolina Pinto, Cristiane Ribeiro, María Rosa Gonzalez, Amantina Peña, Sujey Vargas, Candelaria Nuñez, Maria Victoria Vulcano, Arielina Felix, Maritza Ramos Medina, Nadia Rosario, Taína Malena, Mónica Menzio, Veronica Favareto, Ana Medina, Odris Tejera and Joselyn Acosta.

\section{THE AUTHORS}

Fernando Domínguez-Dieppa (Corresponding author: fddieppa@infomed.sld.edu), neonatologist with a $\mathrm{PhD}$ in medical sciences. Member of the board of directors and ethics department, Ibero-American Neonatology Society (SIBEN) Network. Full (consulting) professor of pediatrics and neonatology, Medical University of Havana, Cuba. https://orcid .org/0000-0003-3971-5612

Marcelo Cardetti, physician. Board member and chief of the Clinical Neonatology and Maternity Services at the Endocrinology and Human Reproduction Center, San Luis, Argentina. https://orcid.org/0000-0001-6697-6389

Susana Rodríguez, physician. Board member, SIBEN Network, director of teaching and research, Juan P. Garrahan Hospital, Buenos Aires, Argentina. https://orcid.org/0000-0001 $-6015-6048$
Alfredo García-Alix, physician. Sant Joan de Deu Pediatric Research Institute, Nene Foundation, University of Barcelona, Barcelona, Spain. https://orcid.org/0000-0002-7972-8453

Augusto Sola, neonatologist. Medical director of the SIBEN Network, California, USA. https:// orcid.org/0000-0002-7608-3872

Submitted: June 9, 2020

Approved for publication: December 29, 2020 Disclosures: None 


\title{
Characterization of Adverse Events Following Childhood Immunizations in Pinar del Río, Cuba
}

\author{
Elba Cruz-Rodríguez MD MS, Belkys M. Galindo-Santana MD MS PhD, Waldemar Baldoquín-Rodríguez MD, \\ Dayana Rodríguez-Velázquez, Damarys Concepción-Díaz, Miriam C. Luis-Martínez MD MS
}

\begin{abstract}
INTRODUCTION The Cuban national program for childhood immunizations began in 1962 and has included a surveillance system for monitoring adverse events following immunization since 1999. The expected rate of adverse events following childhood immunization in Cuba is 50 per 100,000 vaccine doses administered. In 2017, Pinar del Río Province reported higher-than-expected rates of adverse events, which motivated this study on their frequency and types.
\end{abstract}

OBJECTIVE Characterize adverse events following immunization reported in children in Pinar del Río Province in 2017.

METHODS We examined reports of adverse events following immunization in children from 2 months through 14 years of age in Pinar del Río Province, Cuba, from January 1, 2017 through December 31, 2017. We found 487 adverse events that met the criteria established by the national surveillance system. Information was obtained from epidemiological surveys of adverse events following immunization in Pinar del Río Province municipalities. Recorded were age, municipality, signs and symptoms, vaccine type, number of doses, anatomical site and route of vaccine administration, and the institution where the child was vaccinated. We

\section{INTRODUCTION}

With the exception of access to potable water, no other preventive or therapeutic measure has done more than vaccines to reduce morbidity and mortality from communicable diseases worldwide. As a direct result of immunization, diseases like poliomyelitis, diphtheria, pertussis, tetanus, measles, rubella, mumps, and serious complications from neonatal tetanus, congenital rubella syndrome, tuberculosis meningitis or post-parotitis, have ceased to be health problems in Cuba, their transmission rates declining to $<0.1$ per 100,000 vaccine doses.[1] Despite these benefits, adverse events following immunization must be monitored and recorded to ensure vaccine safety.

The term 'immunization' in this text refers to the use of preventive vaccines for the purpose of conferring protection against certain diseases. This term includes all processes that occur after a vaccine product leaves its place of manufacture and packaging, including handling, prescription and administration.

\section{IMPORTANCE}

This paper reviews and analyzes data from a Cuban province that reported higher-than-expected adverse events following childhood immunization in 2017. Evaluation offers further evidence of vaccine safety for children in the Cuban National Immunization Program. estimated proportions for intensity and frequency related to vaccination, and calculated rates for 100,000 vaccine doses administered. We then compared the rates of observed adverse events with those of expected events.

RESULTS The overall rate of adverse events was 305.6 per 100,000 doses administered. Highest rates were reported in children aged $<1$ year (580.9 per 100,000 doses administered); in Guane Municipality (610 per 100,000 doses), for the pentavalent (DTwP-HB-Hib) vaccine (1567.7 per 100,000 doses), and in applications to the anterolateral quadrant of the thigh ( 772.5 per 100,000 doses). Symptoms classified as moderate, common, and general occurred more often, with fever being the most frequent. Severe induration, hypotonic and hyporesponsive episodes, persistent crying and rashes were observed more frequently than expected.

CONCLUSIONS The rate of adverse events following childhood immunization is similar to that reported in other provinces and elsewhere in the world. Of all childhood vaccines, the pentavalent vaccine is the most reactogenic. The absence of serious adverse events demonstrates the safety of childhood immunization in Cuba.

KEYWORDS Immunization programs, vaccination, surveillance system, adverse events, Cuba

Safe vaccination is an essential component of immunization programs, which are responsible for regulating vaccine quality; transportation and storage at appropriate temperatures $\left(2{ }^{\circ} \mathrm{C}-8{ }^{\circ} \mathrm{C}\right)$; inoculation practices that pose minimal risks to recipients, health workers administering the vaccine and the environment; as well as surveillance of adverse events attributable to vaccination or immunization.[1-3]

An adverse event following immunization (AEFI) is defined as any untoward medical occurrence which follows vaccination or immunization, even if it does not have a causal relationship with the vaccine.[4-7] WHO specifies that any signs, symptoms, diseases, altered laboratory results, or other unfavorable events can be considered AEFIs. These also include application of megadoses, changes in vaccines or vaccine diluents, and administration at the wrong site or via the wrong route-whether or not these events have a later clinical manifestation.[6]

In 2016, WHO classified AEFIs as follows: according to intensity of clinical presentation (mild, moderate or severe); whether the event was localized or general; by frequency of occurrence; and according to the event's clinical implications (serious or not serious). AEFIs are classified in five categories according to their cause or origin: whether the event is related to vaccine components; with defects in its quality; with errors in vaccine administration; with manifestations of anxiety in the vaccinated child; or as coincidental, defined as an event not included in the previous four categories.[6,8] 
An AEFI is considered non-serious when it does not represent a potential risk to the recipient's health, although it must be monitored carefully because it may indicate a potential problem with the vaccine or with the immunization process, and thus may impact vaccination acceptance in general. An $\mathrm{AEFI}$ is considered serious if it causes death; endangers life; requires hospitalization or prolongs existing hospitalization; causes a persistent or significant disability or incapacity; results in a congenital abnormality or defect; or requires intervention to prevent deterioration or permanent damage.

An event is classified as coincidental if it coincides temporarily with immunization, which sometimes implies mistakenly attributing the event to the vaccine. Examples of coincidental events include: manifestation or complication of an underlying congenital or hereditary disease or birth injury; manifestation or complication of an underlying acquired disease that may or may not have been diagnosed prior to vaccination; psychogenic disease; adverse reactions to recent or concomitant medications or use of illicit substances; allergic reactions and other hypersensitivity reactions due to exposure to allergens other than those present in the vaccine; injury from exposure to environmental toxins; and injuries attributable to trauma, including surgery. $[6,8]$

It is important that health personnel involved in vaccination be aware of adverse events that may occur after vaccine administration, to be able to protect the vaccinated as well as to respond to public concerns about immunization and reducing the influence of anti-vaccine movements. Disinformation spread by these movements has contributed to a decrease in vaccine coverage in some countries, resulting in re-emergence of communicable diseases that were once eliminated.[9]

The AEFI passive surveillance system was implemented in Cuba in 1999 at the primary care level with the purpose of identifying and reporting all adverse events in accordance with methodology established by the Center for State Control of Medicines and Medical Devices (CECMED), the Cuban regulatory authority. [10-13]

AEFI surveillance is carried out in all Cuban provinces, but there are differences in notification rates.[11,14] In 2017, as in previous years, Pinar del Río Province reported higher AEFI rates in the child population than those expected (the expected AEFI rate in Cuba is 50 per 100,000 doses administered); however, these AEFI had not been characterized with the purpose of comparing them with other territories and with reports made in subsequent years as part of vaccine post-marketing surveillance.

This study was aimed at characterizing AEFI in children in Pinar del Río Province, Cuba, in 2017 and identifying factors related to their occurrence. The results of this research are part of a larger project that includes several years of monitoring and characterization of $\mathrm{AEFI}$ in the Cuban National Immunization Program.

\section{METHODS}

Study design and participants We examined $585 \mathrm{AEFI}$ notifications for children in Pinar del Río Province from January 1 through December 31, 2017. This study was carried out as part of a project examining provinces with the highest rates of AEFIs in years prior to 2019 .
We included 487 AEFI reports in children aged 2 months to 14 years who met the case definitions established by the Cuban surveillance system[15] and the Brighton Collaboration.[16-21] AEFIs were not reported in children younger than 2 months or older than 14 years.

Information on sociodemographic and clinical data, the type of vaccine and vaccination procedures, and the AEFI in question were obtained through a document review of primary sources (an epidemiological survey of adverse events to vaccination).[11]

We collected the following sociodemographic variables: age ( $\geq 2$ months and <1 year; 1-4 years; 5-9 years; 10-14 years) and municipality (Sandino, Mantua, Minas de Matahambre, Viñales, La Palma, Los Palacios, Consolación del Sur, Pinar del Río, San Luis, San Juan y Martínez, and Guane).

AEFIs considered in the study were: reports of pain, mild redness and induration; cellulitis or severe induration at injection site (induration in the puncture area that lasted more than 72 hours, or presented with edema past the nearest joint); fever; persistent crying; rash; episodes of hyporesponsive hypotonia (EHH); irritability; and general malaise. These criteria were established according to guidelines published by the Medical University of Havana.[11]

We recorded the following variables related to vaccines and vaccine administration procedures:

- type of vaccine: pentavalent (DTwP: diptheria-tetanus-whole cell pertussis; HB: hepatitis B; Hib: (Haemophilus influenzae type b); OPV (oral polio vaccine); IPV (intramuscular polio vaccine); AM-BC (meningococcal-BC); MMR (measles-mumpsrubella); DTwP (diptheria-tetanus-whole cell pertussis); DT (diptheria-tetanus); AT (typhoid fever); TT (tetanus toxoid); and AG (influenza)

- ordinal number of vaccine does: first dose or single dose, second dose, third dose, and reactivation or booster

- route of administration: oral, subcutaneous, intradermal or intramuscular

- anatomical region of application: by mouth, deltoid or middle third of the anterolateral quadrant of the thigh

- location of application: vaccination center of a community polyclinic, school, or hospital

We classified AEFIs into the following frequencies of those vaccinated:

- very common: $>10 \%$

- common: $\geq 1 \%-10 \%$

- infrequent: $\geq 0.1 \%-<1 \%$

- rare: $\geq 0.01 \%-<0.1 \%$

- very rare: $<0.01 \%$

We classified AEFIs according to their location as follows:

- local: pain, redness and induration; cellulitis; or severe induration at the injection site

- general: fever; malaise; irritability; rash; persistent crying; and $\mathrm{EHH}$

We classified AEFIs according to the intensity of the clinical picture:

- mild: pain, redness and slight induration at or near the injection site $<5 \mathrm{~cm}^{2}$, lasting $24-48$ hours; fever of $38{ }^{\circ} \mathrm{C}-38.9{ }^{\circ} \mathrm{C}$; general malaise; irritability; and rash 
- moderate: cellulitis in the deltoids or anterolateral quadrant of the thigh $5-10 \mathrm{~cm}^{2}$, lasting $48-72$ hours; fever of $39{ }^{\circ} \mathrm{C}-39.9$ ${ }^{\circ} \mathrm{C}$; and persistent crying

- severe: severe induration of the puncture area $>10 \mathrm{~cm}^{2}$, or induration that went past the nearest joint, lasting $>72$ hours; fever $\geq 40{ }^{\circ} \mathrm{C}$; and $\mathrm{EHH}$

AEFIs were classified according to the following clinical implications:

- serious: symptoms and signs resulted in prolonged hospitalization, in persistent or significant disability, if they endangered life, or if they resulted in the death of the child

- not serious: symptoms and signs did not result in any of the above consequences

Hospitalizations that were not prolonged were excluded from the serious category, because according to the regulations of Cuba's Maternal-Child Health Program, children under one year of age who are seen by emergency services are evaluated and hospitalized regardless of the AEFI in question.

Finally, AEFIs were classified according to cause or origin as follows:

- related to vaccine components (mild pain, redness and induration at the injection site, fever, general malaise, irritability, rash, persistent crying, EHH)

- related to procedural errors (cellulitis and severe induration at the injection site)

- coincidental: any event not included in the previous categories

Data analysis Observed AEFI rates were calculated per 100,000 vaccine doses administered (DA) to compare them with expected rates, in accordance with methodology recommended by $\mathrm{WHO}$. [22] The observed rates are the sum of the average rates plus the effect of the vaccine, and the expected rate is the rate described for each vaccine according to the WHO Global Manual for Adverse Events Surveillance.[6]

Ethics This project was approved by the research ethics committees of the Pedro Kourí Tropical Medicine Institute in Havana and Pinar del Río Provincial health authorities. Anonymity and confidentiality of information were assured.

\section{RESULTS}

In 2017, Pinar del Río Province reported 585 AEFIs in children to the national surveillance system. Of these, 487 were complete and useful for our analysis. In 2017, 159,376 doses of vaccines were given to children in the province, so the general $\mathrm{AEFI}$ rate was 305.6 per 100,000 DA. AEFI rates were broken down by administration route, anatomical region, and location where the vaccines were administered (Table 1).

The observed AEFI rate was higher than expected in children aged $<5$ years, and the greatest difference between observed and expected rates occurred in children aged $<1$ year.

By municipality (data not tabulated), Guane Municipality had the highest AEFI rate at 715.5 per 100,000 DA. Mantua (570.7 per 100,000 DA), Minas de Matahambre (561.7 per 100,000 DA), La Palma (485.9 per 100,000 DA) and Los Palacios (608.4 per 100,000 DA) registered values above the provincial average of
305.6 per 100,000 DA. Sandino (298.2 per 100,000 DA), Pinar del Río (207.6 per 100,000 DA) and Consolación del Sur (193.7 per 100,000 DA) remained below that value. Viñales and San Juan y Martínez municipalities did not report AEFIs. An increase in the general rate to $336.9 \mathrm{AEFI}$ per 100,000 DA was reported in Pinar del Río province for seven vaccines within the national vaccine program and for the influenza vaccine given to pediatric groups at risk for influenza-like illness. Rates higher than the provincial average were found for the pentavalent vaccines (in each of its three doses and in total), the DTwP reactivation booster and AM-BC (in both its two doses and in the total). For OPV, PRS, Hib, AT, and AG, rates below the provincial average were recorded, and no events were reported for BCG, HB, OPV, DT, and TT (Table 3).

A total of 644 signs or symptoms were identified, an average of 1.3 for each reported AEFI (487). General signs and symptoms were the most common (93.1\%). Fever was the most frequently reported sign or symptom, and $\mathrm{EHH}$ the most infrequent. The remaining $6.9 \%$ of signs or symptoms were local, with the highest rates corresponding to pain, redness and mild induration, followed by severe induration and cellulitis (Table 4).

Of all reported signs and symptoms, $71.5 \%$ were classified as moderate (mainly fever), $26.3 \%$ as mild, and $2.0 \%$ as severe. No serious events were reported. Three children were hospitalized for fever, their average length of stay was two days, and they had no other complications.

Table 1: AEFI rates per vaccine doses, by vaccination factor

\begin{tabular}{|l|r|r|r|}
\hline Factors & $\begin{array}{c}\text { AEFI } \\
\mathbf{n}\end{array}$ & $\begin{array}{r}\text { Doses } \\
\text { administered }\end{array}$ & $\begin{array}{r}\text { Rate per } \\
\mathbf{1 0 0 , 0 0 0} \text { DA }\end{array}$ \\
\hline Administration route & & & \\
\hline Oral & 0 & 44,393 & 0.00 \\
\hline Intradermal & 0 & 5,988 & 0.00 \\
\hline Subcutaneous & 14 & 11,430 & 122.48 \\
\hline Intramuscular & 473 & 97,565 & 484.80 \\
\hline Anatomical region & & & 0.00 \\
\hline Mouth & 0 & 44,393 & 130.00 \\
\hline Deltoids & 96 & 64,366 & 772.50 \\
\hline ALT & 391 & 50,617 & 0.00 \\
\hline Location of application & & & 6.89 \\
\hline Hospital & 0 & 12,053 & 409.97 \\
\hline School & 2 & 29,021 & \\
\hline Polyclinic & 485 & 118,302 & \\
\hline
\end{tabular}

AEFI: Adverse events following immunization

ALT: anterolateral quadrant of the thigh DA: doses administered

Table 2: AEFI rates per administered vaccine doses, by age

\begin{tabular}{|l|r|r|r|r|}
\hline Age group & $\begin{array}{c}\text { Doses } \\
\text { administered }\end{array}$ & $\begin{array}{c}\text { AEFI } \\
\mathbf{n}\end{array}$ & $\begin{array}{c}\text { ER per } \\
\text { 100,000 DA }\end{array}$ & $\begin{array}{c}\text { OR per } \\
\text { 100,000 DA }\end{array}$ \\
\hline <1 year & 66,792 & 388 & 33 & 580.9 \\
\hline 1-4 years & 57,388 & 95 & 29 & 165.5 \\
\hline 5-9 years & 14,933 & 3 & 8 & 20.0 \\
\hline 10-14 years & 15,828 & 1 & 8 & 6.3 \\
\hline 15-18 years & 4,435 & 0 & 2 & 0.0 \\
\hline Total AEFI & 159,376 & 487 & 80 & 305.6 \\
\hline
\end{tabular}

AEFI: Adverse events following immunization DA: administered doses ER: expected rate OR: observed rate 
No AEFI was classified as very common; $53.1 \%$ were classified as common, $36.8 \%$ as infrequent, $9.7 \%$ as rare and $0.3 \%$ as very rare. The most commonly categorized $\mathrm{AEFI}$ was fever, and $\mathrm{EHH}$ was categorized as a very rare event.

Vaccine components caused $92.3 \%$ of reported AEFI, $6.1 \%$ were coincidental and $1.5 \%$ were classified as errors in vaccine administration. Cellulitis and severe induration were both considered the result of errors in vaccine administration. Fever secondary to the PRS vaccine was considered to be coincidental, since the reported febrile episodes appeared in the first 72 hours after vaccination and could not be attributed to known causes.

Table 3: AEFI rates per 100,000 doses administered, according to vaccine type and number of serial doses

\begin{tabular}{|l|r|r|r|r|r|}
\hline Vaccine & Dose 1 & Dose 2 & Dose 3 & Booster & General rate \\
\hline Pentavalent & 2039.8 & 1408.5 & 1257.8 & - & 1567.7 \\
\hline AM-BC & 790.9 & 781.1 & - & - & 786.0 \\
\hline IPV & 43.7 & - & - & - & 43.7 \\
\hline MMR & 171.0 & - & - & 60.0 & 122.5 \\
\hline DTwP & - & - & - & 1163.3 & 1163.3 \\
\hline Hib & - & - & - & 30.7 & 30.5 \\
\hline AT & 0.0 & 20.4 & 0.0 & - & 7.4 \\
\hline AG & 71.5 & 21.2 & - & - & 46.8 \\
\hline Total & 280.1 & 299.1 & 730.0 & 234.9 & 305.6 \\
\hline
\end{tabular}

AG: flu vaccine AM-BC: meningococcal $B C$ vaccine $\quad A T$ : typhoid fever vaccine DTwP: triple bacterial vaccine (diptheria, tetanus, and whole-cell pertussis) AEFI: Adverse events following vaccination Hib: Haemophilus influenzae type b vaccine IPV: inactivated polio vaccine MMR vaccine (measles, mumps, rubella)

\begin{tabular}{l|r|r|}
\hline \begin{tabular}{l} 
Table 4: AEFI rates, by generalized and local signs and symptoms \\
\hline Signs and symptoms
\end{tabular} & AEFI & Rate per 100,000 DA \\
\hline General & 448 & 281.1 \\
\hline Fever & 78 & 48.9 \\
\hline General malaise & 54 & 33.9 \\
\hline Persistent crying & 11 & 6.9 \\
\hline Irritability & 7 & 4.4 \\
\hline Rash & 2 & 1.3 \\
\hline Hypotonic hyporesponsive episode & & \\
\hline At injection site & 34 & 21.3 \\
\hline Mild pain, redness, and induration & 7 & 4.4 \\
\hline Severe induration & 3 & 1.9 \\
\hline Cellulitis
\end{tabular}

AEFI: Adverse events following immunization DA: Doses administered
Fever, malaise, and irritability had lower rates than expected for all vaccines, while rash, persistent crying, $\mathrm{EHH}$, cellulitis and severe induration were reported at values higher than expected for vaccines (Table 5).

\section{DISCUSSION}

AEFI recording and analysis is an important step in post-marketing vaccine surveillance.[22]

The $A E F I$ rate in our research is similar to those reported in other studies in Cuba. Galindo reported a rate of 106 events per 100,000 DA in Pinar del Río Province and 115 in Sancti Spíritus Province.[14] González obtained annual rates of 119-604 per 100,000 DA in the Isle of Youth Special Municipality,[23] and Mantecón identified 150 events per 100,000 DA in Camagüey Province.[24]

The rates in our study were higher than those found by Guo in a systematic meta-analysis that included 33 studies conducted in China and other countries, based on an international comparison of AEFI reporting rates divided by pediatric age group.[25] Our rates were also higher than those reported by other investigations carried out at different times in populations that use passive surveillance, by populations that perform their data analysis according to doses administered (not distributed), and who have vaccine schedules similar to those in Cuba.[26-31]

The high AEFI rates in Pinar del Río could be attributed to Cuba's surveillance system, which identifies and reports all events that occur within the vaccinated community, which leaves little margin for underreporting. This makes the Cuban vaccination surveillance system highly sensitive.

However, since high rates are not always the result of high sensitivity in surveillance systems, it is important to consider both relevance of the reported cases and data quality in addition to the number of notifications. These values could be influenced by average rates of certain signs and symptoms that occur within the community which could be considered AEFI if they appear after vaccination.

A higher frequency of events was recorded in children under one year of age. Other investigations carried out in Cuba[10,14,23] and in other countries[30-33] describe similar results, although other research has found higher AEFI rates in other pediatric age groups.[26,27]
Table 5: Observed versus expected rates of signs and symptoms, by vaccine type

\begin{tabular}{|c|c|c|c|c|c|c|c|c|c|c|}
\hline \multirow[t]{2}{*}{ Vaccine } & \multicolumn{2}{|c|}{ Rash } & \multicolumn{2}{|c|}{$\begin{array}{l}\text { Persistent } \\
\text { Crying }\end{array}$} & \multicolumn{2}{|c|}{$\begin{array}{c}\text { Hypotonic } \\
\text { hyporesponsive } \\
\text { episode }\end{array}$} & \multicolumn{2}{|c|}{ Cellulitis } & \multicolumn{2}{|c|}{$\begin{array}{l}\text { Severe } \\
\text { induration }\end{array}$} \\
\hline & ER & OR & ER & OR & ER & OR & ER & OR & ER & OR \\
\hline Penta & 0.0 & 21.8 & $<1 / 1000$ & 1.4 & $<1 / 10,000$ & 0.5 & - & - & 0.0 & 10.9 \\
\hline AM-BC & - & - & $<1 / 1000$ & 1.3 & - & - & - & - & 0.0 & 16.4 \\
\hline MMR & $\leq 1 / 100$ & 8.7 & - & - & 0.0 & 8.7 & - & - & 0.0 & 15.2 \\
\hline DTwP & - & - & $<1 / 1000$ & 0.1 & - & - & 0.0 & 45.5 & 0.0 & 17.5 \\
\hline AT & 0.0 & 7.4 & - & - & - & - & - & - & - & - \\
\hline$A G$ & $<1 / 1000$ & 0.05 & $<1 / 1000$ & 0.1 & - & - & - & - & - & - \\
\hline
\end{tabular}

$A G$ : flu vaccine AM-BC: meningococcal BC vaccine AT: typhoid fever vaccine DTwP: triple bacterial vaccine (diptheria, tetanus, and whole-cell pertussis) ER: expected rate per 100,000 doses administered OR: observed rate per 100,000 doses administered Penta: Pentavalent vaccine (DTwPHB-Hib) MMR: measles, mumps, rubella
The first year of life is a period of rapid body transformation when the immune system is also rapidly maturing.[34] During this period, alterations to expected growth and development patterns caused by underlying congenital diseases can occur, acquired diseases can be more serious, and reactions to drugs can be more diverse. Children also receive the highest number of vaccine doses during their first year, so it is entirely possible that many medical incidents could occur following a routine vaccination, even if such incidents were not caused by the vaccine.

The differences observed in $\mathrm{AEFI}$ rates and patterns between Cuba and other countries 
could be explained by differing population compositions, by the fact that some countries rely on different vaccination schedules, and because each country's vaccines have different origins and rely on different production technologies. In Cuba, for example, most of the immunobiologicals used in the Cuban population are produced domestically, while other countries often purchase vaccines from international pharmaceutical firms. In Brazil, to give another example, the group most affected by AEFI were children between the ages of one and four years old, and the national vaccine schedule includes a tetraviral vaccine (measlesmumps-rubella-varicella) administered during that period, as well as a vaccine for hepatitis $A[26]$ that is not administered in Cuba. In Canada, the highest rates of AEFI are reported in children between the ages of one and two, and the immunization schedule includes both the tetraviral vaccine and a live attenuated influenza vaccine.[27]

In Pinar del Río, 82\% of municipalities reported adverse events during the study period, a rate similar to that found in Camagüey Province in eastern Cuba (84.6\%),[24] and higher than those reported in other countries.[26,35] In Cuba, AEFI surveillance and notification is the responsibility of physicians and nurses in family practice at the primary healthcare level. [14] Surveillance increases confidence in vaccine programs, completes the safety profile of vaccines during the postmarketing stage, guarantees that detection of problems related to vaccine use is accompanied by preventive and corrective actions, and favors communication with the professionals responsible for both designing and administering vaccines and with the families who receive them. Underreporting of AEFIs reveals weaknesses in the surveillance system and calls into question the results of investigations.

The vaccines combined with DTP were the most reactogenic, as seen in results of previous research in Cuba[10,14,22,24,36] and in other countries.[25,33,37,38] However, the Republic of Korea reports more AEFIs for the BCG vaccine,[29] Australia reports more for the seasonal influenza vaccine[33] and China reports higher rates for the measles vaccine.[32]

It is well established in the literature that vaccines combined with DTP are the most reactogenic, especially those that contain the whole-cell pertussis component.[4,6] The pentavalent and DTP vaccines used in Cuba are produced nationally, include whole cells and are considered the most reactogenic of all vaccines in the Cuban vaccine schedule. Internationally, other formulations use acellular DTP which is less reactogenic but more expensive and less effective.[14]

The highest AEFI rates were reported for the first dose of different vaccines, for those administered intramuscularly, those administered in the anterolateral quadrant of the thigh, and those administered in polyclinics. These results coincide with those reported in national Cuban studies[24,36,39,40] and by other countries.[32,41-43]

As outlined by the standards published in the Expanded Program on Immunizations[44] the route of administration of immunobiologicals is specific to each immunobiologic compound, and each has recommendations for optimal techniques designed to reduce adverse events resulting from errors in administration. [45-47] The higher rates observed in the intramuscular route of administration could be due to the fact that it is used for the DTP and pentavalent vaccines-which carry the highest rates of AEFIs reported in this study-or because recommended optimal techniques for administration of these particular compounds were not followed. These guidelines indicate the anatomical region in which each vaccine should be injected to ensure that damage to tissue, nerves, veins and arteries is minimal. The higher rates of AEFIs associated with vaccine administration to the anterolateral quadrant of the thigh could be due to the fact that it is the anatomical site that requires the greatest navigational expertise from vaccinators.

The greater number of AEFIs registered during polyclinic vaccinations could be due to the fact that polyclinics are the places that administer the highest number of vaccine doses in the Cuban program (11 of 18 total vaccine doses in the national childhood vaccination schedule), and community-based polyclinics allow for closer post-vaccination observation and thus often better management of AEFIs by health professionals.

Common and general signs and symptoms occurred more frequently, with fever the most often reported symptom. Some researchers report similar findings, $[10,14,23,26]$ while other studies found a higher frequency of local events.[27,29,30-33] Moderate and mild intensity AEFIs were reported more frequently, which coincides with results of other national[10,14,23] and international studies,[30] with the exception of reports from Colombia (with $76 \%$ events classified as severe).[48] No AEFI in this study was classified as severe, consistent with some authors[24] but differing from others, both in Cuba and internationally.[14,23,26,35]

Differences in AEFI frequency and location may be due at least in part to the fact that some AEFIs result from physiological inflammatory responses intrinsic to the organism's innate immune system; may be due to factors such as individual susceptibility, different types of vaccines, vaccine composition; or can be the result of program errors.[4,49,50] Clinical manifestations can be localized at the injection site or can be systemic. The higher prevalence found in our study for general AEFIs is explained by the high rate reported for the pentavalent vaccine, for which systemic events are more common than local ones.[50]

Our results coincide with the literature reporting higher frequencies of mild AEFIs.[4,5] As there were no severe AEFIs, we can conclude that the vaccines administered in the country are safe, and that risks to pediatric patients following administration of immunobiologic agents are extremely low.

Signs and symptoms were related to vaccines, immunization errors, or to a lesser extent, were coincidental, similar to behavior described in other investigations.[14,52] Establishing or ruling out causal relationships between appearance of signs and symptoms and vaccine administration is a complex process, especially in young children. It requires considering aspects of the episode, establishing a chronological relationship with exposure to the vaccine according to the underlying pathophysiology, and the possible effects of other causal agents or conditions.[52]

The low rate of events related to immunization errors speaks to the competence of Pinar del Río's health professionals and the quality of processes related to correct administration procedures for vaccination, as these are preventable events. AEFIs related to 
the vaccines themselves cannot be avoided, as they depend on factors related to vaccine components or the innate susceptibilities of the vaccinated population.

In this study, some signs and symptoms occurred at higher rates than would have been expected. AEFI secondary to immunization are considered expected when there is substantiated or consistent information on what may occur, and otherwise unexpected, regardless of whether they are related to vaccine administration.[52]

The higher-than-expected rates we observed could be due to a study limitation, as the average rates of the signs and symptoms examined in the reference population are unknown. This made the proportion of AEFIs related to the vaccine impossible to separate entirely from the portion unrelated to vaccination. False positive cases (those not due to vaccines) could also have been reported, which is common in passive surveillance systems or because, as explained above, the system in question has little room for underreporting.

\section{CONCLUSIONS}

The rates of AEFI in the population studied do not show relevant clinical-epidemiological differences with those reported in Cuba as a whole or in other countries, and the absence of serious events demonstrates the low risk presented by the childhood vaccines included in the Cuban National Vaccination Program. - 1 -

\section{REFERENCES}

1. López Ambrón L, Egües Torres LI, Pérez A, Galindo BM, Galindo MA, Resik S, et al. Experiencia cubana en inmunización, 1962-2016. Rev Panam Salud Pública [Internet]. 2018 [cited 2017 Nov 22];42(34):40-8. Available at: https:// doi.org/10.26633/RPSP.2018.34. Spanish.

2. Rodríguez A, Zunino $C$, Speranza N, Fernández S, Varela A, Picón T, et al. Seguimiento de eventos supuestamente atribuibles a la vacunación e inmunización graves notificados al Ministerio de Salud Pública entre 2010 y 2014. Rev Méd Urug [Internet]. 2017 [cited 2018 Jun 6];33(1):47-58. Available at: http://www.rmu.org .uy/revista/2017v1/art6.pdf. Spanish.

3. Secretaría de Salud. Manual de Eventos Supuestamente Atribuibles a la Vacunación o Inmunización. 1st ed [Internet]. Mexico, D.F.: Editorial Soluciones Gráficas Lithomat; 2014 Jun [cited 2018 Mar 9]. p. 7-14. Available at: https://www gob.mx/cms/uploads/attachment/file/287240/ ESAVI_2014.pdf. Spanish.

4. Spanish Paediatric Association. Manual de vacunas en línea de la AEP [Internet]. Madrid: Spanish Paediatric Association; c1999-2019. Section 1, Chapter 5.2 Efectos adversos de las vacunas; [cited 2017 Dec 15]. Available at: https://vacunasaep.org/documentos/manual/ cap-5. Spanish.

5. World Health Organization [Internet]. Geneva: World Health Organization; c2020. Iniciativa global sobre la seguridad de las vacunas. Eventos adversos posvacunales; [updated $2015 \mathrm{Apr}$ 1; cited 2017 Dec 12]. Available at: http://www .who.int/vaccine_safety/initiative/detection/AEFI/ es/. Spanish.

6. World Health Organization. Global Manual on Surveillance of Adverse Events Following Immunization [Internet]. Geneva: World Health Organization; 2014 [cited 2017 Dec 17]. 111 p. Available at: http://www.who.int/vaccine_safety/publications/ Global_Manual_on_Surveillance_of_AEFI.pdf. Spanish.

7. Ministry of Health (PE). Centro Nacional de Epidemiologia, Prevención y Control de Enfermedades. Vigilancia de ESAVI [Internet]. Lima: Ministry of Health (PE); 2013 [cited 2018 Jun 22]; [about 2 screens]. Available at: http://www.dge .gob.pe/portal/index.php?option=com_content\& view=article \&id=432\&Itemid=109. Spanish.

8. World Health Organization [Internet]. Geneva: World Health Organization; c2020. Vaccine Safety Basics e-learning course. Adverse events: Classification; 2013 [cited 2018 Feb 27]. Available at: http://vaccine-safety-training.org/ adverse-events-classification.html. Spanish.

9. Galindo-Santana BM, Cruz-Rodríguez E, LópezAmbrón L. A Cuban perspective on the antivaccination movement. MEDICC Rev [Internet]. 2019 Oct [cited 2020 May 27];21(4):64-9. Available at: http://mediccreview.org/a-cuban-perspective-on -the-antivaccination-movement/

10. Díaz Pinera AM, Cuevas Valdespino IE. Eventos adversos en la vacunación de menores de 2 años, Hospital Pediátrico de Centro Habana (20022007). Rev Cubana Hig Epidemiol [Internet]. 2014 [cited 2017 Nov 7];52(1):81-97. Available at: http://scielo.sld.cu/scielo.php?script=sci_abs tract\&pid=S1561-30032014000100008\&lng=es \&nrm=iso. Spanish.

11. Galindo BM. Diseño, implementación y evaluación de la vigilancia de eventos adversos a vacunas en Cuba. 1999-2010 [thesis] [Internet]. [Havana]: University of Medical Sciences of Havana; 2017 [cited 2017 Nov 22]. 135 p. Available at: http://tesis.sld.cu/index.php ?P=FullRecord\&ID=216. Spanish.

12. Cruz Martínez G, Verdasquera Corcho D, Corcho Quintero A, Delgado Díaz OL, Díaz Fuentes C, Carbó Riverón M. Eventos adversos de la vacuna cubana antimeningocóccica. Rev Cubana Med Gen Integr [Internet]. 2011 Apr-Jun [cited 2019 Jun 13];27(2):187-96. Available at: http://scielo .sld.cu/scielo.php?script=sci_arttext\&pid=S0864 $-21252011000200007 \& n r m=$ iso. Spanish.

13. Center for State Control of Medicines and Medical Devices - CECMED (CU). Regulación No. 17 2008. Directrices para la investigación de los eventos adversos supuestamente atribuibles a la vacunación o inmunización (ESAVI) [Internet]. Havana: Ministry of Public Health (CU); 2008 [cited 2017 May 14]. 27 p. Available at: http://www .cecmed.cu/reglamentacion-vigilancia?page $=1$. Spanish.

14. Galindo-Santana BM, Concepción Díaz D, Galindo-Sardiña MA, Pérez-Rodríguez A, Saíz-Sánchez J. Vaccine-related adverse events in Cuban children, 1999-2008. MEDICC Rev [Internet]. 2012 Jan [cited 2017 Nov 22];14(1):38-43. Available at: https://mediccreview.org/vaccine-related -adverse-events-in-cuban-children-1999-2008/

15. Galindo Sardiña MA, Galido Santana BM, Pérez Rodríguez A, Santín Peña M. Programa del Sistema de vigilancia de eventos adversos consecutivos a la vacunación [Internet]. Havana: Ministry of Public Health (CU); 1999 [cited 2017 Nov 22]. 21 p. Available at: http://www.cecmed .cu/sites/default/files/adjuntos/vigilancia/farma cov/sist vig-eventadv_vacunas.pdf. Spanish.

16. Gidudu J, Kohl KS, Halperin S, Hammer SJ, Heath PT, Hennig R, et al. A local reaction at or near injection site: case definition and guidelines for collection, analysis, and presentation of immunization safety data. Vaccine [Internet]. 2008 [cited 2018 Apr 10];26(52):6800-13. Available at: https://www.sciencedirect.com/science/ article/pii/S0264410X08013868

17. Ministry of Health (AR) [Internet]. Buenos Aires: Ministry of Health (AR); c2020. Banco de Recur- sos. La fiebre como evento adverso después de la inmunización: definición de caso y guías para la recogida, análisis y presentación de datos [Internet]. Basel: The Brighton Collaboration; 2003 Mar 13 [cited 2018 Apr 10]. 12 p. Available at: https://bancos.salud.gob.ar/sites/ default/files/2018-10/0000000491cnt-2013-10 _fever_2004_with_2007_addendum_spanish. pdf. Spanish.

18. Rüggeberg JU, Gold MS, Bayas JM, Blum MD, Bonhoeffer J, Friedlander S, et al. Brighton Collaboration Anaphylaxis Working Group. Anaphylaxis: case definition and guidelines for data collection, analysis, and presentation of immunization safety data. Vaccine [Internet]. 2007 [cited 2018 Apr 10];25:5675-84. Available at: https:// docplayer.es/6978087-Anafilaxia-definicion-de -caso-y-lineamientos-para-la-recoleccion-ana lisis-y-presentacion-de-datos-sobre-seguridad -relativa-a-la-inmunizacion.html

19. Ministry of Health (AR) [Internet]. Buenos Aires: Ministry of Health (AR); c2020. Banco de Recursos. El llanto persistente en lactantes y niños pequeños como evento adverso después de la inmunización: definición de caso y guías para la recogida, análisis y presentación de datos; 2003 [cited 2018 Apr 10]. 12 p. Available at: https:// bancos.salud.gob.ar/recurso/el-Ilanto-persis tente-en-lactantes-y-ninos-pequenos-como -evento-adverso-despues-de-la. Spanish.

20. Buettcher $M$, Heininger $U$, Braun $M$, Bonhoeffer $\mathrm{J}$, Halperin S, Heijbel $\mathrm{H}$, et al. Hypotonic-hyporesponsive episode (HHE) as an adverse event following immunization in early childhood: case definition and guidelines for data collection, analysis, and presentation. Vaccine [Internet]. 2007 Aug 1 [cited 2018 Apr 10];25(31):5875-81. Available at: https://www.sciencedirect.com/science/ article/pii/S0264410X07005026?via\%3Dihub

21. Bonhoeffer J, Menkes J, Gold MS, De SouzaBrito G, Fisher MC, Halsey N, et al. Generalized convulsive seizure as an adverse event following immunization: case definition and guidelines for data collection, analysis, and presentation. Vaccine [Internet]. 2004 Jan 26 [cited 2018 Apr 10];22(5-6):557-62. Available at: https://jhu .pure.elsevier.com/en/publications/generalized -convulsive-seizure-as-an-adverse-event-follow ing-immu-5

22. World Health Organization. Guía para las hojas de información de la OMS sobre eventos supuestamente atribuibles a la vacunación o la inmunización (ESAVI) [Internet]. Geneva: World Health Organization; 2012 [cited 2018 May 7]. 3 p. Available at: http://www.who.int/vaccine safe ty/initiative/tools/Guide_Vaccine_rates_informa tion_sheet_ES.pdf. Spanish.

23. González Fiallo S, Bell Morales B, García Sanz D, Moreno Gell M. Eventos adversos supuesta- 
mente atribuidos a la vacunación o inmunización. Isla de la Juventud, Cuba, enero/2013-octubre/2016. VacciMonitor [Internet]. 2017 [cited 2019 Jan 28];26(3):102-9. Available at: http:// www.redalyc. org/articulo. oa? id=203454509005. Spanish.

24. Mantecón MC. Evaluación del sistema de vigilancia de eventos adversos a la vacunación en la provincia Camagüey, 2016 [thesis]. [Havana]: Dr Pedro Kourí Institute of Tropical Medicine; 2018. Spanish.

25. Guo B, Page A, Wang H, Taylor R, McIntyre P. Systematic review of reporting rates of adverse events following immunization: an international comparison of post-marketing surveillance programs with reference to China. Vaccine [Internet]. 2013 Jan 11 [cited 2019 Jan 3];31(4):603-17. Available at: http://dx.doi.org/10.1016/j.vaccine .2012.11.051

26. Caselli F, Santos CMA, Kalume AG, Deotti SM, da Silva AM, Moreira R, et al. Análise do Sistema de Informação da Vigilância de Eventos Adversos Pós-Vacinação no Brasil, 2014 a 2016. Rev Panam Salud Pública [Internet]. 2018 [cited 2018 Jun 21];42(12):1-12. Available at: https://doi org/10.26633/RPSP.2018.12. Portuguese.

27. Law BJ, Laflèche J, Ahmadipour N, Anyoti H. Canadian Adverse Events Following Immunization SurveillanceSystem (CAEFISS): Annual report for vaccines administered in 2012. CCDR [Internet]. 2014 Dec 4 [cited 2018 Jun 29];40(3). Available at: https://doi.org/10.14745/ccdr.v40 is $3 \mathrm{a} 02$

28. Alicino C, Merlano C, Zappettini S, Schiaffino S, Della Luna G, Accardo C, et al. Routine surveillance of adverse events following immunization as an important tool to monitor vaccine safety. The two-years' experience of the Liguria Region, Italy. Hum Vaccin Immunother [Internet]. 2015 Jan [cited 2018 Jun 29];11(1):91-4. Available at: https://www.ncbi.nlm.nih.gov/pmc/articles/ PMC4514437/

29. Kim M-K, Lee YK, Kim TE, Kong I, Yang H-J, Suh ES. Surveillance and compensation claims for adverse events following immunization from 2011 to 2016 in the Republic of Korea. Clin Exp Vaccine Res [Internet]. 2017 Jul [cited 2018 Jun 29];6(2):146-55. Available at: https://www.ncbi .nlm.nih.gov/pmc/articles/PMC5540963/

30. Dey A, Wang $\mathrm{H}$, Quinn $\mathrm{H}$, Cook J, McCartney $\mathrm{K}$. Annual report: surveillance of adverse events following immunization in Australia, 2015. Commun Dis Intell [Internet]. 2017 Sep [cited 2018 Dec 11];41(3):E264-78. Available at: http://www .health.gov.au/internet/main/publishing.nsf/Content/cdi4103-I

31. Deverell M, Phu A, Zurynski Y, Elliott E; APSU Surveillance Studies investigators. Australian Pediatric Surveillance Unit Annual Report, 2016. Commun Dis Intell [Internet]. 2017 Sep [cited 2018 Dec 11];41(3):E288-93. Available at: http:// www.health.gov.au/internet/main/publishing.nsf/ Content/cdi4103-I

32. Ye Y, Wang CS, Ma YT, Lu MX, Zhang XX, Zhang $Y Y$, et al. [Surveillance of adverse events following immunization in Henan Province, China between 2010-2011]. Zhongguo Dang Dai Er Ke Za Zhi [Internet]. 2013 Jun [cited 2018 Dec 12];15(6):466-71. Available at: https://www ncbi.nlm.nih.gov/pubmed/23791064http://www .zgddek.com/EN/abstract/abstract13096.shtm

33. González V, Gutiérrez S, Quian J. Eventos adversos supuestamente atribuibles a la vacunación e inmunización en hijos de madres infectadas con el virus de la inmunodeficiencia humana. Arch Pediatr Urug [Internet]. 2013 [cited 2019 Jan 15];84(1):4-9. Available at: http://www.scielo.edu .uy/scielo.php?script=sci_arttext\&pid=S1688 $-12492013000100002 \&$ Ing=es. Spanish.
34. Parentalis [Internet]. [place unknown]: Parentalis. Las vacunas durante el primer año de vida del bebé; 2018 [cited 2018 May 8]. Available at: https://parentalis.com/blog/las-vacunas-durante -el-primer-ano-de-vida-del-bebe/. Spanish.

35. Arboleda de Chacón LM. Informe anual de ESA$\mathrm{VI}$, Caldas [Internet]. Caldas (CO): Dirección Territorial de Salud; 2014 [cited 2019 Feb 11]. 8 p. Available at: http://observatorio.saluddecaldas .gov.co/desca/vacunacion/ESAVI\%202014.pdf. Spanish.

36. Pérez JA. Evaluación del sistema de vigilancia de eventos adversos a la vacunación. La Lisa, 2015 [thesis]. [Havana]: University of Medical Sciences of Havana; 2017. Spanish.

37. González Montiel AR. Evaluación del Sistema de Farmacovigilancia utilizado en México, 2012 [thesis]. [Cuernavaca]: National Institute of Public Health (MX); 2012 [cited 2019 Jan 15]. 63 p. Available at: http://catalogoinsp.mx/files/ tes/052574.pdf. Spanish.

38. Ministry of Health of Uruguay. Informe del Sistema de Notificación de Efectos Adversos supuestamente atribuibles a la vacunación o inmunización [Internet]. Montevideo: Ministry of Health of Uruguay; 2015 [cited 2018 Dec 9]. 9 p. Available at: https://www.gub.uy/ministerio -salud-publica/sites/ministerio-salud-publica/ files/documentos/publicaciones/Informe\%20 ESAVI\%202015.pdf. Spanish.

39. Alfonso OL, Pérez E. Comportamiento del ensayo clínico de la vacuna pentavalente en la Policlínica Docente Área Norte de Placetas. Rev Acta Médica Centro [Internet]. 2010 [cited 2018 Dec 9];4(3). Available at: http://www.revacta medicacentro.sld.cu/index.php/amc/article/ view/514/682. Spanish.

40. Peña Machado MA, Triana Rodríguez TM, Menéndez J, Mirabal M, Armesto M, Baró Suárez M, et al. Seguimiento de la reactogenicidad de la vacuna DTP cubana, utilizando dos métodos paralelos. VacciMonitor [Internet]. 2005 May [cited 2017 Nov 7];12(1). Available at: https:// www.researchgate.net/profile/Giset_Lopez/ publication/26516949 Seguimiento de la _reactogenicidad_de_la_vacuna_DTP_cubana utilizando_dos_metodos_paralelos/links/54218 3c50cf203f155c6df9d/. Spanish.

41. Goyetche R, Pérez A, Morena G, Pérez G, Giachetto G, Pírez MC, et al. Efectos adversos asociados a la vacuna antimeningocóccica VA-MENGOCC-BC ${ }^{\circledR}$. Rev Méd Urug [Internet]. 2004 Aug [cited 2019 Jan 17];20(2):102-5. Available at: http://www.scielo.edu.uy/scielo .php?script=sci_arttext $\&$ pid $=$ S1688-0390200 4000200003\&lng=es. Spanish.

42. Zafack Guetsop J, De Serres G, Kiely M, Gariepy MC, Rouleau I, Anne-Marie K, et al. Risk of recurrence of adverse events following immunization: a systematic review. Pediatrics [Internet]. 2017 Sep [cited 2018 Dec 9];140(3):e20163707. Available at: http://pediatrics.aappublications.org/content/ 140/3/e20163707

43. Ramírez T, Arroyo R, Castro O, Ramírez LA, López JD. Inyecciones intramusculares en niños, aspectos generales y análisis de aplicación en nuestro medio [Internet]. [place unknown]: DocPlayer.es; c2020 [cited 2019 Jan 17]. 5 p. Available at: https://docplayer es/8145589-Inyecciones-intramusculares-en -ninos-aspectos-generales-y-analisis-de-aplica cion-en-nuestro-medio.html. Spanish.

44. Principios generales de inmunización. Cap. VIII. In: Normas y Procedimientos del Programa Ampliado de Inmunizaciones (PAI) de Honduras [Internet]. Tegucigalpa: Secretaria de Salud; 2011 Jul [cited 2017 Nov 22]. p. 24-5. Available at: http://www.bvs.hn/Honduras/PAl/ManualNormas yProcedimientos/MNPPAIH1-7.pdf. Spanish.
45. Merino M, Bravo J. Generalidades sobre vacunas: cosas prácticas. In: AEP. Curso de Actualización Pediatría 2018. Madrid: Lúa Ediciones 3.0; 2018. p. 67-76. Spanish.

46. Cook IF, Murtagh J. Optimal technique for intramuscular injection of infants and toddlers: a randomized trial. Med J Aust [Internet]. $2005 \mathrm{Jul}$ 18 [cited 2018 Dec 16];183:60-3. Available at: https://www.mja.com.au/journal/2005/183/2/opti mal-technique-intramuscular-injection-infants -and-toddlers-randomised-trial

47. Diggle L, Deeks J. Effect of needle length on incidence of local reactions to routine immunisation in infants aged 4 months: randomised controlled trial. BMJ [Internet]. 2000 Oct 14 [cited 2018 Mar 9];321(7266):931-3. Available at: https://www .ncbi.nlm.nih.gov/pmc/articles/pmid/11030682/. Spanish.

48. Sastoque Díaz LA. Vigilancia en salud pública de los eventos supuestamente atribuibles a la vacunación o inmunización [PowerPoint] [Internet]. Bogotá: National Institute of Health (CO); 2017 Mar 29 [cited 2017 Nov 7]. PowerPoint: 14 slides. Available at: https://www.cali.gov.co/loader.php? IServicio=Tools2\&|Tipo=descargas \&IFuncion=de scargar\&idFile=21666. Spanish.

49. World Health Organization [Internet]. Geneva: World Health Organization; c2020. Vaccine safety basics e-learning course. Adverse events fallowing immunization; 2018 [cited 2018 Jun 20]. Available at: http://vaccine-safety-training.org/ vaccine-reactions.html

50. Clínica Alemana [Internet]. Santiago de Chile: Clínica Alemana; c2020. Los efectos secundarios de las vacunas; 2006 [updated 2019 Dec 25; cited 2018 Dec 12]. Available at: https://portal .alemana.cl/wps/wcm/connect//nternet/Home/ blog-de-noticias/Ano+2011/01/Los+efectos+sec undarios+de+las+vacunas. Spanish.

51. Formulario Nacional de Medicamentos [Internet]. Havana: INFOMED; c2020. Vacuna Muerta Pentavalente Heberpenta; 2013 [cited 2018 Dec 9]. Available at: http://fnmedicamentos.sld.cu/index .php?P=FullRecord\&ID=391. Spanish.

52. CIOMS Guide to vaccine safety communication. Report by topic group 3 of the CIOMS Working Group on Vaccine Safety [Internet]. Geneva: Council for International Organizations of Medical Sciences; 2018 [cited 2018 Feb 27]. 66 p. Available at: https://cioms.ch/wp-content/ uploads/2019/05/WEB-CIOMS-Communication -Guide-2018.pdf

\section{THE AUTHORS}

Elba Cruz-Rodríguez (Corresponding author: elba@ipk.sld.cu; elbacr@infomed.sld.cu), physician with dual specialties in family medicine and epidemiology, and a master's degree in epidemiology. Associate professor and adjunct researcher, Epidemiological Surveillance and Research Department, Pedro Kourí Tropical Medicine Institute (IPK), Havana, Cuba. https:// orcid.org/0000-0002-9322-0875

Belkys María Galindo-Santana, physician with dual specialties in family medicine and epidemiology, a master's degree in epidemiology and a doctorate in the medical sciences. Senior researcher and full professor, Epidemiological Surveillance and Research Department, IPK, Havana, Cuba. https://orcid.org/0000-0002 $-8757-4036$

Waldemar Baldoquín-Rodríguez, physician with dual specialties in family medicine and 


\section{Original Research}

biostatistics. Assistant professor and associate researcher, Epidemiological Surveillance and Research Department, IPK, Havana, Cuba. https://orcid.org/0000-0001-9231-7109

Dayana Rodríguez-Velázquez, geographer, Epidemiological Surveillance and Research Department, IPK, Havana, Cuba. https://orcid .org/0000-0002-6473-5650
Damarys Concepción-Díaz, laboratory technician specializing in computer sciences, Epidemiological Surveillance and Research Department, IPK, Havana, Cuba. https://orcid .org/0000-0003-2403-6801

Miriam Caridad Luis-Martínez, physician with dual specialties in family medicine and epidemiology, and a master's degree in satisfactory longevity, Provincial Hygiene, Epidemiology and Microbiology Center, Pinar del Río, Cuba. https://orcid.org/0000-0001-7896-8837

Submitted: April 24, 2020

Approved for publication: December 20, 2020

Disclosures: None 


\title{
Urinary Metabolic Disorders Associated with Urolithiasis in Cuban Pediatric Patients
}

\author{
Raymed A. Bacallao-Méndez MD MS, Reynaldo Mañalich-Comas MD PhD, Francisco Gutiérrez-García MD MS, \\ Carlos F. Madrid-Mancia MD, Catalina Lucero-Méndez MD, Magaly J. Smith-González
}

\begin{abstract}
INTRODUCTION Pediatric urinary lithiasis (urolithiasis) is an important health issue linked to urinary metabolic disorders. In the United States alone, annual costs associated with urolithiasis are \$229 million for hospital admissions and \$146 million for emergency care.
\end{abstract}

OBJECTIVE Identify urinary metabolic disorders in Cuban pediatric patients with urolithiasis and better understand the relationship of age, demographic and anthropometric variables to urinary metabolic disorders strongly associated with urolithiasis.

METHODS We carried out a descriptive, cross-sectional study. The study universe was comprised of Cuban patients aged 2 to 19 years with urinary lithiasis who underwent renal metabolic studies at the $\mathrm{Dr}$ Abelardo Buch López Nephrology Institute in Havana, Cuba, from 2008 through 2019. All data were obtained from reports of the aforementioned metabolic studies. We collected the following variables: age, sex, nutritional status, urinary volume, plasma and urinary creatine concentrations; and calcium, uric acid, oxalate and citrate urinary excretions collected during a 24 -hour period. We included results of urinary cystine tests and urine mini-cultures. We obtained frequency distributions for categorical and qualitative variables and calculated means and standard deviations for quantitative variables. We also

\section{INTRODUCTION}

Urinary lithiasis is an important health problem in the general population and, although its occurrence is comparatively rare in pediatric ages, evidence suggests that its incidence is increasing in this population.[1,2] Additionally, the disease is characterized by high recurrence rates that can require surgical intervention and is associated with high treatment costs and the risk of developing renal dysfunction requiring renal replacement therapy (dialysis or transplantation).[3] Added to these risks is the decrease in bone mineral density in patients who develop calcium stones, which increases the risk of fractures and can compromise patients' quality of life.[4]

Although overall incidence of pediatric hospital admissions for urinary lithiasis in high-income countries is 1\%-3\%,[5] the USA has experienced an increase from 18.4 cases per 100,000 admissions in 1999 to 57 cases per 100,000 admissions in 2008, an adjusted annual increase of $10.6 \%$.[1,5] Estimated recurrence rates in that country range from $16 \%$ to $67 \%$,[6] and annual estimated costs for

\section{IMPORTANCE}

This study comprises the best evidence currently available in Cuba on urinary metabolic disorders predisposed to causing urolithiasis in children and adolescents, and offers insights for its primary and secondary prevention. evaluated homogeneity of metabolic disorders between children and adolescents.

RESULTS We studied 1592 pediatric patients, of whom $67.7 \%$ $(1078 / 1592)$ were adolescents. The main metabolic disorders included hypercalciuria (39.1\%; 622/1592), decreased urinary flow $(22.4 \%$; $357 / 1592)$ and hypocitraturia $(18.2 \% ; 289 / 1592)$. Hypercalciuria, hypocitraturia and hyperoxaluria were more common in children, while decreased urinary flow and hyperuricosuria were more common in adolescents. Hyperuricosuria was more frequent in male patients (6.3\%; $40 / 639$ vs. $1.8 \% ; 8 / 439)$ and had the greatest impact on lithogenesis. Hypercalciuria was more frequent in undernourished children $(62.5 \% ; 30 / 48)$ than in overweight children $(21.7 \% ; 10 / 46)$, or those with obesity $(33.3 \% ; 15 / 45)$.

CONCLUSIONS The main metabolic disorders among Cuban pediatric patients with urinary lithiasis are: hypercalciuria, decreased urinary flow and hypocitraturia. Hypercalciuria, hypocitraturia and hyperoxaluria are more common in children, and decreased urinary flow and hyperuricosuria are more common in adolescents. Identifying urinary metabolic disorders facilitates formulation of treatment plans tailored to decreasing the likelihood of urolithiasis.

KEYWORDS Pediatrics, urolithiasis, urinary lithiasis, hypercalciuria, urine, Cuba

pediatric patients with urinary lithiasis are $\$ 229$ million in hospital admissions and \$146 million for emergency care.[7]

Development of urinary stones in children and adolescents is associated primarily with urinary metabolic disorders and urinary tract malformations.[8] Consequently, patients presenting with urolithiasis must be rigorously evaluated in order to identify underlying urinary metabolic disorders promoting lithogenesis, and treatments must be tailored to prevent recurrence.[8,9] Data are scarce on metabolic disorders in the Cuban and Latin American pediatric populations, making it difficult to implement strategies for primary and secondary prevention of urolithiasis.[9-11]

The objective of this study was to identify urinary metabolic disorders in the Cuban pediatric population with urolithiasis according to age, demographic and anthropometric variables, and the relation of these variables to disorders with the greatest lithogenic potential.

\section{METHODS}

Design and participants We conducted a descriptive, crosssectional observational study. The study universe consisted of all Cuban patients aged 2-19 years who presented with urinary lithiasis (demonstrated by imaging studies, or by spontaneous or instrumental elimination) who underwent renal metabolic studies at the Dr Abelardo Buch López Nephrology Institute in Havana, Cuba from January 2008 through December 2019. 
Individuals who had suffered renal colic in the six weeks prior to recruitment or who had poorly collected samples were excluded from our research, as were pregnant individuals, foreign patients, vegetarians, amputees, those with chronic diarrhea or muscular dystrophies, or who were short for their age, according to Cuban height-for-age tables.[12] These patients were excluded because they presented with factors that could either interfere with the quality of the urine sample or could modify excretion of urinary solutes.

Variables Age (two groups: 2-9 years and 10-19 years); sex (female, male); nutritional status (undernourished, thin, normal weight, overweight, obese); urinary volume; plasma and urinary creatinine concentrations; urinary excretion of calcium, uric acid, oxalate and citrate over a 24-hour period; and the results of urinary cystine tests and urine mini-cultures.

Procedures We interviewed all patients (or patients' caregivers, if patients were pre-verbal) to ensure that they did not meet any exclusion criteria. All medications were suspended for five days before the study. We collected 24-hour urine samples (in washed bottles with $5 \%$ thymol included as a preservative) and $5 \mathrm{~mL}$ fasting blood samples. Independent urine samples were used for the mini-cultures. We collected anthropometric data (height and weight), estimated the nutritional status of patients according to body mass index (BMI) in $\mathrm{kg} / \mathrm{m}^{2}$, and classified patients according to the Cuban BMI-for-age tables.[13] Body surface area (BS) was calculated using the Dubois-Dubois formula.[14] A urine sample was considered 'well-collected' when creatinine excretion was less than \pm 1 standard deviation (SD) from the reference value according to the patient's age, height and sex, as pathologies that may influence the generation and excretion of creatinine were exclusion criteria.[15]

Analytical determinations were made with a Microlab 300 spectrophotometer (Elitech Clinical Systems, Germany) in the case of urinary citrate and oxalate. For all other analyses, we used a HumaStar 80 spectrophotometric autoanalyzer (Human Diagnostics, Magdeburg, Germany). We followed manufacturer's guides for both. Citrate and oxalate concentrations were determined via direct ferric cyanide/ citrate reaction or formic acid/chromotrophic reaction methods, respectively. Creatinine was measured using the Jaffé kinetic method (alkaline picrate); uric acid using the enzymatic uricase/peroxidase method; and calcium using the calciumarsenazo method. All reagents were provided by the Carlos J. Finlay Pharmaceutical Laboratory Company in Havana, Cuba. Urinary cystine tests were performed by reaction with sodium nitroprusside (Merck, Darmstadt, Germany). Urine mini-cultures were cultured in MacConkey's Agar and CLED (cysteine lactose electrolyte deficient) Agar media (National Biopreparations Center, BIOCEN, Cuba).

Renal function was measured by creatinine clearance in $\mathrm{mL}$ / $\mathrm{min} / 1.73 \mathrm{~m}^{2}$ body surface (BS) and serum creatinine in $\mathrm{mg} / \mathrm{dL}$. Cystinuria and urinary tract infections were diagnosed by qualitative methods, the results used to classify patients as positive or negative.

\section{Metabolic disorder diagnostic cut-off values}

Hypercalciuria Urinary calcium $>4.0 \mathrm{mg}$ or $0.10 \mathrm{mmol} / \mathrm{kg} /$ day Hyperuricosuria Uric acid $>815 \mathrm{mg}$ or $4.85 \mathrm{mmol} / 1.73 \mathrm{~m}^{2} /$ day Hyperoxaluria Urinary oxalate $>45 \mathrm{mg}$ or $0.5 \mathrm{mmol} / 1.73 \mathrm{~m}^{2} /$ day
Hypocitraturia Daily urinary citrate $<365 \mathrm{mg}$ or $1.90 \mathrm{mmol} / 1.73 \mathrm{~m}^{2}$ in males and $<310 \mathrm{mg}$ or $1.61 \mathrm{mmol} / 1.73 \mathrm{~m}^{2}$ in females Low urinary flow Urinary volume $<20 \mathrm{~mL} / \mathrm{kg} /$ day[16]

Data collection and analysis We obtained information for the above selected variables from the first metabolic study conducted on each patient. All information was processed using the Statistical Package for Social Science (SPSS) version 22.0 for Windows (IBM, USA). We constructed frequency distributions for qualitative variables and calculated absolute frequencies and percentages. For quantitiative variables, we calculated means and standard deviations. The age distribution was divided into quartiles. In order to analyze associations between patient demographics and nutritional status, and metabolic disorders with the greatest lithogenic potential (hypercalciuria, hyperuicosuria, hyperoxaluria and hypocitraturia) we constructed double- and triple-entry contingency tables to provide a descriptive analysis of homogeneity.

Ethics This study was approved by the Scientific Council and the Research Ethics Committee of the Dr Abelardo Buch López Nephrology Institute. Confidentiality of all data obtained during the investigation was guaranteed.

\section{RESULTS}

We studied 1592 pediatric patients who presented with urolithiasis, 67.7\% (1078/1592) were adolescents, aged 10-19 years. Children studied had an average age of 6.4 years (SD: 2.2 years) and adolescents, 13.9 years (SD: 2.6 years). There was a higher proportion of male patients, both in children (aged 2-9 years) and adolescents, at 56.8\% (292/514) and 59.3\% (639/1078), respectively (Table 1$)$.

Children had a mean renal function of $104.5 \mathrm{~mL} / \mathrm{min} / 1.73 \mathrm{~m}^{2} \mathrm{BS}$ (SD: 21.5); mean BMI of $16.2 \mathrm{~kg} / \mathrm{m}^{2}$ (SD: 3.3 ) and mean body surface area of $0.87 \mathrm{~m}^{2}$ (SD: 0.22 ), while $321 / 514(62.5 \%)$ of children were classified as normal weight; $10.5 \%$ (54/514) thin; $9.3 \%$ (48/514) undernourished; $8.9 \%$ (46/514) overweight; and $8.8 \%(45 / 514)$ obese.

Adolescents had a mean renal function of $105.7 \mathrm{~mL} / \mathrm{min} / 1.73 \mathrm{~m}^{2}$ BS (SD: 20.2); mean BMI of $19.4 \mathrm{~kg} / \mathrm{m}^{2}$ (SD: 3.6) and mean body surface area of $1.43 \mathrm{~m}^{2}$ (SD: 0.26). Of the adolescents, $66.0 \%$ (712/1078) were of normal weight, 5.3\% (57/1078) were classified as thin; $4.5 \%(49 / 1078)$ undernourished; $14.1 \%(152 / 1078)$ overweight and 10.0\% (108/1078) obese.

The most frequent renal metabolic disorder was hypercalciuria (39.1\%; 622/1592). This was followed in order of frequency by decreased urinary flow $(22.4 \% ; 357 / 1592)$ and hypocitraturia (18.2\%; 289/1592). Other urinary metabolic disorders in the study had an overall frequency of $<10 \%$. Comparing children and adolescents, we found statistically significant differences

Table 1: Patient distribution by age and sex

\begin{tabular}{|l|r|r|r|r|r|r|}
\hline \multirow{2}{*}{ Age (years) } & \multicolumn{4}{|c|}{ Sex } & \multicolumn{3}{c|}{ Total } \\
\cline { 2 - 7 } & \multicolumn{2}{|c|}{ Male } & \multicolumn{2}{c|}{ Female } & \multicolumn{1}{c}{} \\
\cline { 2 - 7 } & No. & $\%$ & No. & $\%$ & No. & $\%$ \\
\hline $2-9$ & 292 & 56.8 & 222 & 43.2 & 514 & 32.3 \\
\hline $10-19$ & 639 & 59.3 & 439 & 40.7 & 1078 & 67.7 \\
\hline Total & 931 & 58.5 & 661 & 41.5 & 1592 & 100.0 \\
\hline
\end{tabular}


in the relative frequencies of hypercalciuria, hypocitraturia and hyperoxaluria, which were higher in children; and also for decreased urinary flow and hyperuricosuria, which were more common in adolescents. Urinary tract infection was low in overall frequency and similar between the two groups (Table 2).

In terms of frequency of urinary metabolic disorders, it should be noted that we found minimal differences between the sexes in either children or adolescents. The greatest differences were found in hypocitraturia in children: $45.5 \%(101 / 222)$ in girls versus $37.3 \%$ $(109 / 292)$ in boys, and in hyperuricosuria in adolescents; $1.8 \%$ $(8 / 439)$ in female patients versus $6.3 \%(40 / 639)$ in male (Table 3$)$.

There were notable differences in the frequencies of hypercalciuria and hypocitraturia in children and in the frequencies of hyperuricosuria and hypocitraturia in adolescents (Table 4).

Table 2: Absolute and relative frequencies of urinary metabolic disorders in children and adolescents

\begin{tabular}{|c|c|c|c|c|c|c|c|}
\hline \multirow{2}{*}{$\begin{array}{l}\text { Urinary } \\
\text { metabolic } \\
\text { disorder }\end{array}$} & \multicolumn{2}{|c|}{$\begin{array}{c}2-9 \text { years } \\
n=514\end{array}$} & \multicolumn{2}{|c|}{$\begin{array}{c}\text { 10-19 years } \\
n=1078\end{array}$} & \multicolumn{2}{|c|}{$\begin{array}{c}\text { Total } \\
n=1592\end{array}$} & \multirow[t]{2}{*}{$\mathbf{p}^{*}$} \\
\hline & No. & $\%$ & No. & $\%$ & No. & $\%$ & \\
\hline Hypercalciuria & 257 & 50.0 & 365 & 33.9 & 622 & 39.1 & $<0.01$ \\
\hline Low urinary flow & 78 & 15.2 & 279 & 25.9 & 357 & 22.4 & $<0.01$ \\
\hline Hypocitraturia & 209 & 40.7 & 80 & 7.4 & 289 & 18.2 & $<0.01$ \\
\hline $\begin{array}{l}\text { Urinary } \\
\text { tract infection }\end{array}$ & 42 & 8.2 & 95 & 8.8 & 137 & 8.6 & 0.11 \\
\hline Hyperoxaluria & 25 & 4.9 & 29 & 2.7 & 54 & 3.4 & 0.04 \\
\hline Hyperuricosuria & 3 & 0.6 & 48 & 4.5 & 51 & 3.2 & $<0.01$ \\
\hline Cystinuria & 1 & 0.2 & 5 & 0.5 & 6 & 0.4 & 0.70 \\
\hline
\end{tabular}

${ }^{*} \mathrm{p}$ value associated with testing homogeneity between children and adolescents

Table 3: Absolute and relative frequencies of the main urinary metabolic disorders in children and adolescents by sex

\begin{tabular}{|c|c|c|c|c|c|c|c|c|c|}
\hline \multirow{3}{*}{$\begin{array}{l}\text { Age } \\
\text { (years) }\end{array}$} & \multirow{3}{*}{ Sex } & \multicolumn{8}{|c|}{ Metabolic disorder } \\
\hline & & \multicolumn{2}{|c|}{$\begin{array}{l}\text { Hyper- } \\
\text { calciuria }\end{array}$} & \multicolumn{2}{|c|}{$\begin{array}{l}\text { Hyper- } \\
\text { oxaluria }\end{array}$} & \multicolumn{2}{|c|}{$\begin{array}{l}\text { Hyper- } \\
\text { uricosuria }\end{array}$} & \multicolumn{2}{|c|}{$\begin{array}{l}\text { Hypo- } \\
\text { citraturia }\end{array}$} \\
\hline & & No. & $\%$ & No. & $\%$ & No. & $\%$ & No. & $\%$ \\
\hline \multirow{2}{*}{$2-9$} & Male & 144 & 49.3 & 18 & 6.2 & 2 & 0.7 & 109 & 37.3 \\
\hline & Female & 113 & 50.9 & 6 & 2.7 & 1 & 0.5 & 101 & 45.5 \\
\hline \multirow{2}{*}{ 10-19 } & Male & 219 & 34.3 & 17 & 2.7 & 40 & 6.3 & 47 & 7.4 \\
\hline & Female & 146 & 33.3 & 13 & 3.0 & 8 & 1.8 & 32 & 7.3 \\
\hline
\end{tabular}

Table 4: Absolute and relative frequencies of the main urinary metabolic disorders in children and adolescents by age

\begin{tabular}{|c|c|c|c|c|c|c|c|c|c|}
\hline \multirow{3}{*}{$\begin{array}{l}\text { Age } \\
\text { (years) }\end{array}$} & \multirow{3}{*}{ No. } & \multicolumn{8}{|c|}{ Metabolic disorder } \\
\hline & & \multicolumn{2}{|c|}{$\begin{array}{l}\text { Hyper- } \\
\text { calciuria }\end{array}$} & \multicolumn{2}{|c|}{$\begin{array}{l}\text { Hyper- } \\
\text { oxaluria }\end{array}$} & \multicolumn{2}{|c|}{$\begin{array}{c}\text { Hyper- } \\
\text { uricosuria }\end{array}$} & \multicolumn{2}{|c|}{$\begin{array}{c}\text { Нуро- } \\
\text { citraturia }\end{array}$} \\
\hline & & No. & $\%$ & No. & $\%$ & No. & $\%$ & No. & $\%$ \\
\hline 2-4.9 & 99 & 52 & 52.5 & 6 & 6.1 & 0 & 0.0 & 55 & 55.6 \\
\hline $5-6.9$ & 140 & 83 & 59.3 & 6 & 4.3 & 1 & 0.7 & 68 & 48.6 \\
\hline $7-7.9$ & 82 & 28 & 34.1 & 4 & 4.9 & 0 & 0.0 & 29 & 35.4 \\
\hline $8-9.9$ & 193 & 94 & 48.7 & 9 & 4.7 & 2 & 1.0 & 57 & 29.5 \\
\hline 10-11.9 & 242 & 87 & 36.0 & 9 & 3.7 & 4 & 1.7 & 37 & 15.3 \\
\hline $12-13.9$ & 266 & 97 & 36.5 & 10 & 3.8 & 9 & 3.4 & 13 & 4.9 \\
\hline $14-15.9$ & 271 & 94 & 34.7 & 6 & 2.2 & 15 & 5.5 & 16 & 5.9 \\
\hline 16-19 & 299 & 87 & 29.1 & 4 & 1.3 & 20 & 6.7 & 14 & 4.7 \\
\hline
\end{tabular}

Table 5: Absolute and relative frequencies of the main urinary metabolic disorders in children and adolescents by nutritional status

\begin{tabular}{|c|c|c|c|c|c|c|c|c|c|}
\hline \multirow{3}{*}{$\begin{array}{l}\text { Age } \\
\text { (years) }\end{array}$} & \multirow{3}{*}{$\begin{array}{l}\text { Nutritional } \\
\text { status }\end{array}$} & \multicolumn{8}{|c|}{ Metabolic disorder } \\
\hline & & \multicolumn{2}{|c|}{$\begin{array}{c}\text { Hyper- } \\
\text { calciuria }\end{array}$} & \multicolumn{2}{|c|}{$\begin{array}{l}\text { Hyper- } \\
\text { oxaluria }\end{array}$} & \multicolumn{2}{|c|}{$\begin{array}{c}\text { Hyper- } \\
\text { uricosuria }\end{array}$} & \multicolumn{2}{|c|}{$\begin{array}{c}\text { Hypo- } \\
\text { citraturia } \\
\end{array}$} \\
\hline & & No. & $\%$ & No. & $\%$ & No. & $\%$ & No. & $\%$ \\
\hline \multirow{5}{*}{$\begin{array}{l}2-9 \\
(n=514)\end{array}$} & $\begin{array}{l}\text { Undernourished } \\
\mathrm{n}=48\end{array}$ & 30 & 62.5 & 1 & 2.1 & 0 & 0.0 & 30 & 62.5 \\
\hline & $\begin{array}{l}\text { Thin } \\
\mathrm{n}=54\end{array}$ & 29 & 53.7 & 5 & 9.3 & 0 & 0.0 & 26 & 48.1 \\
\hline & $\begin{array}{l}\text { Normal weight } \\
n=321\end{array}$ & 173 & 53.9 & 16 & 5.0 & 3 & 0.9 & 128 & 39.9 \\
\hline & $\begin{array}{l}\text { Overweight } \\
n=46\end{array}$ & 10 & 21.7 & 2 & 4.3 & 0 & 0.0 & 17 & 37.0 \\
\hline & $\begin{array}{l}\text { Obese } \\
n=45\end{array}$ & 15 & 33.3 & 1 & 2.2 & 0 & 0.0 & 8 & 17.8 \\
\hline \multirow{5}{*}{$\begin{array}{l}10-19 \\
(n=1078)\end{array}$} & $\begin{array}{l}\text { Undernourished } \\
n=49\end{array}$ & 27 & 55.1 & 1 & 2.0 & 0 & 0.0 & 6 & 12.2 \\
\hline & $\begin{array}{l}\text { Thin } \\
\mathrm{n}=57\end{array}$ & 25 & 43.9 & 0 & 0.0 & 1 & 1.8 & 10 & 17.5 \\
\hline & $\begin{array}{l}\text { Normal weight } \\
n=712\end{array}$ & 245 & 34.4 & 24 & 3.4 & 23 & 3.2 & 52 & 7.3 \\
\hline & $\begin{array}{l}\text { Overweight } \\
\mathrm{n}=152\end{array}$ & 47 & 30.9 & 3 & 2.0 & 11 & 7.2 & 3 & 2.0 \\
\hline & $\begin{array}{l}\text { Obese } \\
n=108\end{array}$ & 21 & 19.4 & 1 & 0.9 & 13 & 12.0 & 9 & 8.3 \\
\hline
\end{tabular}

In children, hypercalciuria appeared more often in children aged $5.0-6.9$ years $(59.3 \%, 83 / 140)$, while least often found in children aged $7.0-7.9$ years $(34.1 \%, 28 / 82)$. Hypocitraturia presented at higher rates in children at younger ages, which decreased as they grew older. In adolescents, frequency of hypocitraturia was higher in patients aged 10.0-11.9 years (15.3\%, 37/242), compared with other age groups. Frequency of hyperuricosuria increased from $1.7 \%(4 / 242)$ in patients aged $10.0-11.9$ years to $6.7 \%(20 / 299)$ in those aged 16.0-19.9 years.

There were also appreciable differences for hypercalciuria and hypocitraturia in children, and for hypercalciuria, hyperuricosuria and hypocitraturia in adolescents when comparing disorder frequencies with groups according to patient nutritional status (Table 5). Frequencies of hypercalciuria and hypocitraturia were higher in undernourished children (62.5\%; 30/48 for both disorders); frequencies of hypercalciuria were lower among overweight children $(21.7 \% ; 10 / 46)$ and cases of hypocitraturia were less frequent in obese children (17.8\%; 8/45). Among adolescents, frequency of hypercalciuria and hypocitraturia were also high in undernourished patients, at 55.1\% (27/49) and $12.2 \%$ (6/49) respectively. However, contrary to what we observed in children, frequency of hyperuricosuria was higher in obese adolescents $(12.0 \% ; 13 / 108)$ than in other weight categories.

\section{DISCUSSION}

Although 24-hour urine composition tests are essential for diagnosing urinary metabolic disorders that promote lithogenesis and, consequently, for preventing lithogenesis recurrence, studies of this type in significant numbers of pediatric patients are rare on the global scale and nonexistent in Cuba. Additionally, urinary metabolic disorders are conditioned by dietary, genetic, water quality and climatic factors, among others, which does not allow data from other populations to be extrapolated to the Cuban population.[17] 
The higher frequency of urolithiasis we found in the male sex coincides with results from both national and international epidemiological studies in adults.[18,19] However, the results in the pediatric population are less consistent.[20-22] Prevalence of lithiasis has also been described in adolescents,[23] and it is believed that the recent increase of the disorder in pediatric patients has occurred mainly within this age group. However, we can make no such assertions in the context of this study, since it was not conducted in an open population but only in urolithiastic patients who underwent urinary composition studies. It should also be noted that while urinary composition studies may have been conducted during adolescence, a first lithiastic episode could have happened during childhood. But to conduct such tests in children is difficult, as problems with 24-hour urine collection are more common in younger individuals.[24]

Worth noting is that approximately one fifth of the children in our study were in either the thin or undernourished categories. This may be due to the fact that several causes of lithiasis during childhood have an impact on nutritional status. One of the most important is renal tubular acidosis, whose incidence peaks during childhood and is a known cause of malnutrition in children. We were not able to explore this possible link since our research did not include urinary acidification studies. [25] It is also noteworthy that nearly a quarter of adolescents were either overweight or obese, both well-known risk factors for lithogenesis in adults and whose rates have increased in adolescent populations worldwide.[26]

Renal function was preserved in the vast majority of patients, to be expected given their young age, as the damage to renal function caused by stones in the urinary tract is cumulative, and often due to obstructive nephropathy. Another consideration is that urinary tract infections are often associated with lithiasis, which can contribute to impaired kidney function.[27] However, in this study, the frequency of urinary tract infections was low and similar between all groups.

In the absence of 24-hour urinary composition studies in healthy Cuban children, for this study we used internationally-accepted reference values in defining each disorder.[16] One problem with these definitions is that the risk of lithiasis increases with an increase in excretion or in concentration of the metabolite in question, which does not necessarily occur within a defined threshold, even when healthy individuals have been used to determine these thresholds.[20]

Frequencies of hypocitraturia and low urinary flow are higher in the pediatric populations with lithiasis than in the Cuban adult population with lithiasis. However, frequency of hyperuricosuria and urinary infections is higher in the adult population, consistent with findings in other studies. [8,28,29] Relative frequencies of urinary metabolic disorders in pediatric patients are similar to those found by Celiksoy in Turkey[30] and Amancio in Brazil.[10] Other studies, including Yang in China,[31] and Akhavan in Iran,[32] found hypocitraturia to be the most common disorder. These differences may be due to dietary habits or genetics.

Unfortunately, relative frequencies of disorders in these kinds of studies are not usually stratified in children and adolescents. Our findings are similar to those of the Cambareri study, which was carried out in four US centers and identified higher frequencies of hypercalciuria and hyperoxaluria in children $\leq 10$ years of age and decreased urinary flow in those over the age of 10.[33]

Our finding of low urinary flow in adolescents stands out, and its cause should be investigated. This could be due to engaging in demanding physical activity without adequate hydration, which is common in school, sports and military settings, or to the trend in these age groups, as identified in the general pediatric population in the United States, to fail to comply with dietary recommendations. [34] We consider promoting increased water intake a fundamental therapeutic recommendation for these age groups, and vital for both primary and secondary urolithiasis prevention.

The low frequency of cystinuria found in this study is consistent with findings in Cuban adults with lithiasis,[28] and contrasts with other studies in China and Turkey, revealing considerably higher frequency. This may be due to genetics underlying the frequency of cystinuria, which exhibits great variability between populations with different ethnic origins. [8,30,31]

The higher frequency of hyperuricosuria in male adolescents seems to be linked to increased concentration of male sex hormones that occurs in the second decade of life. These hormones do not have a direct effect on the frequency of hyperuricosuria, but act through other metabolic mediators.[21,35] Uric acid is produced in the liver as a byproduct of digestion, and, as it cannot be metabolized by humans, constitutes a final metabolic product. This product is then eliminated in the gastrointestinal tract by bacteria that break down uric acid (intestinal uricholysis), a process that is responsible for one third of excretion (the remaining two thirds are excreted in urine).[35] Endogenous production of uric acid is the element that seems to be the most heavily influenced by sex hormones and thus may be responsible for an increase in urinary excretion (hyperuricosuria), which occurs in higher frequencies among overweight and obese adolescents, both of which are nutritional states that are linked to higher incidence rates of hyperuricemia and hyperuricosuria.[36]

Both children and adolescents experience development through notable changes in relatively short periods of time, so it is important to understand how frequencies of disorders most prone to lithogenesis vary by age subgroups. However, there are no other studies that include comparisons between age groups, probably due to the relatively large number of patients that would be required to perform this stratification.

The higher frequency of hypercalciuria in children aged $<7$ years is consistent with Bergland's findings in male children aged $<8$ years,[37] and other evidence pointing to decreased urinary calcium excretion with aging.[38] No dietary modifications were made before this study was carried out, so hypercalciuria could not be classified into renal, intestinal or bone (resorptive hypercalciuria).[20]

The increased rate of hypocitraturia in earlier ages, both in children and adolescent subgroups, is likely due to a progressive increase in urinary citrate excretion with age, as identified by Kirejczyk in a study of 2334 Polish children and adolescents.[39] This is of particular interest, considering the trend pointing to increased frequency of hypocitraturia in several studies of lithiasis patients. This increased rate also points to the importance of urinary citrate, 
which is the most abundant organic anion in urine and is a notable inhibitor of urinary calculi, as it bonds to ionic calcium and reduces urinary calcium saturation, which in turn prevents the growth of calcium crystals in addition to promoting an increase in urinary $\mathrm{pH}$ that decreases uric acid lithogenesis. $[9,16,30,32,40]$ In light of the results of this study, young children and younger adolescents would benefit the most from oral citrate salt supplements.

Although the influence of diet on urolithiasis is well known, surprisingly little work has been done exploring the relationship between urolithiasis and nutritional status.[41] This makes it difficult to draw larger comparisons using the results of this study.

Association between hypercalciuria and malnutrition has been studied in particular disorders, like renal tubular acidosis, but at least part of this association is due to a defined calcium cut-off value of $4 \mathrm{mg} / \mathrm{kg} /$ day for this disorder, as undernourished and lean individuals, who as a matter of definition have lower body weights than their peers, are diagnosed with hypercalciuria despite having levels of calcium excretion similar to that of other children their age.[16,25] Added to this is new evidence suggesting monogenic causes of urolithiasis, many of which are characterized by the presence of hypercalciuria, which in turn may affect patient nutritional status.[42]

Association of hypocitraturia with thinness and undernutrition have been classically attributed to states of chronic metabolic acidosis that cause increased proximal citrate reabsorption and tissue catabolism.[20,25] Other causes include chronic diarrhea, use of drugs influencing urinary acidification (which were not considered in our study, due to exclusion criteria), and distal renal tubular acidosis (including incomplete forms).[20,43] Although we did not evaluate urinary acidification for the purpose of diagnosing renal tubular acidosis, and this precludes us from making categorical attributions, we are aware that idiopathic hypocitraturia must have made at least some contribution to our study results.[25]

Association of hyperuricosuria with obesity in adolescents was expected, as the relationship between obesity and increased trunk fat with hyperuricemia and hyperuricosuria is known. This has been proposed as an explanation for the increased incidence of lithiasis in adolescents, although not all studies have drawn this conclusion. [36,44-46] Hyperuricosuria not only causes uric acid lithiasis, but also urinary calculi. Obesity and states of insulin resistance create conditions of acidic urinary $\mathrm{pH}$, which in turn favors the formation of urate crystals that can constitute nuclei leading to the formation of uric and calcium stones (a phenomenom known as epitaxis). $[43,47,48]$ Prevention and treatment of obesity in adolescents should be included in guidelines for preventing pediatric lithiasis.

The main limitations of this study are the use of only one 24-hour urine sample per patient (more samples are ideal, but these are difficult to obtain in children),[49] the poor representation of children in the total study sample, the use of international cut-off values in defining metabolic disorders and the failure to study urinary acidification or control patients' diets prior to sample collection, which would have allowed for greater diagnostic precision. However, this research included a considerable number of individuals from across Cuba, with a standardized study protocol, and constitutes the best evidence available for the country on urinary metabolic disorders prone to causing urolithiasis in the pediatric population. It can thus serve as a reference in designing strategies for primary and secondary urolithiasis prevention in Cuban pediatric patients.

\section{CONCLUSIONS}

Hypercalciuria, decreased urinary flow and hypocitraturia are the main metabolic disorders identified in the Cuban pediatric population with urolithiasis. Hypercalciuria, hypocitraturia and hyperoxaluria are more frequent in children, while decreased urinary flow and hyperuricosuria are more frequent in adolescents. Hypercalciuria in children is most closely related to age and nutritional status. Hyperuricosuria in adolescents is most closely related to age, sex and nutritional status. The findings of this study provide a foundation for the prevention of urolithiasis in Cuban children and adolescents. - 1 -

\section{REFERENCES}

1. Sas DJ, Hulsey TC, Shatat IF, Orak JK. Increasing incidence of kidney stones in children evaluated in the emergency department. J Pediatr. 2010 Jul;157(1):132-7.

2. Van Dervoort K, Wiesen J, Frank R, Vento $\mathrm{S}$, Crosby V, Chandra M, et al. Urolithiasis in pediatric patients: a single center study of incidence, clinical presentation and outcome. J Urol. 2007 Jun;177(6):2300-5.

3. Pong YH, Huang WY, Lu YC, Tsai VF, Chen YF, Chang $\mathrm{HC}$, et al. Temporal trend of newly diagnosed incidence, medical utilization, and costs for pediatric urolithiasis, 1998-2007: a nationwide population-based study in Taiwan. Urology. 2015 Jan;85(1):216-20.

4. Schwaderer AL, Cronin R, Mahan JD, Bates CM. Low bone density in children with hypercalciuria and/or nephrolithiasis. Pediatr Nephrol. 2008 Dec;23(12):2209-14.

5. Routh JC, Graham DA, Nelson CP. Epidemiological trends in pediatric urolithiasis at United States freestanding pediatric hospitals. J Urol. 2010 Sep;184(3):1100-4.

6. Pietrow PK, Pope JC 4th, Adams MC, Shyr Y, Brock JW 3rd. Clinical outcome of pediatric stone disease. J Urol. 2002 Feb;167(2 Pt 1):670-3.
7. Wang HHS, Wiener JS, Lipkin ME, Scales CD Jr, Ross SS, Routh JC. Estimating the nationwide, hospital based economic impact of pediatric urolithiasis. J Urol. 2015 May;193(5 Suppl):1855-9.

8. Spivacow FR, Negri AL, del Valle EE, Calviño I, Fradinger E, Zanchetta JR. Metabolic risk factors in children with kidney stone disease. Pediatr Nephrol. 2008 Jul;23(7):1129-33.

9. Velásquez-Forero $F$, Esparza $M$, Salas $A$, Medeiros M, Toussaint G, Llach F. Risk factors evaluation for urolithiasis among children. Bol Med Hosp Infant Mex. 2016 Jul-Aug;73(4):228 -36 .

10. Amancio L, Fedrizzi M, Bresolin NL, Penido MGMG. [Pediatric urolithiasis: experience at a tertiary care pediatric hospital. J Bras Nefrol] [Internet]. 2016 Jan-Mar [cited 2020 Mar 7];38(1):90-8. Available at: http://www.scielo .br/scielo.php?script=sci_arttext\&pid=S0101 -28002016000100090\&lng=en. Portuguese.

11. Funes P, Echagüe G, Ruiz I, Rivas L, Zenteno J, Guillén R. Perfil de riesgo litogénico en pacientes con urolitiasis en Paraguay. Rev Méd Chile. 2016 Jun;144(6):716-22. Spanish.

12. Berdasco A, Esquivel M, Gutiérrez JA, Jiménez JM, Mesa D, Posada E, et al. Segundo estu- dio nacional de crecimiento y desarrollo. Cuba, 1982: valores del peso y talla para la edad. Rev Cubana Pediatr. 1991 Jan-Apr;63(1):4-21. Spanish.

13. Esquivel M, Rubí A. Valores cubanos del índice de masa corporal en niños y adolescentes de 0 a 19 años. Rev Cubana Pediatr. 1991 May -Aug;63(3):181-90. Spanish.

14. Dubois D, Dubois EF. A formula to estimate the approximate surface area if height and weight be known. 1916. Nutrition. 1989 Sep-Oct;5(5):303-11.

15. Badell Moore A, Bacallao Méndez RA, Mañalich Comas R. Sobre el establecimiento de valores de referencia de la excreción de creatinina para la población cubana. Rev Cubana Aliment Nutr. 2015 Jan-Jun;25(1 Suppl 1):S28-S60. Spanish.

16. Hoppe B, Kemper MJ. Diagnostic examination of the child with urolithiasis or nephrocalcinosis. Pediatr Nephrol. 2010 Mar;25(3):403-13.

17. Durán Álvarez S. Urolitiasis en el niño. Rev Cubana Pediatr. 2013 Jul-Sep;85(3):371-85. Spanish.

18. Sorokin I, Mamoulakis C, Miyazawa K, Rodgers A, Talati J, Lotan Y. Epidemiology of stone disease across the world. World J Urol. 2017 Sep;35(9):1301-20. 
19. Bacallao Méndez RA, Victores Aguiar I, Mañalich Comas R, Gutiérrez García F, Llerena Ferrer B, Almaguer López M. Caracterización clínico epidemiológica de la litiasis urinaria en un área rural de Artemisa. Rev Cubana Invest Bioméd. 2016 Oct-Dec;35(4):300-10. Spanish.

20. Cameron MA, Sakhaee K, Moe OW. Nephrolithiasis in children. Pediatr Nephrol. 2005 Nov;20(11):1587-92.

21. Seitz C, Fajkovic H. Epidemiological genderspecific aspects in urolithiasis. World J Urol. 2013 Oct;31(5):1087-92.

22. Coward RJM, Peters CJ, Duffy PG, Corry D, Kellett MJ, Choong S, et al. Epidemiology of paediatric renal stone disease in the UK. Arch Dis Child. 2003 Nov;88(11):962-5.

23. Dwyer ME, Krambeck AE, Bergstralh EJ, Milliner DS, Lieske JC, Rule AD. Temporal trends in the incidence of kidney stones among children: a 25-year population-based study. J Urol. 2012 Jul;188(1):247-52.

24. Chan KH, Moser EA, Whittam BM, Misseri R, Cain MP, Krambeck A, et al. Initial collection of an inadequate 24-hour urine sample in children does not predict subsequent inadequate collections. J Pediatr Urol [Internet]. 2019 Feb [cited 2020 Mar 17];15(1):74.e1-74.e7. Available at: http://www.sciencedirect.com/science/article/ abs/pii/S1477513118306387

25. Besouw MTP, Bienias M, Walsh P, Kleta R, Van't Hoff WG, Ashton E, et al. Clinical and molecular aspects of distal renal tubular acidosis in children. Pediatr Nephrol. 2017 Jun;32(6):987-96.

26. NCD Risk Factor Collaboration (NCD-RisC). Worldwide trends in body-mass index, underweight, overweight, and obesity from 1975 to 2016: a pooled analysis of 2416 populationbased measurement studies in 128.9 million children, adolescents, and adults. Lancet. 2017 Dec 16:390(10113):2627-42.

27. El-Zoghby ZM, Lieske JC, Foley RN, Bergstralh EJ, Li X, Melton LJ 3rd, et al. Urolithiasis and the Risk of ESRD. Clin J Am Soc Nephrol. 2012 Sep;7(9):1409-15.

28. Bacallao Méndez RA, Madrid Mancia C, Mañalich Comas R, Gutiérrez García F, Badell Moore A. Trastornos metabólicos renales en pacientes cubanos adultos con litiasis urinarias. Rev Cubana Med. 2014 Sep-Dec;53(4):456-67. Spanish.

29. Spivacow FR, Negri AL, del Valle EE, Calvino I, Zanchetta JR. Clinical and metabolic risk factor evaluation in young adults with kidney stones. Int Urol Nephrol. 2010 Jun;42(2):471-5.

30. Celiksoy MH, Yilmaz A, Aydogan G, Kiyak A, Topal E, Sander S. Metabolic disorders in Turkish children with urolithiasis. Urology. 2015 Apr;85(4):909-13.

31. Yang D, Tiselius HG, Lan C, Chen D, Chen K, $\mathrm{Ou} \mathrm{L}$, et al. Metabolic disturbances in Chinese children with urolithiasis: a single center report. Urolithiasis. 2017 Jun;45(3):285-90.

32. Sepahi MA, Eftekhari SS, Shahmoradi S, Talebizadeh M, Rashidinia S, Hejazi SS. Metabolic and anatomic abnormalities associated with pediatric nephrolithiasis: a cross-sectional study. Int J Pediatr. 2017 May;5(5):4833-8.

33. Cambareri GM, Kovacevic L, Bayne AP, Giel D, Corbett S, Schurtz E, et al. National multi-institutional cooperative on urolithiasis in children: age is a significant predictor of urine abnormalities. J Pediatr Urol. 2015 Aug;11(4):218-23.

34. Kant AK, Graubard BI. Contributors of water intake in US children and adolescents: associations with dietary and meal characteristics - National Health and Nutrition Examination Survey 2005-2006. Am J Clin Nutr. 2010 Oct;92(4):887-96.

35. Kubota M. Hyperuricemia in children and adolescents: present knowledge and future directions. J Nutr Metab [Internet]. 2019 May 2 [cited 2020 Mar 17];2019:Art ID 3480718. Available at: https:// www.hindawi.com/journals/jnme/2019/3480718/

36. Shatat IF, Abdallah RT, Sas DJ, Hailpern SM. Serum uric acid in U.S. adolescents: distribution and relationship to demographic characteristics and cardiovascular risk factors. Pediatr Res. 2012 Jul;72(1):95-100.

37. Bergsland $\mathrm{KJ}$, Coe FL, White MD, Erhard MJ, DeFoor WR, Mahan JD. Urine risk factors in children with calcium kidney stones and their siblings. Kidney Int. 2012 Jun;81(11):1140-8.

38. Butani L, Kalia A. Idiopathic hypercalciuria in children how valid are the existing diagnostic criteria? Pediatr Nephrol. 2004 Jun;19(6):577-82.

39. Kirejczyk JK, Porowski T, Konstantynowicz J, Kozerska A, Nazarkiewicz A, Hoppe B, et al. Urinary citrate excretion in healthy children depends on age and gender. Pediatr Nephrol. 2014 Sep;29(9):1575-82.

40. Kovacevic L, Wolfe-Christensen C, Edwards L, Sadaps M, Lakshmanan Y. From hypercalciuria to hypocitraturia a shifting trend in pediatric urolithiasis? J Urol. 2012 Oct;188(4 Suppl):1623-7.

41. Saxena A, Sharma RK. Nutritional aspect of nephrolithiasis. Indian J Urol. 2010 Oct;26(4):523-30.

42. Daga A, Majmundar AJ, Braun DA, Gee HY, Lawson JA, Shril S, et al. Whole exome sequencing frequently detects a monogenic cause in early onset nephrolithiasis and nephrocalcinosis. Kidney Int. 2018 Jan;93(1):204-13.

43. Copelovitch L. Urolithiasis in children. Pediatr Clin North Am. 2012 Aug;59(4):881-96.

44. Shavit L, Ferraro PM, Johri N, Robertson W, Walsh SB, Moochhala S, et al. Effect of being overweight on urinary metabolic risk factors for kidney stone formation. Nephrol Dial Transplant. 2015 Apr;30(4):607-13.

45. Kokorowski PJ, Routh JC, Hubert KC, Graham DA, Nelson CP. Association of urolithiasis with systemic conditions among pediatric patients at children's hospitals. J Urol. 2012 Oct;188(4 Suppl):1618-22.

46. Sarica K, Eryildirim B, Yencilek F, Kuyumcuoglu $U$. Role of overweight status on stone-forming risk factors in children: a prospective study. Urology. 2009 May;73(5):1003-7.
47. Bacallao Méndez RA, Mañalich Comas R, Gutiérrez García F, Badell Moore A, Caldevilla Rodríguez Y. pH urinario y estado nutricional en pacientes cubanos con urolitiasis. Rev Cubana Med. 2015;54(2):119-28. Spanish.

48. Murphy MO, Erpelding SG, Chishti AS, Dugan A, Ziadab A, Kiessling SG. Influence of BMI in nephrolithiasis in an Appalachian pediatric population: a single-center experience. J Pediatr Urol [Internet]. 2018 Aug [cited 2020 Mar 19];14(4):330. e1-330.e8. Available at: http://www.sciencedirect .com/science/article/pii/S1477513118301931

49. Parks JH, Goldfisher E, Asplin JR, Coe FL. A single 24-hour urine collection is inadequate for the medical evaluation of nephrolithiasis. J Urol. 2002 Apr;167(4):1607-12.

\section{THE AUTHORS}

Raymed Antonio Bacallao-Méndez (Corresponding author: raymed@infomed.sld.cu), nephrologist with master's degrees in emergency medicine and diagnostic methods. Associate professor and associate researcher, Dr Abelardo Buch López Nephrology Institute (INEF), Havana, Cuba. https://orcid.org/0000-0002-7043-0597

Reynaldo Mañalich-Comas, nephrologist with a doctorate in medical sciences. Senior professor and senior researcher, INEF, Havana, Cuba. https://orcid.org/0000-0002-9424-5839

Francisco Gutiérrez-García, physician specializing in biostatistics, with a master's degree in bioethics. Associate professor and researcher, INEF, Havana, Cuba. https://orcid.org/0000 $-0002-9972-4142$

Carlos Fernando Madrid-Mancia, physician specializing in family medicine and nephrology, INEF, Havana, Cuba. https://orcid.org/0000 -0003-2037-7799

Catalina Lucero-Méndez, physician specializing in family medicine and nephrology, INEF, Havana,Cuba. https://orcid.org/0000-0003-2000 $-452 X$

Magaly Julieta Smith-González, laboratory technician, INEF, Havana, Cuba. https://orcid. org/0000-0003-4386-9526

Submitted: May 25, 2020

Approved for publication: January 16, 2021 Disclosures: None 


\title{
Short-Term Tolerance of Nasally-Administered NeuroEPO in Patients with Parkinson Disease
}

\author{
Marité García-Llano MD MS, Ivonne Pedroso-Ibáñez MD MS, Lilia Morales-Chacón MD PhD DSc, Teresita Rodríguez-Obaya MD PhD, \\ Leslie Pérez-Ruiz MS, Iliana Sosa-Testé DVM PhD, Daniel Amaro González PhD, María Luisa Bringas-Vega PhD
}

\begin{abstract}
INTRODUCTION No neuroprotective treatment has been able to successfully halt the progression of Parkinson disease or prevent development of associated complications. Recombinant erythropoetin (EPO), an erythropoiesis-stimulating agent originally indicated in anemia, produced and manufactured in Cuba (iorEPOCIM, CIMAB S.A, Havana, Cuba) has neuroprotective properties. NeuroEPO is a new nasal formulation of recombinant EPO with a low content of sialic acid and without hematopoietic effects. It has neuroprotective effects in animal models.
\end{abstract}

OBJECTIVE Evaluate short-term tolerance of intranasal NeuroEPO in patients with Parkinson disease.

METHODS As part of a monocentric randomized placebo-controlled double-blind study (registered at www.clinicaltrials.gov number NCT04110678), 26 patients with Parkinson disease (stages 1 and 2 on Hoehn \& Yahr Scale), were randomly divided into two groups: NeuroEPO $(n=15)$ and placebo $(n=11)$, both treated intranasally either with the drug ( $1 \mathrm{~mL}$, at a concentration of $1 \mathrm{mg} / \mathrm{mL}$ of NeuroEPO) or

\section{INTRODUCTION}

Parkinson disease (PD) is the second leading neurodegenerative disorder in the world after Alzheimer disease.[1] Disability caused by $\mathrm{PD}$ is a growing economic and social burden that parallels the aging of the world's population.[2] PD is characterized by progressive loss of dopaminergic neurons. Dopamine precursors (such as L-3,4-dihydroxyphenylalanine, L-DOPA) are the first line of therapy, but only provide a symptomatic remedy since they do not modify the course of the disease. For this reason, one of the main lines of investigation worldwide is the search for neuroprotective agents.[3,4]

There is evidence that erythropoietin (EPO), an erythropoiesisstimulating agent important in tissue oxygenation, with roles originally indicated in anemia and kidney failure, has neuroprotective properties.[5,6] EPO has a demonstrated effect on mechanisms involved in cell death due to its antiapoptotic and antioxidant qualities, which prevent cell damage during the nitric oxide cascade. These qualities also lend themselves to EPO's neurotrophic effects and its effects on neurogenesis. It is believed that EPO protects neurons through a combination of these mechanisms. $[7,8]$ EPO modulates neuroinflammation through neurotrophic

\section{IMPORTANCE}

This article shows that NeuroEPO is safe and well tolerated by patients with Parkinson disease and proposes recommendations for the use of this compound as a neuroprotector. placebo once a week for 5 weeks. At each application, we recorded any adverse events and blood pressure. To assess potential hematopoietic effects of the drug, hematological and biochemical variables were evaluated one week before and one week after the intervention.

RESULTS There were no significant differences $(p=0.22)$ between the two groups in terms of frequency of adverse events $(20.0 \%$ in NeuroEPO and $9.1 \%$ in placebo groups). Three patients in NeuroEPO presented nausea, and one vomited (possibly due to the patient's positioning during drug application). One patient in placebo group reported polyuria and nasal irritation. In both groups, the adverse events were mild, brief, required no treatment and did not present sequelae.

CONCLUSION Nasally administered NeuroEPO for five weeks in patients with Parkinson disease stages 1 and 2 on Hoehn \& Yahr Scale is well tolerated.

KEYWORDS Parkinson disease, intranasal drug, neurodegenerative diseases, erythropoietin, biopharmaceutics, Cuba

actions on astrocytes, microglia and neurons.[9] It can pass through the blood-brain barrier and acts on the central nervous system through inhibition of apoptosis in microvascular endothelial cells and activation of astrocytes.[10,11]

EPO has a high content of sialic acid, which protects it from hepatic degradation and enables its erythropoietic function, causing a rise in hemoglobin synthesis and blood pressure.[12] These effects are not present in NeuroEPO due to its low content of sialic acid. The molecule thus conserves its neuroprotective properties without its hematopoietic activity, which makes it a better candidate as a neuroprotective agent.[10,11]

NeuroEPO is produced by the Molecular Immunology Center (CIM, CIMAB S.A., Havana, Cuba) and is under study at the Center for Drug Research and Development (CIDEM, Havana, Cuba.)

The safety and tolerance of NeuroEPO have been proven in healthy people[13] (Cuban Public Registry of Clinical Trials RPCEC00000157) but there is no evidence yet of PD patients' tolerance of the drug.

This study evaluates short-term tolerance of intranasally administered NeuroEPO in patients with PD stages 1 and 2 on the Hoehn and Yahr Scale.[14] It examines the onset of adverse events and their potential effect on blood pressure and hematological variables.

\section{METHODS}

A monocentric randomized placebo-controlled double-blind clinical trial (registered at www.clinicaltrials.gov number NCT04110678) was conducted to evaluate tolerance and safety of NeuroEPO in PD patients. 
Participants Participants were recruited from February 1, 2015 through July 31, 2015 at the outpatient services at the Movement Disorder Clinic, International Neurological Restoration Center (CIREN) in Havana, Cuba, 46 of whom were diagnosed with idiopathic Parkinson disease in accordance with the operational criteria of the Brain Bank of London (BBL).[15]

Inclusion criteria A prior EPO-tolerance study by our group[16] using ior EPOCIM provided the framework for inclusion criteria:

- at least one year since PD onset, so disease progression can confirm diagnosis

- no limit on number of years since disease onset of PD whenever patient's severity is between stages 1 and 2 on the Hoehn \& Yahr (H\&Y) Scale[14]

- age 40-70 years

- good response to dopaminergic stimulation with $>30 \%$ change in score on the motor section of the Movement Disorders SocietyUnified Parkinson Disease Rating Scale (MDS-UPDRS)[17]

- no cognitive decline (>26 points) as measured by the MiniMental State Examination (MMSE).[18]

Exclusion criteria Because EPO stimulates erythrocyte formation and is a leading natural erythropoiesis-stimulating agent, the following individuals should be excluded from its use and were excluded from the study: pregnant and breastfeeding women; women of childbearing age who use contraceptives; patients with hematological disorders (sickle cell disease, myelodysplastic syndromes, active clotting and bleeding disorders), peripheral vascular diseases, renal or hepatic insufficiency, polycythemia, or hematocrit $\geq 50$. Due to the intranasal administration, patients with allergic rhinitis or vasomotor rhinitis in its acute phase were excluded, as well as those with nasal cavity malformations. We also excluded patients with sepsis or active acute or chronic inflammatory diseases; malignant tumors or cancer treatment; alcoholism or drug addiction in the two years prior to the study; high blood pressure or other decompensated chronic illnesses; or patients receiving immunosuppressant, androgen or anabolic steroid treatments in the month prior to recruitment.

The sample size was selected following the established international practice for tolerance clinical trials that emphasize the need to minimize the number of subjects exposed to an experimental product.[19,20]

In order to assign patients to the groups, the Molecular Immunology Center (CIM, provider of the drug) automatically generated a single list of randomized numbers and labeled the vials containing the product and cases with the corresponding code. Although the initial study design called for only 20 patients, the decision was made to include more patients due to the satisfactory tolerance results obtained in a clinical trial on healthy subjects and subjects with ataxia.[13] The same coding method was applied until completion of the final sample $(n=26)$, made up of 15 patients treated with NeuroEPO and 11 patients treated with placebo.

Criteria for removal from the study Accidents or another disease diagnosed during the study that would exclude a participant; patient's expressed interest in abandoning the study; treatment suspended for more than one dose, consecutively or in isolated instances; and death.
Product and administration NeuroEPO is presented in a singledose 1-mL vial, containing $1 \mathrm{mg} / \mathrm{mL}$ of low sialic acid, recombinant human erythropoietin (rHu-EPO) produced in cultures of the ovarian cells of Chinese hamsters ( $\mathrm{CHO}$ cells). Each vial also contains polysorbate 80 , sodium edetic acid, sodium chloride, medium molecular weight hydroxypropyl methylcellulose thickener and water for injection. The placebo formula is identical except for absence of the active ingredient. The drug was administered intranasally once a week for five consecutive weeks with the patient lying in a supine position. During the first application, the patient's head was inclined at a 45-degree angle below the horizontal plane of the body, to ensure that the product arrives to its site of action. A dose of $0.5 \mathrm{~mL}$ was administered slowly in each nostril as two doses of $0.25 \mathrm{~mL} 15$ minutes apart. This ensured arrival at the superior turbinate while keeping in mind the maximum capacity for intranasal medications.[21,22] The initial maximum dose was based on preclinical and clinical studies, as well as safety guidelines.[23-28]

Hematological and biochemical tests Blood tests were conducted prior to start of treatment and one week after completion. These included: hemoglobin, hematocrit, platelet count and erythrocyte-sedimentation rate, creatinine, uric acid, glutamic oxaloacetic transaminase, glutamic pyruvic transaminase, gamma-glutamyl transpeptidase, cholesterol and triglycerides. For statistical analysis, calculations were made of the relative change in all hematological and biochemical parameters, defined as the difference between the two measurements divided by the initial value.

Clinical evaluation Vital signs were measured before treatment and one hour after drug application. Tolerance was evaluated during the entire study through investigation of adverse events via patient surveys after each treatment session. In the case of an adverse event, the medical researcher acted in accordance with its nature and severity.

Definition and classification of adverse events An adverse event was considered as any unfavorable medical event presenting in patients receiving the product without necessarily having a causal relation with treatment. Adverse events were classified as local (site of application) or systemic,[29] in accordance with guidelines provided by the Center for State Control of Medicines and Medical Devices (CECMED). An event was considered mild if it was well tolerated, caused minimum bother, and did not interfere with daily activities; moderate if it was a bother but did not interfere with daily activities; and severe if it did interfere with daily activities.[30] The causal relation was classified as: "Extremely likely/sure," "Likely," "Possible," "Unlikely," "Not related," or "Not able to be evaluated/unclassifiable," according to WHO causality criteria.[31] The participants' code was opened after study completion, which enabled identification of patients belonging to each group.

Ethical considerations The study adhered to the ethical considerations of the Declaration of Helsinki.[32] Written informed consent was obtained from all participants; and confidentiality was ensured.

Statistical procedures Information was summarized in means and standard deviations for quantitative data and in percentages for qualitative data. To compare distribution of frequencies of the 
two groups' adverse events, the Chi square $\left(X^{2}\right)$ test was used. For comparisons of the groups with respect to the continuous variables, two analytically equivalent procedures were used: (a) an analysis of variance for repeated observations in the readings of systolic and diastolic blood pressure (taking the pretreatment value as a covariant); and (b) for all other variables, comparison of means for independent groups based on relative change.

\section{RESULTS}

Participants' demographic and clinical characteristics were collected during enrollment (Table 1). All participants remained in the study through its completion.

Adverse events occurred in both groups: four adverse events in three patients in the NeuroEPO group (20.0\%) and two adverse events in one patient in the placebo group (9.1\%), with no significant differences between groups $(p=0.22)$ (Table 2$)$. All events were mild and likely related to the patient's positioning during product administration. One patient in the placebo group presented polyuria and nasal irritation in the second application, apparently unrelated to the product, as this effect was not reported

Table 1: Demographic and clinical characteristics of the NeuroEPO group and placebo group

\begin{tabular}{|c|c|c|c|}
\hline Parameter & NeuroEPO & Placebo & Total \\
\hline \multicolumn{4}{|l|}{ Age } \\
\hline Mean (SD) & $56.4(7.8)$ & $61.1(6.6)$ & $58.4(7.6)$ \\
\hline \multicolumn{4}{|l|}{ Sex } \\
\hline Male & $7(46.6 \%)$ & $8(72.7 \%)$ & $15(55 \%)$ \\
\hline Female & $8(53.4 \%)$ & $3(27.2 \%)$ & $11(45 \%)$ \\
\hline \multicolumn{4}{|l|}{ H\&Y Scale } \\
\hline 1 & $4(26.6 \%)$ & $1(9.1 \%)$ & $5(19.2 \%)$ \\
\hline 2 & $11(73.4 \%)$ & $10(90.9 \%)$ & $21(80.8 \%)$ \\
\hline \multicolumn{4}{|c|}{ PD Progression (years post-diagnosis) } \\
\hline & $5.4(3.2)$ & $5.8(4.1)$ & $5.6(3.5)$ \\
\hline \multicolumn{4}{|c|}{ PD in family history } \\
\hline Yes & $6(40 \%)$ & $3(27.2 \%)$ & $9(34.6 \%)$ \\
\hline No & $9(60 \%)$ & $8(72.8 \%)$ & $17(65.4 \%)$ \\
\hline \multicolumn{4}{|c|}{ Personal history of other chronic disorders } \\
\hline Yes & $8(53.4 \%)$ & $7(63.6 \%)$ & $15(57.7 \%)$ \\
\hline No & $7(46.6 \%)$ & $4(36.4 \%)$ & $11(42.3 \%)$ \\
\hline \multicolumn{4}{|c|}{ Use of levodopa } \\
\hline Yes & $11(73.3 \%)$ & $9(81.8 \%)$ & $20(76.9 \%)$ \\
\hline No & $4(26.7 \%)$ & $2(18.2 \%)$ & $6(23.1 \%)$ \\
\hline \multicolumn{4}{|c|}{ Use of precursors } \\
\hline Yes & $9(60 \%)$ & $6(54.5 \%)$ & $15(57.7 \%)$ \\
\hline No & $6(40 \%)$ & $5(45.5 \%)$ & $11(42.3 \%)$ \\
\hline \multicolumn{4}{|c|}{ Use of neuroprotectors } \\
\hline Yes & $1(6.7 \%)$ & $2(18.2 \%)$ & $3(11.5 \%)$ \\
\hline No & $14(93.3 \%)$ & $9(81.8 \%)$ & $23(88.5 \%)$ \\
\hline \multicolumn{4}{|c|}{ Use of other drugs } \\
\hline Yes & $8(53.3 \%)$ & $5(45.4 \%)$ & $13(50 \%)$ \\
\hline No & $7(46.7 \%)$ & $6(54.6 \%)$ & $13(50 \%)$ \\
\hline
\end{tabular}

H\&Y Scale: disease severity according to Hoehn \& Yahr Scale;[14] PD: Parkinson disease; Precursors: dopaminergic drug precursors; neuroprotectors: drugs with proven neuroprotective action; other drugs: those used for PD patients' comorbidities (anti-hypertensives, lipid-lowering, etc.)
Table 2: Description and follow-up for adverse events upon NeuroEPO or placebo application

\begin{tabular}{|c|c|c|c|c|}
\hline \multirow[b]{2}{*}{ Parameter } & \multicolumn{4}{|c|}{ Participant } \\
\hline & $\begin{array}{c}\text { JDA-02 } \\
\text { (placebo) }\end{array}$ & $\begin{array}{c}\text { MRLL-06 } \\
\text { (NeuroEPO) }\end{array}$ & $\begin{array}{c}\text { LAPG-12 } \\
\text { (NeuroEPO) }\end{array}$ & $\begin{array}{c}\text { NAR-09 } \\
\text { (NeuroEPO) }\end{array}$ \\
\hline Adverse events & 2 & 2 & 1 & 1 \\
\hline Nausea & & 1 & 1 & 1 \\
\hline Vomiting & & 1 & & \\
\hline Nasal itching & 1 & & & \\
\hline Polyuria & 1 & & & \\
\hline Onset & $\begin{array}{r}2 \mathrm{nd} \\
\text { application }\end{array}$ & $\begin{array}{r}1 \mathrm{st} \\
\text { application }\end{array}$ & $\begin{array}{r}1 \mathrm{st} \\
\text { application }\end{array}$ & $\begin{array}{r}1 \mathrm{st} \\
\text { application }\end{array}$ \\
\hline Duration & 4 hours & 3 hours & 2 hours & 10 hours \\
\hline Intensity* & Mild & Mild & Mild & Mild \\
\hline Causality & Not related & $\begin{array}{r}\text { Extremely likely/ } \\
\text { sure }\end{array}$ & $\begin{array}{r}\text { Extremely likely/ } \\
\text { sure }\end{array}$ & $\begin{array}{r}\text { Extremely likely/ } \\
\text { sure }\end{array}$ \\
\hline Outcome & Recovery & Recovery & Recovery & Recovery \\
\hline Conduct & Observation & Observation & Observation & Observation \\
\hline
\end{tabular}

* Intensity of event was classified based on CDER guidelines.[27] Mild corresponds to Grade 1 in the Common Terminology Criteria for Adverse Events (CTCAE, https://www.uptodate.com/ contents/common-terminology-criteria-for-adverse-events)

Table 3: Blood pressure for both groups pretreatment, during study and post-treatment

\begin{tabular}{|l|r|r|}
\hline Parameter & \multicolumn{2}{|c|}{ Group } \\
\hline Blood pressure & NeuroEPO & \multicolumn{1}{|c|}{ Placebo } \\
\hline Pre-SBP & $125.6(9.4)$ & $129(9.2)$ \\
\hline Pre-DBP & $79.3(7.0)$ & $79.1(4.9)$ \\
\hline SBP 1 & $122.3(10.4)$ & $126.3(14.8)$ \\
\hline DBP 1 & $77(5.9)$ & $79.5(9.1)$ \\
\hline SBP 2 & $121(8.4)$ & $121.3(10.0)$ \\
\hline DBP 2 & $79(5.9)$ & $77.7(6.1)$ \\
\hline SBP 3 & $121(8.4)$ & $125.9(11.3)$ \\
\hline DBP 3 & $74(7.1)$ & $78.3(6.7)$ \\
SBP 4 & $122.6(15.1)$ & $126.8(9.5)$ \\
\hline DBP 4 & $70(4.4)$ & $80.4(5.6)$ \\
SBP 5 & $120.3(8.1)$ & $123.6(8.9)$ \\
DBP 5 & $70(4.4)$ & $78.6(5.5)$ \\
Post-SBP & $122.3(8.4)$ & $124.1(10.4)$ \\
Post-DBP & $70(3.2)$ & $78.1(2.5)$ \\
F $=0.27(p=0.90)$ & &
\end{tabular}

SBP: systolic blood pressure ( $\mathrm{mmHg})$; DBP: diastolic blood pressure $(\mathrm{mmHg})$; pre: pre-treatment; post: post-treatment (one week after final application of product). Numbers correspond to week of treatment. Figures correspond to means and standard deviations (in parentheses). a: Fisher's overall test for the effect of change in a repeated observations analysis of variance.

for recombinant EPO or in the NeuroEPO tolerance study involving healthy subjects.[13] Three patients in the NeuroEPO group presented systemic events: immediate nausea on first administration and in one case, vomiting. Event duration was three to ten hours, with a steady decline in symptom intensity over time. All events required only observation, and patients experiencing the adverse event spontaneously recovered without sequelae or need for medication.

Blood pressure readings were within normal range for participants in both groups, both before application of the product and in the five post-application measurements (Table 3 ). The hematological and biochemical parameters remained steady and with- 


\begin{tabular}{|c|c|c|c|c|}
\hline \multirow{2}{*}{ Parameter } & \multicolumn{2}{|c|}{ Group } & \multirow{2}{*}{$\mathbf{t}^{\mathrm{a}}$} & \multirow{2}{*}{$\mathbf{p}^{b}$} \\
\hline & NeuroEPO & Placebo & & \\
\hline Pre-hemoglobin & $13.1(1.4)$ & $13.6(1.4)$ & \multirow{2}{*}{0.36} & \multirow{2}{*}{0.72} \\
\hline Post-hemoglobin & $13.1(1.2)$ & 13.7 (1.4) & & \\
\hline Pre-hematocrit & $41.6(3.8)$ & $41.6(3.2)$ & \multirow{2}{*}{0.47} & \multirow{2}{*}{0.64} \\
\hline Post-hematocrit & $43.3(4.9)$ & $41.6(3.2)$ & & \\
\hline $\begin{array}{l}\text { Pre-erythrocyte } \\
\text { sedimentation rate }\end{array}$ & $8.6(5.8)$ & $9.8(9.4)$ & \multirow{2}{*}{0.73} & \multirow{2}{*}{0.47} \\
\hline $\begin{array}{l}\text { Post-erythrocyte } \\
\text { sedimentation rate }\end{array}$ & $8.0(6.9)$ & $9.2(8.7)$ & & \\
\hline Pre-platelet & 242.4 (51.3) & $236.6(57.4)$ & \multirow{2}{*}{0.29} & \multirow{2}{*}{0.77} \\
\hline Post-platelet & $236.1(50.6)$ & $226.2(56.5)$ & & \\
\hline
\end{tabular}

Pre: pre-treatment; Post: Post-treatment (1 week after final application of product). Data presented as means and standard deviations in parentheses.

a: Value of comparison t-Student test (means over relative change) in the groups.

$b$ : $p$ value associated with comparison test

Table 5: Relative changes of pre-and post-treatment biochemical parameters in the NeuroEPO and placebo groups

\begin{tabular}{|l|r|r|c|c|}
\hline Parameter & NeuroEPO & \multicolumn{1}{|c|}{ Placebo } & $\mathbf{t}^{\mathrm{a}}$ & $\mathbf{p}^{\mathrm{b}}$ \\
\hline Pre-creatinine $(\mu \mathrm{mol} / \mathrm{L})$ & $89.9(25.3)$ & $90.6(11.6)$ & & \\
\hline Post-creatinine $(\mu \mathrm{mol} / \mathrm{L})$ & $95.7(13.8)$ & $88.7(15.2)$ & & 0.10 \\
\hline Pre-uric acid $(\mu \mathrm{mol} / \mathrm{L})$ & $288.8(77.0)$ & $291.3(68.7)$ & & \\
\hline Post-uric acid $(\mu \mathrm{mol} / \mathrm{L})$ & $294.3(58.9)$ & $279.4(88.6)$ & & \\
\hline Pre-GPT $(\mathrm{u} / \mathrm{L})$ & $22.1(6.2)$ & $16.7(10.6)$ & & \\
\hline Post-GPT $(\mathrm{u} / \mathrm{L})$ & $15.6(9.0)$ & $17.4(6.14)$ & & 0.48 \\
\hline Pre-GOT $(\mathrm{u} / \mathrm{L})$ & $22.1(6.2)$ & $27.2(17.8)$ & & \\
\hline Post-GOT $(\mathrm{u} / \mathrm{L})$ & $20.2(5.2)$ & $20.1(4.02)$ & & \\
\hline Pre-GGT $(\mathrm{u} / \mathrm{L})$ & $28(24.9)$ & $37.6(33.7)$ & & \\
\hline Post-GGT $(\mathrm{u} / \mathrm{L})$ & $23.2(13.1)$ & $30(25.5)$ & & \\
\hline Pre-TGC $(\mathrm{mmol} / \mathrm{L})$ & $0.9(0.5)$ & $1.0(0.6)$ & 0.51 \\
\hline Post-TGC $(\mathrm{mmol} / \mathrm{L})$ & $0.9(0.4)$ & $0.9(0.5)$ & & \\
\hline Pre-cholesterol $(\mathrm{mmol} / \mathrm{L})$ & $4.5(1.0)$ & $4.9(0.9)$ & & \\
\hline Post-cholesterol $(\mathrm{mmol} / \mathrm{L})$ & $4.5(0.9)$ & $4.6(1.0)$ & & \\
\hline
\end{tabular}

Legend: GPT: glutamic pyruvic transaminase; GOT: glutamic oxaloacetic transaminase; GGT: gamma-glutamyl transpeptidase, TGC: Triglycerides; Pre: day zero, pre-treatment, Post: post- treatment (1 week after final application of product). Data presented as means and standard deviations in parentheses.

a: $t$-Student comparison test (means over relative change) in the groups.

$\mathrm{b}$ : $\mathrm{p}$ value associated with comparison test.

in normal limits (Tables 4 and 5), and for this reason statistical tests (intra- and inter-group) were not performed. The means of each parameter for each group were similar before treatment and one week after treatment completion (Tables 3-5).

\section{DISCUSSION}

This clinical trial confirms PD patients' short-term tolerance to intranasally administered NeuroEPO at the doses employed. There is an imbalance in sex and severity in both groups. In our opinion, this disparity did not influence the results of the trial.

Sex The prevalence of PD is lower in females than in males, in a proportion 1:3.[32,33] In our study, the placebo group had fewer women $(n=3)$ than the NeuroEPO group $(n=8)$. This is an effect of general randomization; it does not have the same implication as in a drug-efficacy study. Due to its angiogenic effect, EPO could act in females as a hormone, playing a role in reproductive organ function; [34,45] this effect is not present in NeuroEPO, a form of EPO without the hematopoietic effect. In addition, women of childbearing age/pregnant women were excluded in the recruitment process.

Severity PD severity was evaluated using the H\&Y scale. The placebo group had only one patient in $\mathrm{H} \& \mathrm{Y}$ stage 1 , while the NeuroEPO group had four. This imbalance was present in recruited participants (only 10 of the 46 patients who met the $\mathrm{BBL}$ criteria were in $\mathrm{H} \& \mathrm{Y}$ stage 1 while 36 were in $\mathrm{H} \& \mathrm{Y}$ stage 2). In our experience the symptoms of stage-1 patients are mild and patients rarely seek treatment, while stage-2 patients present bilateral motor compromise so they often volunteer to participate in clinical trials.

Tolerance We did not find significant changes in the hematological parameters. Four adverse events occurred in three patients treated with NeuroEPO (20\%); all were mild and happened after the first intranasal administration. The frequency of adverse events reported here is lower than that found in the NeuroEPO clinical trial conducted in healthy individuals,[13] where $80 \%$ of the subjects who received NeuroEPO reported at least 1 mild adverse event. This can be related to the lower doses and frequency employed in our study (1 mg, once per week for five weeks), where for the first time, patients with Parkinson were exposed to this molecule, in comparison with $1 \mathrm{mg}$ every eight hours for four days.[13]

Evidence showed good local tolerance. The mild adverse events at site of administration are similar to those observed in preclinical studies with both NeuroEPO and controls in the nasal irritation test and could be considered to be common when using this route of administration.[23]

The nausea reported by three patients in the NeuroEPO group was not reported in the study with healthy volunteers. This adverse event could be explained by the positioning of the patient's head for half an hour during the administration of the drug (lowered at an angle to the body). These events occurred in the first administration. In subsequent applications of the drug, head position was modified, adopting a horizontal position, and this effect disappeared.

The data indicate an appropriate dose level at which NeuroE$\mathrm{PO}$ can be safely nasally administered to PD patients. A phase 2-3 clinical trial of NeuroEPO is now underway to evaluate its possible beneficial effects.

\section{CONCLUSIONS}

Nasal administration of NeuroEPO in patients with Parkinson disease (stages 1 and 2 on the Hoehn \& Yahr Scale) is well tolerated. These results endorse further clinical study of this product for PD treatment.

\section{ACKNOWLEDGMENTS}

We thank the patients and their providers who volunteered to participate in this clinical trial, as well as all those who cooperated with the study: nurses, physicians, laboratory technicians and employees of CIREN, and the CIM specialists who provided the product and methodology used in the study. -1 - 


\section{REFERENCES}

1. Leverenz JB, Quinn JF, Zabetian C, Zhang J, Montine K, Montine T. Cognitive impairment and dementia in patients with Parkinson disease. Curr Top Med Chem. 2009;9(10):903-12.

2. GBD 2016 Parkinson's Disease Collaborators. Global, regional, and national burden of Parkinson's disease, 1990-2016: a systematic analysis for the Global Burden of Disease Study 2016. Lancet Neurol. 2018 Nov 1;17(11):93953.

3. Braak H, Del Tredici K, Rüb U, de Vos RA, Jansen Steur ENH, Braak E. Staging of brain pathology related to sporadic Parkinson's disease. Neurobiol Aging. 2003 Mar-Apr;24(2):197-211.

4. Nutt JG, Wooten GF. Clinical practice. Diagnosis and initial management of Parkinson's disease. N Engl J Med. 2005 Sep 8;353(10):1021-7.

5. Toba H, Kojima Y, Wang J, Noda K, Tian W, Kobara $M$, et al. Erythropoietin attenuated vascular dysfunction and inflammation by inhibiting NADPH oxidase-derived superoxide production in nitric oxide synthase-inhibited hypertensive rat aorta. Eur J Pharmacol. 2012 Sep;691(1-3):190-7.

6. Ge XH, Zhu GJ, Geng DQ, Zhang ZJ, Liu CF. Erythropoietin attenuates 6-hydroxydopamineinduced apoptosis via glycogen synthase kinase 3beta-mediated mitochondrial translocation of Bax in PC12 cells. Neurol Sci. 2012 Dec;33(6):1249-56.

7. Liu P, Liu X, Liou AK, Xing J, Jing Z, Ji X, et al. The neuroprotective mechanism of erythropoietinTAT fusion protein against neurodegeneration from ischemic brain injury. CNS Neurol Disord Drug Targets. 2014;13(8):1465-74.

8. Ugurluer G, Cebi A, Mert H, Mert N, Serin M, Erkal HS. Neuroprotective effects of erythropoietin against oxidant injury following brain irradiation: an experimental study. Arch Med Sci. 2016 Dec 1:12(6):1348-53.

9. Bond WS, Rex TS. Evidence that erythropoietin modulates neuroinflammation through differential action on neurons, astrocytes, and microglia. Front Immunol. 2014 Oct 24;5:523.

10. Maiese K, Chong ZZ, Shang YC, Wang S. Erythropoietin: new directions for the nervous system. Int J Mol Sci. 2012;13(9):11102-29.

11. Erbas O, Cinar BP, Solmaz V, Çavuşoğlu T, Ates $U$. The neuroprotective effect of erythropoietin on experimental Parkinson model in rats. Neuropeptides. 2015 Feb;49:1-5.

12. FARMACODIVULGACION: Eritropoyetina humana recombinante. Rev Cubana Farm. 2012 AprJun;46(2):287-8. Spanish.

13. Santos-Morales O, Díaz-Machado A, JiménezRodríguez D, Pomares-Iturralde Y, FesteryCasanovas T, González-Delgado CA, et al. Nasal administration of the neuroprotective candidate NeuroEPO to healthy volunteers: a randomized, parallel, open level safety study. BMC Neurol. 2017 Jul 4;17(1):129.

14. Hoehn MM \& Yahr MD. Parkinsonism: onset, progression and mortality. Neurology. 1967;17:427-27

15. Hughes AJ, Daniel SE, Kilford L, Lees AJ. Accuracy of clinical diagnosis of idiopathic Parkinson's disease: a clinico-pathological study of 100 cases. J Neurol Neurosurg Psychiatry.1992 Mar;55(3):181-4.

16. Pedroso I, Bringas ML, Aguiar A, Morales L, Álvarez M, Valdés PA. Use of Cuban recombinant human erythropoietin in Parkinson's disease treatment. MEDICC Rev. 2012 Jan;14(1):11-7.

17. Goetz CG, Tilley BC, Shaftman SR, Stebbins GT, Fahn S, Martínez-Martín P, et al. Movement Disorder Society-sponsored revision of the Unified Parkinson's Disease Rating Scale (MDSUPDRS): scale presentation and clinometric testing results. Move Disord. 2008 Nov 15;23(15):2129-70.

18. Folstein M, Robins N, Helzer, J. The minimental state examination. Arch Gen Psychiatry. 1983;40:812.

19. Buoen C, Bjerrum OJ, Thomsen MS. How firsttime-in-human studies are being performed: a survey of phase I dose-escalation trials in healthy volunteers published between 1995 and 2004. J Clin Pharmacol. 2005 Oct;45(10):1123-36.

20. European Medicines Agency. Committee for Medicinal Products for Human Use (CHMP). Guideline on strategies to identify and mitigate risks for first-in-human and early clinical trials with investigational medicinal products. Draft [Internet]. London: European Medicines Agency Committee for Medicinal Products for Human Use (CHMP); 2016 Nov 15 [cited 2020 May 5]. 22 p. Available at: https://www.ema.europa .eu/en/documents/scientific-guideline/draft -guideline-strategies-identify-mitigate-risks-first -human-early-clinical-trials-investigational_en.pdf

21. Dhuria SV, Hanson LR, Frey WH 2nd. Intranasal delivery to the central nervous system: mechanisms and experimental considerations. J Pharm Sci. 2010 Apr;99(4):1654-73.

22. Muñoz-Cernada A, Fernández-Cervera $M$, García-Rodríguez JC. Factors involved in the design of nasal delivery systems for peptides and proteins. Biotecnol Apl. 2013;30(2):88-96.

23. Sosa Testé I, García Rodríguez JC, García JD, Santana J, Subirós N, González C. Intranasal administration of recombinant human erythropoietin exerts neuroprotective effects on post-ischemic brain injury in Mongolian gerbils. Pharmacol Online. 2006;1:100-12.

24. Lagarto A, Bueno V, Guerra I, Valdés O, Couret M, López R, et al. Absence of hematological side effects in acute and subacute nasal dosing of erythropoietin with a low content of sialic acid. Exp Toxicol Pathol. 2011 Sep;63(6):563-7.

25. Ehrenreich $H$, Hasselblatt $M$, Dembowski C, Cepek L, Lewczuk $P$, Stiefel $M$, et al. Erythropoietin therapy for acute stroke is both safe and beneficial. Mol Med. 2002 Aug; 8(8):495-505.

26. Ehrenreich $\mathrm{H}$, Weissenborn $\mathrm{K}$, Prange $\mathrm{H}$, Schneider D, Weimar C, Wartenberg K, et al. Recombinant human erythropoietin in the treatment of acute ischemic stroke. Stroke. 2009 Dec;40(12):e647-56

27. Center for Drug Evaluation and Research (CDER). Guidance for industry: estimating the maximum safe starting dose in initial clinical trials for therapeutics in adult healthy volunteers [Internet]. Washington, D.C.: Department of Health and Human Services; Food and Drug Administration (FDA); 2005 [cited 2020 Apr 21]. 27 p. Available at: https://www.fda.gov/ media/72309/download

28. Sosa Testé I, Megana Tamos Y, Rodríguez Cruz Y, Muñoz Cernada A, Cruz Rodríguez J, Subirós Martínez N, et al. Dose effect evaluation and therapeutic window of the Neuro-EPO nasal application for the treatment of the focal ischemia model in the Mongolian gerbil. Sci World J. 2012;2012:607498. DOI: 10.1100/2012/607498

29. Reglamento para la vigilancia de productos farmacéuticos de uso humano durante la comercialización. Resolución 69/2019 [Internet] Havana: Center for State Control of Medicines, Equipment and Medical Devices (CECMED) 2019 [cited 2020 May 18]. 49 p. Available at: https://www.cecmed.cu/sites/default/files/ adjuntos/Reglamentacion/Res.No_.69.2019\%20 Peq.pdf. Spanish.

30. De Cos MA, Flórez J. Reacciones Adversas de los Medicamentos. In: Flórez J, editor.
Farmacología Humana. 3rd ed. Barcelona: Masson; 1998. p. 155-64. Spanish.

31. Theuse oftheWHO-UMCsystemforstandardized case causality assessment [Internet]. Uppsala (SW): The Uppsala Monitoring Center; [date unknown; cited 2020 Apr 21]. 2 p. Available at: http://www.who.int/medicines/areas/quality _safety/safety_efficacy/WHOcausality_assess ment.pdf

32. Declaración de Helsinki de La Asociación Médica Mundial. Principios éticos para las investigaciones médicas en seres humanos. Fortaleza: 64 ${ }^{\mathrm{a}}$ Asamblea General [Internet]. Pamplona (SP): Universidad de Navarra, Centro de Documentación de Bioética; 2013 [updated 2013 Oct; cited 2019 Jul 23]. 7 p. Available at: http://www.redsamid.net/archivos/201606/2013 -declaracion-helsinki-brasil.pdf?1. Spanish.

33. Wooten GF, Currie LJ, Bovbjerg VE, Lee JK, Patrie J. Are men at greater risk for Parkinson's disease than women? J Neurol Neurosurg Psychiatry [Internet]. 2004 Apr [cited 2020 Apr 21];75(4):637-9. Available at: https://doi .org/10.1136/jnnp.2003.020982

34. Pringsheim T, Jette N, Frolkis A, Steeves TDL. The prevalence of Parkinson's disease: a systematic review and meta-analysis. Move Disord [Internet]. 2014 [cited 2020 21];29(13):1583-90. Available at: https://doi .org/10.1002/mds.25945

35. Lombardero M, Kovacs K, Scheithauer BW. Erythropoietin: a hormone with multiple functions. Pathobiology [Internet]. 2011 [cited 2020 Mar 18];78(1):41-53. Available at: https:// doi.org/10.1159/000322975

36. Ribatti D, Vacca A, Roccaro AM, Crivellato E, Presta M. Erythropoietin as an angiogenic factor. Eur J Clin Invest. 2003 Oct;33(10):891-6.

\section{THE AUTHORS}

Marité García-Llano, physician with dual specialties in family medicine and neurology, and a master's degree in medical emergencies. Head of the Neurology Department, Abel Santamaría Cuadrado Provincial Clinical-Surgical Hospital, Pinar del Río, Cuba. https://orcid.org/0000 $-0002-4896-8948$

Ivonne Pedroso-Ibáñez, physician with dual specialties in family medicine and neurology, and a master's degree in clinical neuroscience. Head of the Movement Disorders Clinic, International Neurological Restoration Center (CIREN), Havana, Cuba. Associate researcher and assistant professor, Cuban Neurosciences Center (CNEURO). https://orcid.org/0000-0001-6983 $-9398$

Lilia Morales-Chacón, physician specializing in neurophysiology, with dual doctorates in physiology and medical sciences. Senior researcher at CIREN and full professor at the Medical University of Havana, Cuba. Deputy director, CIREN, Havana, Cuba. https://orcid.org/0000-0003 $-0205-0733$

Teresita Rodríguez-Obaya, physician specializing in cellular biology and histology with a doctorate in biological sciences. NeuroEPO product manager, associate researcher, Molecular Immunology Center (CIM), and full professor, Medical University of Havana, Cuba. https://orcid.org/0000 -0002-2918-4267 
Leslie Pérez-Ruiz, pharmacist with master's degrees in pharmacology and health economics. Assistant researcher and assistant professor, Molecular Immunology Center (CIM), Havana, Cuba. https://orcid.org/0000-0001 $-8492-3774$

Iliana Sosa-Testé, veterinarian with a doctorate in veterinary sciences. Head of Toxicology and Animal Experimentation Department, senior researcher and professor at the National Laboratory Animal Production Center (CENPALAB), Havana, Cuba. https://orcid.org/0000-0001 $-6588-5397$
Daniel Amaro-González, chemical engineer with a doctorate in the field. Head of the Department of Vaccine Development, full professor and associate researcher, CIM, Havana, Cuba. https://orcid.org/0000-0001 $-5729-2743$

María Luisa Bringas-Vega (Corresponding author: maria.bringas@neuroinformatics-collaboratory.org), psychologist with a doctorate in psychophysiology. Coordinator of the Cuba-China Joint Lab for Neurotechnology. Full professor of neuropsychology in the master's degree pro- gram in cognitive neurosciences, CNEURO, Havana, Cuba. https://orcid.org/0000-0003 $-2507-1959$

Submitted: March 17, 2020

Approval date: December 5, 2020

Disclosures: Teresita Rodríguez-Obaya, Leslie Pérez-Ruiz and Daniel Amaro-González work at the Molecular Immunology Center (CIM), the developer of EPOCIM and NeuroEPO. 


\title{
Evaluating Cerebral Perfusion in Alzheimer Patients and First-Degree Relatives: Lessons from Artemisa Province, Cuba
}

\author{
Yamilé Peña-Quián MD PhD, Saily Sosa-Pérez MD MS, Juan F. Batista-Cuéllar MD, Chryslaine Rodríguez-Tanty PhD, \\ Leonel A. Torres-Aroche PhD, Elvia Luz-Sánchez RN MS, Susana Romero-Collado RN MS
}

\begin{abstract}
INTRODUCTION Alzheimer disease is related to several risk factors including aging, family history, high blood pressure and diabetes. Studies have shown specific regional cerebral perfusion changes in patients with Alzheimer disease. Some authors state that these changes could appear years before patient memory becomes impaired, enabling early diagnosis in high-risk persons who appear to be healthy.

OBJECTIVE Determine the usefulness of cerebral perfusion studies in Alzheimer patients and first-degree relatives for obtaining additional diagnostic information and detecting functional changes that may suggest elevated disease risk.

METHODS This study involved 128 persons (87 clinically diagnosed with Alzheimer disease and 41 of their first-degree relatives with normal cognition), all from Artemisa Province, Cuba. We performed clinical, laboratory, neuropsychological and genetic (apolipoprotein E-ApoE, e4 allele) tests, as well as cerebral perfusion studies using single photon emission computed tomography after administering $740-925 \mathrm{MBq}$ of $99 \mathrm{~m}$ TC-ECD, following internationally standardized protocols.
\end{abstract}

RESULTS In the Alzheimer disease group, the cerebral single photon emission computed tomography showed a typical Alzheimer pattern

\section{INTRODUCTION}

Alzheimer disease (AD) is a neurodegenerative condition with insidious onset and slow progression. The disease is responsible for $70 \%$ of dementia cases and is the main cause of dementia in persons aged $\geq 65$. [1]

The main risk factors for onset of the disease are age, family history of $A D$, high blood pressure, high cholesterol, obesity, diabetes mellitus and low education level. The disease is more common in women and has been linked to the e 4 allele of the gene that codes for ApoE.[2]

Longer life expectancy leads to an older population and increases in $A D$ incidence. Cuba has one of the oldest populations in Latin America.[3] According to the annual Cuban Health Statistics Report, in 2019 the Cuban population

\section{IMPORTANCE}

This study confirms the usefulness of cerebral perfusion single photon emission computed tomography in evaluating patients with different stages of Alzheimer disease and their first-degree relatives. In first-degree relatives, diagnosing abnormalities may allow for early diagnosis of the disease and possible early interventions in the community. (bilateral posterior temporal-parietal hypoperfusion) in $77 \%(67 / 87)$ of participants; $35.9 \%(28 / 67)$ in stage $1 ; 51.3 \%(40 / 67)$ in stage 2; and $12.8 \%(10 / 67)$ in stage 3 of the disease. In this group, $12.7 \%$ $(11 / 87)$ had mild or unilateral cerebral perfusion changes; $5.7 \%(5 / 87)$ vascular dementia; 3.4\% (3/87) frontal dementia; and 1.2\% (1/87) normal cerebral perfusion. Of the patients, $28.7 \%(25 / 87)$ received a different classification of stage and disease diagnosis after cerebral perfusion results were considered. In the relative group, $14.6 \%(6 / 41)$ had cerebral perfusion abnormalities. Among these, $7.1 \%(3 / 41)$ were mild bilateral temporal-parietal hypoperfusion; $4.8 \%(2 / 41)$ mild unilateral temporal-parietal hypoperfusion; and 2.4\% (1/41) had perfusion defecits in their right frontal lobes. Of patients with typical Alzheimer disease patterns in the cerebral single photon emission computed tomography, $76.6 \%$ (52/67) had positive ApoE e4. All relatives with perfusion abnormalities (6/6) had positive ApoE e4.

CONCLUSIONS Cerebral perfusion studies confirmed the Alzheimer disease diagnosis, classified disease stages, and differentiated between the types of dementia. The test showed perfusion changes in several asymptomatic first-degree relatives with positive ApoE e4, which could be predictors of disease. The technique was useful for evaluating patients and their relatives.

KEYWORDS Cerebrovascular circulation; tomography, emissioncomputed, single-photon; Alzheimer disease; Alzheimer's disease; Cuba

was $11,201,549$, with an average life expectancy of 78.4 years. The number of persons aged $\geq 60$ has doubled in less than 40 years and comprised $20 \%$ of the population.[3] It is estimated that in 2025, 1 in every 4 persons will be aged $\geq 60$ and about 500,000 will be aged $\geq 80$. [2]

Dementia is the sixth leading cause of death in Cuba.[3] In 2019, dementia was the cause of death in 5097 persons, with a gross rate of 45.4 and an adjusted rate of 16.7 per 100,000 population.[3] A 2012 prospective longitudinal study in Havana and Matanzas Provinces showed an annual dementia incidence of 21.2 per 100,000 population.[4] Dementia prevalence is $6.4 \%-10.2 \%$ in persons aged $\geq 65$ years, and is more common in women. In the 2012 study, AD was the most common cause of dementia.[4] Considering the rapid aging of the Cuban population, it is estimated that 130,000 persons would have AD or another type of dementia by $2025 .[4]$

$A D$ is one of the main causes of disability in older adults and also a disability that leads to the greatest dependence, financial burden and psychological stress on caregivers. [5] Without an effective intervention, by 2050 the number of new dementia cases in persons aged $\geq 65$ will substantially increase yearly costs. The long-term demands on caregivers of persons with dementia will increase far beyond current levels, with significant social and economic impacts.[2,6,7] 
Diagnosing $A D$ is primarily a clinical endeavor and based on a triad of medical history, caregiver-provided information and cognitive testing. With current technological advances, structural biomarkers, biological biomarkers and nuclear neuroimaging have been added to confirmatory diagnostic criteria.[8-10] In summary, the criteria are:

Hippocampal amnesia (alone or associated with other cognitive or behavioral impairments) appearing at any age, with insidious onset and progressive worsening, associated with one or more of the following biomarkers:

- Structural: Medial temporal lobe atrophy (detected by MRI)

- Biological: Abnormalities in cerebrospinal fluid biomarkers

- Functional or metabolic: Regional cerebral hypoperfusion detected by single photon emission computed tomography (SPECT), fluorodeoxyglucose hypometabolism and observation of amyloid or tau protein buildups using positron emission tomography (PET).

The new diagnostic criteria show that AD's physiopathological process starts several years before the first clinical symptoms appear. These criteria support the use of biomarkers that can predict $A D$ progression in preclinical phases and support diagnosis in stages of mild cognitive impairment or dementia. While some biomarkers are currently used for research purposes, they may also be available in clinical practice in the near future.[9]

SPECT is a minimally invasive technique that plays a fundamental role in brain function assessment in establishing AD diagnosis, disease stage, prognosis, differential diagnosis and evaluation of treatment options for AD patients.[11,12] Patients receive an intravenous radiopharmaceutical that crosses the blood-brain barrier, permitting SPECT gamma cameras to acquire 3D images.[11,12]

$A D$ patients show specific changes in cerebral perfusion diagnosed by SPECT.[13] In stage 1 (disease onset), there tends to be mild perfusion changes in the cerebral cortex, which can be unilateral and localized. As the disease progresses to stage 2, these changes form a typical bilateral posterior temporal-parietal hypoperfusion pattern. In advanced stages, hypoperfusion can extend to the frontal lobes of the cerebral cortex. Hypoperfusion of the posterior cingulate can also occur.[13] In AD, perfusion remains normal in the sensory-motor cortex, basal ganglia, cerebellum and brainstem. These patterns, along with clinical manifestations and other test results, allow for evaluation and differential diagnosis of the types of dementia.[13]

In practice, diagnosing dementia continues to be a clinical endeavor, which substantially contributes to delayed diagnoses because once symptoms manifest, the neuropathological abnormalities are generally already extensive. This leads to failure of current drug and non-drug therapies. The fundamental role of and the challenge in developing new neuroimaging techniques is being able to detect with a high degree of sensitivity and specificity the predictive functional abnormalities that lead to irreversible structural damage.[14]

Some authors suggest that these functional abnormalities could appear in persons many years before memory impairment. $[8,14,15]$ In high-risk populations, tests such as SPECT could lead to early diagnosis, allowing for timely intervention before irreversible memory loss occurs. Lopera reported on SPECT's value in evaluating patients' relatives.[16] However, research is still insufficient.

Detecting abnormality patterns in functional neuroimaging in asymptomatic carriers of familial Alzheimer disease could serve as an early diagnostic marker before the age of onset in subjects at risk of sporadic AD.[16]

Cuba's Ministry of Public Health has been working for years to develop stratified active screening programs at all three levels of health care-primary, secondary and tertiary. These programs could be optimized with neuroimaging.[17] Yet the usefulness of neuroimaging has not been defined in our setting, and it is not widely used by specialists charged with AD patient care.

The objective of this study is to determine the usefulness of the SPECT cerebral perfusion test in $A D$ patients and their firstdegree relatives in obtaining additional diagnostic information and detecting functional changes that suggest elevated disease risk.

\section{METHODS}

Type of study and participants We conducted an observational, analytic cohort study from January 2018 through March 2020. 128 participants were seen at the Comprehensive Memory Disorder Community Care Service in San Antonio de los Baños, Artemisa Province, Cuba, and were screened based on criteria described below. We conducted a medical interview, clinical examination, laboratory tests (complete blood count, blood glucose, urea, creatinine and lipid panel), neuropsychological evaluation, ApoE e4 test, non-contrasted CT scan, and cerebral perfusion SPECT. The SPECT was conducted at the Isotope Center's Clinical Research Division in Havana.

We divided participants into two groups: AD patients (87 with a clinical diagnosis of $A D$ ) and their first-degree relatives with normal cognition (41 parents, children or siblings).

Inclusion criteria AD patients, first-degree relatives of AD patients with normal cognition, age $\geq 40$ years, agreement to participate expressed in written informed consent or, for patients unable to provide this, written consent by legal guardian.

Exclusion criteria Patients with neurological symptoms or signs of other medical conditions (e.g., non-Alzheimer dementia, major depressive disorder, cerebrovascular disease, toxic and metabolic abnormalities); head injury or recent intracranial surgery; patients with another demonstrated comorbidity that causes significant disability (cancer, septic embolism, endocarditis, myeloproliferative disease, creatinine $>3 \mathrm{mg} / \mathrm{dL}$ or $265 \mu \mathrm{mol} / \mathrm{L}$, hyperkalemia $>5.0 \mathrm{mmol} / \mathrm{L}$, chronic or severe liver, kidney, or heart disorders); patients or relatives of patients with histories of alcoholism and/or drug dependence.

\section{Variables included in the study} Clinical diagnosis

Alzheimer disease Persons with clinical disorders consistent with AD who meet the National Institute of Neurological and Communicative Disorders and Stroke and the Alzheimer's Disease and Related Disorders Association (NINCDS-ADRDA) 
Alzheimer criteria (significant and early episodic memory impairment associated with supporting characteristics such as medial temporal lobe atrophy, abnormal cerebrospinal fluid biomarkers, specific patterns in functional and/or metabolic neuroimaging, and autosomal dominant mutation of ApoE).[8-10] Neuropsychological tests were conducted with scores from:

- Montreal Cognitive Assessment (MOCA): <16 points[5]

- Clinical Dementia Rating (CDR): $\geq 1$ point[18,19]

- Mini-Mental State Examination (MMSE): $\leq 23$ points[5]

- Global Deterioration Scale (GDS): $\geq 4$ points[20]

Normal cognition (NC) Lack of memory impairment or other cognitive function impairment according to the patient or the relative. Preserved independence in basic activities of daily living and instrumental activities of daily living. Neuropsychological tests were conducted with scores from:

- MOCA: $\geq 26$ points[5]

- CDR: 0 points[18,19]

- MMSE: 27-30 points[5]

- GDS: 1 point[20]

Age Confirmed by the participant's legal identification document (official identity card)

Skin color Based on direct observation and official identity card

Atherogenic risk factors From medical interview

Family history of $A D$ From medical interview

ApoE e4 (Polymerase chain reaction-based genotyping of ApoE) We performed ApoE DNA genotyping using the protocol described by Hixon and Vernier.[21] After this determination, we researched status of participants' ApoE e4 carrier and frequency of the e4 allele. A blood test determined presence of ApoE e4 alleles, recorded as positive or negative.

Cerebral perfusion SPECT We performed SPECT scans after administering the radiopharmaceutical, once participants had been prepared according to internationally standardized protocols.[12]

To perform the SPECT scan, we placed participants in the supine position on a bed in a room with a calm atmosphere and inserted a line into a vein. We left participants to rest, relaxed, in silence, in a dimly lit room, with their eyes closed and without speaking for 10 minutes. Then we administered 740-925 megabecquerels (MBq), at 20-25 millicurie ( $\mathrm{mCi}$ ) of Technium-99m-ethyl cysteinate dimer (99m TC-ECD) (Tecnonucleo, Argentina) intravenously and waited 10 more minutes in the same conditions before sitting participants up. For the next 30 minutes, we ensured that participants had no intense visual or auditory stimuli. We acquired images 30-45 minutes after radiopharmaceutical administration.

Image acquisition parameters A Nucline Spirit DH-V (Mediso, Hungary) dual-head gamma camera acquired the images. The camera used SPECT acquisition mode with a low-energy highresolution collimator, and a 15\% window centered on the $140 \mathrm{KeV}$ (Kiloelectronvolt) technetium-99m photopeak. Detectors were placed in anterior projection as close as possible to the patient's head. The detector moved automatically along one orbit, rotating $360^{\circ}$, permitting the camera to acquire 180 shots, with a $128 \times 128$ matrix and 1.2 zoom.

\section{Image processing}

Reconstruction Filtered backprojection, with borders right above and below the brain (including the cerebellum).

Filter 4th-order Butterworth, slice frequency 0.25

Attenuation correction Chang's method, coefficient of $0.11 \mathrm{~cm}^{-1}$

Zoom Post-reconstruction variable based on operator's discretion The three axes (sagittal, coronal and transverse) were reoriented so that the transverse slices were parallel to the orbitomeatal line (in the sagittal slice, this line is tangential to the inferior border of the frontal and occipital lobes).

Scan interpretation At least two observers evaluated the SPECT scans, reporting observations independently and subsequently resolving differences by consensus. They evaluated the images in the context of relevant anatomical information provided by CT structural methods. The programs used for image processing contained a database of persons with normal results.

The unprocessed SPECT images ('raw' projections) were reviewed in film mode before CT slices were created, to verify whether the study was complete and to evaluate the presence and degree of movement, abnormal biodistributions, ratio of organ to background activity, and other potential sources of artifacts.

The observers interpreted scans directly from the computer screen, without subtracting background activity. They evaluated scans using continuous color scales and visually evaluated them with slice-by-slice analysis (sagittal, coronal and transverse slices), establishing automatic correlation with the CT. The analysis included 3D images.

Researchers also conducted a color-scale semiquantitative analysis and a quantitative analysis by cerebral region using processing software programs (Mediso, Hungary). This evaluation showed perfusion in the different cerebral lobes and compared one cerebral hemisphere with the other, determining differences between the two.

The results were classified as:

Normal Symmetric distribution of the radiopharmaceutical in one hemisphere with respect to the other. Uniform distribution of the radiopharmaceutical in the cerebral cortex and cerebellum. Basal nuclei with normal and symmetric uptake.

Pathological Focal or diffuse cortical hypoperfusion image, identified in three spatial projections and not corresponding to the interlobar sulci.

Typical $A D$ pattern Evidence of symmetric and predominantly posterior bilateral temporal-parietal cortical hypoperfusion. Enhancement of interhemispheric fissure and sulci suggesting frontal atrophy in the high slice. In advanced stages of the disease, this hypoperfusion included the frontal lobes of the cerebral cortex and the posterior cingulate. Basal nuclei and occipital lobe show normal perfusion.

\section{SPECT stages consistent with AD}

Stage 1 Any abnormality of diffuse unilateral posterior temporalparietal perfusion. 
Stage 2 Symmetric and predominantly posterior bilateral temporal-parietal cortical hypoperfusion, of moderate intensity.

Stage 3 Symmetric and predominantly posterior bilateral temporal-parietal cortical hypoperfusion, of severe intensity and extending to the frontal lobe, associated with generalized cerebral cortex thinning.

Data compilation and analysis We evaluated 128 clinical charts and medical reports of patients and relatives who provided written informed consent. Data were coded on an Excel spreadsheet, maintaining confidentially and anonymity, and entered into double-entry tables with participants' general characteristics. We divided patients into two study groups (patients with $A D$ and first-degree relatives with NC), determined the number and percentage of patients based on SPECT results, and created graphs with the data obtained. We obtained the absolute and relative frequencies of patients with $A D$ based on the three clinical stages of the disease.

We created cross-classification tables to explore the association between clinical classification and the presence or absence of ApoE e4 with the results of the cerebral perfusion SPECT.

Ethical considerations The ethics committees of all participating institutions (Isotope Center, Cuban Neuroscience Center, and the Artemisa Provincial Health Department Comprehensive Memory Disorder Community Care Service) analyzed and approved the research. We encrypted participant data for analysis. All participants (patients or their legal guardians, and their relatives) gave informed consent in writing.

\section{RESULTS}

AD patient group Included in this group were 60 women and 27 men. The mean age was 74 , and skin color was classified in $60.9 \%(53 / 87)$ as white and $39.1 \%(34 / 87)$ as mestizo (according to categories established by the Cuban census). The atherogenic risk factors in the patients were diabetes mellitus in 62\% (54/87), dyslipidemia in 50\% (44/87) and arterial hypertension in 31\% (27/87). A family history of AD was reported in $62 \%$ (54/87) of patients.

Cerebral perfusion SPECT Evaluation showed a typical AD pattern (bilateral posterior temporal-parietal hypoperfusion) in $77 \%(67 / 87)$ of patients. A lower percentage, $12.7 \%(11 / 87)$, showed mild or unilateral perfusion changes consistent with the initial stage of AD. We observed mild-to-moderate focal hypoperfusion patterns consistent with vascular disease in $5.7 \%(5 / 87)$ of patients (individuals with an initial diagnosis of $A D)$. In only $3.4 \%(3 / 87)$ of patients did we observe frontal hypoperfusion with good perfusion in the rest of the cerebral cortex (pattern consistent with frontal dementia), and we observed in 1.2\% (1/87) normal cerebral perfusion (Figure 1).

Cerebral SPECT results showed changes consistent with $A D$ in 78 patients-typical AD pattern or minimal unilateral perfusion changes (Figure 2). Most AD patients, $51.3 \%$ (40/78), were in stage 2 of the disease (moderate); $35.9 \%$ (28/78) were in stage 1 (mild); and $12.8 \%$ (10/78) were in stage 3 (advanced). The bottom of the figure shows the cross-
Figure 1: Patients with clinical diagnosis of Alzheimer disease group $(n=87)$ : SPECT cerebral perfusion results

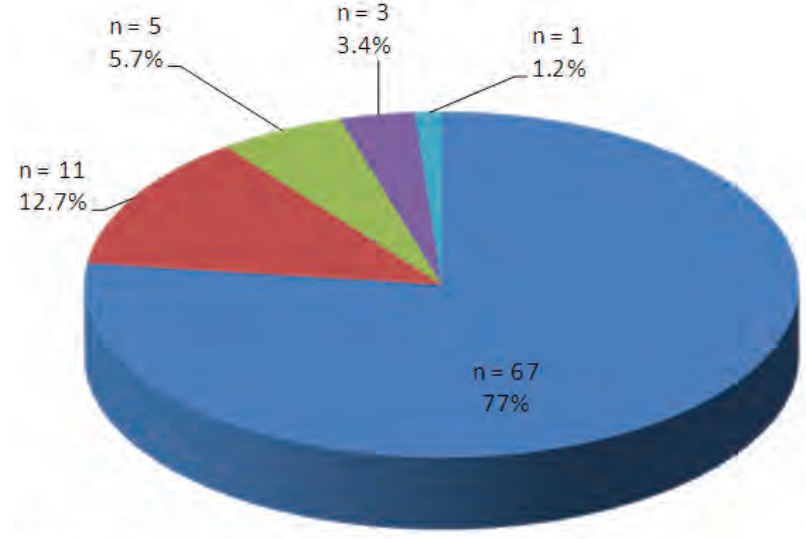

- Typical AD pattern Mild and/or unilateral changes in cerebral perfusion ivocal hypoperfusion Erontäl hypoperfusion = Normal perfusion

Figure 2: Patients by Alzheimer Disease stages according to cerebral SPECT $(n=78)$

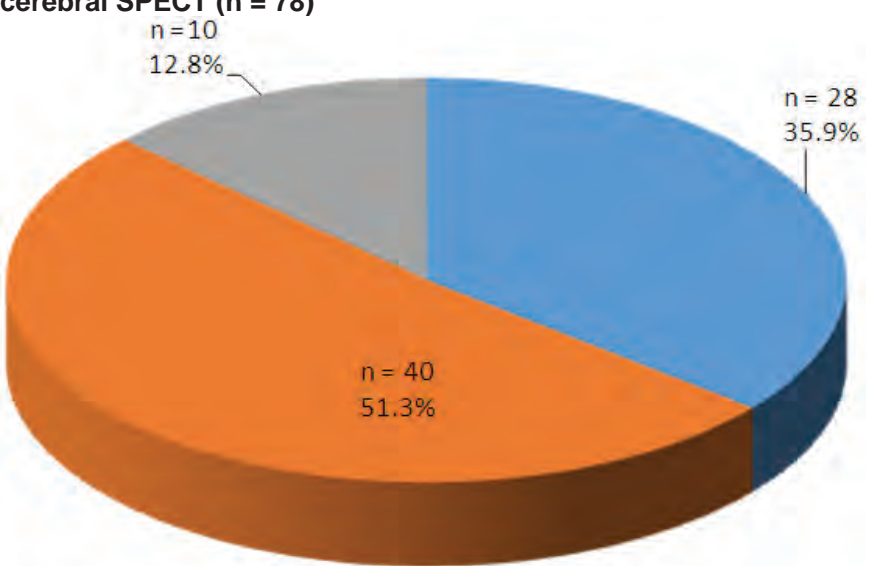

Stage 1 Stage 2 - Stage 3

SPECT: Single photon emission computed tomography

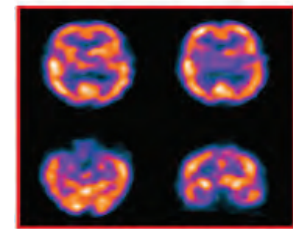

Alzheimer stage1

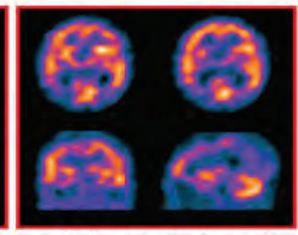

Alzheimer stage 2

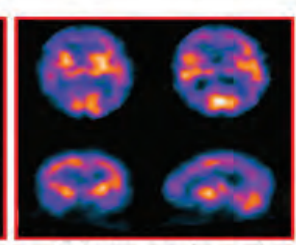

Alzheimer stage 3
Stage 1: Any abnormality of diffuse unilateral posterior temporalparietal perfusion

Stage 2: Symmetric and predominantly posterior bilateral temporalparietal cortical hypoperfusion, of moderate intensity

Stage 3: Symmetric and predominantly posterior bilateral temporalparietal cortical hypoperfusion, of severe intensity and extending to the frontal lobe, associated with generalized cerebral cortex thinning

sections of cerebral perfusion SPECT with typical patterns for each of the three AD stages.

In most patients, clinical diagnoses matched SPECT results. However, 28.7\% (25/87) of patients received a different classification of disease stage and disease diagnosis after cerebral perfusion results were considered; five patients with vascular dementia and three patients with frontal-temporal dementia. 
Figure 3: First-degree relatives with normal cognition group $(n=41)$ : SPECT cerebral perfusion results

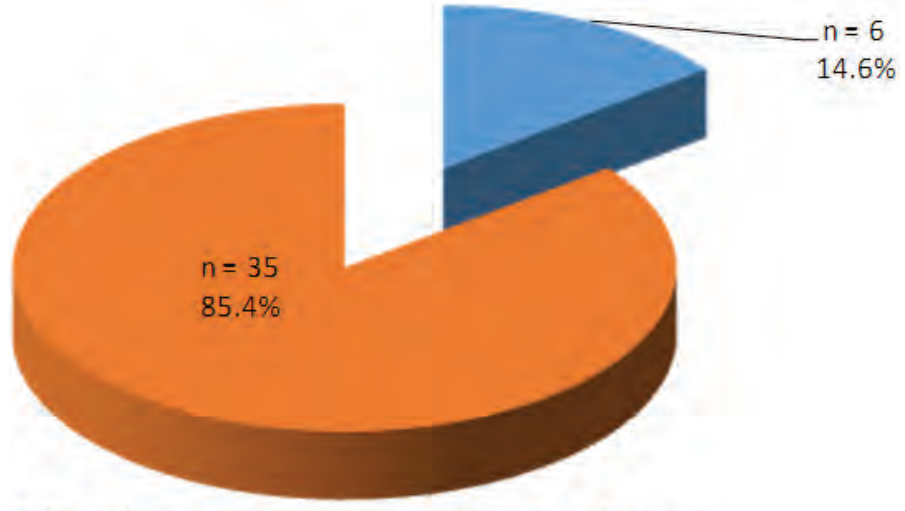

intered perfusion

= Normal perfusion

SPECT: Single photon emission computed tomography

Figure 4: Transverse slices of cerebral perfusion SPECT of a 67-year-old woman (relative with normal cognition), positive ApoE e4
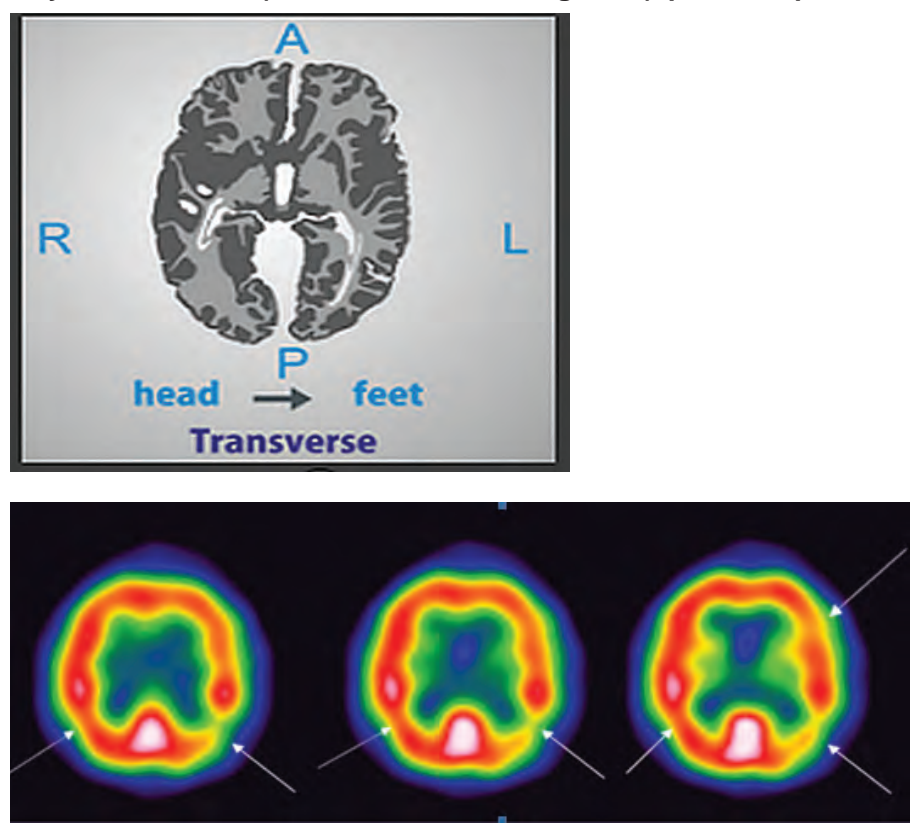

ApoE e4: APOE genotype

The arrows point to regions with mild bilateral temporal-parietal hypoperfusion, more severe in the left hemisphere. Images also show mild diffuse hypoperfusion in the left frontal lobe. A: Anterior; L: Left; P: Posterior; R: Right

First-degree relatives group This group included 28 women and 13 men. The mean age was 56, and skin color in $60 \%$ (25/41) of participants was classified as white, and as mestizo in $40 \%(16 / 41)$ of patients. Atherogenic risk factors were diabetes mellitus in 58\% (24/41), dyslipidemia in 41\% (17/41), and arterial hypertension in 29\% (12/41). All participants (41/41) had a family history of AD.

Cerebral perfusion SPECT This showed regional cerebral perfusion abnormalities in $14.6 \%$ (6/41) of evaluated participants (Figure 3 ). We found mild bilateral temporalparietal hypoperfusion in $7.1 \%$ (3/41), unilateral mild temporal and parietal hypoperfusion in $4.8 \%(2 / 41)$, and a diffuse perfusion defect of the right frontal lobe in 2.4\% (1/41). None of these cases had a result consistent with normal variants. Changes in cerebral perfusion could be predictors of AD.

The cerebral perfusion SPECT of a first-degree relative with normal cognition (a woman aged 67 with hypertension and type 2 diabetes, daughter of a patient with $A D$ ) showed mild bilateral temporal-parietal hypoperfusion, more severe in the left hemisphere (Figure 4). The images also revealed mild diffuse hypoperfusion in the left frontal lobe. Before the study, this relative had not reported any symptoms suggestive of $A D$.

Cerebral perfusion SPECT and ApoE e4 We conducted a cross-comparison between the cerebral perfusion SPECT results and presence or absence of ApoE e4 in blood for both groups evaluated in the study (patients with AD and first-degree relatives with $\mathrm{NC}$ ) (Table 1 ). We observed a link between ApoE e4 presence in blood and alterations in perfusion reported by the SPECT. Of participants with a typical AD pattern in the cerebral SPECT, $76.5 \%$ had positive ApoE e4. In the AD patients' group, ApoE e4 was also positive in $45.5 \%$ of cases with mild and/or unilateral changes in cerebral perfusion. All first-degree relatives with SPECT perfusion abnormalities had positive ApoE e4. All participants who had frontal and focal hypoperfusion, with normal perfusion in parietal and temporal regions, had negative ApoE e4.

\section{DISCUSSION}

Neuroimaging techniques have made remarkable advances, specifically in the areas of AD diagnosis, prognosis and predicting response to treatment. The most frequently used techniques include MRI, PET, and cerebral perfusion SPECT. $[12,15,22,23]$

Advances in neurosciences have raised awareness of the following: 1) existence of patients who have diffuse amyloid plaques typical of AD without dementia; 2) that characteristic disease pathology can be accompanied by atypical clinical manifestations; and 3) abnormal pathology occurs years before the first clinical symptoms appear-dementia is the final stage of the disease. It is therefore possible to differentiate two AD stages: a first preclinical, asymptomatic stage; and a second, symptomatic stage, from the appearance of the first cognitive manifestations to the more advanced phases of dementia.[8]

Nuclear medicine studies such as SPECT and PET could be important in supporting early AD diagnosis.[8,10] Currently, the sensitivity and specificity values of PET scan metabolic imaging are higher than those of SPECT. PET scans are able to detect glucose metabolism in brain cells as well as deposits of beta-amyloid plaques and tau proteins using specific radiopharmaceuticals. Multiple clinical trials are being conducted with these specific markers.[24] However, high cost, limited availability in most countries, and the need to rely on radioactive isotopes with a short or ultra-short half lives have limited the use of PET scans as a screening method on asymptomatic patients.[11]

Although PET and SPECT scans use different tracers and instruments, the principles of interpretation and underlying neurobiological processes are similar. There is a confirmed association between perfusion SPECT results and PET results, 
Table 1: Comparison of cerebral perfusion SPECT results and presence or absence of ApoE e4 in patients and family members

\begin{tabular}{|c|c|c|c|c|c|}
\hline \multirow[b]{2}{*}{ Group } & \multirow{2}{*}{\multicolumn{2}{|c|}{$\begin{array}{c}\text { Cerebral SPECT } \\
\text { result }\end{array}$}} & \multicolumn{3}{|c|}{ ApoE e4 } \\
\hline & & & $\begin{array}{l}\text { ApoE e4 } \\
\text { Positive }\end{array}$ & $\begin{array}{l}\text { ApoE e4 } \\
\text { Negative }\end{array}$ & Total \\
\hline \multirow{10}{*}{$\begin{array}{l}\text { Alzheimer } \\
\text { patients }\end{array}$} & \multirow{2}{*}{$\begin{array}{l}\text { Typical AD } \\
\text { pattern }\end{array}$} & $\mathrm{n}$ & 52 & 16 & 68 \\
\hline & & $\%$ & 76.5 & 23.5 & 100 \\
\hline & \multirow{2}{*}{$\begin{array}{l}\text { Minimal changes } \\
\text { in perfusion }\end{array}$} & $\mathrm{n}$ & 5 & 6 & 11 \\
\hline & & $\%$ & 45.5 & 54.5 & 100 \\
\hline & \multirow{2}{*}{$\begin{array}{l}\text { Focal } \\
\text { hypoperfusion }\end{array}$} & $\mathrm{n}$ & 0 & 5 & 5 \\
\hline & & $\%$ & 0 & 100 & 100 \\
\hline & \multirow{2}{*}{$\begin{array}{l}\text { Frontal } \\
\text { hypoperfusion }\end{array}$} & $\mathrm{n}$ & 0 & 3 & 3 \\
\hline & & $\%$ & 0 & 100 & 100 \\
\hline & \multirow{2}{*}{ Normal perfusion } & $\mathrm{n}$ & 1 & 0 & 1 \\
\hline & & $\%$ & 100 & 0 & 100 \\
\hline \multirow{4}{*}{$\begin{array}{l}\text { First-degree } \\
\text { relatives }\end{array}$} & \multirow{2}{*}{$\begin{array}{l}\text { Minimal changes } \\
\text { in perfusion }\end{array}$} & $\mathrm{n}$ & 6 & 0 & 6 \\
\hline & & $\%$ & 100 & 0 & 100 \\
\hline & \multirow{2}{*}{ Normal perfusion } & $\mathrm{n}$ & 9 & 25 & 34 \\
\hline & & $\%$ & 26.5 & 73.5 & 100 \\
\hline \multirow{2}{*}{ Total } & & $\mathrm{n}$ & 73 & 55 & 128 \\
\hline & & $\%$ & 57 & 43 & 100 \\
\hline
\end{tabular}

AD: Alzheimer disease ApoE e4: APOE genotype

SPECT: Single photon emission computed tomography

and in degenerative diseases, the two have shown links between cerebral blood flow and metabolism.[11] Regional cerebral blood flow changes are an indirect manifestation of changes in oxygen use and metabolism; therefore, SPECT scans can identify patterns that are repeated in PET scans. SPECT scans also have the added advantage of being cheaper and more widely available.[11]

Cuba's Ministry of Public Health has recently outlined a plan to optimize medical equipment in the country, increasing availability of cerebral SPECT tests and facilitating use of the perfusion test to be used in clinical practice. However, as far as we know, ours is the first study in Cuba related to cerebral SPECT tests on AD. SPECT not only evaluates cerebral blood flow, but also provides valuable information to support diagnosis in early stages of $A D$ and provides a useful tool for minimally invasive research on human cognition.[12,13]

This study describes the results of evaluating patients with $A D$ and their relatives using cerebral SPECT tests; shows the usefulness of this technique in diagnosis, progression, and differential diagnosis of the patients; provides information about usefulness of SPECT tests for studying first-degree relatives; and compares the SPECT results with clinical evaluation and ApoE e4 tests.

AD Patient group Characteristics were similar to those reported in other Cuban studies of AD patients. In our study, the mean age was $\geq 65$ years, and participants were predominantly women. Many studies show a greater prevalence of $A D$ in women and show that most long-term caregivers of patients are women, which indicates that the disease doubly affects women, who therefore require greater care and support.[2,4]

Most patients evaluated were white, which is similar to studies by other authors that report lower prevalences of AD in persons of African descent.[2] Ethnicity is also related to predispositions for cognitive disorders, and ApoE e4 has been shown to vary based on ethnicity, with lower expression in persons of African descent.[2]

We found three AD risk factors—diabetes mellitus, dyslipidemia and high blood pressure-in a high percentage of patients, similar to findings of other authors who posit that risk factors associated with heart disease and stroke can also increase AD risk.[27] They argue that high blood pressure can damage blood vessels in the brain, resulting in abnormalities in regions important for decision-making, memory and verbal skills, therefore affecting AD progression.[27] These authors also suggest that high cholesterol can inhibit the blood's ability to eliminate unwanted proteins (beta-amyloid plaques and tau) from the brain. Additionally, growing evidence supports a link between $A D$ and type 2 diabetes, since higher glucose levels in the blood can damage the brain and contribute to the $A D$ progression.[27]

A high percentage of patients had a family history of AD. Studies have shown that persons have a greater chance of $A D$ when their father, mother, brother or sister has had the disease. [28] The risk increases if more than one relative has had the disease. When diseases such as AD tend to recur in families, environmental as well as hereditary factors may be important. [28]

Cerebral SPECT images showed a typical AD pattern in a high percentage of patients (77\%). A lower proportion of patients showed patterns consistent with cerebrovascular disease and frontal dementia, and in one patient the cerebral perfusion result was normal. These results confirm the value of SPECT for supporting $A D$ diagnosis generally and for establishing a differential diagnosis between dementia, depressive disorders, psychiatric disorders and other diseases that could be initially confused with AD.[29-31]

SPECT also helps classify patients based on disease progression stages, identify patients' functional status, and thus evaluate possible interventions and drug therapies. While disease-stage classification reported by medical orders sent to nuclear medicine usually matched SPECT findings, a number of patients $(n=25)$ were diagnosed in a different stage based on imaging results. Most of them were in the initial disease stage, when intervention to slow progression is more useful.

Many studies conducted internationally also show that SPECT brain imaging has become a valuable tool for evaluating dementia,[29-32] with the aim of better understanding functional impairments associated with the disease and improving diagnostics. The insidious onset of AD is often confused with normal aging processes. In these stages, the SPECT technique plays a fundamental role.[12,13,29-31]

SPECT findings characteristic of $A D$ are bilateral temporalparietal hypoperfusion with limited participation in sensorymotor and occipital regions. This perfusion pattern can distinguish $A D$ patients from those with normal results, with a sensitivity of $70 \%-100 \%$, a specificity of $87 \%-100 \%$, and a diagnostic confidence of $98 \%$.[13] In advanced stages, in 
addition to temporal-parietal hypoperfusion, blood flow is reduced in the frontal, parietal and occipital cortex areas.[13]

Some 25 years ago, McMurdo used SPECT brain imaging to assess 26 patients with a clinical diagnosis of AD: 15 showed bilateral temporal-parietal hypoperfusion, 4 normal perfusion, 4 signs of ischemic episodes, and 3 frontal hypoperfusion with normal perfusion of the temporal-parietal cerebral cortex.[32] These results were similar to our study findings.

Other research in $A D$ patients has revealed an association between cerebral blood flow patterns and the histopathological findings typical of the disease. Authors of a prospective study estimated the predictive value of SPECT in AD diagnosis and found that a patient with memory loss and a normal SPECT has a $19 \%$ probability of developing $A D$. In comparison, the probability of developing $A D$ in patients with memory loss and bilateral temporal-parietal hypoperfusion increases to $82 \%$. Patients without perfusion defects in the SPECT have a very low probability of getting AD.[29]

Several studies have used SPECT for differential diagnosis in dementia and have described some characteristic perfusion patterns. Dementia of vascular origin shows single or multiple areas of hypoperfusion with wedge-shaped or semicircular appearances in any region of the cerebral cortex. In Parkinson disease, the results are variable as cerebral regional blood flow changes are based on L-Dopa levels and on the presence or absence of dementia (and, if present, its severity). Early stages exhibit hypoperfusion in the caudate nuclei and thalamus, which, among other areas, are involved in disease progression. Studies have described hypoperfusion of the basal ganglia, specifically in the caudate nuclei, in patients with Huntington disease. Patients with Creutzfeldt-Jakob disease exhibit cortical hypoperfusion of the frontal and parietal lobes. Patients with depression show decreased cerebral blood flow in the prefrontal cortex and in the limbic and paralimbic systems.[29]

First-degree relatives with normal cognition Several general characteristics of this group are similar to those of the patient group. The mean age in this case was $<65$, which was expected, since the group included the children of some study patients. These results once again show the effect of age on symptom onset and imply that cerebral perfusion assessment could assist with early detection.

Like the patient group, this group was predominantly women. The fact that many patients arrived with their female caregivers (relatives who also participated in the study) could explain this finding. Due to family connections with the patients, participants in this group were predominantly white. The most common atherogenic risk factors were also diabetes, dyslipidemia, and hypertension, but in a smaller percentage than the patient group.

Approximately $15 \%$ of the relatives showed changes in cerebral perfusion consistent with initial AD stages. Tests confirmed that $100 \%$ of these subjects had positive ApoE e4, which increases risk. These results enabled early screening of a group with a high probability of developing $A D$, who can then be provided with early clinical and therapeutic support to slow the onset of disease.
SPECT brain imaging and ApoE e4 There was a strong association between SPECT results and presence or absence of ApoE e4 for the 128 study subjects (Table 1 ). More than $70 \%$ of AD patients with typical AD patterns in the cerebral SPECT had a positive ApoE e4, which matched reports by other authors.[16] All the relatives with changes in cerebral perfusion had positive ApoE e4.

For years, the e4 allele of ApoE has been associated with increased risk of dementia. The ApoE gene seems to be a risk factor for late-onset $A D$. There are three forms of this gene: ApoE e2, ApoE e3 and ApoE e4. Even though inheriting ApoE e4 increases AD risk, APO e2 provides substantial protection against the disease. Some research focuses on the association between these two forms of ApoE and Alzheimer disease.[16,33]

Previous studies confirm that the ApoE e4 allele's involvement in cerebral blood flow may have therapeutic implications for AD patients. Although presence of the ApoE e4 allele increases $A D$ risk and decreases the mean age of onset, the association between positive ApoE e4 and cerebral blood flow is disputed. Some authors suggest that this association may depend on the patient's age and AD stage.[34]

This study found an association between presence of ApoE e4 and decreased cerebral perfusion, but additional studies are needed on potential associations between cerebral blood flow, ApoE, vascular risk factors, and neuroimaging markers of cerebrovascular disease to provide more information about ApoE interaction and neurovascular changes in brain function in older adults at risk for dementia.

Despite the limitations of this study-small sample size, lack of comparison with anatomic and metabolic imaging results such as MRI and PET, and lack of a control group of healthy persons properly balanced regarding age and other relevant covariates-the research is important because this is the first time that a group of patients with $A D$ and first-degree relatives in a community have been jointly evaluated in Cuba using SPECT and the ApoE e4 test. The study showed the usefulness of cerebral SPECT, which is not often used to evaluate AD patients in our setting and revealed the usefulness in patients and populations with identified risk factors (first-degree relatives with NC who are ApoE e4 positive) for timely diagnosis and subsequent intervention strategies at the primary care level.

\section{CONCLUSIONS}

The cerebral perfusion test allowed us to confirm the diagnosis of Alzheimer disease, classify the disease stage, and differentiate between the types of dementia. The SPECT brain imaging showed perfusion changes in several asymptomatic first-degree relatives with positive ApoE e4, which could be predictors of disease. The technique was useful for evaluating both patients and relatives, who received an early warning of their risk of developing the disease.

\section{ACKNOWLEDGMENTS}

We conducted this study as part of a project with the Cuban Agency of Nuclear Energy and Advanced Technology (AENTA) program: PNUOLU/3-1/1/2019-2020: "Developing skills in nuclear medicine departments for clinical use of functional neuroimaging in Alzheimer's disease." - 1 - 


\section{REFERENCES}

1. Harvard Health. Recognizing Alzheimer's disease. Early Warning Signs and Diagnosis [Internet]. Santa Monica: Help Guide.org; 2020 [cited 2020 Apr 28]; [about 9 p.]. Available at: https:// www.helpguide.org/harvard/recognizing-and -diagnosing-alzheimers.htm

2. Llibre Guerra JJ, Díaz Marante JP, Rodríguez Salgado AM, Peñalver Al, Guartazaca Guerrero EP, Rousseaux Mola E, et al. Determinantes del estado de salud de la población y su influencia en el desarrollo de los trastornos cognitivos. Rev Cubana Salud Pública. 2018 Jan-Mar;44(1):141-52. Spanish.

3. National Medical Records and Health Statistics Division (CU). Anuario Estadístico de Salud 2019 [Internet]. Havana: Ministry of Public Health (CU); 2019 [cited 2020 May 21]. p. 39-43. Available at: https://files.sld.cu/bvscu ba/files/2020/05/Anuario-Electr\%c3\%b3nicoEspa\%c3\%b1ol-2019-ed-2020.pdf. Spanish.

4. Llibre Rodríguez JJ. Envejecimiento y demencias: implicaciones para la comunidad científica la salud pública y la sociedad cubana. Rev An Acad Ciencias Cuba. 2012;2(2):1-18. Spanish.

5. Romero Cabrera AJ, Fernández Casteleiro E, López Argüelles J, Suz Piña JD, Cordero Jiménez JR. Actualización en diagnóstico y manejo de las demencias. Aportes prácticos en nuestro contexto. Rev Finlay [Internet]. 2012 [cited 2020 May 8];2(1):76-87. Available at: http://revfinlay. sld.cu/index.php/finlay/article/view/76Quijano. Spanish.

6. Alzheimer's Disease International. World Alzheimer Report 2015. The Global Impact of Dementia. An analysis of prevalence, incidence, cost and trends [Internet]. London: Alzheimer's Disease International; 2015 [cited 2020 May 8]. 82 p. Available at: https://www.alz.co.uk/ research/world-report-2015

7. Llibre Rodríguez JJ, Gutiérrez Herrera RF. Demencias y enfermedad de Alzheimer en América Latina y el Caribe. Rev Cubana Salud Pública. 2014;40(3):378-87. Spanish.

8. López-Álvarez J, Agüera-Ortiz LF. Nuevos criterios diagnósticos de la demencia y la enfermedad de Alzheimer: una visión desde la psicogeriatría Psicogeriatría. 2015 Mar;5(1):3-14. Spanish.

9. Rojo Martínez E. Enfermedad de Alzheimer. Nuevos criterios diagnósticos e implicaciones en la práctica clínica. An Real Acad Med Cir Vall. 2014;51:67-76. Spanish.

10. Dubois B, Feldman HH, Jacova C, Dekosky ST, Barberger-Gateau P, Cummings J, et al Research criteria for the diagnosis of Alzheimer's disease: revising the NINCDS-ADRDA criteria Lancet Neurol. 2007 Aug;6(8):734-46.

11. Jiménez JF, Carril Carril JM. La neuroimagen molecular en las demencias degenerativas. Rev Española Med Nucl Imagen Mol. 2013 Sep-Oct;32(5):301-9. Spanish.

12. Juni JE, Waxman AD, Devous MD, Tikosfky RS, Ichise M, Van Heertum RL, et al. Procedure Guideline for Brain Perfusion SPECT Using 99mTc Radiopharmaceuticals 3.0*[Internet]. Virginia: Society of Nuclear Medicine and Molecular Imaging; 2009 [cited 2020 Apr 28]. 5 p. Available at: https://s3.amazonaws.com/rdcms-snmmi/files/ production/public/docs/Brain_SPECT_Guideline 2003.pdf

13. Rojas G, Ladrón de Guevara D, Jaimovich R. Neuroimágenes en demencias. Rev Med Clin Condes. 2016;27(3):336-56. Spanish.

14. Teipel S, Drzezga A, Grothe MJ, Barthel H, Chételat $\mathrm{G}$, Schuff $\mathrm{N}$, et al. Multimodal imaging in Alzheimer's disease: validity and usefulness for early detection. Lancet Neurol. 2015 Oct;14(10):1037-53.

15. Narayanan L, Murray AD. What can imaging tell us about cognitive impairment and dementia? World J Radiol. 2016 Mar 28;8(3):240-54.

16. Lopera F, Siegert I, Arcos-Burgos M, Ríos A. Alteraciones en el SPECT cerebral antes del inicio de la enfermedad de Alzheimer precoz producida por la mutación E280A de la PS1. Acta Med Colomb. 2000 May-Jun;25(3):144-9.

17. Bosch-Bayard R, Llibre-Rodríguez JJ, Fernández-Seco A, Borrego-Calzadilla C, CarrascoGarcía MR, Zayas-Llerena T, et al. Cuba's Ssrategy for Alzheimer disease and dementia syndromes. MEDICC Rev. 2016 Oct;18(4):9-13.

18. Morris JC. The Clinical Dementia Rating (CDR): current version and scoring rules. Neurology. 1993 Nov;43(11):2412-4

19. Williams MM, Storandt M, Roe CM, Morris JC. Progression of Alzheimer disease as measured by Clinical Dementia Rating sum of boxes scores. Alzheimers Dement. 2013 Feb;9(1 Suppl):S39-44.

20. Custodio N, Becerra-Becerra Y, Alva-Díaz C, Montesinos R, Lira D, Herrera-Pérez E, et al. Validación y precisión de la Escala de Deterioro Global (GDS) para establecer severidad de demencia en una población de Lima. Rev CES Med. 2017 Jan-Jun;31(1):14-26. Spanish.

21. Hixson JE, Vernier DT. Restriction isotyping of human apoli $E$ by gene amplification and cleavage with Hhal. J Lipid Res. 1990;31:545-8. Spanish.

22. European Association of Nuclear Medicine (EANM) [Internet]. Vienna: European Association of Nuclear Medicine (EANM); c2020. Publications. Technologist's guide. Brain Imaging; 2016 [cited 2020 May 11]. Available at: https://www .eanm.org/publications/technologists-guide/ brain-imaging/

23. Soricelli A. Nuclear medicine resources manual. IAEA [Internet]. Vienna: International Atomic Energy Agency; 2006 [cited 2020 May 11]. 532 p. Available at: https://www.iaea.org/publica tions/7038/nuclear-medicine-resources-manual

24. La Joie Renaud, Visani AV, Baker SL, Brown JA, Bourakova Viktoriya, Cha J. Prospective longitudinal atrophy in Alzheimer's disease correlates with the intensity and topography of baseline tauPET. Sci Translat Med. 2020 Jan 1;12(524):5732. DOI: 10.1126 / scitranslmed.aau5732.

25. Ecuador Ministry of Health, Health Sector Stratetig Development Plan, Department of Health Economics Estudio de costos del equipo de diagnóstico PET-CT [Internet]. Washington, D.C.: Pan American Health Organization, RedETSA; 2012 [cited 2020 May 11]. Available at: https://sites. bvsalud.org/redetsa/brisa/resource/?id=biblioref .referencesource.905780. Spanish

26. Hlatky MA, Shilane D, Hachamovitch R, DiCarli MF; SPARC Investigators. Economic outcomes in the study of myocardial perfusion and coronary anatomy imaging roles in coronary artery disease registry. J Am Coll Cardiol. 2014 Mar 18;63(10):1002-8. DOI:10.1016/j.jacc .2013.11.038.

27. Santos CY, Snyder PJ, Wu WC, Zhang M, Echeverría A, Alber J. Pathophysiologic relationship between Alzheimers's disease, cerebrovascular disease, and cardiovascular risk: a review and synthesis. Alzheimeers Dement (Amst). 2017 Feb 9;7:69-87.

28. Padrón Pérez N, Gra Menéndez S, Llibre Rodríguez JJ. Presenilinas, Apo E y Enfermedad de Alzheimer. Rev Cubana Invest Bioméd. 2002 Oct-Dec;21(4):262-9. Spanish

29. Castañeda M, García JC, García JA, Gutierrez LM, Ostrosky F. Actualización por temas. SPECT cerebral y enfermedad de Alzheimer: una revisión. Salud Mental. 2000 Feb;23(1):39-45. Spanish

30. Valotassiou V, Malamitsi J, Papatriantafyllou J, Dardiotis E, Tsougos I, Psimadas D, et al. SPECT and PET imaging in Alzheimer's disease. Ann Nucl Med. 2018 Nov;32(9):583-93.

31. Yeo JM, Lim X, Khan Z, Pal S. Systematic review of the diagnostic utility of SPECT imaging in dementia. Eur Arch Psychiatry Clin Neurosci. 2013 Oct;263(7):539-52.

32. McMurdo M, Grant DJ, Kennedy NS, Gilchrist J, Findlay D, McLenna JM. The value of HMPAO SPECT scanning in the diagnosis of early Alzheimer's disease inpatients attending a memory clinic. Nucl Med Commun. 1994 Jun;15(6):405-9.

33. Samper Noa JA, Llibre Rodríguez JJ, Sánchez Catases C, Sosa Pérez S. El deterioro cognitivo leve. Un paso antes de la enfermedad de Alzheimer. Rev Haban Cienc Méd. 2011 Jan -Mar;10(1):27-36. Spanish.

34. Wierenga CE, Clark LR, Dev SI, Shin DD, Jurick $\mathrm{SM}$, Rissman RA, et al. Interaction of age and APOE genotype on cerebral blood flow at rest. J Alzheimers Dis. 2013;34(4):921-35.

\section{THE AUTHORS}

Yamilé Peña-Quián (corresponding author: yamilepq@infomed.sld.cu; yamicuba2014@ gmail.com), physician specializing in internal medicine and nuclear medicine, with a doctorate in medical sciences. Senior researcher, Clinical Research Department, Isotope Center, Havana, Cuba. https://orcid.org/0000-0002 $-6598-6099$

Saily Sosa-Pérez, internist with a master's degree in satisfactory longevity. Adjunct researcher, Artemisa Provincial Health Department Comprehensive Memory Disorder Com- 
munity Care Service, Artemisa, Cuba. https:// orcid.org/0000-0002-8221-332X

Juan Felipe Batista-Cuéllar, physician specializing in internal medicine and nuclear medicine. Clinical Research Department, Isotope Center, Havana, Cuba. https://orcid.org/0000-0001 $-9420-4255$

Chryslaine Rodríguez-Tanty, chemist with a doctorate in organic chemistry. Senior researcher and head of the Experimental Neuroscience
Department, Cuban Neuroscience Center, Havana, Cuba. https://orcid.org/0000-0002-3958 $-183 X$

Leonel Alberto Torres-Aroche, nuclear physicist with a doctorate in pharmaceutical sciences. Senior researcher, Clinical Research Department, Isotope Center, Havana, Cuba. https:// orcid.org/0000-0001-5019-1915

Elvia Luz-Sánchez, nurse with a master's degree in intensive care. Clinical Research
Department, Isotope Center, Havana, Cuba. https://orcid.org/0000-0001-6870-5339

Susana Romero-Collado, nurse with a master's degree in intensive care Clinical Research Department, Isotope Center, Havana, Cuba. https://orcid.org/0000-0003-2616-8349

Submitted: June 22, 2020

Approved for publication: January 14, 2021

Disclosures: None 


\title{
Non-Alcoholic Fatty Liver Disease in Cuba
}

\author{
Marlen I. Castellanos-Fernández MD PhD, Eduardo Crespo-Ramírez MD MS, Sergio del Valle-Díaz MD MS, \\ Eduardo Barreto-Suárez MD MS, Javier O. Díaz-Elías MD MS, Lorenzo Santaló-Rodríguez MD, Sahili Corrales-Alonso MD, \\ Ignacio Morales-Martínez MD, Elisa Cedeño-Ramírez MD, Teresita Pérez-González MD, Sila M. González-Suero MD MS, \\ Caridad Ruenes-Domech MD MS, Mirtha Infante-Velázquez MD PhD, Susana Á. Borges-González MD MS, \\ Angela Elvírez-Gutiérrez MD MS, Sacha Lazo-del Vallín MD MS, Oscar M. Villa-Jiménez MD MS, \\ Liana M. Labrada-Moreno MD MS
}

\begin{abstract}
INTRODUCTION With a global adult prevalence of $24 \%$, nonalcoholic fatty liver disease is a global health problem that parallels the worldwide increase of obesity. Its frequency, clinical characteristics and related diseases in Cuba remain unknown.

OBJECTIVE Describe the clinical characteristics, comorbidities and personal habits of patients with non-alcoholic fatty liver disease who are being treated in secondary and tertiary health facilities in seven Cuban provinces.

METHODS A cross-sectional, multicenter study was carried out in 6601 adults seen at gastroenterology outpatient clinics of nine hospitals in seven Cuban provinces from September 2018 through May 2019. Non-alcoholic fatty liver disease was diagnosed by abdominal ultrasound. The study included 1070 patients who met the diagnostic and study criteria and agreed to participate. Their personal habits and anthropometric and clinical characteristics, comorbidities and other aspects of their medical histories were recorded.
\end{abstract}

\section{INTRODUCTION}

Non-alcoholic fatty liver disease (NAFLD) includes a broad spectrum of metabolic damage associated with fatty deposits in the liver. Its diagnosis excludes other causes that may lead to steatosis, such as excessive alcohol consumption, viral infections, use of steatogenic drugs and/or hereditary disorders.[1]

NAFLD is generally diagnosed in one of three clinical scenarios: patients with abnormal liver enzymes, abnormalities in abdominal imaging or clinical characteristics associated with metabolic syndrome (MetS).[1-3] NAFLD has a diverse clinical presentation, and diagnosis is established when $>5 \%$ of liver cells are composed of fat. Although a liver biopsy remains the gold standard, noninvasive diagnosis of NAFLD can be carried out via liver imaging in most patients.[4] This clinical form is known as non-alcoholic fatty liver (NAFL), which, by definition, does not progress beyond the first stages of liver disease. Another form is non-alcoholic steatohepatitis accompanied by necroinflammation of hepatocytes with or without liver fibrosis, considered a type of progressive liver disease that leads to fibrosis in $41 \%$ of cases. Hepatocellular carcinoma is detected in $2 \%-3 \%$ of patients, with annual mortality rates estimated at 25.6 per 1000 population.[5,6]

\section{IMPORTANCE}

This is the first study of the frequency of non-alcoholic liver disease in Cuba, for which there were no national data available at the time this article was written.
RESULTS Of the 1070 participants, 60.7\% (649) were women. Participants' average age was 54.5 years and average body mass index was $30.5 \mathrm{~kg} / \mathrm{m} 2$. A total of $397(37.1 \%)$ were overweight and $574(53.6 \%)$ were obese, 945 (88.3\%) led a sedentary lifestyle, 564 (52.7\%) had high blood pressure, 406 (37.9\%) had lipid disorders and 301 (28.1\%) were diabetic. While 484 (45.2\%) of patients were asymptomatic, the most frequent clinical signs and symptoms were fatigue (262; $24.5 \%)$, dyspepsia $(209 ; 19.5 \%)$, abdominal pain $(306 ; 28.5 \%)$ and hepatomegaly (189; $17.7 \%)$. Liver cirrhosis was present in $37(3.5 \%)$ patients at the time of diagnosis. Family history of type 2 diabetes mellitus and obesity were identified in 391 (36.5\%) and 279 (26.1\%) of participants, respectively.

CONCLUSIONS Prevalence of non-alcoholic fatty liver disease in these Cuban patients coincides with that reported in the Caribbean region, which has high levels of obesity, overweight and sedentary lifestyles. Most were asymptomatic, female or had metabolism-related comorbidities such as high blood pressure, type 2 diabetes mellitus and dyslipidemia.

KEYWORDS Non-alcoholic fatty liver disease, overweight, obesity, type 2 diabetes mellitus, Cuba

The epidemic of chronic liver disease is related to the burden of NAFLD, itself associated with the global increase in obesity. $[7,8]$ An overall prevalence of $24 \%$ is reported globally with highest rates in the Middle East (32\%) and South America (31\%), followed by Asia (27\%) and Europe (23\%); it is less common in Africa (14\%).[8]

Since obesity is associated with presence and severity of NAFLD, it is useful to note that in $2016,39 \%$ of adults worldwide (39\% of men and $40 \%$ of women) were overweight, and some $13 \%(11 \%$ of men and $15 \%$ of women) were obese.[9] Prevalence of excess weight and obesity in Latin America is much higher (62.8\% in men and $59.8 \%$ in women), explaining why estimated NAFLD rates are increasing in this region. Based on obesity rates, it is estimated that NAFLD prevalence is $26 \%$ in Mexico and $15 \%-20 \%$ in Central America.[10-12]

There is a bidirectional association between NAFLD and the components of MetS, as the latter is frequent in NAFLD patients and MetS, in turn, increases risk for NAFLD. NAFLD has been reported in $22.5 \%$ of patients with type 2 diabetes mellitus (DM), in $51.3 \%$ of those who are obese, $42.5 \%$ of patients with MetS, $39.3 \%$ of hypertensive patients and $69.2 \%$ of those with hyperlipidemia.[4]

NAFLD prevalence is expected to increase, accompanying the upward trend of the global obesity epidemic and the increase observed in type 2 DM.[6] A number of MetS characteristics, particularly type $2 \mathrm{DM}$ and family history of MetS, are risk factors for NAFLD.[13] 
In Cuba, overweight and obesity are major health problems and their prevalence increased from 35.5\% in 1982 to $44.3 \%$ in 2012. [14] In 2010, the rates for high blood pressure (HBP) and type 2 DM were 202.7 and 40.4 per 1000 population, respectively. In 2019, these rates increased to 233 and 66.7.[15,16]

Post-mortem studies of 3317 persons who had been diagnosed with NALFD from 1991 to 2009 revealed that 53\% had simple hepatic steatosis, $44.2 \%$ steatohepatitis and $2.6 \%$ hepatic steatosis with fibrosis or cirrhosis, which highlights the impact this disease has on the liver. In this group, the main cause of death was coronary atherosclerosis.[17]

In Cuba, NAFLD is most often diagnosed in gastroenterology services and its current prevalence in the country is unknown. The purpose of our study was to describe the clinical characteristics at diagnosis, associated comorbidities and personal habits of NAFLD patients seen in secondary and tertiary health facilities in seven Cuban provinces.

\section{METHODS}

Design and sample A cross-sectional study was carried out from September 2018 through May 2019 in patients seen at gastroenterology outpatient services in nine Cuban hospitals in seven provinces. These services provided care and monitoring of patients with gastrointestinal, liver, biliary and pancreatic conditions who were referred from community-based polyclinics, family doctors or other specialists. NAFLD diagnosis was based on presence of hepatic steatosis in abdominal ultrasound (US) in the absence of known secondary causes of fat accumulation in the liver, in accordance with the criteria of the American Association for the Study of Liver Diseases.[1]

Personal and family medical history, personal habits, medications used at the time of recruitment and anthropometric data were obtained through a questionnaire developed for that purpose.

A total of 6601 patients seen in gastroenterology consultations during the study period were considered. Those who met NAFLD diagnostic and our own research criteria were included. Excluded were persons who did not want to participate and those who had other causes of chronic liver disease that can lead to steatosis (Figure 1). Specific traits that led to exclusion were: 1) Alcoholics or individuals who consume more than the maximum recommended weekly alcohol intake,[1] 2) individuals who suffered from chronic autoimmune or inherited liver diseases, 3) individuals who had a history of steatogenic drug use in the six months prior to recruitment date (corticosteroids, methotrexate, tetracycline, amiodarone, diltiazem or tamoxifen), 4) women who were pregnant, breastfeeding or taking hormonal contraceptives, 5) those diagnosed with an active malignant tumor and 6) individuals who tested positive for the surface antigen of the hepatitis B virus (HBV) or hepatitis C virus (HCV) antibodies. We included patients with a history of HCV infection when the viral load had remained negative for more than a year.

Patients were recruited consecutively during the study period, resulting in inclusion of 1070 persons: 420 men (39.3\%) and 650 women $(60.7 \%)$, with a median age of 55 years and age range 18 to 88 years.
Figure 1: Flow of patients in the study. Cuba, 2018-2019

Evaluated in clinic

September 2018 to May 2019

$$
\mathrm{n}=6601
$$

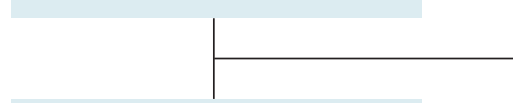

Excluded due to other causes of liver disease

Eligible with probable diagnosis of NAFLD $\mathrm{n}=1291$ $n=5310(80.4 \%)$

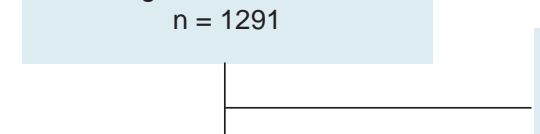

Refused to participate in the study $n=96(7.4 \%)$

Responded with the required data $\mathrm{n}=1070$

Didn't complete the evaluation $\mathrm{n}=125(9.7 \%)$

NAFLD diagnosis by abdominal US was defined by presence of liver homogeneous or heterogeneous hyperechogenicity (increased echogenicity with respect to the kidney parenchyma) and attenuation of the liver's deep structures (diaphragm, vessels, posterior segments). For US diagnosis of steatosis, longitudinal and transverse cuts were made with a low frequency (2.5-5 $\mathrm{MHz}$ ) convex probe. The following ultrasound scanners were used: Toshiba Aplio 300 (Toshiba Medical Systems Europe, The Netherlands), Aloka SSD-4000 (Hitachi Aloka Medical, Japan) and EPIQ 5 (Philips Ltd, UK). US was performed and diagnosis made by radiologists in all units participating in the study.

Sex, age, area of residence (urban or rural) and skin color (white, black, or mestizo) were recorded according to the classification of Cuba's National Statistics and Information Bureau (http://www .onei.gob.cu/).

Actual weight $(\mathrm{AW}, \mathrm{kg})$ and height $(\mathrm{cm})$ were measured at the time of study enrollment and body mass index (BMI) calculated. A BMI of $<18 \mathrm{~kg} / \mathrm{m}^{2}$ was considered underweight, $18-24.9 \mathrm{~kg} / \mathrm{m}^{2}$ normal weight, $25-29.9 \mathrm{~kg} / \mathrm{m}^{2}$ overweight and $\geq 30 \mathrm{~kg} / \mathrm{m}^{2}$ obese. Waist circumference was measured to ascertain central obesity, a condition associated with metabolic complications. Criteria of the National Cholesterol Education Program Adult Treatment Panel III (NCEP ATPIII) were used as reference points for waist circumference: $102 \mathrm{~cm}$ in men and $88 \mathrm{~cm}$ in women.[18] Anthropometric measurements were carried out during patient recruitment and doctor visits, according to methodology outlined for nutritional studies by the Nutrition and Food Hygiene Institute of Cuba.[19] A calculation was to determine ideal weight (IW), with IW $=0.75$ (height in $\mathrm{cm}-150$ ) +50 and was used to determine the difference between actual and ideal weight according to the expression IW $=(\text { AW-IW })^{\star} 100 / I W$.

Any medical history of interest was recorded: HBP, type 2 DM, hyperuricemia, dyslipidemia (high cholesterol and/or triglycerides), 
thyroid disease, myocardial infarction and cancer, as well as treatments for these conditions. Medical history considered in first-degree relatives were fatty liver, cirrhosis of the liver, type 2 DM, obesity and cancer.

Personal habits considered included smoking, degree of physical activity and alcohol consumption. These were categorized as follows:

Smoking Smoker: regular or occasional consumption of tobacco products; non-smoker: no consumption of tobacco products.

Physical activity Adapted from WHO criteria on physical activity. [20] Sedentary lifestyle: physical activity $<15$ minutes $<3$ times per week during the last quarter, or performing only everyday tasks (occupational activities, traveling, household chores and recreational activities). Moderate or intense physical activity: walking (30 minutes a day $\geq 5$ days a week), games, dancing, non-intense extra work, light weights $(\leq 20 \mathrm{~kg})$ or jogging, racing, aerobics, sports, intense work, heavy weights ( $\geq 20 \mathrm{~kg}$ ).

Alcohol consumption We used guidelines of the American Association for the Study of Liver Diseases and the National Institute on Alcohol Abuse and Alcoholism (USA) to define risks associated with alcohol consumption, as women who consume $\geq 7$ standard drink units and men who consume $\geq 14$ every week are at increased risk for alcohol-related problems.

Patients who had no symptoms and in which NAFLD was found incidentally by US ordered for other reasons, or because they had abnormal liver enzymes, were recorded as asymptomatic. Patients were recorded as symptomatic if they reported any symptoms usually linked to NAFLD such as: fatigue, chronic abdominal pain, myalgia and dyspepsia. Among the included signs detected during physical examination were hepatomegaly, xanthomas/xanthelasmas and signs of liver cirrhosis (noninvasive US diagnosis or presence of edema, ascites, splenomegaly, collateral circulation, jaundice, palmar erythema, telangiectasia, petechiae, ecchymosis).

In the initial patient recruitment consultation, blood pressure (BP) was measured and the average of the last two measurements from a total of three measurements, carried out in intervals of one minute with a mercury sphygmomanometer (Kindcare Medical System, China) were recorded. In accordance with the characteristics of the sample, $\geq 130 / 85 \mathrm{mmHg}$ was considered high, following the criteria of the American College of Cardiology, the American Heart Association (USA), and the working group for treatment of high blood pressure of the European Society of Cardiology and the European Society of Hypertension.[22,23]

Infection by hepatitis B and C viruses was ruled out by using an enzyme-linked immunosorbent assay (ELISA) kit (Ultra Micro Analytical System, SUMA, Tecnosuma International, Cuba) for the surface antigen of the hepatitis B virus (HBsAg), the hepatitis B core antibody (anti-HBc) and hepatitis $\mathrm{C}$ virus antibody (AcHCV).

To ensure consistency of information reported at participating sites, criteria unification workshops were held for researchers and guidelines were established for information collection and data entry in an Excel (Microsoft, USA) database designed for this purpose. The principal investigator at each center controlled the quality of data and standardization of procedures according to the established protocol.

Ethics The study was approved by the research ethics committees of Cuba's Gastroenterology Institute and of participating hospitals. Patients were provided with detailed information on study purposes, importance of their participation and benefits. There were no potential risks to patient health. All participants provided written informed consent. The information was kept confidential and in no case will participant identity be revealed.

Diagnostic tools were selected according to principles of maximum beneficence. They followed the Declaration of Helsinki's Good Clinical Practices guidelines[24] and the Guidelines of the Council for International Organizations of Medical Sciences.[25]

Patients who did not meet the selection criteria were informed of the reasons for their non-inclusion in the study and were sent to specialized clinics in each institution for monitoring and control. Benefits received by the patients included the diagnosis and treatment of diseases.

Statistical analysis Variables were processed in a database created in the statistical package for social sciences for Windows version 21.0 (IBM-SPSS, USA). Descriptive statistics, absolute and relative frequencies, averages and standard deviations and the difference of the average of waist circumference $(\mathrm{cm})$ with respect to the cutoff point in both sexes were calculated (confidence interval, 95\%).

\section{RESULTS}

Of the 1070 patients studied, $786(73.5 \%)$ resided in provinces in Cuba's western region, 169 (15.8\%) in the central region and 115 $(10.7 \%)$ in eastern Cuba; 650 participants (60.7\%) were women. NAFLD was diagnosed in $16.2 \%$ of all participants. The range of the frequency of patients with NAFLD among centers was $10.8 \%$ 19.5\% (Table 1).

Sociodemographic characteristics, personal habits and personal medical history of the patients revealed that sedentary lifestyle was a frequently observed phenomenon. HBP, dyslipidemia and type $2 \mathrm{DM}$ were the most frequent previous medical issues, followed by acute myocardial infarction, hyperuricemia, thyroid disease and cancer (Table 2).

Average BMI of participants was $30.5 \mathrm{~kg} / \mathrm{m}^{2}$, or grade I obesity. Distribution of BMI values is shown in Table 3 , where the high percentages of overweight and obesity (37.1\% and 53.6\%, respectively) are of particular note. Average waist circumference was $101.2 \mathrm{~cm}$ in men and $99 \mathrm{~cm}$ in women. Difference in average waist circumference $(\mathrm{cm})$ with respect to the cut-off point in both sexes was $-0.77(-1.9$ to $-0.4 ; p=0.208)$ in men and 11.05 (10.0 to $12.0 ; p<0.001$ ) in women, which implies that women had a rate of central obesity averaging $11 \mathrm{~cm}$ above the reference value for abdominal circumference, while men had a rate $0.7 \mathrm{~cm}$ below the reference value. Average excess weight of patients with respect to ideal weight was $36.3 \mathrm{~kg}$.

The most frequent symptoms and signs, blood pressure readings, and the proportion of patients with liver cirrhosis can be found 
Table 1: Total patients and study participants by center and province

\begin{tabular}{|c|c|c|c|c|}
\hline Province & Hospital & $\begin{array}{c}\text { Study } \\
\text { participants } \\
\text { (n) }\end{array}$ & $\begin{array}{c}\text { Total } \\
\text { patients } \\
\text { seen }(n)\end{array}$ & $\begin{array}{c}\text { Proportion } \\
\text { of NAFLD } \\
(\%)\end{array}$ \\
\hline Pinar del Río & $\begin{array}{l}\text { Abel Santamaría Cuadrado } \\
\text { Provincial Clinical-Surgical } \\
\text { Hospital }\end{array}$ & 301 & 1536 & 19.6 \\
\hline Santiago de Cuba & $\begin{array}{l}\text { Saturnino Lora Torres } \\
\text { Provincial Clinical-Surgical } \\
\text { Teaching Hospital }\end{array}$ & 115 & 970 & 11.9 \\
\hline Camagüey & $\begin{array}{l}\text { Manuel Ascunce Domenech } \\
\text { Provincial Clinical-Surgical } \\
\text { Teaching Hospital }\end{array}$ & 109 & 656 & 16.6 \\
\hline Matanzas & $\begin{array}{l}\text { Faustino Pérez Hernández } \\
\text { University Clinical-Surgical } \\
\text { Teaching Hospital }\end{array}$ & 60 & 432 & 13.9 \\
\hline Artemisa & $\begin{array}{l}\text { Iván Portuondo General } \\
\text { Teaching Hospital }\end{array}$ & 28 & 257 & 10.9 \\
\hline Villa Clara & $\begin{array}{l}\text { Celestino Hernández Robau } \\
\text { Provincial Oncology University } \\
\text { Hospital }\end{array}$ & 60 & 442 & 13.6 \\
\hline Havana & $\begin{array}{l}\text { Calixto García University } \\
\text { Clinical-Surgical Hospital }\end{array}$ & 99 & 652 & 15.2 \\
\hline Havana & $\begin{array}{l}\text { Manuel Fajardo Clinical- } \\
\text { Surgical Teaching Hospital }\end{array}$ & 45 & 310 & 14.5 \\
\hline Havana & Gastroenterology Institute & 253 & 1346 & 18.8 \\
\hline Total & & 1070 & 6601 & 16.2 \\
\hline
\end{tabular}

NAFLD: Non-alcoholic fatty liver disease

Table 2: Sociodemographic characteristics, personal habits and medical history of study participants

\begin{tabular}{|l|r|}
\hline Variable & \multicolumn{1}{c|}{$\begin{array}{c}\text { Total } \\
\mathbf{n}=1070\end{array}$} \\
\hline Age (years) (mean/SD) & $54.5(11.1)$ \\
\hline Skin color, $\mathbf{n}(\%)$ & $698(65.2)$ \\
White & $156(14.6)$ \\
Black & $216(20.2)$ \\
Mestizo & \\
\hline Area of residence, $\mathbf{n}(\%)$ & $1010(94.4)$ \\
\hline Urban & $60(5.6)$ \\
\hline Rural & $183(17.1)$ \\
\hline Smokers, $\mathbf{n}$ (\%) & \\
\hline Physical activity, $\mathbf{n}(\%)$ & $945(88.3)$ \\
\hline Sedentary & $125(11.7)$ \\
\hline Moderate or Intense & \\
\hline Personal medical history, $\mathbf{n}(\%)$ & $564(52.7)$ \\
\hline High blood pressure & $406(37.9)$ \\
\hline Dyslipidemia & $301(28.1)$ \\
\hline Diabetes mellitus & $191(17.9)$ \\
\hline Myocardial Infarction & $142(13.3)$ \\
\hline Hyperuricemia & $59(5.5)$ \\
\hline Thyroid Diseases & $26(2.4)$ \\
\hline Cancer & \\
\hline
\end{tabular}

in Table 3, in which fatigue, dyspepsia, abdominal pain, and hepatomegaly stand out due to their higher frequencies. Nearly half of the patients were asymptomatic.

The most frequent conditions observed in the patients' family medical history were type $2 \mathrm{DM}$, obesity and cancer, with notably high values for the first two (Table 4).

\section{DISCUSSION}

This is the first study on the disease conducted with a large number of patients and in several hospitals in three regions of Cuba. It fills a gap in knowledge on NAFLD frequency in Cuba, although smaller-sample studies have been published.[26-30]

Despite the fact that this study was carried out in each patient's gastroenterology department, which allows for standardized measuring conditions, its results do not differ from those reported in the literature. Fleischman[31] carried out a multi-ethnic study on atherosclerosis (MESA) in a Hispanic population in the United States, finding a NAFLD prevalence of 33\% in those of Mexican descent, $16 \%$ in those of Dominican descent and $18 \%$ in those of Puerto Rican descent, indicating this disease is common among Hispanics in the USA. Various Latin American countries have reported relatively high rates: Brazil (18.0\%-35.2\%), Chile (23\%) and Colombia (26.6\%).[11,32-36] The proportion of patients in this study with NAFLD as measured by center and by province did not exceed $20 \%$.

Prevalence varies according to study method, population characteristics, presence of risk factor, and area of residence, among other factors. NAFLD frequency detected in this study by US was similar to estimates based on obesity prevalence, which are between $15 \%$ and $20 \%$ for Central America and the Caribbean.[11]

The most recent survey on risk factors and non-communicable diseases in Cubans[37] revealed smoking frequency at 23.7\%; excess weight and obesity at $29.8 \%$ and $13.7 \%$, respectively; sedentary lifestyle with no physical activity at $40.4 \%$; and prevalence of chronic diseases-such as HBP, type 2 DM and dyslipidemia-at $30.9 \%, 10 \%$ and $4.6 \%$, respectively. Average BMI and waist circumference was $24.5 \mathrm{~kg} / \mathrm{m}^{2}$ and $85.1 \mathrm{~cm}$ in Cuban men and $25.5 \mathrm{~kg} / \mathrm{m}^{2}$ and $81.8 \mathrm{~cm}$ in women.

In our study, the proportion of smokers was lower, and the relative frequencies of excess weight and obesity were between two and three times higher than those found in the national survey. The higher levels of central obesity and greater presence of metabolic comorbidities are distinctive characteristics that were expected in the sample with NAFLD, which is related to metabolic syndrome.[13] It should be noted that excess weight and obesity in the Cuban population is rising and is already a health problem in the country.[38]

The effects of tobacco on NAFLD progression is a source of controversy. A systematic review showed that both active and passive smoking are associated with this disease, but the mechanisms of this association are unknown because physical activity, diet type, caffeine consumption and some socio-economic factors act as potential confounding variables.[39] The average prevalence of smoking in the Cuban population is higher than that detected in this study.[37] 
Table 3: Anthropometric measurements, clinical signs and symptoms of study participants

\begin{tabular}{l|r}
\hline Variable & \multicolumn{1}{|c}{ Total } \\
$\mathbf{n}=1070$
\end{tabular}

Table 4: Family medical history of study participants

\begin{tabular}{l|r}
\hline Variables & \multicolumn{1}{|c}{$\mathbf{n}(\%)$} \\
\hline Diabetes & \\
Yes & $391(36.5)$ \\
No & $619(57.9)$ \\
Unknown & $60(5.6)$ \\
\hline Obesity & \\
Yes & $279(26.1)$ \\
No & $731(68.3)$ \\
Unknown & $60(5.6)$ \\
\hline Cancer & \\
Yes & $210(19.6)$ \\
No & $800(74.8)$ \\
Unknown & $60(5.6)$ \\
\hline NAFLD & \\
Yes & $105(9.8)$ \\
No & $905(84.6)$ \\
Unknown & $60(5.6)$ \\
\hline Cirrhosis & \\
Yes & $57(5.3)$ \\
No & $953(89.1)$ \\
Unknown & $60(5.6)$ \\
\hline
\end{tabular}

NAFLD: non-alcoholic fatty liver disease

The sedentary lifestyle of our study participants was more than twice the rate reported in the national survey (38.3\%),[37] and in Latin America and the Caribbean, (39.1\%)[14,40] although the rate of sedentary lifestyles among Cubans is one of the highest in the world.[37]
Globally, differences have been reported between men and women in terms of prevalence, risk factors, fibrosis, disease severity and symptoms associated with NAFLD. Being male is considered a NAFLD risk factor and prevalence as great as twice that for women has been reported.[1,2,41] However, there is little consistency in the evidence since other studies show an increased risk for women,[42-44] consistent with our study's finding that NAFLD was more frequent in women than in men.

When the analysis is adjusted for age, studies reveal NAFLD prevalence and incidence is greater in women after menopause because body fat is redistributed toward the abdomen due to loss of estrogen's protective effects, a factor that favors appearance of MetS.[43-45]

Although it is known that insulin resistance and obesity are associated with the metabolic alterations characteristic of NAFLD,[46] some studies have reported a relatively high prevalence of NAFLD in lean people, particularly in young women, who are very unlikely to have insulin resistance and hypercholesterolemia and who have a lipid profile that is different from that of overweight or obese individuals. NAFLD frequency in lean patients in our study (9.2\%) is less than the $18 \%$ reported by Younossi.[47] This is a potential topic for further research.

NAFLD is considered a polygenic disease and an inherited condition involving genetic variants related to disease progression.[48,49] Higher frequencies of NAFLD have been reported in the Hispanic population than in Afro-descendants or indigenous Americans. These differences seem to be associated with genetic variations such as the patatin-like phospholipase domain-containing protein 3 gene (PNPLA-3), which is more frequent in Hispanics. These variations increase the risk of disease progression in persons who do not have metabolic syndrome, regardless of their dietary patterns and metabolic traits.[50] So far, there have been no genetic studies of this type in Cuba and skin color has proven to be unreliable as a proxy for these genetic variations, given the broad admixture in the Cuban population.[51,52]

It has been shown that family history of type $2 \mathrm{DM}$ is closely linked to NAFLD, with a high risk of nonalcoholic steatohepatitis (OR: 1.51, 95\% $\mathrm{Cl}=1.01-2.25 ; \mathrm{p}=0.04$ ) and fibrosis (OR: $1.49,95 \% \mathrm{Cl}=1.01-2.20$; $p=0.04),[13]$ which may explain the high frequency of type $2 \mathrm{DM}$ in family medical histories of patients with NAFLD. This should be taken into account when conducting population-based studies.

Liver cirrhosis was diagnosed in a proportion of patients that is alarming if we bear in mind that cirrhosis was not the main subject of this investigation. A large proportion of patients with cryptogenic cirrhosis presented frequent metabolic risk factors that, in most cases, suggested undiagnosed non-alcoholic steatohepatitis that developed undetected over time, and also that the diagnosis of cirrhosis was established at advanced stages.[53]

A multicenter study involving several countries, including Cuba, showed that patients with cirrhosis due to NAFLD (indicative of severe fibrosis) suffer complications related to chronic liver failure, while those with less severe fibrosis present with other conditions such as cancer (not liver cancer) and vascular complications. [54] Studies are needed to identify predictors of liver fibrosis and progression to cirrhosis in Cuban NAFLD patients who have conditions characteristic of metabolic syndrome. 
It was not possible to assess the reliability of measurements in the NAFLD ultrasound diagnosis, as they were carried out at a single point in time, by a single observer (a radiologist) and in differing clinical scenarios, using dissimilar ultrasound equipment. However, in order to minimize bias, standardized diagnostic criteria for this disease were used,[1] and the examination was carried out by the most highly-skilled radiologist in each center. The fact that $17 \%$ of eligible patients with a probable diagnosis of NAFLD were excluded from the study (either because they refused to participate or failed to complete the required information), may represent an underestimation bias of disease frequency. Regions within the country could not be compared and results cannot be generalized to the whole Cuban population, since for practical reasons most participants were recruited in western Cuba. However, outcomes are important as a first approach to the study of this disease in the country.

\section{CONCLUSIONS}

The proportion of NAFLD in these Cuban patients coincides with that reported in the wider Caribbean, which has a high frequency of obesity, overweight and sedentary lifestyles. Most NAFLD patients were asymptomatic, female or had metabolic-related comorbidities such as HBP, type 2 DM and dyslipidemia. In addition, type 2 DM and obesity were frequent in these patients' family medical histories.

\section{ACKNOWLEDGMENTS}

The authors thank Armando Borrego-Rivero and Rosaura PichsBrito, both biostatisticians at the Medical Records Department of the Gastroenterology Institute, for their administrative assistance. - 1h

\section{REFERENCES}

1. Chalasani N, Younossi Z, Lavine JE, Charlton M, Cusi K, Rinella M, et al. The diagnosis and management of nonalcoholic fatty liver disease: Practice guidance from the American Association for the Study of Liver Diseases. Hepatology [Internet]. 2018 Jan [cited 2019 Feb 19];67(1):328-57. Available at: https://doi.org/10.1002/hep.29367

2. European Association for the Study of the Liver (EASL); European Association for the Study of Obesity Diabetes (EASO). EASL-EASDEASO Clinical Practice Guidelines for the management of non-alcoholic fatty liver disease. Obes Facts [Internet]. 2016 May [cited 2020 Feb 19];9(2):65-90. Available at: https://doi .org/10.1159/000443344

3. Patel V, Sanyal AJ, Sterling R. Clinical presentation and patient evaluation in nonalcoholic fatty liver disease. Clin Liver Dis. 2016 May;20(2):277-92.

4. Cotter TG, Rinella M. Nonalcoholic fatty liver dis ease 2020: The State of the Disease. Gastroen terology. 2020 May;158(7):1851-64

5. Younossi ZM, Koenig AB, Abdelatif D, Faze Y, Henry L, Wymer M. Global epidemiology of nonalcoholic fatty liver disease-meta-analytic assessment of prevalence, incidence, and outcomes. Hepatology [Internet]. 2016 Jul [cited 2020 Aug 26];64(1):73-84. Available at: https:// doi.org/10.1002/hep.28431

6. Paul S, Davis AM. Diagnosis and management of nonalcoholic fatty liver disease. JAMA. 2018 Dec 18;320(23):2474-5.

7. Loomba R, Sanyal AJ. The global NAFLD epidemic. Nat Rev Gastroenterol Hepatol. 2013 Nov;10(11):686-90.

8. Younossi Z, Anstee QM, Marietti M, Hardy T, Henry L, Eslam M, et al. Global burden of NAFLD and NASH: trends, predictions, risk factors and prevention. Nat Rev Gastroenterol Hepatol [Internet]. 2018 Jan;15(1):11-20. Available at: http:// dx.doi.org/10.1038/nrgastro.2017.109

9. World Health Organization [Internet]. Geneva: World Health Organization; c2020. Centro de prensa. Notas descriptivas. Obesidad y sobrepeso; 2020 [updated 2020 Apr 1; cited 2020 Jun10]. Available at: https://www.who.int/es/news-room/ fact-sheets/detail/obesity-and-overweight. Spanish.

10. World Health Organization [Internet]. Geneva: World Health Organization; c2020. Global Health Observatory (GHO). Reports. World health statistics 2016: monitoring health for the SDGs sustainable development goals. World Health Organization; 2016 [cited 2020 Feb 15]. Available at: https://www.who.int/gho/publications/ world health statistics/2016/en/

11. López-Velázquez JA, Silva-Vidal KV, PoncianoRodríguez G, Chávez-Tapia NC, Arrese M, Uribe
$M$, et al. The prevalence of nonalcoholic fatty liver disease in the Americas. Ann Hepatol. 2014 MarApr;13(2):166-78.

12. de Oliveira CPMS, Cotrim HP, Arrese M. Factores de riesgo de la enfermedad por hígado graso no alcohólico en poblaciones de Latinoamérica: situación actual y perspectivas. Clin Liver Dis (Hoboken). 2019 May 29;13(Suppl 1):S5-S8. Spanish.

13. Loomba R, Abraham M, Unalp A, Wilson L, Lavine J, Doo E, et al. Association between diabetes, family history of diabetes, and risk of nonalcoholic steatohepatitis and fibrosis. Hepatology. 2012 Sep;56(3):943-51.

14. Jiménez Acosta SM, Magaly $S$, Rodríguez Suárez A, Díaz Sánchez ME. La obesidad en Cuba. Una mirada a su evolución en diferentes grupos poblacionales. Rev Cubana Alimen Nutr. 2013;23(2):297-308. Spanish. Available at: http://www.revalnutricion .sld.cu/index.php/rcan/article/view/299

15. National Health Statistics and Medical Records Division (CU). Anuario Estadístico de Salud 2019 [Internet]. Havana: Ministry of Public Health (CU); 2020 Apr [cited 2020 Jun 15]. 193 p. Available at: https://files.sld.cu/bvscuba/files/2020/05/Anua rio-Electr\%c3\%b3nico-Espa\%c3\%b1ol-2019 -ed-2020.pdf. Spanish.

16. National Health Statistics and Medical Records Division (CU). Anuario Estadístico de Salud 2010. Havana: Ministry of Public Health (CU); 2011 Apr [cited 2020 Jun 15]. 199 p. Available at: https://files.sld.cu/dne/files/2011/04/anuario -2010-e-sin-graficos1.pdf. Spanish.

17. Montero González T, Pérez Lorenzo M, Alarcón Arango I, Infante Velázquez M, Angulo Pérez O, Winogra Lay R, et al. Prevalencia de esteatosis hepática no alcohólica en autopsias y alteraciones morfológicas metabólicas relacionadas. Rev Cub Med Mil. 2011;40(1):32-9. Spanish.

18. Expert Panel on Detection, Evaluation and Treatment of High Blood Cholesterol in Adults. Executive Summary of The Third Report of The National Cholesterol Education Program (NCEP) Expert Panel on Detection, Evaluation, And Treatment of High Blood Cholesterol In Adults (Adult Treatment Panel III). JAMA [Internet]. 2001 May 16 [cited 2020 Feb 15];285(19):2486-97. Available at: https://jamanetwork.com/journals/jama/fullarti cle/vol/285/pg/2486

19. Díaz Sánchez ME. Manual de técnicas antropométricas para estudios nutricionales. Havana: Nutrition and Food Hygiene Institute (CU); 2005. Spanish.

20. World Health Organization [Internet]. Geneva: World Health Organization; c2020. Estrategia mundial sobre régimen alimentario, actividad física y salud. ¿Qué se entiende por actividad moderada y actividad vigorosa?; 2019 [cited 2019 Dec 25]. Available at: https://www.who.int/ dietphysicalactivity/physical_activity_intensity/ es/. Spanish.

21. National Institute on Alcohol Abuse and Alcoholism (US). Helping Patients who Drink Too Much: A Clinician's Guide: Updated 2005 Edition [Internet]. Maryland: National Institutes of Health (US); 2005 [revised 2016 Jul; cited 2019 Dec 20]. 34 p. Available at: https://pubs.niaaa.nih.gov/publica tions/practitioner/cliniciansguide2005/guide.pdf

22. Reboussin DM, Allen NB, Griswold ME, Guallar E, Hong Y, Lackland DT, et al. Systematic Review for the 2017 ACC/AHA/AAPA/ABC/ACPM/AGS/APhA/ ASH/ASPC/NMA/PCNA Guideline for the Prevention, Detection, Evaluation, and Management of High Blood Pressure in Adults: A Report of the American College of Cardiology/American Heart Association Task Force on Clinical Practice Guidelines. Hypertension. 2018 Jun;71(6):e116-e35.

23. Williams B, Mancia G, Spiering W, Agabiti Rosei E, Azizi M, Burnier M, et al. 2018 ESC/ESH Guidelines for the management of arterial hypertension. Eur Heart J. 2018;39(33):3021-104.

24. World Medical Association. World Medical Associatioin Declaration of Helsinki: ethical principles for medical research involving human subjects. JAMA. 2013 Nov 27;310(20):2191-4.

25. van Delden JJ, van der Graaf R. Revised CIOMS International Ethical Guidelines for Health-Related Research Involving Humans. JAMA. 2017 Jan;317(2):135-6.

26. Fernández MTC, Duharte JF, Maren DM, Botiel LBB, Diarra O. Hallazgos clínicos e histomorfológicos en pacientes con esteatosis hepática no alcohólica. MediSan. 2014;18(8):1173-9. Spanish

27. Fondén JD, Pereira Despaigne $\mathrm{OL}$, Columbié $\mathrm{AL}$, Del Valle Díaz S, Hodelín Tablada R. Relación entre los hallazgos ecográficos, laparoscópicos e histológicos en pacientes con esteatosis hepática no alcohólica. MediSan. 2015;19(03):34553. Spanish

28. Canciano Chirino E, Iglesia Reyes CK, de Armas Romero I, Fandiño González L, Iglesia Reyes ME, Río Ponciano O. Hígado graso no alcohólico como marcador de calidad de vida en mujeres de edad mediana. Rev Cubana Obstetr Ginecol. 2011;37(4):533-40. Spanish.

29. Creagh García J, Suárez Sori B, Hernández Rodríguez M, Martínez Paradela T. Resultados de la biopsia hepática en el diagnóstico del hígado graso no alcohólico. Rev Arch Médico Camagüey. 2017 Jul-Aug;21(4):518-27. Spanish.

30. del Busto Mesa A, Cabrera Rego JO, Guanche Valenciano $O$. Cintura hipertrigliceridémica y 
enfermedad por hígado graso no alcohólico en pacientes hipertensos. Rev Cubana Med. 2017 Jan-Mar;56(1):4-14. Spanish.

31. Fleischman MW, Budoff M, Zeb I, Li D, Foster T. NAFLD prevalence differs among hispanic subgroups: the Multi-Ethnic Study of Atherosclerosis. World J Gastroenterol. 2014 May 7:20(17):4987-93.

32. Matteoni L, Boente L, Soares D, Leal R, Campos F, César Araújo, et al. [Nonalcoholic fatty hepatic disease: relevance of the diagnosis on abdominal ultrasound]. Gaz Méd Bahia. 2011 Jan-Jun;81(1):7-9. Portuguese.

33. Karnikowski $M$, Córdova $C$, d'Oliveira $R J$, d'Oliveira Karnikowski MG, de Toledo Nóbrega O. Non-alcoholic fatty liver disease and metabolic syndrome in Brazilian middle-aged and older adults. Sao Paulo Med J. 2007 Nov 1;125(6):333-7.

34. Parise ER, Salgado ALFDA, Secaf R, Cerri LMO, Cerri G. Prevalence of liver steatosis in abdominal ultrasound. GED. 2003 Nov;22(6):235-7.

35. Riquelme A, Arrese M, Soza A, Morales A, Baudrand R, Pérez-Ayuso RM, et al. Non-alcoholic fatty liver disease and its association with obesity, insulin resistance and increased serum levels of C-reactive protein in Hispanics. Liver Int. 2009 Jan;29(1):82-8.

36. Pérez M, Gonzáles L, Olarte R, Rodríguez NI, Tabares M, Salazar JP, et al. Nonalcoholic fatty liver disease is associated with insulin resistance in a young Hispanic population. Prev Med. 2011 Feb;52(2):174-7.

37. Bonet Gorbea M, Varona P, Chang de la Rosa M, García Roche R, Suárez Medina R, Arcia $\mathrm{N}$, et al. III Encuesta Nacional de Factores de Riesgo y Actividades Preventivas de Enfermedades No Transmisibles. Cuba 2010-2011 [Internet]. Havana: ECIMED; 2014 Aug 23 [cited 2015 Jun17]. Available at: https://www.researchgate .net/publication/325370475_III_Encuesta Nacional_de_factores_de_riesgo_y_activi dades preventivas de enfermedades no _trasmisibles_Cuba_2010-2011. Spanish.

38. Jiménez Acosta S, Díaz Sánchez ME, García Roche RG, Bonet Gorbea M, Wong Ordóñez I. Cambios en el estado nutricional de la población cubana adulta de diferentes regiones de Cuba. Rev Cubana Hig Epidemiol [Internet]. 2012 JanApr [cited 2020 May 22];50:4-13. Available at: http://scielo.sld.cu/scielo.php?script=sci arttext \&pid=S1561-30032012000100002. Spanish.

39. Akhavan Rezayat A, Dadgar Moghadam M, Ghasemi Nour M, Shirazinia M, Ghodsi H, Rouhbakhsh Zahmatkesh MR, et al. Association between smoking and nonalcoholic fatty liver disease: a systematic review and meta-analysis. SAGE Open Med. 2018 Jan 24;6:2050312117745223. DOI: $10.1177 / 2050312117745223$.

40. Guthold R, Stevens GA, Riley LM, Bull FC. Worldwide trends in insufficient physical activity from 2001 to 2016: a pooled analysis of 358 population-based surveys with 1.9 million participants. Lancet Global Health. 2018 Oct;6(10):e1077-e86.

41. Fattahi MR, Niknam R, Safarpour A, Sepehrimanesh M, Lotfi $M$. The prevalence of metabolic syndrome in non-alcoholic fatty liver disease: a population-based study. Middle East J Digest Dis [Internet]. 2016 Apr [cited 2020 Mar 14];8(2):131-7. Available at: https://www.ncbi .nlm.nih.gov/pmc/articles/pmid/27252820/

42. Povsic M, Wong OY, Perry R, Bottomley J. A structured literature review of the epidemiology and disease burden of non-alcoholic steatohepatitis (NASH). Adv Ther [Internet]. 2019 Jul [cited 2020 Aug 18];36(7):1574-94. Available at: https://www.ncbi.nlm.nih.gov/pmc/articles/ pmid/31065991/
43. Lonardo A, Nascimbeni F, Ballestri S, Fairweather D, Win S, Than TA, et al. Sex differences in nonalcoholic fatty liver disease: state of the art and identification of research gaps. Hepatology. 2019 Oct;70(4):1457-69.

44. Du T, Sun X, Yuan G, Zhou X, Lu H, Lin X, et al. Sex differences in the impact of nonalcoholic fatty liver disease on cardiovascular risk factors. Nutr Metab Cardiovasc Dis. 2017 Jan;27(1):63-9.

45. Ye ZL, Guo WQ, Li L. Sex-based differences in the association between nonalcoholic fatty liver disease and mortality. Clin Gastroenterol Hepatol. 2019 Jan;17(1):211-2.

46. McCracken E, Monaghan M, Sreenivasan S. Pathophysiology of the metabolic syndrome. Clin Dermatol [Internet]. 2018 Jan-Feb [cited 2020 Apr 18];36(1):14-20. Available at: https:// linkinghub.elsevier.com/retrieve/pii/S0738 -081X(17)30158-X

47. Younossi ZM, Stepanova M, Negro F, Hallaji S, Younossi Y, Lam B, et al. Nonalcoholic fatty liver disease in lean individuals in the United States. Medicine (Baltimore) [Internet]. 2012 Nov [cited 2020 Apr 18];91(6):31927. Available at: https://doi.org/10.1097/ MD.0b013e3182779d49

48. Sookoian S, Pirola CJ. Genetic predisposition in nonalcoholic fatty liver disease. Clin Molecular Hepatol. 2017 Mar;23(1):1-12.

49. Eslam M, Valenti L, Romeo S. Genetics and epigenetics of NAFLD and NASH: Clinical impact. J Hepatol. 2018 Feb;68(2):268-79.

50. Shen J, Wong GLH, Chan HL, Chan HLY, Yeung DKW, Chan RSM, et al. PNPLA3 gene polymorphism accounts for fatty liver in community subjects without metabolic syndrome. Aliment Pharmacol Ther [Internet]. 2014 Mar [cited 2020 Apr 18];39(5):532-9. Available at: https://doi .org/10.1111/apt.12609

51. Cintado A, Companioni O, Nazabal M, Camacho $\mathrm{H}$, Ferrer $\mathrm{A}$, Fernández De Cossio ME, et al. Admixture estimates for the population of Havana City. Ann Human Biol [Internet]. 2009 May-Jun [cited 2020 Apr 20];36(3):350-60. Available at: http://www.tandfonline.com/doi/ full/10.1080/03014460902817984

52. Marcheco-Teruel B, Parra EJ, Fuentes-Smith E, Salas A, Buttenschøn HN, Demontis D, et al. Cuba: exploring the history of admixture and the genetic basis of pigmentation using autosomal and uniparental markers. PLoS Genet. 2014 Jul 24:10(7):e1004488.

53. Caldwell SH, Crespo DM. The spectrum expanded: cryptogenic cirrhosis and the natural history of non-alcoholic fatty liver disease. J Hepatol [Internet]. 2004 Apr [cited 2020 Apr 20];40(4):578-84. Available at: https://linkinghub.elsevier.com/retrieve/pii/ S0168827804000716

54. Vilar-Gómez E, Calzadilla-Bertot L, Wong VWS, Castellanos M, Aller-de la Fuente R, Metwally $\mathrm{M}$, et al. Fibrosis severity as a determinant of cause-specific mortality in patients with advanced nonalcoholic fatty liver disease: a multi-national cohort study. Gastroenterology [Internet]. 2018 Aug [cited 2020 Apr 21];155(2):443-57. Available at: https:// linkinghub.elsevier.com/retrieve/pii/S0016 $-5085(18) 34484-6$

\section{THE AUTHORS}

Marlen Ivón Castellanos-Fernández MD PhD (Corresponding author: mcastell@infomed.sld .cu), gastroenterologist with a doctorate in medical sciences. Full professor and senior researcher, Gastroenterology Institute, Medi- cal University of Havana, Cuba. https://orcid .org/0000-0001-7386-2064

Eduardo Crespo-Ramírez MD MS, gastroenterologist with a master's degree in satisfactory longevity. Associate professor and adjunct researcher, Medical University of Pinar del Río and the Pinar del Río Provincial Teaching Hospital, Cuba. https://orcid.org/0000-0003-1446 $-1230$

Sergio del Valle-Díaz MD MS, physician specializing in internal medicine and gastroenterology, with master's degrees in emergency medicine and medical education. Adjunct professor and adjunct researcher, Medical University of Santiago de Cuba, and Saturnino Lora Torres Provincial Clinical-Surgical Teaching Hospital, Santiago de Cuba. https://orcid .org/0000-0001-7535-0273

Eduardo Barreto-Suárez MD MS, physician specializing in gastroenterology and family medicine, with a master's degree in infectious diseases. Manuel Ascunce Domenech Provincial Clinical-Surgical Teaching Hospital, Camagüey, Cuba. Assistant professor, Medical University of Camagüey, Cuba. https://orcid.org/0000-0002 $-6384-5356$

Javier Orlando Díaz-Elías MD, MS, physician specializing in gastroenterology and family medicine, with a master's degree in infectious diseases. Calixto García University Clinical-Surgical Hospital, Havana, Cuba. Assistant professor, Medical University of Havana, Cuba. https://orcid .org/0000-0002-2160-6947

Lorenzo Santaló-Rodríguez MD, physician specializing in family medicine, Medical University of Havana, Cuba and Calixto García University Clinical-Surgical Hospital, Havana, Cuba. https://orcid.org/0000-0002-7857-4851

Sahili Corrales-Alonso MD, gastroenterologist. Faustino Pérez Hernández University ClinicalSurgical Teaching Hospital, Matanzas, Cuba. Associate professor and adjunct researcher, Medical University of Havana, Cuba. https:// orcid.org/0000-0002-1127-3114

Ignacio Morales-Martínez MD, physician specializing in gastroenterology and family medicine. Celestino Hernández Robau Provincial Oncology University Hospital, Villa Clara, Cuba. Associate professor and adjunct researcher, Medical University of Villa Clara, Cuba. https:// orcid.org/0000-0002-2016-2088

Elisa Cedeño-Ramírez MD, physician specializing in gastroenterology and family medicine. Manuel Fajardo Clinical-Surgical Teaching Hospital, Havana, Cuba. Instructor, Medical University of Havana, Cuba. https:// orcid.org/0000-0003-2541-3939

Teresita Pérez-González MD, physician specializing in gastroenterology and family medicine. Medical University of Havana, Cuba, 
and Iván Portuondo General Teaching Hospital, Artemisa, Cuba. https://orcid.org/0000-0003 $-0318-2914$

Sila María González-Suero MD MS, internist with a master's degree in emergency medicine. Associate professor, Gastroenterology Institute, Medical University of Havana, Cuba. https://orcid .org/0000-0003-4805-7391

Caridad Ruenes Domech MD MS, gastroenterologist with a master's degree in medical education. Associate professor and associate researcher, Gastroenterology Institute, Medical University of Havana, Cuba. https://orcid .org/0000-0001-9015-5257

Mirtha Infante-Velázquez MD PhD, gastroenterologist with a doctorate in medical sciences. Full professor and senior researcher, Gastroenterology Institute, Medical University of Havana, Cuba. https://orcid.org/0000-0003 $-1150-5197$

Susana Ángela Borges-González MD MS, psychiatrist with a master's degree in dementia care and research. Assistant professor, Gastroenterology Institute, Havana, Cuba. https://orcid.org/0000 $-0002-5510-3328$

Angela Elvírez-Gutiérrez MD MS, radiologist with a master's degree in diagnostic procedures. Associate professor, Gastroenterology Institute, Medical University of Havana, Cuba. https:// orcid.org/0000-0002-9740-1403

Sacha Lazo-del Vallín MD MS, radiologist with a master's degree in diagnostic media. Associate professor and associate researcher, Gastroenterology Institute, Medical University of Havana, Cuba. https://orcid.org/0000-0002 $-4001-9596$
Oscar Manuel Villa-Jiménez MD MS, gastroenterologist with a master's degree in infectious diseases. Assistant professor and adjunct researcher, Gastroenterology Institute, Medical University of Havana, Cuba. https://orcid .org/0000-0002-6675-584X

Liana Margarita Labrada-Moreno MD MS, biostatistician with a master's degree in infectious diseases. Instructor, Gastroenterology Institute, Medical University of Havana, Cuba. https://orcid .org/0000-0003-3867-2315

Submitted: January 27, 2020

Approved for publication: November 27, 2020 Disclosures: None 


\title{
Congenital and Intrapartum SARS-CoV-2 Infection in Neonates: Hypotheses, Evidence and Perspectives
}

\author{
Gerardo R. Robaina-Castellanos MD PhD and Solangel de la Caridad Riesgo-Rodríguez MD MS
}

\begin{abstract}
INTRODUCTION Both intrauterine and intrapartum mother-to-child transmission of SARS-CoV-2 have been reported. However, there is still disagreement as to the likelihood and frequency of such vertical transmission.
\end{abstract}

OBJECTIVE Summarize and analyze the published evidence on forms of SARS-CoV-2 vertical transmission (either intrauterine or intrapartum).

EVIDENCE ACQUISITION We carried out a review of literature published in English and Spanish from January 1, 2020 through October 30, 2020. Search engines included PubMed/MEDLINE, SciELO, LILACS, Cochrane, Google Scholar, ResearchGate and medRxiv. There were no restrictions concerning type of study. The review included 48 original research articles, 11 review articles, a meta-analysis, 2 pre-published articles, 15 systematic reviews, and 10 editorials or comments.

DEVELOPMENT Medical thinking on congenital or intrapartum maternal-fetal/neonatal transmission of SARS-CoV-2 has evolved from preliminary evidence that was divided as to whether these forms of vertical transmission were even possible to current evidence support-

\section{INTRODUCTION}

Since the outbreak of the novel coronavirus in late 2019, there have been indications of SARS-CoV-2 infections in neonates.[1] Such infection can be due either to 'vertical' transmission (from mother to child) or to 'horizontal' transmission (from familial contacts or nosocomial infections acquired during hospitalization).

Vertical transmission can occur by one of three mechanisms: intrauterine infection (transplacental or ascending), intrapartum infection (transmission that occurs during birth) and postpartum infection (through breast milk, nasal secretions, etc.) Evidence of transplacental transmission of emerging diseases like HIV, Ebola and Zika suggest the possibility of intrauterine or intra-amniotic transmission of SARS-CoV-2 infection.[3] Positive results from quantitative reverse-transcriptase polymerase chain reaction (RT-PCR) for SARS-CoV-2 RNA during the first few hours or days of life and identification of newborns with manifestations of earlyonset clinical signs and symptoms of COVID-19 would confirm vertical SARS-CoV-2 infection.[1,3]

Given that postnatal transmission from mother to child is also considered 'vertical transmission", the term is imprecise, prompting increasing use of the categories proposed by Shah.[4] Under this

\section{IMPORTANCE}

This article summarizes evidence available on congenital and intrapartum SARS-CoV-2 infection, an understudied aspect of the COVID-19 pandemic that requires more study due to its clinical and healthcare implications. ing both forms of transmission and hypothesizing as to the mechanisms that guide them. The presence of the SARS-CoV-2 virus in maternal, placental, fetal or neonatal tissues has been demonstrated by RT-PCR, specific immunoglobulin detection tests, immunostaining and in-situ hybridization. It is estimated that infections acquired either congenitally or intrapartum occur in $1.8 \%-8.0 \%$ of newborns born to women who test positive for COVID-19 at the end of their pregnancies. This review found 53 neonates who were diagnosed with COVID-19 in the first 48 hours of life by either RT-PCR or specific IgM tests. According to criteria outlined in this review, the timing of infection corresponded to congenital or intrapartum transmission in $39.6 \%$ (21/53) of COVID-19-positive newborns, to postpartum transmission in $15.1 \%(8 / 53)$ and remains unspecified in $45.3 \%(24 / 53)$.

CONCLUSIONS Congenital and intrapartum SARS-CoV-2 infection in the fetus/newborn is possible, but rare. International collaborative studies using common epidemiological surveillance instruments would allow for a more precise specification of the frequency of congenital and intrapartum SARS-CoV-2 infection at the population level.

KEYWORDS COVID-19; SARS-CoV-2; vertical transmission of infectious disease; infant, newborn

definition, 'vertical transmission' includes congenital infections with intrauterine or perinatal fetal death, congenital infections in living newborns, neonatal infections acquired intrapartum and neonatal infections acquired postpartum (Figure 1).

Determining the possibility of maternal SARS-CoV-2 infection during pregnancy has obvious implications for clinical practice and healthcare. Among others, these include: 1) giving parents a better understanding of the probability of vertical transmission and how it could affect their current or future offspring; 2) allowing for compliance by obstetricians and neonatologists with measures suggested by perinatal care protocols designed to minimize the risk of vertical transmission (e.g. transmission related to the birth route, immediate isolation of suspected or study cases) and guidelines for early maternal skin-to-skin contact, newborn care, optimal time for cord clamping, etc;[5] and 3) allowing for implementation and development of specific protection measures for healthcare workers to help prevent infection during delivery, patient care and neonatal resuscitation. It would also allow the scientific community to evaluate treatments and design drugs aimed at minimizing the risk of transplacental or intrapartum transmission.

Even when both intrauterine and intrapartum mother-to-child transmission of SARS-CoV-2 have been reported, there is still disagreement as to their likelihood and frequency. This article presents a review of current available knowledge on congenital and intrapartum transmission of SARS-CoV-2.

\section{EVIDENCE ACQUISITION}

We reviewed literature published on the topic of SARS-CoV-2 vertical transmission through an exhaustive search of the 
Pubmed/MEDLINE, SciELO, LILACS, Cochrane, Google Scholar, Research Gate and medRxiv databases. There were no restrictions on study type. We used the following search terms: COVID-19, SARS-CoV-2, intrauterine infection, neonatal infection, vertical transmission; as well as their Spanish equivalents. We also searched through the references of review papers that emerged during the search for all other relevant sources. When several reports documented the same case, a single report was selected.

The quality of reports and case series were evaluated using an instrument developed by the Mayo Clinic Center for EvidenceBased Practice.[6] Descriptive observational studies were evaluated using a modified version of the Newcastle-Ottawa scale first introduced by Kotlyar.[7] Evaluation of single studies and document classification was performed independently by each of the authors, who then cross-compared their criteria and resolved their discrepancies as a team. After a thorough selection of the reviewed literature using the above criteria, our review contained 87 publications: 48 original articles, 11 review articles, 1 meta-analysis, 2 pre-publication articles (articles that have not yet undergone peer review), 15 systematic reviews, and 10 editorials or comments.

Only cases documenting congenital infection in live newborns or suspected intrapartum infection were selected, and only if the mother had been diagnosed with COVID-19 during her third trimester of pregnancy and the RT-PCR or serological antibody tests for immunoglobulin $\mathrm{M}(\mathrm{Ig} \mathrm{M})$ were positive in the newborn in their first 48 hours of life. In symptomatic neonates, the clinical manifestations should also have occurred within the first 48 hours.

We classified infections according to criteria established by Shah (Figure 1),[4] which specify detection of SARS-CoV-2 in chorionic villi through electron microscopy, through immunohistological techniques using antibodies against viral antigens, and in situ hybridization (detection of RNA targets without affecting cell morphology).[3,8,9]

Patients whose clinical manifestations occurred $\geq 48$ hours after birth were classified as postnatally-acquired neonatal infections. This is in line with Shah's criteria.[4] If it was not possible to specify when the initial infection occurred, the case was classified as 'not yet specified'. We classified maternal infection severity according to guidelines proposed by Wu and McGoogan:[10] mild (without pneumonia or with mild pneumonia); severe (dyspnea, respiratory rate $\geq 30$ respirations per minute, oxygen saturation $\leq 93 \%$, ratio of partial pressure of oxygen to inspired fraction of oxygen $<300$ and/or pulmonary infiltrates $>50 \%$ in $24-48$ hours); or as critical (respiratory failure, septic shock, and/or multiple organ dysfunction or failure.[10]

\section{DEVELOPMENT}

Diagnosis of congenital and intrapartum SARS-CoV-2 infection Evidence of viral replication in fetal lung tissue would provide the most conclusive evidence for intrauterine transmission, but this evidence is inaccessible for obvious technical and ethical reasons. It has therefore been proposed that clinical evidence of vertical transmission be obtained by isolating the virus from samples taken from the placenta, amniotic fluid, umbilical cord and pharyngeal swabs immediately after birth. This last criterion is the one used in clinical practice when testing for intrauterine transmission of SARS-CoV-2.[11]

Among newborns of COVID-19-positive mothers who have also tested positive for SARS-CoV-2, there are asymptomatic cases and cases in which the disease appeared anytime in the first few hours or the first days after birth. Given our current lack of knowledge on infection mechanisms and timing, early-onset disease has been presumed by some authors to be the result of vertical transmission. This practice is under discussion. There is no current consensus defining early-onset neonatal COVID-19; and in fact, time limits vary among studies even for neonatal bacterial infections. $[8,12]$

The classification scheme proposed by Shah[4] attempts to resolve these inconsistencies based on the direction in which disease transmission occurred by including precise indicators of the most frequently used diagnostic methods for detecting the virus. As there is very little knowledge about SARS-CoV-2 incubation periods in the fetus or neonate, the time periods proposed for each category of infection could change as the incubation process becomes better understood. Symptoms present from birth up to 48 hours after birth indicate congenital or intrapartum infection, but do not confirm whether the infection was transplacental, and the presence of SARS-CoV-2 in placental tissue demonstrated by RT-PCR is not necessarily an indication of transplacental transmission. The efficacy of RT-PCR analysis of nasopharyngeal swab samples in newborns in diagnosing congenital or intrapartum infection has not yet been demonstrated. $[8,13,14]$ The classification scheme by Shah[4] makes reference to specific clinical manifestations of SARS-CoV-2 infection, but the clinical presentation of COVID-19 in newborns is still poorly understood, and both clinical markers and imaging findings remain nonspecific.

We present the current state of medical thinking on maternalfetal/neonatal transmission of SARS-CoV-2, based on studies conducted in newborns of mothers diagnosed with COVID-19 in the third trimester of pregnancy. The information is classified into three groups: evidence that supports non-transmission, evidence of early neonatal infection without demonstrated vertical transmission, and evidence that supports congenital or intrapartum transmission with differing degrees of certainty. The evidence supporting congenital or intrapartum infection was classified according to three out of the five case categories proposed by Shah:[4] confirmed (strong evidence of infection with confirmatory microbiology), probable (strong evidence of infection but lacking confirmatory microbiology) and possible (evidence suggestive of infection but inconclusive).

\section{Group one: no evidence of SARS-CoV-2 vertical transmission} The hypothesis that the SARS-CoV-2 virus is not transmissable to the fetus or newborn via transplacental or intrapartum routes is based on the fact that no cases of vertical transmission were documented during previous coronavirus epidemics (SARSCoV-2 in 2002 and MERS-CoV in 2014) or in either disease since. [15]

In most studies carried out early in the COVID-19 pandemic on whether congenital or intrapartum transmission was possible from infected women, presence of the virus could not be demonstrated 
Figure 1: Fetal/neonatal SARS-CoV-2 infection

\begin{tabular}{|c|c|c|c|}
\hline $\begin{array}{l}\text { Congenital infection with } \\
\text { intrauterine fetal } \\
\text { death/stillbirth }\end{array}$ & $\begin{array}{l}\text { Congenital infection in live born } \\
\text { neonate }\end{array}$ & $\begin{array}{l}\text { Neonatal infection acquired } \\
\text { intrapartum }\end{array}$ & $\begin{array}{l}\text { Neonatal infection acquired } \\
\text { postpartum }\end{array}$ \\
\hline $\begin{array}{l}\text { PCR }(+) \text { or culture }(+) \text { fetal or } \\
\text { placental tissue or examination of } \\
\text { chorionic villi placental cells using } \\
\text { IM, IHC or HIS techniques: } \\
\text { Confirmed } \\
\text { Samples from the fetal surface or } \\
\text { fetal side of the placenta }(+): \\
\text { Possible } \\
\text { Maternal side of the placenta PCR } \\
(+) \text {, but fetal or placental tisssue } \\
\text { culture }(-) \text { or not performed: } \\
\text { Unlikely } \\
\text { Fetal tissue samples obtained via } \\
\text { autopsy PCR }(-) \text { or electron } \\
\text { microscopy }(-) \text { : No infection }\end{array}$ & 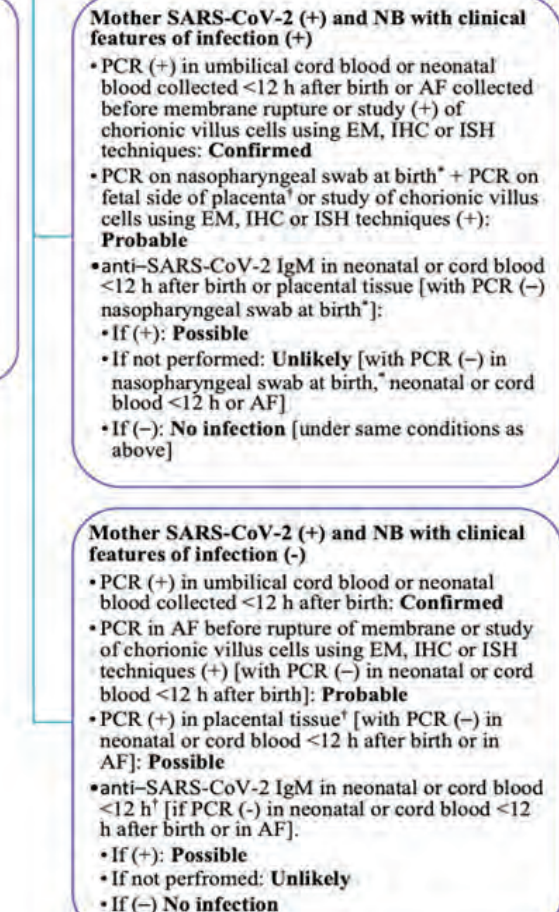 & 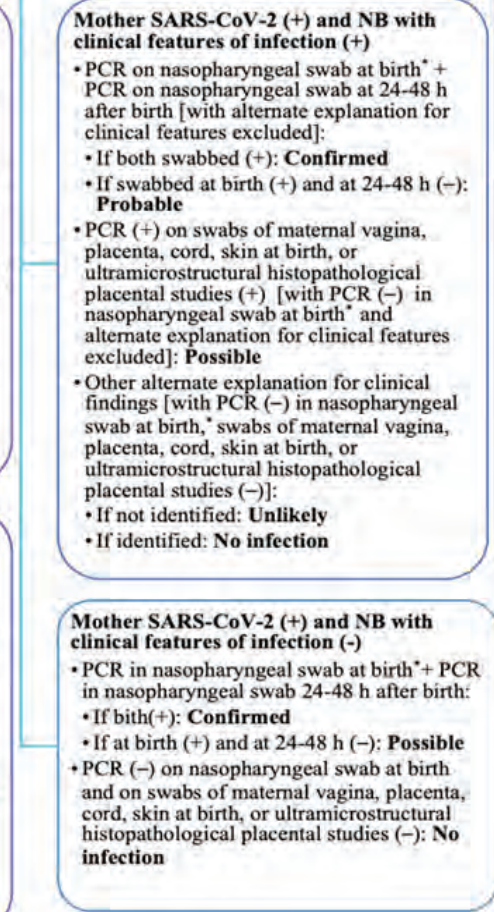 & $\begin{array}{l}\text { NB } \geq 48 \text { h of age with clinical } \\
\text { features of infection }(+) \text {, } \\
\text { parents/caregivers may or may } \\
\text { not have SARS-CoV-2 } \\
\text { infection or were not tested. } \\
\cdot \text { PCR on nasopharyngeal swab } \\
\text { at birth }+ \text { PCR on } \\
\text { nasopharyngeal or rectal swabs } \\
\text { at } \geq 48 \mathrm{~h} \text { after birth } \\
\text { - If }(-) \text { at birth and }(+) \geq 48 \mathrm{~h} \\
\text { after birth: Confirmed } \\
\text { - If at birth (not performed) and } \\
\text { at } \geq 48 \mathrm{~h}(+) \text { : Probable } \\
\text { - If PCR on nasopharyngeal or } \\
\text { rectal swabs at } \geq 48 \mathrm{~h} \text { after } \\
\text { birth }(-) \text { : No infection }\end{array}$ \\
\hline
\end{tabular}

*after cleaning the newborn, tborn via cesarean section before rupture of membrane, NB: newborn, AF: amniotic fluid, (+): positive, (-): negative, EM: electron microscopy, IHC: immunohistochemistry, ISH: in-situ hybridization.

Category definitions: Confirmed, Strong evidence of infection with confirmatory microbiology; Probable, Strong evidence of infection but confirmatory microbiology lacking; Possible, Evidence suggestive of infection but incomplete; Unlikely, Little support for diagnosis but infection cannot be ruled out; Not infected, No evidence of infection.

Prepared by Shah[4] (modified by the authors).

in either vaginal secretions, amniotic fluid, tissue samples from the placenta or umbilical cords, or neonatal pharyngeal swabs. $[1,11,16,17]$

Penfield[18] demonstrated exposure to SARS-CoV-2 in three neonates of mothers with severe or critical COVID-19 whose placental or ovular membrane samples were positive for SARSCoV-2. However, none of the neonate samples were positive and none of the newborns showed symptoms of the disease, so the work in question could not demonstrate maternal-fetal transmission.

In this context, it should be noted that little attention has been paid to the proportion of false negatives in RT-PCR tests in children of COVID-19-positive mothers, which, according to studies performed on other age groups, can be up to $100 \%$ when sampling is performed the first day of the incubation period of the disease and $67 \%$ if performed on the fourth day.[19] Thus, it is entirely possible that cases reported as negative at birth or in the first few hours after birth are false negatives.

Group two: early neonatal SARS-CoV-2 infection without demonstrated vertical transmission The possibility of transmission during childbirth was considered when the first cases of newborns with COVID-19-positive mothers tested positive by RT-PCR. Wang[20] reported a newborn who presented with a positive nasopharyngeal sample 36 hours after birth whose COVID-19-positive mother tested negative (by RT-PCR) in samples taken from the pla- centa, umbilical cord and breast milk (Table 1). For similar reasons, it was not possible to prove intrapartum or congenital infection in case series published in China documenting positive pharyngeal samples taken 24-36 hours after birth.[21-23]

Two neonates of mothers with severe or critical COVID-19 tested positive for SARS-CoV-2, one of them in Peru and one in Great Britain, with nasopharyngeal samples obtained, respectively, at 16 hours of life and at birth.[24,25] A newborn tested positive in Italy one day after birth, after receiving breastmilk from their mother, who was unaware that she was positive for COVID-19. [26] The absence of evidence of SARS-CoV-2 in amniotic fluid, umbilical cord blood or placenta makes it impossible to confirm that any of these cases arose from a congenital or intrapartum infection; nor was it possible to determine the timing of infection in four other positive newborns according to RT-PCR in respiratory samples after birth, one reported by Kalane[27] and three others by Savasi.[28]

A prospective population cohort study in Great Britain found 12 SARSCoV-2-positive infants born to mothers with COVID-19, 6 of whom had samples obtained in the first 12 hours of life.[29] This raises the possibility that these infections were acquired either congenitally or during birth, but this cannot be confirmed due to the lack of evidence that would pinpoint the timing of infection. This means these infections must be classified as 'undetermined' as to the timing and route of infection.[29] The same is true for six neonates reported by Sola,[30] all of whom had positive nasopharyngeal samples obtained 
16-36 hours after birth; this study involved 86 pregnant women with COVID-19 confirmed by RT-PCR in seven countries (6 from Latin America, and Equatorial Guinea).

Group three: SARS-CoV-2 congenital or intrapartum transmission confirmed (strong evidence of infection with confirmatory microbiology), probable (strong evidence of infection but confirmatory microbiology lacking) or possible (evidence suggestive of infection but incomplete). The third category summarizes information on SARS-CoV-2-positive newborns for whom we know the timing of infection, who were diagnosed in the first 48 hours of life, and who were born to mothers who contracted COVID-19 in their third trimester (Table 2). Vivanti[31] offered the strongest evidence of transplacental transmission of SARS-CoV-2; namely a preterm newborn who presented with depression at birth followed by neurological signs. RT-PCR tests on the placenta and amniotic fluid were positive for SARS-CoV-2, and immunohistochemical examination of the placenta detected viral nuclear proteins. RT-PCR performed on samples from neonatal lavage, blood, nasopharynx and rectum were also positive. Only cerebrospinal fluid was negative. This case has been classified as a confirmed congenital infection of SARS-CoV-2, with associated neurological manifestations.

There are three other cases of SARS-CoV-2-positive newborns with confirmed congenital infections. The first was a symptomatic full-term newborn whose RT-PCR on respiratory samples was deemed 'doubtful' at birth and positive at 36 and 72 hours of life. Presence of SARS-CoV-2 was also confirmed by electron microscopy, immunohistochemistry, and in situ hybridization. $[32,33]$ The second case was a symptomatic neonate born to a symptomatic mother whose nasopharyngeal samples were negative for SARS-CoV-2 but whose serological studies were positive for the virus. RT-PCR tests taken from the newborn's nasopharynx, from the placenta and from umbilical cord blood were all positive at birth.[34] The third case involved an asymptomatic neonate with negative RT-PCR tests on nasopharyngeal samples on the first and third days of life who nevertheless had positive molecular studies of cord blood and placenta.[35]

Some of the first evidence of congenital SARS-CoV-2 infection was provided by Zamaniyan, who isolated the virus in amniotic fluid using RT-PCR.[36] Nasopharyngeal samples were positive at 24 hours and 1 week of life, but samples from umbilical cord blood, the nasal cavity and the pharynx were negative at birth, making congenital infection likely, given the presence of the virus in the amniotic fluid. Kirstman demonstrated SARS-CoV-2 presence on both the maternal and fetal sides of the placenta in a neonate whose nasopharyngeal samples were positive at birth.[37]

Patanè found RT-PCR evidence of SARS-CoV-2 infection in the mother, the placenta and the newborn.[38] Patanè's study included 22 mother-child dyads, in which only two neonates tested positive for SARS-CoV-2. The first newborn had positive nasopharyngeal samples at birth, at 24 hours and at 7 days after birth; and the second was negative at birth but positive at 7 days of life, despite having no contact with the COVID-19positive mother during this time. Presence of messenger RNA from SARS-CoV-2 spike proteins at the syncytiotrophoblast level was confirmed via in situ hybridization. Both of these cases were classified as probable congenital infections. However, given that nasopharyngeal samples in the second newborn were only positive after seven days of life, this case pushes the boundaries of what we can consider a congenitally-acquired infection and raises the question of whether a positive nasopharyngeal sample obtained after 48 hours accompanied by viral detection on the fetal side of the placenta via in situ hybridization counts according to the classifications used in this review.[4] Both newborns presented with slight feeding difficulties.

Another neonate reported by Sisman[9] was classified as 'probable' for congenitally-acquired COVID-19, while a newborn in a study published by Carosso[39] was classified as 'possible' for infection acquired intrapartum.

Specific tests for IgG and IgM antibodies against SARS-CoV-2 have suggested the possibility of vertical intrauterine transmission in at least three studies.[40-42] In the first two studies,[40,41] three neonates had elevated levels of SARS-CoV-2-specific IgM and IgG. However, negative RT-PCR tests coupled with rapidly declining levels of SARS-CoV-2-specific antibodies in neonatal serum cast doubt on whether these antibodies were produced in the fetuses or neonates or were, instead, relics from the mothers. [43] Unlike IgG antibodies, IgM antibodies do not usually cross the placental barrier. As they can be produced by the fetus, their presence in neonatal serum has been used in diagnosing congenital infections, although the high proportion of false positives and false negatives (likely due to cross-reactivity) has limited their usefulness as diagnostic tests.[8,43,44]

Gao[42] reported on an asymptomatic neonate born to a mother with confirmed symptomatic COVID-19 at 33 weeks gestation. On the day of delivery, both mother and child had negative RT-PCR results from pharyngeal, placental and amniotic fluid samples, but levels were high for IgG and IgM specific to SARS-CoV-2. The possibility of acute maternal and neonatal postpartum infection was ruled out as serial RT-PCR tests performed on the newborn up to 14 days after birth were all negative, with only one positive single-step reverse-transcriptase droplet digital PCR (RT-ddPCR) test-RT-ddPCR is more sensitive than RT-PCR-on the seventh day of life, and the levels of antibodies steadily decreased. Histological studies showed inflammation in the placenta. According to the criteria proposed by Shah,[4] these last four cases of newborns could be classified as congenitally-acquired SARS-CoV-2 infections.

It was difficult to distinguish whether the case reported in Mexico by Hinojasa-Velasco[45] was acquired congenitally or intrapartum, as no samples from the umbilical cord, neonatal blood, placenta or nasopharynx were tested during the time period specified by the criteria outlined in this study.[4] Postpartum infection was ruled out.

Three neonates reported in the series by Martínez-Pérez[46] and two reported by Schwartz[47] were classified as infections possibly acquired intrapartum, as they could not be confirmed as the positive RT-PCR tests on samples from the nasopharynx taken at birth were not repeated 24-48 hours later. McDevitt [48] described a case of possible intrapartum infection garnered from an observational study of neonates included in a universal screening. The neonate in question had positive RT-PCR results at nine hours after birth. The mother was also positive. Both mother and baby were asymptomatic.[48]

The literature we reviewed includes other cases of probable postpartum SARS-CoV-2 infection diagnosed at 48 hours of life 
Table 1: Neonates of COVID-19-positive mothers who tested positive for SARS-CoV-2 in the first 48 hours of life, for whom the timing of infection cannot be pinpointed

\begin{tabular}{|c|c|c|c|c|c|c|c|c|c|c|c|c|}
\hline Reference & $\begin{array}{l}\text { Wang } \\
\text { [20] }\end{array}$ & $\begin{array}{l}\text { Nie } \\
{[21]}\end{array}$ & $\begin{array}{l}\text { Khan } \\
{[22]}\end{array}$ & $\begin{array}{l}\text { Khan } \\
{[22]}\end{array}$ & $\begin{array}{l}\text { Zhang } \\
\text { [23] }\end{array}$ & $\begin{array}{c}\text { Alzamora } \\
{[24]}\end{array}$ & $\begin{array}{l}\text { Govind } \\
\text { [25] }\end{array}$ & $\begin{array}{c}\text { Ferrazzi } \\
\text { [26] }\end{array}$ & $\begin{array}{l}\text { Kalane } \\
\text { [27] }\end{array}$ & $\begin{array}{c}\text { Savasi } \\
\text { [28] }\end{array}$ & $\begin{array}{l}\text { Knight } \\
\text { [29] }\end{array}$ & $\begin{array}{l}\text { Sola } \\
{[30]}\end{array}$ \\
\hline Country & China & China & China & China & China & Peru & $\begin{array}{l}\text { Great } \\
\text { Britain }\end{array}$ & Italy & India & Italy & $\begin{array}{l}\text { Great } \\
\text { Britain }\end{array}$ & $\begin{array}{l}\text { Latin America and } \\
\text { Equatorial Guinea }\end{array}$ \\
\hline Study type & $\mathrm{CR}$ & DO & CS & CS & CS & CR & $\mathrm{CS}$ & DO & $\mathrm{CR}$ & DO & DO & DO \\
\hline Evidence quality & Good & Fair & Fair & Fair & Fair & Fair & Fair & Fair & Good & Poor & Fair & Fair \\
\hline Mothers (No.) & 1 & 1 & $1^{*}$ & $2^{*}$ & 1 & 1 & 1 & 1 & 1 & $3^{* *}$ & $6^{\star *}$ & $6^{\star \star}$ \\
\hline Maternal symptoms & S-M & S-M & $\mathrm{S}-\mathrm{M}$ & A & $\mathrm{S}-\mathrm{M}$ & S-SC & S-SC & $\mathrm{S}-\mathrm{U}$ & $\mathrm{S}-\mathrm{M}$ & $\mathrm{S}-\mathrm{M}$ & $\mathrm{S}-\mathrm{NS}$ & $\mathrm{S}-\mathrm{NS}$ \\
\hline GA (weeks) & 40 & NS & 40 & 39 & 39 & 33 & 39 & NS & 32 & NS & $\begin{array}{l}\text { PT 3, } \\
\text { FT } 3\end{array}$ & NS \\
\hline Birth type & C & C & C & C & C & C & C & C & C & V & C & NS \\
\hline RT-PCR, NP/OP & $(+)$ & $(+)$ & $(+)$ & $(+)$ & $(+)$ & $(+)$ & $(+)$ & $(+)$ & $(+)$ & $(+)$ & $(+)$ & $(+)$ \\
\hline $\begin{array}{l}\text { RT-PCR, vaginal } \\
\text { secretions }\end{array}$ & NS & NS & NS & NS & NS & NS & NS & NS & NS & NS & No & NS \\
\hline RT-PCR, breast milk & $(-)$ & NS & NS & NS & NS & NS & NS & NS & NS & NS & NS & NS \\
\hline Newborns (No.) & 1 & 1 & $1^{*}$ & $2^{*}$ & 1 & 1 & 1 & 1 & 1 & $3^{* *}$ & $6^{\star \star}$ & $6 * *$ \\
\hline Apgar 1/5/10 min & $8 / 9$ & $\begin{array}{r}8-9 / \\
9-10\end{array}$ & $9 / 10$ & $9 / 10$ & NS & $6 / 8$ & $5 / 9$ & $5 \min >7$ & $7 / 7$ & NS & NS & NS \\
\hline Neonate symptoms & $\mathrm{S}$ & A & A & A & $\mathrm{S}$ & $\mathrm{S}$ & $\mathrm{S}$ & NS & $\mathrm{S}$ & A & NS & $\mathrm{S}$ \\
\hline $\begin{array}{l}\text { RT-PCR, cord/cord } \\
\text { blood }\end{array}$ & $(-)$ & $(-)$ & $(-)$ & $(-)$ & NS & NS & NS & NS & No & NS & No & NS \\
\hline RT-PCR, NP/OP & $(+)$ & $(+)$ & $(+)$ & $(+)$ & $(+)$ & $(+)$ & $(+)$ & $(+)$ & $\begin{array}{r}\text { ET Secr } \\
(+)\end{array}$ & $(+)$ & $(+)$ & $(+)$ \\
\hline $\begin{array}{l}\text { Birth- } 1^{\text {st }} \text { sample } \\
(+)(h)\end{array}$ & 36 & 36 & 24 & 24 & 30 & 16 & At birth & 24 & 24 & 24 & $<12$ & $16-36$ \\
\hline RT-PCR, rectal/stool & $(-)$ & NS & NS & NS & NS & NS & NS & NS & NS & NS & NS & NS \\
\hline $\begin{array}{l}\text { RT-PCR over time } \\
\text { (hours or days) }\end{array}$ & $\begin{array}{r}\mathrm{NP}(-) \\
17 \mathrm{~d}\end{array}$ & $\begin{array}{r}\mathrm{OP}(-) \\
4,8 \mathrm{y} \\
15 \mathrm{~d}\end{array}$ & NS & NS & NS & $\mathrm{NP}(+) 2 \mathrm{~d}$ & NS & NS & $\begin{array}{l}\text { ET Secr } \\
(+) 4 d\end{array}$ & NS & NS & NS \\
\hline RT-PCR, AF & $(-)$ & & No & No & NS & NS & NS & NS & No & NS & NS & NS \\
\hline $\begin{array}{l}\text { RT-PCR, placenta, } \\
\text { membranes }\end{array}$ & $(-)$ & $(-)$ & No & No & NS & NS & NS & NS & No & NS & No & NS \\
\hline $\begin{array}{l}\text { Evidence of SARS- } \\
\text { CoV-2 in placenta } \\
\text { (specific technique) }\end{array}$ & NS & NS & NS & NS & NS & NS & NS & NS & NS & NS & NS & NS \\
\hline $\begin{array}{l}\text { SARS-CoV-2 IgG/ } \\
\text { IgM at birth }\end{array}$ & NS & NS & NS & NS & No & $(-) /(-)$ & NS & NS & NS & NS & NS & NS \\
\hline Classification & NS & NS & NS & NS & NS & NS & NS & NS & NS & NS & NS & NS \\
\hline
\end{tabular}

CR: case report CS: case series DO: descriptive/observational S-SC: symptoms-severe or critical S-M: symptoms-mild S-NS: symptoms-severity not specified GA: gestational age PT: preterm FT: full-term C: cesarean V: vaginal (+): positive (-): negative NS: not specified RT-PCR: real-time polymerase chain reaction S: symptomatic A: asymptomatic NP: nasopharyngeal OP: oropharyngeal ET Secr: endotracheal secretion IgG: immunoglobulin G IgM: immunoglobulin M IP: intrapartum PP: postpartum *Different mothers or newborns reported from a same study **Number of mothers or newborns.

by nasopharyngeal RT-PCR or by bronchoalveolar aspirate in children of pregnant women positive for COVID-19 (Table 2).[4954] During the course of this review, we did not find any casecontrol or cohort studies that reported the presence of congenital and intrapartum infections as the most likely case.

Population studies, systematic reviews and meta-analyses Low incidence of neonatal infection has been found in population studies of COVID-19-positive mothers (confirmed by RT-PCR tests). A prospective cohort study by Khoury in the United States found a 2.5\% (6/236) incidence rate of early-onset neonatal infection in newborns of COVID-19-positive mothers screened with nasopharyngeal swabs at 24 hours of life, repeated serially up to 96 hours of life.[55] The aforementioned study by Knight in the UK reported that of a total of 265 neonates screened for the virus, approximately 5\% (12/265) were positive, half of whom tested positive during the first 12 hours of life.[29]
Universal screening for COVID-19 in neonates born to asymptomatic mothers has shown unexpected results: of 418 newborns screened, $9(2.2 \%)$ were positive for SARS-CoV-2 in the first 12 hours of life; $3(0.7 \%)$ of whom tested positive within the first 3 hours after birth. Eight of nine mothers had negative RT-PCR tests. The only one RT-PCR positive newborn whose mother was COVID-19-positive in this case series is shown in Table 2.[48]

Table 3 summarizes results of systematic reviews focusing on congenital and intrapartum SARS-CoV-2 infections in newborns. [56-68] In the review published by Gajbhiye,[61] the frequency of neonates born to COVID-19-positive mothers testing positive for SARS-CoV-2 via either RT-PCR or antibody tests was $7.6 \%$ (24/313); while Lopes-Sousa found a lower prevalence, with $1.8 \%$ (9/493).[64] A secondary analysis undertaken by Gajbhiye[61] that only took into account neonates diagnosed within the first 48 hours 


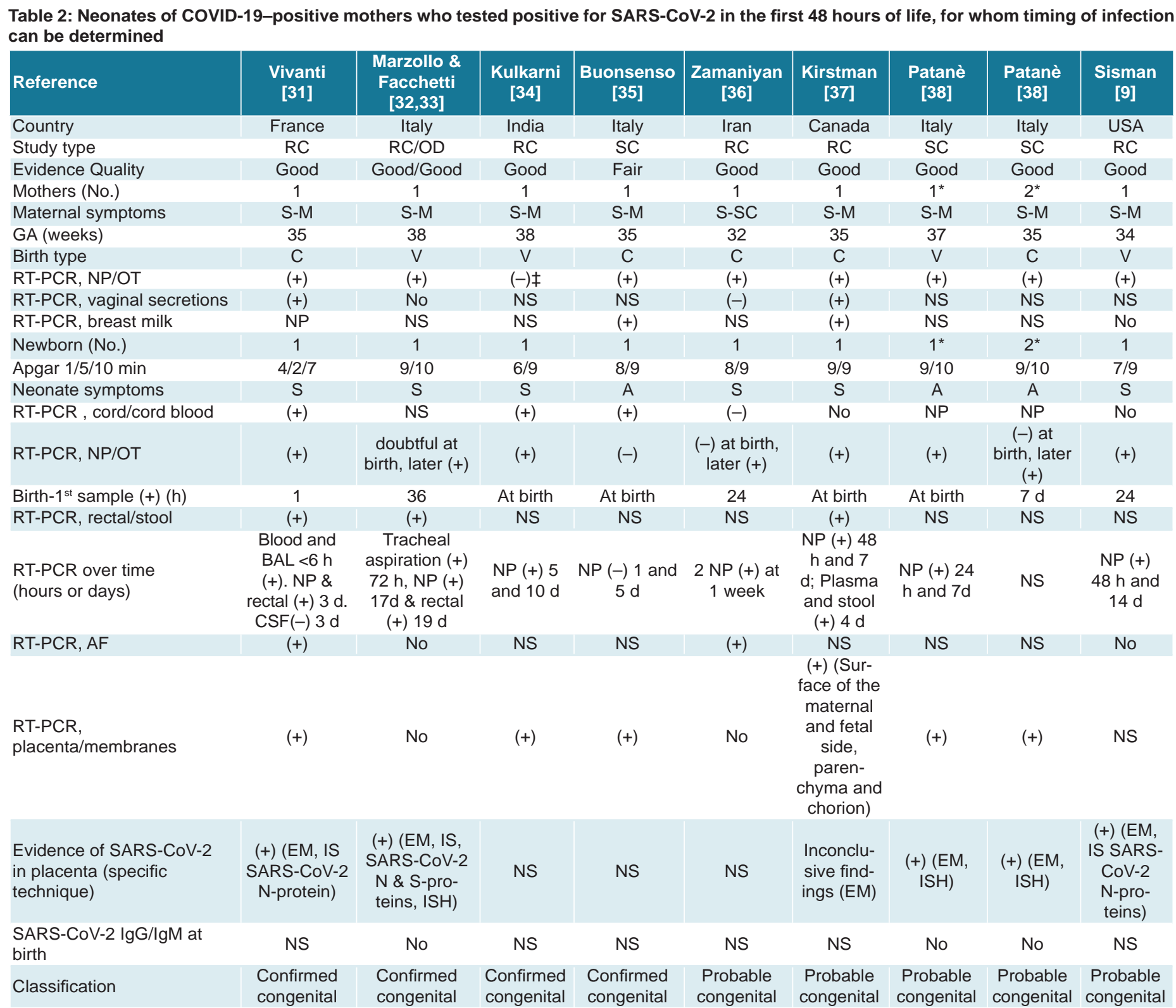

CR: case report CS: case series DO: descriptive/observational S-SC: symptoms-severe or critical S-M: symptoms-mild S-NS: symptoms- severity not specified GA: gestational age PT: preterm FT: full-term C: cesarean V: vaginal (+): positive (-): negative NS: not specified RT-PCR: real-time polymerase chain reaction S: symptomatic A: asymptomatic NP: nasopharyngeal OP: oropharyngeal Secr ET: endotracheal secretion IgG: immunoglobulin G IgM: immunoglobulin M NA: not apply IP: intrapartum PP: postpartum BAL: broncoalveolar lavage CSF: cerebrospinal fluid ABA: broncoalveolar aspirate RT-ddPCR: reverse transcription droplet digital polymerase chain reaction EM: electron microscopy ISH: in-situ hybridization IS: immunostaining IgG: immunoglobulin G IgM: immunoglobulin $M$ *Different mothers or newborns reported from a same study **Number of mothers or newborns łserological studies positive for SARS-CoV-2

found a frequency of $8.0 \%$, which constitutes an estimate of the frequency of infections acquired either congenitally or intrapartum.

A systematic review by Dhir[66] also using criteria developed by Shah[4] includes 58 newborns diagnosed positive for COVID-19 by RT-PCR, regardless of whether or not the mother was positive. Frequency of infections acquired congenitally, intrapartum or postpartum was $6.9 \%$ (4/58), $0.0 \%(0 / 58)$ and $70.7 \%(41 / 58)$, respectively. In $22.4 \%(13 / 58)$ of newborns, the timing of infection could not be determined.

Another systematic review examing all newborns confirmed positive for SARS-CoV-2 by RT-PCR, which did consider either maternal COVID-19 status or the child's age at diagnosis, found 112 neonates whose infection timing was known, 29.5\% (36/122) corresponding to congenital or intrapartum infections, and the remainder to infections acquired postpartum. Of these 36 infants, in $30.6 \%(11 / 36)$ the timing of infections (congenital or intrapartum) was classified as confirmed. In 25/36 (69.4\%) the timing of infections was classified as probable or possible. In addition to the 112 infants assessed in this analysis, the review included another 54 infants for whom it was not possible to specify the timing of infection due to insufficient data in the original articles.[67] Authors of this systematic review used the classification scheme developed by Shah.[4] 


\section{(Continuation of Table 2)}

\begin{tabular}{|c|c|c|c|c|c|c|c|c|c|c|}
\hline Reference & $\begin{array}{l}\text { Carosso } \\
\text { [39] }\end{array}$ & $\begin{array}{l}\text { Dong } \\
\text { [40] }\end{array}$ & $\begin{array}{l}\text { Zeng H } \\
\text { [41] }\end{array}$ & $\begin{array}{l}\text { Zeng H } \\
\text { [41] }\end{array}$ & $\begin{array}{l}\text { Gao } \\
{[42]}\end{array}$ & $\begin{array}{c}\text { Hinojosa- } \\
\text { Velasco } \\
{[45]}\end{array}$ & $\begin{array}{c}\text { Martínez- } \\
\text { Pérez } \\
\text { [46] }\end{array}$ & $\begin{array}{l}\text { Schwartz } \\
\text { [47] }\end{array}$ & $\begin{array}{c}\text { Schwartz } \\
{[47]}\end{array}$ & $\begin{array}{l}\text { McDevitt } \\
\text { [48] }\end{array}$ \\
\hline Country & Italy & China & China & China & China & Mexico & Spain & Iran & Iran & USA \\
\hline Study type & CR & CR & CS & CS & CR & CR & CS & CS & CS & DO \\
\hline Evidence quality & Fair & Fair & Fair & Fair & Good & Good & Poor & Poor & Poor & Fair \\
\hline Mothers (No.) & 1 & 1 & $1^{*}$ & $2^{*}$ & 1 & 1 & $3^{\star \star}$ & $1^{*}$ & $2^{\star}$ & 1 \\
\hline Maternal symptoms & S-M & S-SC & S-NS & S-NS & S-NS & S-SC & A/S-M & S-SC & S-NS & $A$ \\
\hline GA (weeks) & 37 & 34 & ND & NS & 38 & 38 & $\begin{array}{l}\text { PT } 2, \text { GA } \\
\text { NS } 1\end{array}$ & 34 & 34 & 42 \\
\hline Birth type & V & $\mathrm{C}$ & $\mathrm{C}$ & $\mathrm{C}$ & $\mathrm{C}$ & C & V 2, C 1 & C & $\mathrm{C}$ & C \\
\hline RT-PCR, NP/OP & $(+)$ & $(+)$ & $(+)$ & $(+)$ & $(+)$ & $(+)$ & $(+)$ & $(+)$ & $(+)$ & $(+)$ \\
\hline $\begin{array}{l}\text { RT-PCR, vaginal } \\
\text { secretions }\end{array}$ & $(-)$ & $(-)$ & NS & NS & NS & NS & NS & NS & NS & NS \\
\hline RT-PCR, breast milk & $(-)$ & $(-)$ & NS & NS & NS & $(+)$ & NS & NS & NS & NS \\
\hline Newborn (No.) & 1 & 1 & 1 & 2 & 1 & 1 & $3 \dagger$ & 1 & 2 & 1 \\
\hline Apgar $1 / 5 / 10$ min & $9 / 10$ & $9 / 10$ & $8-9 / 9-10$ & $8-9 / 9-10$ & $8 / 9$ & $8 / 9$ & $\begin{array}{c}5 \text { min }>5 \text { in } \\
2 \text { and }<5 \\
\text { in } 1\end{array}$ & $4 / 5$ & $9 / 10$ & NS \\
\hline Neonatal symptoms & 1 & 1 & $1^{*}$ & $2^{*}$ & 1 & 1 & $3^{\star \star}$ & $1^{*}$ & $2^{*}$ & 1 \\
\hline $\begin{array}{l}\text { RT-PCR, cord/cord } \\
\text { blood }\end{array}$ & $(-)$ & NS & $(-)$ & $(-)$ & $(-)$ & No & NS & NS & NS & NS \\
\hline RT-PCR, NP/OP & $(+)$ & $(-)$ & $(-)$ & $(-)$ & $(-)$ & $(+)$ & $(+)$ & $(+)$ & $(+)$ & $(+)$ \\
\hline Birth-1 $1^{\text {st }}$ sample (+) (h) & At birth & NA & NA & NA & NA & At birth & At birth & 2 & 1 & 9 \\
\hline RT-PCR, rectal/stool & NS & NS & NS & NS & $(-)$ & $(+)$ & NS & NS & NS & NS \\
\hline $\begin{array}{l}\text { RT-PR over time } \\
\text { (hours or days) }\end{array}$ & $N P(-) 37 \mathrm{~h}$ & $\begin{array}{c}5 \text { tests }(-) \\
\text { from } 2 \mathrm{~h} \\
\text { to } 15 \mathrm{~d}\end{array}$ & NS & NS & $\begin{array}{l}\text { NP and } \\
\text { rectal (-) } \\
7 \text { d. RT- } \\
\text { ddPCR (+) } \\
7 \text { d }\end{array}$ & $\begin{array}{l}\text { Stool (+) } \\
4 \text { d, NP y } \\
\text { stool (-) } \\
13 \mathrm{~d}\end{array}$ & $N P(-) 2 d$ & NS & NS & No \\
\hline RT-PCR, AF & No & NS & NS & NS & $(-)$ & NS & NS & NS & NS & NS \\
\hline $\begin{array}{l}\text { RT-PCR, placenta/ } \\
\text { membranes }\end{array}$ & $(-)$ & NS & NS & NS & $(-)$ & No & NS & NS & NS & NS \\
\hline $\begin{array}{l}\text { Evidence of SARS- } \\
\text { CoV-2 in placenta } \\
\text { (specific } \\
\text { technique) }\end{array}$ & NS & NS & NS & NS & NS & NS & NS & NS & NS & NS \\
\hline $\begin{array}{l}\text { SARS-CoV-2 IgG/lgM } \\
\text { at birth }\end{array}$ & $(+/-)$ & $+/+$ & $+/+$ & $+/+$ & $+/+$ & NS & NS & NS & NS & NS \\
\hline
\end{tabular}

Classification

CR: case report CS: case series DO: descriptive/observational S-SC: symptoms-severe or critical S-M: symptoms-mild S-NS: symptoms- severity not specified GA: gestational age PT: preterm FT: full-term C: cesarean V: vaginal (+): positive (-): negative NS: not specified RT-PCR: real-time polymerase chain reaction S: symptomatic A: asymptomatic NP: nasopharyngeal OP: oropharyngeal Secr ET: endotracheal secretion IgG: immunoglobulin G IgM: immunoglobulin M NA: not apply IP: intrapartum PP: postpartum BAL: broncoalveolar lavage CSF: cerebrospinal fluid ABA: broncoalveolar aspirate RT-ddPCR: reverse transcription droplet digital polymerase chain reaction EM: electron microscopy ISH: in-situ hybridization IS: immunostaining IgG: immunoglobulin G IgM: immunoglobulin M *Different mothers or newborns reported from a same study **Number of mothers or newborns łserological studies positive for SARS-CoV-2

An article currently in publication summarizes the largest number of COVID-19-positive mothers and their newborns (1787 motherchild pairs). Only $2.7 \%$ (49/1787) of newborns tested positive.[68] However, diagnostic criteria are not specified. This percentage is similar to that found by Lopes-Sousa,[64] at 1.8\% (9/493) and its authors confirm that this percentage is similar to the frequency of newborns (2/71) affected in the three previous coronavirus epidemics (SARS-1, MERS, HKCoVISARS), in which the only two neonates reported were diagnosed during the HKCoVISARS epidemic. Both reviews $[64,68]$ assume these to be cases of vertical transmission.

A meta-analysis by Kotlyar[7] includes newborns with diagnoses of COVID-19 in the first 48 hours after birth born to women diagnosed with COVID-19 in their third trimester of pregnancy. The authors found that frequency of vertical infection varies according to diagnostic method: nasopharyngeal (3.2\%, 27/936), placental $(7.7 \%, 2 / 26)$, serological $(3.7 \%, 3 / 82)$ or umbilical cord blood samples $(2.9 \%, 1 / 34)$.

In our review, we identified 53 reports of COVID-19 cases diagnosed in the first 48 hours of life. The rates of infections acquired either congenitally or intrapartum were $24.5 \%(13 / 53)$ and $15.1 \%(8 / 53)$, respectively, in addition to $15.1 \%(8 / 53)$ whose infection timing was classified as postpartum. The timing of infection could not be determined in $45.3 \%$ (24/53) This was due to the decision by the authors to classify all cases via strict adherence to the classification criteria established for this study, with the aim of gaining precision in classifying cases, especially those acquired either in-utero or during birth (Figure 2).

Epidemiological analyses have confirmed the possibility of intrauterine or intrapartum SARS-CoV-2 transmission, but the frequency of presentation is low. Even in COVID-19-positive 
(Continuation of Table 2)

\begin{tabular}{|c|c|c|c|c|c|c|c|c|}
\hline Reference & $\begin{array}{c}\text { Zeng L } \\
\text { [49] }\end{array}$ & $\begin{array}{c}\text { Zeng L } \\
\text { [49] }\end{array}$ & $\begin{array}{c}\text { Zeng L } \\
\text { [49] }\end{array}$ & $\begin{array}{c}\text { Bordbar } \\
\text { [50] }\end{array}$ & $\begin{array}{l}\text { Lorenz } \\
\text { [51] }\end{array}$ & $\begin{array}{c}\text { Sinelli } \\
\text { [52] }\end{array}$ & $\begin{array}{c}\text { Pierce- } \\
\text { Williams } \\
\text { [53] }\end{array}$ & $\begin{array}{c}\text { Gregorio- } \\
\text { Hernández } \\
\text { [54] }\end{array}$ \\
\hline Country & China & China & China & Iran & Germany & Italy & USA & Spain \\
\hline Study type & DO & DO & DO & $\mathrm{CR}$ & CR & $\mathrm{CR}$ & DO & CS \\
\hline Evidence quality & Fair & Fair & Fair & Good & Good & Good & Fair & Good \\
\hline Mothers (No.) & $1^{*}$ & $2^{*}$ & $3^{*}$ & 1 & 1 & 1 & 1 & 1 \\
\hline Maternal symptoms & S-M & A & A & A & S-L & A & S-SC & S-M \\
\hline GA (weeks) & 40 & 40 & 31 & NS & 40 & FT & NS & 38 \\
\hline Birth type & C & $\mathrm{C}$ & C & $\mathrm{C}$ & V & V & NS & V \\
\hline RT-PCR, NP/OP & $(+)$ & $(+)$ & $(+)$ & $(+)$ & $(+)$ & $(+)$ & $(+)$ & $(+)$ \\
\hline RT-PCR, vaginal secretions & NS & NS & NS & NS & NS & NS & NS & NS \\
\hline RT-PCR, breast milk & NS & NS & NS & NS & NS & NS & NS & NS \\
\hline Newborn (No.) & $1^{*}$ & $2^{*}$ & $3^{*}$ & 1 & 1 & 1 & 1 & 1 \\
\hline Apgar 1/5/10 min & NS & NS & $3 / 4 / 5$ & $8 / 9$ & $9 / 9$ & $9 / 10$ & NS & NS \\
\hline Neonatal symptoms & $\mathrm{S}$ & $\mathrm{S}$ & $S$ & $\mathrm{~S}$ & $\mathrm{~S}$ & $\mathrm{~S}$ & $A$ & $\mathrm{~S}$ \\
\hline RT-PCR, cord/cord blood & NS & NS & NS & No & NS & NS & NS & No \\
\hline RT-PCR, NP/OP & $(+)$ & $(+)$ & $(+)$ & $(+)$ & $(+)$ & $(+)$ & $\begin{array}{l}(-) 24 \mathrm{~h}, \\
\text { after (+) }\end{array}$ & $\mathrm{ABA}(+)$ \\
\hline Birth- $1^{\text {st }}$ sample (+) (h) & 48 & 48 & 48 & 48 & \pm 48 & $48-72$ & 48 & $\geq 48$ \\
\hline RT-PCR, rectal/stool & $(+)$ & $(+)$ & $(+)$ & NS & $(+)$ & NS & NS & NS \\
\hline RT-PR over time (hours or days) & $\begin{array}{l}\mathrm{NP}(+) 4 \mathrm{~d} \\
\text { and }(-) 6 \mathrm{~d}\end{array}$ & $\begin{array}{l}\mathrm{NP}(+) 4 \mathrm{~d} \\
\text { and }(-) 6 \mathrm{~d}\end{array}$ & $\begin{array}{l}\mathrm{NP}(+) 4 \mathrm{~d} \\
\text { and }(-) 7 \mathrm{~d}\end{array}$ & $N P(-)>4 d$ & $\begin{array}{l}\text { NP and rectal } \\
(+) 14 \mathrm{~d}\end{array}$ & $\begin{array}{l}\mathrm{NP}(+) 15 \\
\text { and } 21 \mathrm{~d}\end{array}$ & NS & $N S(-) 8 d$ \\
\hline RT-PCR, AF & NS & NS & NS & NS & NS & NS & NS & NS \\
\hline RT-PCR, placenta/membranes & NS & NS & NS & NS & NS & NS & NS & NS \\
\hline $\begin{array}{l}\text { Evidence of SARS-CoV-2 in } \\
\text { placenta (specific technique) }\end{array}$ & NS & NS & NS & NS & NS & NS & NS & NS \\
\hline SARS-CoV-2 IgG/lgM at birth & NS & NS & NS & NS & NS & NS & NS & NS \\
\hline Classification & $\begin{array}{l}\text { Probable } \\
\text { postpartum }\end{array}$ & $\begin{array}{l}\text { Probable } \\
\text { postpartum }\end{array}$ & $\begin{array}{l}\text { Probable } \\
\text { postpartum }\end{array}$ & $\begin{array}{l}\text { Probable } \\
\text { postpartum }\end{array}$ & $\begin{array}{l}\text { Probable } \\
\text { postpartum }\end{array}$ & $\begin{array}{l}\text { Probable } \\
\text { postpartum }\end{array}$ & $\begin{array}{l}\text { Probable } \\
\text { postpartum }\end{array}$ & $\begin{array}{l}\text { Probable } \\
\text { postpartum }\end{array}$ \\
\hline
\end{tabular}

CR: case report CS: case series DO: descriptive/observational S-SC: symptoms-severe or critical S-M: symptoms-mild S-NS: symptoms- severity not specified GA: gestational age PT: preterm FT: full-term C: cesarean V: vaginal (+): positive (-): negative NS: not specified RT-PCR: real-time polymerase chain reaction S: symptomatic A: asymptomatic NP: nasopharyngeal OP: oropharyngeal Secr ET: endotracheal secretion IgG: immunoglobulin G IgM: immunoglobulin M NA: not apply IP: intrapartum PP: postpartum BAL: broncoalveolar lavage CSF: cerebrospinal fluid ABA: broncoalveolar aspirate RT-ddPCR: reverse transcription droplet digital polymerase chain reaction EM: electron microscopy ISH: in-situ hybridization IS: immunostaining IgG: immunoglobulin G IgM: immunoglobulin M *Different mothers or newborns reported from a same study ${ }^{* *}$ Number of mothers or newborns łserological studies positive for SARS-CoV-2

cases identified during the first 48 hours of life, incidence of vertical transmission represents less than half of all cases, although it should be noted that this figure could be biased as it was not possible to determine the timing of infection in almost half of all cases.

Possible mechanisms driving SARS-CoV-2 vertical transmission The mechanisms by which SARS-CoV-2 can cause

Figure 2: Distribution according to timing of infection. SARS-CoV-2-positive neonates diagnosed during the first $\mathbf{4 8}$ hours of life born to COVID-19-positive mothers, $N=53(n, \%)$

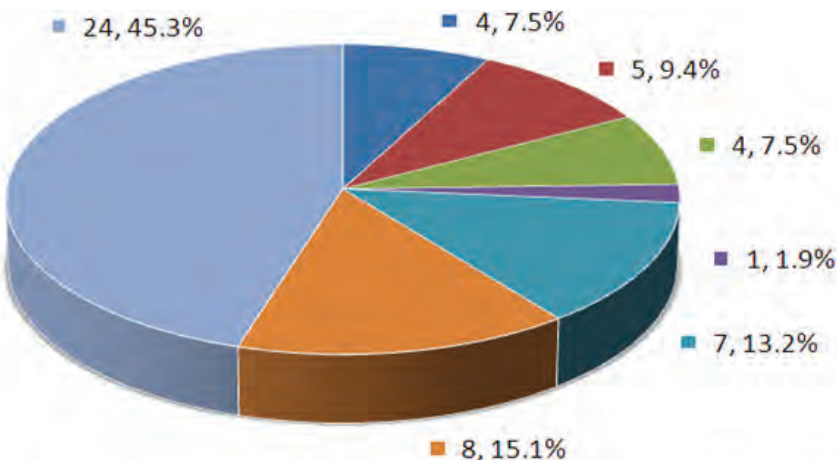

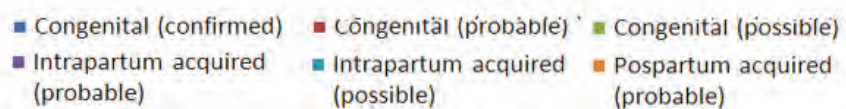

congenital or intrapartum infections are still unknown. In congenital SARS-CoV-2, there are currently four proposed pathways of infection: 1) direct infection of the syncytiotrophoblast and introduction through the syncytial layers via certain receptors, specifically angiotensin-converting enzyme 2 (ACE2) and Fc receptors; 2) exposure to extravillous trophoblasts or other placental cells through maternal circulation; 3) viral passage through cells in the placenta; and 4) ascending infection through the maternal vaginal tract and cervix. In intrapartum infections, one of the main mechanisms of transmission appears to be through maternal vaginal secretions. $[69,70]$ Aspiration of amniotic fluid or maternal blood at birth has also been considered. $[8,14]$

Epidemiological studies have not demonstrated increased risk of miscarriage for COVID-19-positive women.[29] Placental changes consisting of defects in the proliferation and formation of chorionic villi, typical of early stages of pregnancy, occur in a similar proportion to the rate of SARS-CoV-2 infections in the first trimester of pregnancy, which might suggest a correlation between these two rare phenomena. In more advanced stages of pregnancy, placental insufficiency and its direct consequence, intrauterine hypoxia, become more important from both pathophysiological and epidemiological standpoints. Research suggests that placental insufficiency and intrauterine hypoxia occur in 20\% (9/45) of pregnancies involving COVID-19-positive mothers.[68] 
Table 3: Systematic reviews of SARS-CoV-2 vertical transmission in living newborns

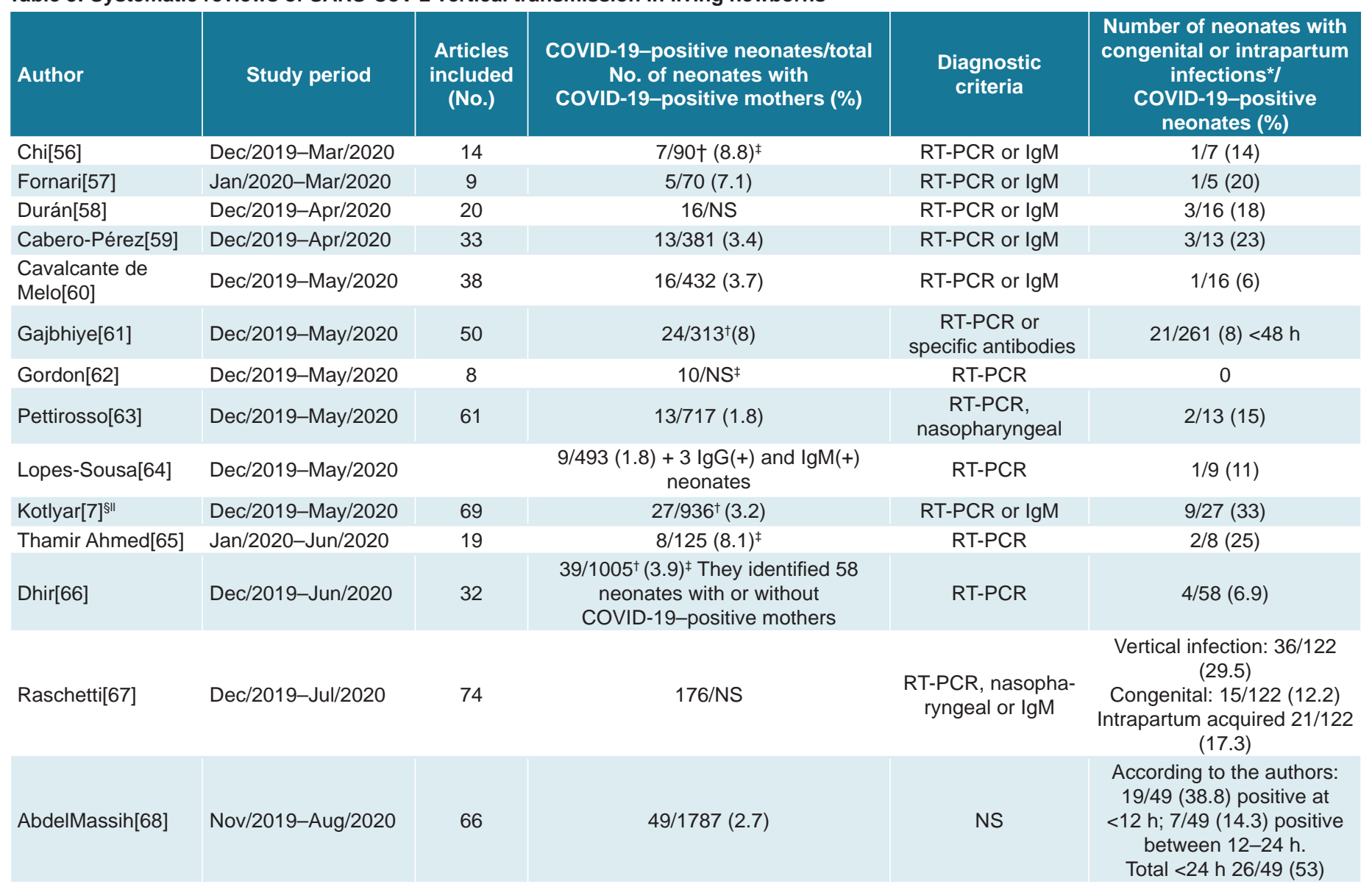

*According to modified criteria by Shah et al.[4] †Number of newborns tested łPatients who recur in different studies were excluded §Includes only COVID-19-positive neonates diagnosed at $\leq 48 \mathrm{~h}$ after birth II Includes meta-analysis of vertical transmission NS: not specified IgG: immunoglobulin G IgM: immunoglobulin M

Placental studies of women diagnosed with COVID-19 in their third trimester have shown signs of poor maternal and fetal vascular perfusion in fetuses and newborns negative for SARSCoV-2.[69] Studies of COVID-19-positive neonates have shown chronic intervillitis with macrophage infiltrates at the placental level.[38] This was also the case in the placenta of a dead fetus, also COVID-19-positive.[71] Evidence of placental SARS-CoV-2 by in situ hybridization, immunostaining or visualization of viral particles by transmission electron microscopy in newborns whose nucleic acid tests were negative suggests that even in cases where SARS-CoV-2 is present in the placenta, the risk of vertical transmission is limited.[70,72]

The placenta constitutes an immunological barrier guarding against vertical transmission of pathogens, which could minimize colonization of the syncytiotrophoblast and subsequent transmission of SARSCoV-2 to the fetus. An important immunomodulatory factor is the maternal-fetal interface, which is composed in turn of the decidua derived from the mother and the placenta derived from the fetus.[73]

ACE2 expression is extensive in the female genital tract and in the feto-placental unit. ACE2 expression varies during the stages of pregnancy; via RNA sequencing of individual cells, some authors have found that it tends to increase as gestation progresses, [74] while others report ACE2 messenger RNA expression is higher in placental cells during the early phases of pregnancy.[75]
Analysis of transcriptomes in placental cells has shown low co-expression levels of ACE2 receptors and transmembraneserine protease 2 (TMPRSS2), suggesting that the virus may use other pathways to enter placental cells, which could differ from the pathways currently being suggested.[76]

Facchetti[33] analyzed expression of SARS-CoV-2 spike proteins (S) in 101 placentas using immunohistochemical techniques. Of the 101 placentas, 15 belonged to mothers who tested positive for COVID-19. Of all the placentas studied, only one-belonging to a newborn with pneumonia who had previously been described as positive for SARS-CoV-2-showed high expression of viral S and nucleocapsid (NC) proteins in the syncytiotrophoblast.[32] SARS-CoV-2 RNA was detected in synctiotrophoblast and intervillous inflammatory cells by in situ hybridization, and particles morphologically consistent with the novel coronavirus were visualized by electron microscopy in the cytoplasm of syncytiotrophoblast cells, the endothelium of fetal capillaries, fibroblasts and mononuclear cells. High expression of $\mathbf{S}$ and NC viral proteins were found in areas of dense inflammation, with a predominance of monocytes and macrophages, as well as in maternal and fetal villous cells. These findings suggest that infections can spread via circulating viruses present in infected fetal mononuclear cells, after recruitment of maternal inflammatory cells, without resulting in villitis. The fact that this was found in only 1 of the 101 placentas examined in the study also supports the notion that vertical transmission of SARSCoV-2 via the transplacental route is a rare event. 
The rarity of this phenomenon has also been suggested by results of other research. Hecht studied 19 placentas from mothers with COVID-19 and detected presence of SARSCoV-2 by in situ hybridization in only 2.[13] Examinations using immunohistochemical techniques demonstrated ACE2 expression differs from that of TMPRSS2 in placentas of women who contracted COVID-19 during pregnancy. ACE2 was localized in the synctiotrophoblast, away from maternal blood sources and mainly in the stroma. TMPRSS2 was present only and sparsely in the villous endothelium and rarely in the syncytiotrophoblast. Taglauer[77] visualized the location and relative abundance of the SARS-CoV-2 spike glycoprotein and the colocalization of the ACE2 and TMPRSS2 proteins using comparative immunofluorescence in placental samples from 15 pregnant women with COVID-19, 5 of whom showed evidence of vertical transmission. In cases with and without evidence of vertical transmission, there was evidence of the presence of the SARS-CoV-2 spike glycoprotein in the villous compartment of placental tissues and predominance of ACE2 protein expression over TMPRSS2 protein expression. Both ACE2 and spike gylcoproteins were consistently expressed in the outer layer of the syncytiotrophoblast of placental villi, in juxtaposition with placental regions associated with maternal blood flow.

The fact that viremia has been found in only $1 \%$ of COVID-19 patients[78] also supports the proposition that vertical transmission of SARS-CoV-2 via the transplacental route is a rare event.

The impact of disease severity in the mother on the likelihood of congenital infection is still under discussion. It has been suggested that congenital infection could be more frequent in cases of women with severe or critical infections,[24] and less frequent after a short-term exposure to the virus in the early stages of fetal development. Speculative explanations have been proposed based on viral incubation periods and the limitations of diagnostic tests. [14] However, a recent study reports presence of SARS-CoV-2 in chorionic villi endothelial cells and, to a lesser extent, in trophoblasts, in COVID-19-positive pregnant women with mild manifestations of the disease.[79] Maternal comorbidities such as preeclampsia, diabetes mellitus and other diseases that can influence expression of ACE2 receptors, as well as certain HLA haplotypes and polymorphisms of immunoregulatory genes, should be taken into account.[70]

In our review, in eight of nine confirmed or probable cases of congenital infection, maternal disease was mild, which seems to suggest that congenital infection can occur regardless of the severity of maternal presentation; or perhaps might even be more common in children born to mothers with mild symptoms. A retrospective cohort study from a US hospital shows that severe or critical infection in the mother was not associated with vertical transmission of COVID-19.[80]

Transmission of protective antibodies from mother to fetus through the placenta could provide a tentative explanation for the lower proportion of congenital infections in newborns of mothers with severe or critical illness presentations found in this review; however there is no certainty regarding the role of antibodies transferred from the mother. Although some of these antibodies can neutralize viral particles, others facilitate their capture by cells with a high presence of Fc receptors, such as endothelial and syncytiotrophoblast cells, which would favor transplacental viral transmission.[70] Asymptomatic neonates or neonates presenting with mild symptoms born to women with COVID-19 confirmed either via nucleic acid tests or serology have presented with elevated levels of anti-SARSCoV-2-specific IgG but negative RT-PCR tests.[81]

\section{PERSPECTIVES}

More studies are required on intrauterine and intrapartum SARSCoV-2 transmission, and larger datasets are required before we can estimate the incidence of this phenomenon or perform causality analyses. Some registries have been working in this direction and various initiatives have emerged to catalogue vertical transmission. $[2,29,82]$

Current mathematical modeling suggests that combining drug-based therapies with vaccines could optimize treatment of diseases capable of both vertical and horizontal transmission.[83]

Although it is premature to propose drugs to prevent maternal-fetal transmission of SARS-CoV-2 and its effects on pregnancy, drugs that can influence levels of gene expression or enzymatic activity of ACE2 could be potential candidates. However, a better understanding is still needed of the ACE2-receptor contribution to facilitating viral entry into placental cells.[76,84] Passive immunization could be another option, due to its potential for minimizing effects of maternal viral infection in gestational products and in the fetal systemic inflammatory response.[85]

An ideal proposal would involve active immunization of pregnant women, but historically, pregnant and lactating women have not been included in such studies for safety reasons. It is possible that effective vaccination of the general population will prevent SARSCoV-2 infection in pregnant women through herd immunity. New proposals have been forwarded allowing for the use of vaccines in pregnant women during epidemics of emerging diseases, including WHO support for recommendations in 2019 by the Working Group on Research Ethics in Pregnancy, Epidemics and New Technologies. $[86,87]$ Nevertheless, before considering vaccination of pregnant women, the short- and long-term effects of COVID-19 on pregnancy, as well as on fetuses and newborns, should be investigated, as sufficient information is lacking. Related elements for further research are the type of vaccine to be used (platform, adjuvants, immunogenicity, toxicological analysis, etc.) and the likelihood of vaccine acceptance in this population group.

The main limitation of this review is the high level of uncertainty that persists regarding the timing of infection, which could not be determined in all cases. The strengths of the review lie in the novelty of the case-by-case analysis, the use of a new classification system, the decision to include only newborns of COVID-19-positive mothers who tested positive for the virus in the first 48 hours after birth or near this time limit, and the extensive review of articles published in both Spanish and English.

\section{CONCLUSIONS}

Congenital and intrapartum SARS-CoV-2 infection in the fetus/ newborn is possible, but rare. In the published literature, among newborns of COVID-19-positive mothers who tested positive in the first 48 hours of life, congenital and intrapartum infections account for just over a third of all infections. We recommend undertaking international collaborative studies at the population level using standardized instruments to determine the frequency of vertical transmission of SARS-CoV-2. - 1/ 


\section{REFERENCES}

1. Yang Z, Liu Y. Vertical transmission of Severe Acute Respiratory Syndrome Coronavirus 2: a systematic review. Am J Perinatol. 2020 Aug;37(10):1055-60.

2. Gale C, Knight M, Ladhani S, Draper ES, Sharkey D, Doherty $C$, et al. National active surveillance to understand and inform neonatal care in COVID-19. Arch Dis Child Fetal Neonatal Ed. 2020 Jul;105(4):346-7.

3. Schwartz DA, Thomas KM. Characterizing COVID-19 maternal-fetal transmission and placental infection using comprehensive molecular pathology. EBioMedicine. 2020 Oct;60:102983. DOI: https://doi.org/10.1016/j.ebiom.2020.102983.

4. Shah PS, Diambomba Y, Acharya G, Morris SK, Bitnun A. Classification system and case definition for SARS-CoV-2 infection in pregnant women, fetuses, and neonates. Acta Obstet Gynecol Scand. 2020 May;99(5):565-8.

5. Sola A, Maksimovic L, Montes Bueno MT, Rodríguez S, Cardetti M, Golombek SG, et al. Sociedad Iberoamericana de Neonatología y COVID-19 perinatal: Información y recomendaciones de SIBEN. [place unknown]: Ediciones SIBEN; 2020 Apr 17. 68 p. ISBN 978-1-7923-3225-8. Spanish.

6. Murad HM, Sultan S, Haffar S, Bazerbachi F. Methodological quality and synthesis of case series and case reports. BMJ. Evid Based Med. 2018 Apr;23(2):60-3.

7. Kotlyar A, Grechukhina O, Chen A, Popkhadze S, Grimshaw A, Tal O, et al. Vertical transmission of COVID-19: a systematic review and metaanalysis. Am J Obstet Gynecol. 2020 Jul 31. DOI: https://doi.org/10.1016/j.ajog.2020.07.049. Online ahead of print

8. Schwartz DA, Morotti D, Beigi B, Moshfegh F, Zafaranloo N, Patané L. Confirming vertical fetal infection with COVID-19: neonatal and pathology criteria for early onset and transplacental transmission of SARS-CoV-2 from infected pregnant mothers. Arch Pathol Lab Med. 2020 Dec 1;144(12):1451-6.

9. Sisman J, Jaleel MA, Moreno W, Rajaram V, Collins RR, Savani RC, et al. Intrauterine transmission of SARSCOV-2 infection in a preterm infant. Pediatr Inf Dis J. 2020;39:e265-7.

10. Wu Z, McGoogan JM. Characteristics of and important lessons from the coronavirus disease 2019 (COVID-19) outbreak in China: summary of a report of 72314 cases from the Chinese Center for Disease Control and Prevention. JAMA. 2020 Apr 7;323(13):1239-42. Online ahead of print 2020 Feb 24.

11. Wang C, Zhou YH, Yang HX, Poon LC. Intrauterine vertical transmission of SARS-CoV-2: what we know so far. Ultrasound Obstet Gynecol. 2020 Jun;55(6):724-5.

12. Schwartz DA. Vertical transmission of Severe Acute Respiratory Syndrome Coronavirus 2 from the mother to the infant. JAMA Pediatr. 2020 Oct 1;174(10):1004-5.

13. Hecht JL, Quade B, Deshpande V, Mino-Kenudson $M$, Ting DT, Desai N, et al. SARS-CoV-2 can infect the placenta and is not associated with specific placental histopathology: a series of 19 placentas from COVID-19-positive mothers. Mod Pathol. 2020 Nov;33(11):20922103. Online ahead of print 2020 Aug 2. DOI: https://doi.org/10.1038/s41379-020-0639-4.

14. Bahadur G, Homburg R, Yoong W, Singh C, Bhat $M$, Kotabagi $P$, et al. Adverse outcomes in SAR-CoV-2 (COVID-19) and SARS virus related pregnancies with probable vertical transmission. JBRA Assist Reprod. 2020 JulSep;24(3):351-7.

15. Diriba K, Awulachew E, Getu E. The effect of coronavirus infection (SARS-CoV-2, MERSCoV, and SARS-CoV) during pregnancy and the possibility of vertical maternal-fetal transmission: a systematic review and meta-anal- ysis. Eur J Med Res, 2020 Sep 4:25(1):39. DOI: https://doi.org/10.1186/s40001-020-00439-w.

16. Antoun L, Taweel NE, Ahmed I, Patni S, Honest H. Maternal COVID-19 infection, clinical characteristics, pregnancy, and neonatal outcome: a prospective cohort study. Eur J Obstet Gynecol Reprod Biol. 2020 Sep;252:559-62.

17. Akhtar H, Patel C, Abuelgasim E, Harky A. COVID-19 (SARS-CoV-2) infection in pregnancy: a systematic review. Gynecol Obstet Invest. 2020;85(4):295-306.

18. Kucirka LM, Lauer SA, Laeyendecker O, Boon D, Lessler J. Variation in false-negative rate of reverse transcriptase polymerase chain reaction-based SARS-CoV-2 tests by time since exposure. Ann Intern Med. 2020 Aug 18;173(4):262-7.

19. Penfield CA, Brubaker SG, Limaye MA, Lighter J, Ratner AJ, Thomas KM, et al. Detection of SARSCOV-2 in placental and fetal membrane samples. Am J Obstet Gynecol MFM. 2020 Aug;2(3):100133. DOI: 10.1016/j.ajogmf.2020.100133.

20. Wang S, Guo L, Chen L, Liu W, Cao Y, Zhang J, et al. A case report of neonatal COVID-19 infection in China. Clin Infect Dis. 2020 Jul 28;71(15):853-7.

21. Nie R, Wang S, Yang Q, Fan C, Liu Y, He W, et al. Clinical features and the maternal and neonatal outcomes of pregnant women with coronavirus disease 2019. J Infect. 2020 Jul;81(1):e40-e4

22. Khan S, Jun L, Nawsherwan, Siddique R, Li Y, Han $\mathrm{G}$, et al. Association of COVID-19 with pregnancy outcomes in health-care workers and general women. Clin Microbiol Infect. 2020 Jun;26(6):788-90.

23. Zhang Z-J, Yu X-J, Fu T, Liu Y, Jiang Y, Xiang Yang $B$, et al. Novel coronavirus infection in newborn babies aged $<28$ days in China. Eur Respir J. 2020 Jun 18:55(6):2000697. DOI: 10.1183/13993003.00697-2020.

24. Alzamora MC, Paredes T, Caceres D, Webb CM, Valdez LM, La Rosa M. Severe COVID-19 during pregnancy and possible vertical transmission. Am J Perinatol. 2020 Jun;37(8):861-5.

25. Govind A, Essien S, Karthikeyan A, Fakokunde A, Janga D, Yoong W. Re: Novel Coronavirus COVID-19 in late pregnancy: outcomes of fi rst nine cases in an inner city London hospital. Eur J Obstet Gynecol Reprod Biol. 2020 Aug;251:272-4.

26. Ferrazzi E, Frigerio L, Savasi V, Vergani P, Prefumo $\mathrm{F}$, Barresi S, et al. Vaginal delivery in SARS-CoV-2 infected pregnant women in Northern Italy: a retrospective analysis. BJOG. 2020 Aug;127(9):1116-21.

27. Kalane S, Gokhale A, Patwardhan S. Early onset SARS-CoV-2 pneumonia in a preterm neonate Probably acquired through vertical transmission [Internet]. Durham: Research Square; 2020 Aug 14 [cited 2020 Sep 2]. DOI: https://doi.org/10.21203/ rs.3.rs-58363/v1.

28. Savasi VM, Parisi F, Patanè L, Ferrazzi E, Frigerio L, Pellegrino A, et al. Clinical Findings and disease severity in hospitalized pregnant women with Coronavirus disease 2019 (COVID-19). Obstet Gynecol. 2020 Aug;136(2):252-8.

29. Knight M, Bunch K, Vousden N, Morris E, Simpson N, Gale C, et al. Characteristics and outcomes of pregnant women admitted to hospital with confirmed SARS-CoV-2 infection in UK: national population based cohort study. BMJ. 2020 Jun 8;369:m2107.

30. Sola A, Rodríguez S, Cardetti M, Dávila C. COVID-19 perinatal en América Latina. Rev Panam Salud Pública. 2020 Jul 31;44e: 47. DOI: https:// doi.org/10.26633/RPSP.2020.47. Spanish.

31. Vivanti $\mathrm{AJ}$, Vauloup-Fellous $\mathrm{C}$, Prevot $\mathrm{S}$, Zupan V, Suffee C, Do Cao J, et al. Transplacental transmission of SARS-CoV-2 infection. Nat Commun. 2020 Jul 14;11(1):3572. DOI: $10.1038 / s 41467-020-17436-6$.

32. Marzollo R, Aversa S, Prefumo F, Saccani B, Rodríguez Pérez C, Sartori E, et al. Possible Coro- navirus disease 2019 pandemic and pregnancy: vertical transmission is not excluded. Pediatr Inf Dis J. 2020 Sep;39(9):e261-2.

33. Facchetti F, Bugatti M, Drera E, Tripodo C, Sartori E, Cancila V, et al. SARS-CoV2 vertical transmission with adverse effects on the newborn revealed through integrated immunohistochemical, electron microscopy and molecular analyses of placenta. EBioMedicine. 2020 Sep;59:102951. DOI: https:// doi.org/10.1016/j.ebiom.2020.102951.

34. Kulkarni R, Rajput U, Dawre R, Valvi C, Nagpal R, Magdum N, et al. Early-onset symptomatic neonatal COVID-19 infection with high probability of vertical transmission Infection. 2020 Aug 2;1-5. DOI: https://doi.org/10.1007/s15010-020-01493-6. Online ahead of print.

35. Buonsenso D, Costa S, Sanguinetti M, Cattani P, Posteraro B, Marchetti S, et al. Neonatal late onset infection with severe acute respiratory syndrome coronavirus 2. Am J Perinatol. 2020 Jun;37(8):869-72.

36. Zamaniyan M, Ebadi A, Aghajanpoor S, Rahmani Z, Haghshenas M, Azizi S. Preterm delivery, maternal death, and vertical transmission in a pregnant woman with COVID-19 infection. Prenat Diagn. 2020 Apr 17:1-3. DOI: 10.1002/pd.5713. Online ahead of print.

37. Kirtsman $M$, Diambomba $\mathrm{Y}$, Poutanen SM, Malinowski AK, Vlachodimitropoulou E, Parks WT, et al. Probable congenital SARS-CoV-2 in a neonate born to a woman with active SARS-CoV-2 infection. CMAJ. 2020 Jun15;192(24):E647-50.

38. Patanè L, Morotti D, Giunta MR, Sigismondi C, Piccoli MG, Frigerio $\mathrm{L}$, et al. Vertical transmission of COVID-19: SARS-CoV-2 RNA on the fetal side of the placenta in pregnancies with COVID-19 positive mothers and neonates at birth. Am J Obstet Gynecol MFM. 2020 Aug;2(3):100145. DOI: 10.1016/j.ajogmf.2020.100145.

39. Carosso A, Cosma S, Borella F, Marozio L, Coscia A, Ghisetti $V$, et al. Pre-labor anorectal swab for SARS-CoV-2 in COVID-19 pregnant patients: is it time to think about it? Eur J Obstet Gynecol Reprod Biol. 2020 Jun;249:98-9.

40. Dong L, Tian J, He S, Zhu C, Wang J, Liu C, et al. Possible vertical transmission of SARS-CoV-2 from an infected mother to her newborn. JAMA. 2020 May 12;323(18):1846-8.

41. Zeng $\mathrm{H}, \mathrm{Xu} \mathrm{C}$, Fan J, Tang $\mathrm{Y}$, Deng $\mathrm{Q}$, Zhang $W$, et al. Antibodies in infants born to mothers with COVID-19 pneumonia. JAMA. 2020 May 12;323(18):1848-9.

42. Gao J, Hu X, Sun X, Luo X, Chen L. Possible intrauterine SARS-CoV-2 infection: Positive nucleic acid testing results and consecutive positive SARSCoV-2-specific antibody levels within 50 days after birth. Int J Infect Dis. 2020 Oct;99:272-5.

43. Kimberlin DW, Stagno S. Can SARS-CoV-2 infection be acquired in utero? More definitive evidence is needed. JAMA. 2020 May 12;323(18):1788-9.

44. Simões E Silva AC, Leal CRV. Is SARS-CoV-2 vertically transmitted? Front Pediatr. 2020 May 15:8:276. DOI: 10.3389/fped 2020.00276.

45. Hinojosa-Velasco A, Bobadilla-Montes de Oca PV, García-Sosa LE, Mendoza-Durán JG, Pérez-Méndez MJ, Dávila-González E, et al. A case report of newborn infant with severe COVID-19 in Mexico: detection of SARS-CoV-2 in human breast milk and stool. Int J Infect Dis. 2020 Nov;100:21-4.

46. Martínez-Pérez $\mathrm{O}$, Vouga $\mathrm{M}$, Cruz Melguizo $\mathrm{S}$, Forcen Acebal L, Panchaud A, Muñoz-Chápuli M, et al. Association between mode of delivery among pregnant women with COVID-19 and maternal and neonatal outcomes in Spain. JAMA. 2020 Jul 21;324(3):296-9.

47. Schwartz DA, Mohagheghi $P$, Beigi B, Zafaranloo N, Moshfegh F, Yazdani A. Spectrum of neonatal COVID-19 in Iran: 19 infants with 
SARS-CoV-2 perinatal infections with varying test results, clinical findings and outcomes. J Matern Fetal Neonatal Med. 2020 Aug 12;1-10. DOI: 10.1080/14767058.2020.1797672.

48. McDevitt KEM, Ganjoo N, Mlangeni D, Pathak S. Outcome of universal screening of neonates for COVID-19 from asymptomatic mothers. J Infect. 2020 Sep;81(3):452 -82.

49. Zeng L, Xia S, Yuan W, Yan K, Xiao F, Shao J, et al. Neonatal early-onset infection with SARSCoV-2 in 33 neonates born to mothers with COVID-19 in Wuhan, China. JAMA Pediatr. 2020 Jul 1;174(7):722-5

50. Bordbar A, Kashaki M, Rezaei F, Jafari R. Vertical transmission of COVID-19 in a 1-day-old neonate. Travel Med Infect Dis. 2020 Sep 17;38:101879. DOI: 10.1016/j.tmaid.2020.101879.

51. Lorenz N, Treptow A, Schmidt S, Hofmann R, Raumer-Engler M, Heubner G, et al. Neonatal early-onset infection with SARS-CoV-2 in a newborn presenting with encephalitic symptoms. Pediatr Infect Dis J. 2020 Aug;39(8): e212.

52. Sinelli M, Paterlini G, Citterio M, Di Marco A, Fedeli T, Ventura ML. Early neonatal SARS-CoV-2 infection manifesting with hypoxemia requiring respiratory support. Pediatrics. 2020 Jul;146(1):e20201121.

53. Pierce-Williams RAM, Burd $\mathrm{J}$, Felder $\mathrm{L}$, et al. Clinical course of severe and critical COVID-19 in hospitalized pregnancies: a US cohort study. Am J Obstet Gynecol. 2020;100134.

54. Gregorio-Hernández R, Escobar-Izquierdo $A B$, Cobas-Pazos J, Martínez-Gimeno A. Point-of-care lung ultrasound in three neonates with COVID-19. Eur J Pediatr. 2020 Aug;179(8):1279-85.

55. Khoury R, Bernstein PS, Debolt C, Stone J, Sutton DM, Simpson LL, et al. Characteristics and outcomes of 241 births to women with severe acute respiratory syndrome Coronavirus 2 (SARSCoV-2) infection at five New York City Medical Centers. Obstet Gynecol. 2020 Aug:136(2):273-82.

56. Chi H, Chiu NC, Tai YL, Chang HY, Lin CH, Sung $\mathrm{YH}$, et al. Clinical features of neonates born to mothers with coronavirus disease-2019: a systematic review of 105 neonates. J Microbiol Immunol Infect. 2020 Aug 14. DOI: 10.1016/j.jmii.2020.07.024. Online ahead of print.

57. Fornari F. Vertical transmission of Covid-19: a systematic review. J Pediatr Perinatol Child Health. 2020 Apr 20;4(2):7-13.

58. Duran $\mathrm{P}$, Berman $\mathrm{S}$, Niermeyer $\mathrm{S}$, Jaenisch $\mathrm{T}$, Forster T, Gómez Ponce de León R, et al. COVID-19 and newborn health: systematic review. Rev Panam Salud Pública. 2020 Apr 27:44:e54. DOI: 10.26633/RPSP.2020.54.

59. Cabero-Pérez MJ, Gómez-Acebo I, DierssenSotos T, Llorca J. Infección por SARS-CoV-2 en el embarazo y posibilidad de transmisión al neonato: una revisión sistemática. Semergen. 2020 Aug;46 Suppl 1:40-7. Spanish.

60. Cavalcante de Melo G, Gomes Machado de Araújo KC. COVID-19 infection in pregnant women, preterm delivery, birth weight, and vertical transmission: a systematic review and meta-analysis. Cad Saúde Pública. 2020 Jul 17;36(7):e00087320. Online ahead of print

61. Gajbhiye RK, Modi DN, Mahale SD. Pregnancy outcomes, newborn complications and maternal-fetal transmission of SARS-CoV-2 2 in women with COVID-19: a systematic review of 441 cases. medRxiv [Internet]. New York: Cold Spring Harbor Laboratory; 2020 May 5 [cited 2020 May 20]. Available at: https://doi.org/10.1101/2020.04.11.20062356

62. Gordon M, Kagalwala T, Rezk K, Rawlingson C, Idris Ahmed M, Guleri A. Rapid systematic review of neonatal COVID-19 including a case of presumed vertical transmission. BMJ Paediatr Open. 2020 May 25;4(1):e000718. DOI: 10.1136/ bmjpo-2020-000718.

https://doi.org/10.37757/MR2021.V23.N1.13
63. Pettirosso E, Giles M, Cole S, Rees M. COVID-19 and pregnancy: a review of clinical characteristics, obstetric outcomes and vertical transmission. Aust N Z J Obstet Gynaecol. 2020 Oct;60(5):640-59.

64. Lopes de Sousa AF, Félix de Carvalho HEF, Oliveira LB, Schneider G, Camargo ELS, Watanabe $E$, et al. Effects of COVID-19 infection during pregnancy and neonatal prognosis: what is the evidence? Int J Environ Res Public Health. 2020 Jun 11;17(11):4176

65. Thamir Ahmed F, Sattar Jabbar S. Neonatal outcomes and vertical transmission in Covid-19 infected pregnant women; a systematic review. J Global Trends Pharm Sci. 2020 Jul;11(4):8589-95.

66. Dhir SK, Kumar J, Meena J, Kumar P. Clinical features and outcome of SARS-CoV-2 infection in neonates: a systematic review. J Trop Pediatr. 2020 Aug 28:fmaa059. DOI 10.1093/tropej/fmaa059. Online ahead of print.

67. Raschetti R, Vivanti A, Vauloup C, Loi B, Benachi A, De Luca D. Synthesis and systematic review of reported neonatal SARS-CoV-2 infections. Nat Commun. 2020 Oct 15;11(1):5164. DOI: https://doi .org/10.1038/s41467-020-18982

68. AbdelMassih A, Fouda R, Essam R, Negm A, Khalil D, Habib D, et al. COVID-19 during pregnancy should we really worry from vertical transmission or rather from fetal hypoxia and placental insufficiency? A systematic review and meta-analysis [Internet]. Durham: Research Square; 2020 Sep [cited 2020 May 20]. Available at: https://doi .org/10.21203/rs.3.rs-71847/v1

69. Mahyuddin AP, Kanneganti A, Wong JJL, Dimri PS, Su LL, Biswas A, et al. Mechanisms and evidence of vertical transmission of infections in pregnancy including SARS-CoV-2. Prenat Diagn. 2020 Jun 12:10.1002/pd.5765. DOI: 10.1002/pd.5765. Online ahead of print.

70. Hosier H, Farhadian SF, Morotti RA, Deshmukh U, Lu-Culligan A, Campbell $\mathrm{KH}$, et al. SARS-CoV-2 infection of the placenta. J Clin Invest. 2020 Sep 1;130(9):4947-53.

71. Algarroba GN, Rekawek P, Vahanian SA, Khullar P, Palaia T, Peltier MR, et al. Visualization of SARSCoV-2 virus invading the human placenta using electron microscopy. Am J Obstet Gynecol. 2020 Aug;223(2):275-8.

72. Komine-Aizawa S, Takada K, Hayakawa S. Placental barrier against COVID-19. Placenta [Internet]. 2020 Sep 15 [cited 2020 Sep 25];99:45-9. Available at: https://doi.org/10.1016/j.placenta.2020.07.022

73. Kreis NN, Ritter A, Louwen F, Yuan J. A message from the human placenta: structural and immunomodulatory defense against SARS-CoV-2. Cells. 2020 Jul 25;9(8):1777. DOI:10.3390/cells9081777.

74. Li M, Chen L, Zhang J, Xiong C, Li X. The SARSCoV-2 receptor ACE2 expression of maternalfetal interface and fetal organs by single-cell transcriptome study. PLoS One. 2020 Apr 16;15(4):e0230295. DOI: 10.1371/journal.pone .0230295 .

75. Pringle KG, Tadros MA, Callister RJ, Lumbers ER. The expression and localization of the human placental prorenin/renin-angiotensin system throughout pregnancy: roles in trophoblast invasion and angiogenesis? Placenta. 2011 Dec;32(12):95662.

76. Pique-Regi $R$, Romero $R$, Tarca $A L$, Luca $F$, $X u$ Y, Alazizi A, et al. Does the human placenta express the canonical cell entry mediators for SARS-CoV-2? Elife. 2020 Jul 14;9:e58716. DOI: https://doi.org/10.7554/eLife.58716.

77. Taglauer E, Benarroch Y, Rop K, Barnett E, Sabharwal $V$, Yarrington $C$, et al. Consistent localization of SARS-CoV-2 spike glycoprotein and ACE2 over TMPRSS2 predominance in placental villi of 15 COVID-19 positive maternal-fetal dyads. Placenta. 2020 Oct;100:69-74.
78. Wang W, Xu Y, Gao R, Lu R, Han K, Wu G, et al. Detection of SARSCoV-2 in different types of clinical specimens. JAMA. 2020 May 12;323(18):1843-4.

79. Hsu AL, Guan M, Johannesen E, Stephens AJ, Khaleel N, Kagan N, et al. Placental SARS-CoV-2 in a pregnant woman with mild COVID-19 disease. J Med Virol. 2020 Aug 4;101002/jmv.26386. DOI: 10.1002/jmv.26386. Online ahead of print.

80. Dumitriu D, Emeruwa UN, Hanft E, Liao GV, Ludwig E, Walzer $L$, et al. Outcomes of neonates born to mothers with severe acute respiratory syndrome Coronavirus 2 infection at a large medical center in New York City. JAMA Pediatr. 2020 Oct 12;e204298. DOI:10.1001/jamapedia trics.2020.4298. Online ahead of print.

81. Vendola N, Stampini V, Amadori R, Gerbino M, Curatolo A, Surico D. Vertical transmission of antibodies in infants born from mothers with positive serology to COVID-19 pneumonia. Eur J Obstet Gynecol Reprod Biol. 2020 Oct;253:331-2.

82. De Luca D, Rava L, Nadel S, Tissieres P, Gawronskiet O, Perkins E, et al. The EPICENTRE (ESPNIC Covid pEdiatric Neonatal Registry) initiative: background and protocol for the international SARS-CoV-2 infections registry. Eur J Pediatr. 2020 Aug:179(8):1271-8.

83. Bhattacharyya S, Ghosh S. Optimal control of vertically transmitted disease: an integrated approach. Comput Math Methods Med. 2010 Dec; 11(4):369-87.

84. Dambha-Miller $\mathrm{H}$, Albasri A, Hodgson S, Wilcox $\mathrm{CR}$, Khan S, Islam N, et al. Currently prescribed drugs in the UK that could up or downregulate ACE2 in COVID-19 disease: a systematic review. BMJ Open. 2020 Sep 14;10(9): e040644.

85. Kaur SP, Gupta V. COVID-19 Vaccine: a comprehensive status report. Virus Res. 2020 Oct 15;288:198114. DOI: 10.1016/j.virusres.2020.198 114. Epub 2020 Aug 13

86. Krubiner $\mathrm{CB}$, Faden RR, Karron RA, Little $M O$, Lyerly AD, Abramson JS, et al. Pregnant women and vaccines against emerging epidemic threats: ethics guidance for preparedness, research, and response. Vaccine. 2019 May 3. DOI: https://doi.org.10.1016/j.vaccine.2019.01.011. [Epub ahead of print]

87. Heath PT, Le Doare K, Khalil A. Inclusion of pregnant women in COVID-19 vaccine development. Lancet Infect Dis. 2020 Sep;20(9):1007-8. Epub 2020 Aug 11.

\section{THE AUTHORS}

Gerardo Rogelio Robaina-Castellanos (Corresponding author: grcastellanos.mtz@ infomed.sld.cu), neonatologist with a doctorate in medical sciences. Full professor and senior researcher, neonatology service, José Ramón López Tabrane Provincial Women's and Children's Hospital, Medical University of Matanzas, Matanzas, Cuba. https://orcid.org/0000-0003 $-0300-9871$

Solangel de la Caridad Riesgo-Rodríguez, physician with dual specialties in family medicine and pediatrics, and a master's degree in comprehensive child health. Head professor and adjunct researcher, Teaching and Research Department, Eliseo Noel Caamaño Pediatric Provincial Hospital, Medical University of Matanzas, Matanzas, Cuba. https://orcid.org/0000 $-0002-4634-6563$

Submitted: July 25, 2020

Approved for publication: December 31, 2020 Disclosures: None 


\title{
Psychocardiology's Contributions to Comprehensive Cardiovascular Care in Cuba
}

\author{
Teresa Rodríguez-Rodríguez MS PhD, Juan José Navarro-López MD MS, Claudio González-Rodríguez MD MS, \\ Luis F. Herrera-Jiménez PhD, Arelys Falcón-Hernández MD MS, Rolando L. Rivera-López MS, Aleany Nohaya-Alonso MS
}

\begin{abstract}
This paper describes psychocardiology studies conducted from 2002 through 2018 in the Cardiology Department of the Dr Gustavo Aldereguía Lima University General Hospital in Cienfuegos Province, Cuba. Given the strong association between cardiovascular diseases and lifestyle, negative emotions and personality traits, psychology and medicine are equally necessary components of prevention and patient care, indispensable to primary and secondary prevention and to rehabilitation. When its therapeutic principles are appropriately applied, psychology can have a positive impact on the course of the disease and on patients' adaptation to new habits and lifestyles. The psychocardiologist's job is fundamental in achieving conscious participation by patients in their rehabilitation. Theoretical and practical contributions include a gender-based approach, addressing patients' sexual needs, neuropsychological assessment of damage associated with cardiovascular diseases, the particularities of pediatric patient care, family involvement in rehabilitation, and services for families at risk for cardiovascular events due to genetic factors. Results of these studies are included in published methodology for intensive psychological treatment for patients and health care workers.
\end{abstract}

KEYWORDS Psychology, cardiology, cardiac rehabilitation, Cuba

\section{INTRODUCTION}

The importance of risk factors in cardiovascular diseases has been acknowledged by medical science for over 60 years. WHO has called for cooperation and collaboration toward reducing premature mortality from noncommunicable diseases by 2025 , including cardiovascular diseases, which remain the main cause of death and disability worldwide.[1] Preventive activities and lifestyle modifications are needed to reduce the risk, morbidity and mortality of cardiovascular diseases.[2] In Cuba, these diseases have followed an upward trend for the last 10 years and are the leading cause of death.[3]

The key role of psychological factors in the onset and evolution of cardiovascular diseases and their risk factors, including sociopsychological factors, has been recognized for years.[4] In Cuba, psychocardiology has contributed new theoretical and practical approaches based on outcomes of research conducted in 2002-

\section{IMPORTANCE}

The theoretical and practical contributions of psychocardiology to comprehensive care of patients with cardiovascular diseases make a positive impact on their rehabilitation. This article describes those contributions, emphasizing the multidisciplinary approach adopted in a Cuban provincial hospital.
2018 in the Cardiology Department of the Dr Gustavo Aldereguía Lima University General Hospital (HGAL) in the central province of Cienfuegos.[5-8] As a result of these studies, psychocardiologists are incorporated into treatment in phase 1 cardiovascular rehabilitation (during hospitalization) and continue through phase 2 convalescence (generally, two to six months after discharge) and phase 3 (lifelong maintenance).

\section{DEVELOPMENT}

Background Certain personality traits increase the risk of cardiovascular diseases, particularly type A personality, in which hostility is a predictive factor,[9] and type D personality, characterized by depression, social alienation and suppression of negative emotions.[10] Depression accelerates disease progression; induces tachycardia, ventricular arrhythmia and fatal fibrillation; and is associated with functional deterioration and adverse cardiac events.[10] Stress can raise blood pressure and heart rate, and affect other physiological mechanisms and lifestyle. Hemodynamic activation can trigger acute coronary episodes in individuals with atherosclerotic plaque and is associated with recurrence of cardiac events and death. Anxiety diminishes quality of life. Among anxiety disorders, post-traumatic stress is a risk factor for cardiovascular diseases.[10] Socioeconomic factors and poor social support are predictive of adverse clinical outcomes in cardiovascular diseases.[10]

In line with this, in 1998, the Status and Consensus Conference on Psychocardiology noted the importance of behavior and several psychosocial risk factors in the etiology, development, rehabilitation and management of cardiovascular diseases.[11,12] These factors include socioeconomic inequality, emotional stress, exhaustion, anxiety and depression, chronic emotions, type A personality, hostility, and lack of family and social support. Importance was given to preventive treatment (diet, exercise, smoking cessation and introducing medication) to reduce stress. Recommendations included gender studies with emphasis on risk factors in women, behavioral and other psychosocial risks, and the benefits of postmenopausal hormone replacement.[11] These contributions are the foundation of the cardiac rehabilitation guidelines currently in use in many countries.

Psychocardiology emphasizes the high comorbidity between psychiatric disorders and cardiovascular diseases, including psychosocial risk factors in primary prevention, as well as the importance of psychotherapeutic intervention in early stages of the disease, in hospital care and in outpatient cardiac rehabilitation.[13]

As a result of these contributions, a medical subspeciality in psychocardiology was proposed, covering epidemiological, biological and psychosocial factors; clinical disease management; and integration of cardiology, psychology and psychiatry in cardiology research.[14] Despite extensive knowledge about the role of psychological and social variables in cardiovascular diseases, collaboration between medicine and psychology is lacking and 
comprehensive, multidisciplinary approaches in medical practice are rare.

Theoretical contributions Psychological intervention is indispensable in primary and secondary prevention, and rehabilitation. Given the strong association between cardiovascular diseases, negative emotions, personality and lifestyle, disease prevention and treatment require equal provision of clinical and psychological care. Psychology must go hand in hand with prevention activities and clinical procedures throughout cardiovascular patients rehabilitation. When the therapeutic principles of psychocardiology are appropriately applied, they make a favorable impact on the course of the disease and on patients' adaptation to a new lifestyle. Furthermore, psychocardiological care is an important resource for ameliorating negative emotional responses to the invasive procedures needed to treat many patients. Together with physicians, psychocardiologists participate in modifying unhealthy behaviors and also play a fundamental role in preparing families, who provide indispensable patient support and can be promoters of lifestyle changes. In primary prevention, the specialty also plays an important role in identifying hereditary predispositions. The psychocardiologist intervenes in the treatment of neurological damage and its neuropsychological effects, applies a gender-based approach, and addresses sexual issues and their association with coronary conditions throughout the prevention and rehabilitation process. In Cuba, psychocardiology has presented new theoretical arguments in this field.[5-7]

Practical contributions to cardiovascular rehabilitation Theoretical knowledge of these conditions' psychosocial aspects is extensive but seldom applied in clinical care.[12] This section describes practical applications of these principles.

Conscious participation by patients in cardiovascular rehabilitation Psychocardiologist interaction with patients begins in the disease's acute stage and aims to modify behavior following hospital discharge by raising awareness of necessary lifestyle changes. Psychocardiologists help patients understand their condition, as well as the need to modify their lifestyle and control their emotions to improve recovery. This includes providing resources facilitating the behavior modification that is essential for clinical stabilization and success of clinical treatments. These health professionals help patients redesign their behavior by introducing heart-healthy habits as a means to self-care, which will later become selfregulated and conscious daily behaviors. The family-an essential component in rehabilitation-participates in this process as an agent of lifestyle change.[6,7]

Psychological intervention in phase 1 of cardiovascular rehabilitation developed in the Dr Gustavo Aldereguía Lima University General Hospital is termed "intensive psychological treatment in special situations," $[6,7]$ unprecedented in Cuba and undocumented in the scientific literature reviewed from other countries.[12] It initiates tertiary prevention through attitude modification and by helping patients cope with hospitalization, emotional control in crisis situations, and modifying physiological processes exacerbated by such emotional states. It is applied as soon as patients are admitted and continues in a planned, systematic way until discharge, respecting both the disease complexity and patient disposition. $[6,7]$

These results have been applied in other settings for patients with stroke and other cardiovascular or circulatory conditions, as well as for diabetics, pregnant women with chronic conditions, and health workers with chronic conditions or risk factors.

Neuropsychological assessment Patients suffering cerebral hypoperfusion may present cognitive decline associated with cortical pseudolaminar necrosis and hippocampal sclerosis. Traditional risk factors for cardiovascular diseases are also associated with a decline in cognitive function in people with heart disease.[15] Patients whose condition compromised oxygen supply to the brain may present alterations in their ability to plan and anticipate their actions, in processing information, and in mobilizing the resources needed to correctly maintain cortical tone.[7] Damage to cognitive functions interferes with rehabilitation and hinders therapeutic adherence. The psychocardiologist's job is to detect possible cognitive damage during phase 1 and to design therapeutic strategies aimed at cognitive stimulation to be implemented with family participation and extended through phases 2 and 3.[7]

Gender-based approach Implementation of specific genderbased strategies is needed to improve outcomes of cardiovascular therapy.[16] The specificities of prevention and treatment in women has gained importance, and there is growing research on the interactions between psychosocial and biomedical factors in women with heart disease.[17] Some studies look only at traditional risk factors in these conditions in women;[11] others highlight the need to investigate gender differences.[12] Our approach takes into account from the start of therapy[7] the differences between men and women with ischemic heart disease that are associated with personality traits presenting as differences in expression and control of emotion, in fulfillment of productive and reproductive roles, in willingness to actively participate in selfcare,[7] and in vulnerability to health risks.[18]

Addressing altered sexual response Alterations in sexual response are common in people with cardiovascular diseases, due to organic or psychological causes, or the effects of medication.[19] Several authors address the impact of sexual dysfunction on patients' quality of life, and recommend guidance based on lifestyle, physical activity, and the possibility of medication (sildenafil); $[2,19,20]$ however, this assistance is rarely provided. [19] Our psychocardiology care program includes sexual counseling that takes into account subjective factors. It is carried out by means of consensus between the cardiologist and the psychocardiologist at the acute phase, during which a sexological diagnosis is made, which can include drug therapy and counseling for the patient and their spouse or partner. These therapeutic components are also included in outpatient treatment.[7,8]

Multidisciplinary approach to cardiovascular rehabilitation Phase 1 cardiovascular rehabilitation requires teamwork involving cardiologists, psychologists, nurses and rehabilitation specialists. Data of psychological interest are recorded in the patient's chart. Nursing staff have been trained in applying emotional control techniques reflected in clinical indications. In the days leading up to hospital discharge, doctors, nurses and psychotherapists participate in group activities with patients and their families to reinforce learned techniques, motivate lifestyle changes and prepare for the return home. Cardiologists have gained an understanding of patients' psychophysiological responses and assist with psychological interventions, particularly in severely ill 
patients. This approach integrates knowledge in designing selfhelp methods and materials for phases 2 and 3.[6,7]

Pediatric psychocardiology Children with congenital heart disease frequently present anxiety, depression, psychological conflicts, low self-esteem, learning difficulties and rejection of lifestyles imposed by the disease as well as medical care. In Cuba, cardiovascular rehabilitation provides psychological resources for coping with and adapting to the particular living conditions the disease implies for children and their families. It supports the process of social integration in phase 3 , which includes education for school-age children.[21]

Psychological care addresses needs of pediatric patients and their families, who have the difficult task of establishing an appropriate lifestyle, detecting psychological changes generated by the disease and notifying specialists responsible for care. A psychological care protocol for school-age pediatric cardiology patients has been created and is being evaluated in Cienfuegos Province to verify its benefits and make necessary adjustments. The protocol's introduction in other Cuban institutions is expected, culminating with a set of nationally standardized guidelines for psychocardiac care of pediatric patients and their families.

\section{CONCLUSIONS}

Despite the importance of psychological interventions in hospitalized heart patients, there are few published studies.[2,12,20,22] The described approach provides a methodology for psychocardiological intervention in acute-phase cardiovascular patients. It contains diagnostic techniques, self-help materials, relaxation methods and other psychotherapeutic techniques for phases 2 and 3 described in the Programs and Methodologies section of the book Psychocardiology in the Health-Disease Process: from Theory to Practice,[7] integrating knowledge from the fields of cardiology and psychology, and which was awarded the 2014 Annual Health Prize by the Ministry of Public Health. In 2019, the supporting studies were also awarded the Annual Health Prize for applied research.

Generalizing these results to all cardiology services in the country requires postgraduate training of cardiologists, psychologists and health policymakers in the comprehensive management of cardiovascular disease. These activities respond to WHO's call to reduce the burden of cardiovascular disease by 2025, and they rely on the political will to guarantee free, universal access to health care in Cuba, from the primary level to specialized cardiology services. -1/

\section{REFERENCES}

1. Pan American Health Organization. Situación de la Salud en las Américas: indicadores básicos 2016 [Internet]. Washington, D.C: Pan American Health Organization; 2016 Oct [cited 2020 May 10]. 20 p. Available at: https://iris.paho.org/ handle/10665.2/31288. Spanish.

2. Grupo de Trabajo de la SEC para la Guía ESC 2019 sobre síndromes coronarios crónicos; Grupo de Revisores Expertos para la Guía ESC 2019 sobre síndromes coronarios crónicos; Comité de Guías ESC. Rev Esp Cardiol [Internet]. 2020 [cited 2020 May 10];73(6):439-44. Available at: https://www.revespcardiol.org/es -pdf-S0300893219306050. Spanish.

3. National Health Statistics and Medical Records Division (CU). Anuario Estadístico de Salud 2019 [Internet]. Havana: Ministry of Public Health (CU); 2020 [cited 2020 May 25]. 193 p. Available at: https://files.sld.cu/bvscuba/files/2020/05/Anua rio-Electr\%c3\%b3nico-Espa\%c3\%b1ol-2019 -ed-2020.pdf. Spanish

4. Mahmood SS, Levy D, Vasan RS, Wang TJ. The Framingham Heart Study and the epidemiology of cardiovascular disease: a historical perspective. Lancet [Internet]. 2014 Mar 15-21 [cited 2020 May 25];383(9921):999-1008. Available at: http://www.sciencedirect.com/science/article/pii/ S0140673613617523

5. Rodríguez Rodríguez T. La Psicocardiología, disciplina indispensable de estos tiempos. MediSur [Internet]. 2010 Jun [cited 2020 May 25];8(3):14. Available at: http://scielo.sld.cu/pdf/ms/v8n3/ v8n3a1156.pdf. Spanish.

6. Rodríguez T. Estrategia de atención psicológica a pacientes con infarto agudo de miocardio en fase hospitalaria [thesis] [Internet]. [Santa Clara] (CU): University of Medical Sciences of Villa Clara; School of Psychology; 2008 [cited 2020 May 25]. 295 p. Available at: http://tesis. sld.cu/index. php?P=FullRecord\&ID=162. Spanish.

7. Rodríguez T, Navarro JJ, González C. Psicocardiología en el proceso salud-enfermedad: de la teoría a la práctica [Internet]. Havana: ECIMED; 2013 [cited 2020 Jun 7]. p. 1-220. Available at: http://articulos.sld.cu/editorhome/2013/12/22/ psicocardiologia-en-el-proceso-salud-enferme dad-de-la-teoria-a-la-practica/. Spanish.

8. Rodríguez Rodríguez T. La atención a la respuesta sexual del paciente con cardiopatía isquémica de debut en fase hospitalaria: consideraciones desde la Psicocardiología. Rev Sexología [Internet]. 2020 Jun [cited 2020 Jun 19];9(1):34-7. Available at: https://www.researchgate.net/publi cation/343452325_La_atencion_a_la_respuesta sexual del paciente con cardiopatia isquemica_de_debut_en_fase_hospitalaria_Con sideraciones_desde_la_Psicocardiologia. Spanish.

9. Myrtek M. Meta-analyses of prospective studies on coronary heart disease, type A personality, and hostility. Int J Cardiol [Internet]. 2001 Jul [cited 2020 Jun 19];79(2-3):245-51. Available at: https://linkinghub.elsevier.com/retrieve/pii/ S0167527301004417

10. Smith PJ, Blumenthal JA. Aspectos psiquiátricos y conductuales de la enfermedad cardiovascular: epidemiología, mecanismos y tratamiento. Rev Esp Cardiol [Internet]. 2011 Oct [cited 2020 Jun 22];64(10):924-33. Available at: https:// www.sciencedirect.com/science/article/abs/pii/ S030089321100594X. Spanish.

11. Canadian Cardiovascular Society 1998 Consensus Conference on the Prevention of Cardiovascular Disease: The Role of Cardiovascular Specialist [Internet]. Ottawa: Canadian Cardiovascular Society; 1998 [cited 2020 Jun 19]. 331 p. Available at: https://ccs.ca/app/uploads/2020/12/ Prev_CC_1998.pdf

12. Jordan J, Bardé B, Zeiher AM, editors. Contributions toward evidence-based psychocardiology: a systematic review of the literature [Internet]. Washington, D.C.: American Psychological Association; 2007 [cited 2020 Jun 22]. 373 p. Available at: https://psycnet.apa.org/ record/2006-13513-000

13. Laham M. Psicocardiología: su importancia en la prevención y la rehabilitación coronaria. Rev Suma Psicolog [Internet]. 2008 Mar 1 [cited 2020 Jun 21];15(1). Available at: https://www.redalyc .org/pdf/1342/134212604006.pdf. Spanish.

14. Byrne D, Alvarenga E. Psychogenesis and Heart Disease Now: The Thinking Heart in Action.
In: Alvarenga M, Byrne D, editors. Handbook of Psychocardiology [Internet]. Singapore: Springer Nature Singapore Pte Ltd; 2016 [cited 2020 Jun 26]. p. 3-12. Available at: https:// link.springer.com/referencework/10.1007\% 2F978-981-4560-53-5

15. Sociedad Andaluza de Neurología. Recomendaciones para el manejo del deterioro cognitivo [Internet]. Sevilla: Editorial Fundación Sociedad Andaluza de Neurología; 2019 [cited 2020 Jun 26]. p. 39-43, 58-60. Available at: http://www.saneurologia.org/ wp-content/uploads/2019/10/LIBRO-DETERIORO -COGNITIVO-DEF.pdf. Spanish.

16. Aggarwal NR, Patel HN, Mehta LS, Sanghani RM, Lundberg GP, Lewis SJ, et al. Differences in ischemic heart disease. Advances, obstacles, and next steps. Circ Cardiovasc Qual Outcomes [Internet]. 2018 Feb [cited 2020 Jun 26];11(2):e004437. Available at: https://www.ahajournals.org/doi/10.1161/ CIRCOUTCOMES.117.004437?url_ver=Z39.88 -2003\&rfr_id=ori:rid:crossref.org\&rfr_dat $=c r$ pub\%20\%200pubmed

17. Espnes GA, Nguyen C, Byrne D. Gender Differences in Psychological Risk Factors for Development of Heart Disease. In: Alvarenga M, Byrne D, editors. Handbook of Psychocardiology [Internet]. Singapore: Springer Nature Singapore Pte Ltd; 2016 [cited 2020 Jun 24]. Available at: https://link.springer.com/referencework/10.1007 \%2F978-981-4560-53-5

18. World Health Organization [Internet]. Geneva: World Health Organization; c2020. Centro de prensa. Notas descriptivas. Salud de la mujer; 2018 Sep 25 [cited 2020 Jul 2]; [about 7 p.]. Available at: https://www.who.int/es/news-room/ fact-sheets/detail/women-s-health. Spanish.

19. Levine GN, Steinke EE, Bakaeen FG, Bozkurt B, Cheitlin, MD, Conti JB, et al. Sexual activity and cardiovascular disease: a scientific statement from the American Heart Association. Circulation [Internet]. 2012 Feb 28 [cited 2020 Jul 2];125(8):1058-72. Available at: https://www.ahajournals.org/doi/10.1161/ CIR.0b013e3182447787?url_ver $=$ Z39.88 $-2003 \&$ rfr_id=ori:rid:crossref.org\&rfr_dat $=c r$ pub\%20\%200pubmed 
20. López-Jiménez F, Pérez-Terzic C, Zeballos PC, Anchique CV, Burdiat G, González K, et al. Consenso de Rehabilitación Cardiovascular y Prevención Secundaria de las Sociedades Interamericana y Sudamericana de Cardiología. Rev Urug Cardiol [Internet]. 2013 [cited 2020 Jul 2]:28:189-224. Available at: https://g-se.com/uploads/blog_adjuntos/rcv28n2 consenso rehabilitacion 2.pdf. Spanish.

21. Carballés JF. García. Evaluación del programa cubano de rehabilitación cardiaca del niño durante los años 1992 a 2010 [thesis] [Internet]. [Havana]: University of Medical Sciences of Havana; 2012 [cited 2020 Jul 2]. 163 p. Available at: http://tesis.sld.cu/FileStorage/000120-2F3A -Jes\%C3\%BAs_Francisco_Carball\%C3\%A9s Garc\%C3\%ADā.pdf. Spanish.

22. Una M. In-Hospital Management of Psychological Responses to Acute Cardiac Events. In: Alvarenga $M$, Byrne $D$, editors. Handbook of Psychocardiology [Internet]. Singapore: Springer Nature Singapore Pte Ltd; 2016 [cited 2020 Jul 2]. Available at: https://link.springer.com/referen cework/10.1007\%2F978-981-4560-53-5

\section{THE AUTHORS}

Teresa Rodríguez-Rodríguez (Corresponding author: teresarr559@gmail.com), psychologist with both a master's degree and a doctorate in the field. Head of the Behavioral Medicine Group in Cuba. Full professor and senior researcher, Dr Gustavo Aldereguía Lima University General Hospital (HGAL), Cienfuegos, Cuba. https:// orcid.org/0000-0003-3114-4624

Juan José Navarro-López, cardiologist with a master's degree in emergency medicine. Associate professor, HGAL, Cienfuegos, Cuba. https://orcid.org/0000-0002-9774-959X

Claudio González-Rodríguez, cardiologist with a master's degree in emergency medicine. Associate professor, HGAL, Cienfuegos, Cuba. https://orcid.org/0000-0003-3774-7258

Luis F Herrera-Jiménez, psychologist with a $\mathrm{PhD}$ in the field. Full professor, Marta Abreu University, Santa Clara, Villa Clara, Cuba. https:// orcid.org/0000-0002-2135-2107

Arelys Falcón-Hernández, physician with dual specialties in family medicine and intensive care, and a master's degree in emergency medicine. Associate researcher, associate professor and rector, Medical University of Cienfuegos, Cuba. https://orcid.org/000-0002-4578-5505

Rolando Lázaro Rivera-López, psychologist with a master's degree in health psychology. HGAL, Cienfuegos, Cuba https://orcid. org/0000-0001-9471-1724

Aleany Nohaya-Alonso, psychologist with a master's degree in health psychology. Paquito González Cueto University Pediatric Hospital. Cienfuegos, Cuba. https://orcid.org/0000-0002 $-3424-0366$

Submitted: August 5, 2020

Accepted for publication: January 8, 2021 Disclosures: None 


\section{MEDICC \\ Review}

\section{A Call for Papers}

\section{To Latin American \& Caribbean Health \& Related Professionals}

- MEDICC Review welcomes papers from Latin American and Caribbean authors, addressing today's critical interactions between human health, development of sustainable societies, and the health of our planet.

- In the era of the COVID-19 pandemic, MEDICC Review editors are fast-tracking peer review of papers that provide results of regional, national or local experiences with prevention, control, diagnosis, and therapies, as well as development of medications and vaccines. See Author Guidelines at www.mediccreview.org for Short Article, Lessons From the Field, and Original Research sections.

- Your evidence-, experience-based commentaries are also welcome for our Perspective and Viewpoint sections.

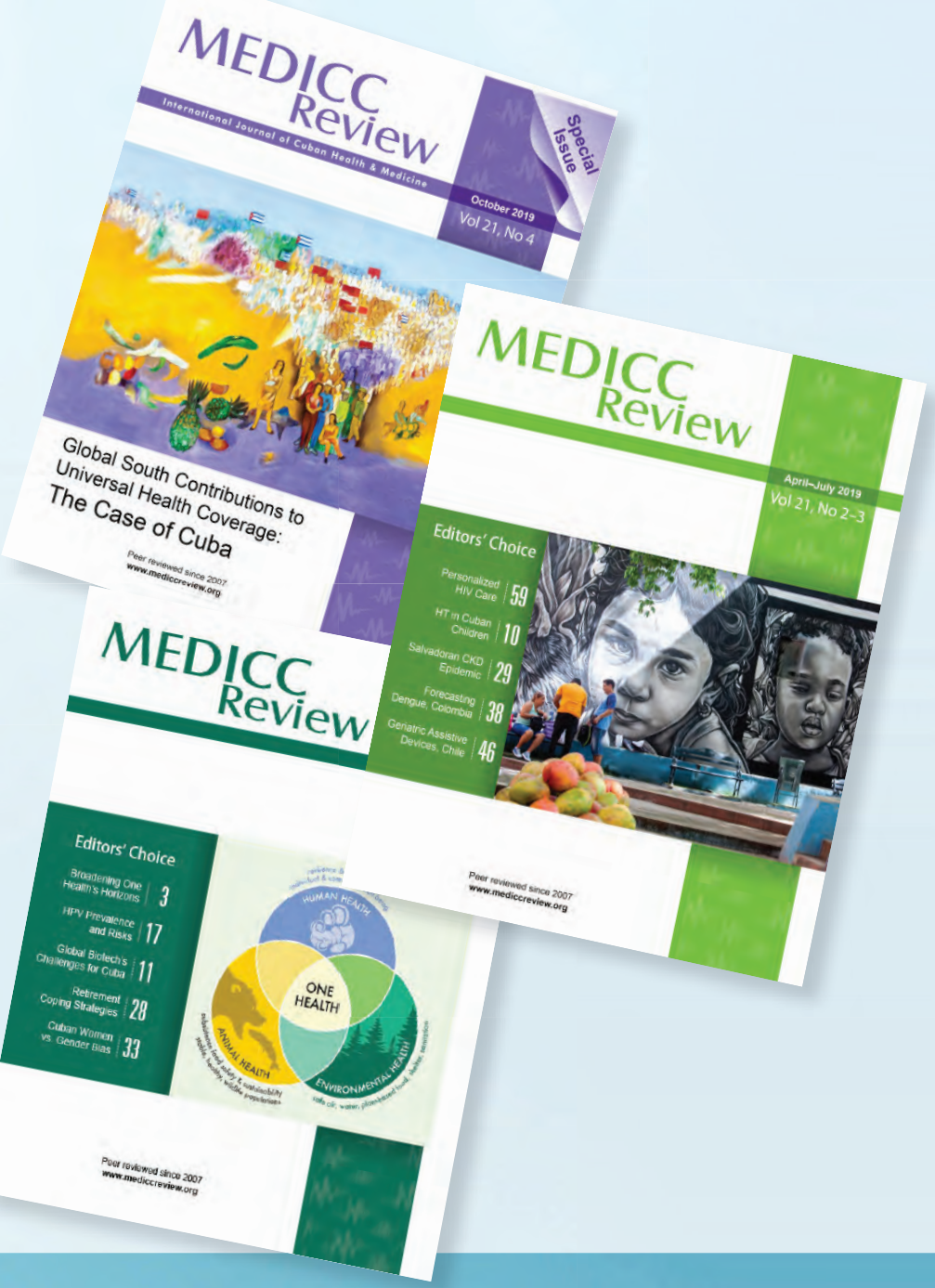

MEDICC Review is an open-access journal published by MEDICC, a non-profit organization based in Oakland, California, USA. The journal is indexed by PubMed, Clarivate Analytics, SciELO, Elsevier (Embase and SCOPUS), EBSCO, CABI Global Health, Redalyc, Latindex and Road.
We consider submissions in Spanish, English and Portuguese for publication in English. No author fees are charged. 


\section{Cuba-US Collaboration: The Pandemic Imperative}

\section{Roberto Cañete MD PhD and Kenneth W. Goodman PhD}

It is unclear why we constantly need reminding, but COVID-19 serves as a blatant reminder of the importance of international scientific cooperation-this should include cooperation between political rivals. In the case of Cuba and the United States, this might again be possible with the new US President, Joe Biden.

Globalization, climate change and social determinants will continue to fledge new pathogens, some of them highly contagious and dangerous. The One Health approach advocated by WHO, the Food and Agriculture Organization (FAO), World Organization for Animal Health (OIE), the US Centers for Disease Control and Prevention and others is an effort to study and recognize the many global connections between and among people, animals and the environment and implement relevant inter-disciplinary policies. COVID-19, which originated in animals, is a clear example and provides another lesson in collaboration.

In 2015, we saluted apolitical efforts by the Cuban and US bioethics communities to contribute to mutual goals and objectives in science and public health (primarily epidemiology), and to the role of bioethics in the process.[1] It was later suggested these efforts improved health in both countries and fostered the creation of knowledge and new tools.[2,3]

A June 2016 memorandum of understanding between the US Department of Health and Human Services and the Cuban Ministry of Public Health supported cooperation in public health and medical research.[4] There was reason for optimism that scientists in countries with fraught relationships could rise above politics and ideology and help improve the health of populations. The Trump administration unfortunately embraced other values.

COVID-19 was first identified in December 2019 and declared a global pandemic by WHO in March 2020. Many countries mounted a response. Most seem to have made a hash of it. Nevertheless, some governments, businesses and scientists collaborated with each other, and international drug and vaccine trials commenced. We now have promising treatments and vaccines.

\section{Health science collaboration between and among political rivals could serve as an exemplar and guide the nations of the world to share data and resources to stem the pandemic}

Health science collaboration between and among political rivals could serve as an exemplar and guide the nations of the world to share data and resources to stem the pandemic. Indeed, there have been a number of examples of international cooperation, but we have also endured competition, 'vaccine nationalism' and continued growth in cases and deaths.

Were we overly optimistic five years ago? Were we naïve in thinking that because Cuba and the United States are neighbors with a long and complex historical relationship they would allow enlightened self-interest to drive collaboration? Perhaps. But a bolder and more optimistic assessment is this: If Cuba and the United
States could take steps, however small, to link their scientific communities, then surely other countries could as well.

We are not yet prepared to surrender to the idea that global scientific collaboration is impossible; that politics will invariably undermine research and development; that selfishness will always prevail over symbiosis. If we are wrong, there is no telling how bad the next pandemic will be. If we are right, however, and rivals can collaborate in the service of shared interests-public health might be the best opportunity, especially for Cuba and the United States-then there is room for optimism. 1 .

1. Cañete R, Goodman KW. Cuba-US collaboration and the role of bioethics. Lancet. 2015 Mar 14;385(9972):945.

2. Isasi R, Zuchner SL, Villafranca RC. Community genetics: genetics boosts USCuban links. Nature. 2016 Nov 17;539(7629):357.

3. Bausch DG, Kourí V, Resik S, Acosta B, Guillén G, Goraleski K, et al. The Cuba-United States Thaw: building bridges through science and global health. Am J Trop Med Hyg. 2017 Jun;96(6):1267-9. DOI:10.4269/ajtmh.17-0136.

4. Keck CW. The United States and Cuba: turning enemies into partners for health. N Engl J Med. 2016 Oct 20;375(16):1507-9.

5. Cañete R. The Cuban Public Health System focuses research on community needs. Curr Ther Res Clin Exp. 2016 Dec 28;85:1. DOI: 10.1016/j.curtheres.2016.11.003.

Submitted: December 28, 2020

Approved for publication: January 7, 2021

Disclosures: None

Correspondence: roberto.villafranca@infomed.sld.cu 


\section{Can Anti-Ribosomal Antibodies Improve Systemic Lupus Erythematosus Diagnosis?}

Elena Kokuina MD PhD

Systemic lupus erythematosus (SLE) is an autoimmune disease of unknown etiology. The only means of reducing its morbidity and mortality remains early diagnosis followed by timely medical treatment. SLE affects all populations worldwide, although prevalence rates differ between population groups, with higher rates among women of reproductive age and for African, Asian, and Hispanic ethnicities.[1]

The possibility of SLE diagnosis should be kept in mind during daily medical practice, not because of its high frequency, but because of the pronounced heterogenicity of its clinical presentation; of all autoimmune diseases, SLE probably has the greatest diversity in clinical manifestations. Biomarkers that can diagnose and differentiate SLE from other rheumatic autoimmune diseases are needed. However, in more than 50 years of research, no single biomarker has emerged capable of identifying SLE in diagnostic tests.

SLE's serological hallmark is the presence of circulating antinuclear antibodies (ANA). A positive ANA test is the starting point for diagnosing and classifying SLE, but by itself is not conclusive, because although ANA are expressed in virtually all SLE patients, they also occur in other autoimmune and non-autoimmune conditions. Consequently, SLE diagnosis and classification also require that patients meet certain clinical and immunological criteria defined by the American College of Rheumatology (ACR), and more recently by the European League Against Rheumatism (EULAR).[2]

ANAs have been the largest pool of serological biomarkers for SLE. Of the dozens of antinuclear specificities associated with SLE, only two have been included in the condition's diagnostic criteria: the double-stranded deoxyribonucleic acid antibodies (anti-dsDNA) and the Smith spliceosome antibody (anti-Sm). Both autoantibodies traditionally have been used to confirm an SLE diagnosis due to their high specificity for the disease. Nevertheless, their specificity-as well as sensitivity in the 90-98\% range-depends on the assay used and the population in which it is employed. Recent studies reveal that presence of dsDNA antibodies is not exclusive to SLE. Considerable amounts of antidsDNA are found in other rheumatic diseases, neoplasms, infections and endocrine disorders, as well as in healthy older adults, which lessens specificity, and thus utility, of dsDNA antibodies in diagnosing SLE.[3]

In addition to the autoantibodies noted above, a number of novel immunological markers have been suggested as criteria for inclusion in the most recent SLE classification. The nominated biomarkers include cytokines such as B lymphocyte stimulator (BLys) and tumor necrosis factor (TNF); chemokines including monocyte chemoattractant protein 1 , or chemokine (C-C motif) ligand 2 (MCP-1/CCL2) and interferon gamma-induced protein 10, also known as C-X-C motif chemokine ligand 10 (IP10/CXCL10); the expression of genes regulated by interferon I (type I IFN) and markers of the T helper 17 cell (Th17) subpopulation.[4] Although these markers have been associated with SLE pathogenesis or activity, the lack of technical wherewithal for their measurement in clinical settings-especially in low-resource contexts-has kept them from practical employment. Thus, the proposed novel immunologic markers may be important for classifying SLE in the future, but serological evidence of autoantibody production is still the prevalent diagnostic criteria for SLE.[2]

A subset of antibodies A subset of antibodies directed directed adainst against ribosomal $P$ proteins ribosomal (referred to as anti-RibP) has ribosomal P proteins proven useful for SLE diagnohas proven useful for sis in Cuba and elsewhere. AntiSLE diagnosis in Cuba RibP reactivity is localized in three phosphoproteins: P0, P1 and P2 and elsewhere

(with molecular masses of 38, 19 and $17 \mathrm{kDa}$, respectively) of the $60 \mathrm{~S}$ ribosomal subunit. These phosphoproteins are located mainly in cell cytoplasm in the form of a pentameric protein complex whose functions likely include intervention in the elongation step of protein synthesis. RibP antibodies show intriguing pathogenic potential based on evidence of their ability to penetrate living cells and inhibit in vivo and in vitro protein synthesis.[5]

Antibodies to ribosomal proteins have not fared as well as other nuclear antibodies like anti-dsDNA and anti-Sm. Although ribosomal antibodies' specificity to SLE was evident early on, RibP antibody determinations only became widespread in clinical laboratories in this century.[6] The late emphasis on the value of RibP antibodies in diagnosing SLE is likely due to the fact that the most widely-used method for ANA screening, indirect immunofluorescence assays (IFA), is of limited value in detecting RibP antibodies. The low sensitivity of IFA in detecting RibP antibodies has been aggravated by omission of IFA cytoplasmic staining patterns (resulting from antibodies against cytoplasmic components like ribosomal $P$ ) by laboratories focused on ANA, which underestimated the utility of anti-cellular antibodies (ACA) as diagnostic agents.[7]

More recently, enzyme-linked immunosorbent assay (ELISA) kits have been used to detect RibP antibodies, allowing for high diagnostic flow at relatively low cost. Certainly, the current variety of diagnostic platforms with different antigenic preparations requires greater standardization, but most available assays rely on the specificity of RibP antibodies even within diverse populations of SLE patients. The ELISA test has shown the most consistent and least heterogeneous results among laboratories. $[6,8]$ Detection of RibP antibodies using the ELISA method in human P0, P1 and P2 ribosomal proteins in both Cuban SLE patients and healthy controls have shown extraordinary specificity for SLE, exceeding that of dsDNA and Sm antibodies.[9] RibP antibodies are not abundant in patients with SLE-in the Cuban population, as in other populations, they were only found in a fifth of SLE patients. Rather, their diagnostic value lies in their great specificity, allowing for a definitive SLE diagnosis when 
they are detected. The high specificity of RibP antibodies is of particular importance in the diagnosis of anti-dsDNA- and antiSm-negative patients, representing a significant proportion of patients with anti-RibP-positive SLE.[10] Failure to consider the presence of RibP antibodies in these patients may delay diagnosis and medical treatment.

The high specificity of RibP antibodies for SLE, now confirmed in multiple studies from different geographical regions, merits their inclusion in SLE classification and diagnostic criteria. Furthermore, since anti-RibP specificity exceeds that of other serological markers for SLE, it is time to make greater use of this marker in establishing early SLE diagnosis. - 1 1 -

\section{REFERENCES}

1. Stojan G, Petri M. Epidemiology of systemic lupus erythematosus: an update. Curr Opin Rheumatol. 2018 Mar;30(2):144-50.

2. Aringer M, Costenbader K, Daikh D, Brinks R, Mosca M, Ramsey-Goldman R, et al. European league against rheumatism/American College of Rheumatology classification criteria for systemic lupus erythematosus. Ann Rheum Dis. 2019 Sep;78(9):1151-9.

3. Arriens C, Wren JD, Munroe ME, Mohan C. Systemic lupus erythematosus biomarkers: the challenging quest. Rheumatology (Oxford). 2017 Apr 1;56(Suppl 1):i32-i45.

4. Schmajuk G, Hoyer BF, Aringer M, Johnson SR, Daikh DI, Dörner T, et al. Multicenter Delphi exercise to identify important key items for classify- ing systemic lupus erythematosus. Arthritis Care Res (Hoboken). 2018 Oct;70(10):1488-94.

5. Toubi E, Shoenfeld Y. Clinical and biological aspects of anti-P-ribosomal protein autoantibodies. Autoimmun Rev. 2007 Jan;6(3):119-25.

6. Choi MY, FitzPatrick RD, Buhler K, Mahler M, Fritzler MJ. A review and metaanalysis of anti-ribosomal $\mathrm{P}$ autoantibodies in systemic lupus erythematosus. Autoimmun Rev. 2020 Mar;19(3). Art 102463. DOI: https://doi.org/10.1016/j .autrev.2020.102463

7. Damoiseaux J, von Mühlen CA, García-de la Torre I, Carballo OG, de Melo CW, Francescantonio $\mathrm{PL}$, et al. International consensus on ANA patterns (ICAP): the bumpy road towards a consensus on reporting ANA results. Auto Immun Highlights. 2016 Dec;7(1):1.

8. Li J, Shen Y, He J, Jia R, Wang X, Chen X, et al. Significance of antibodies against the native ribosomal $\mathrm{P}$ protein complex and recombinant $\mathrm{P} 0, \mathrm{P} 1$, and $\mathrm{P} 2$ proteins in the diagnosis of Chinese patients with systemic lupus erythematosus. J Clin Lab Anal. 2013 Mar;27(2):87-95.

9. Kokuina E, Milian OlivaresY, Tamargo Barbeito TO, Chico Capote A, Estevez del Toro M, Andux Valdés JL. Inmunocomplejos circulantes en el lupus eritematoso sistémico. Rev Cuba Med. 2020 Jan-Mar;59(1):e1337. Spanish.

10. Kokuina E, Chico Capote A, Estevez del Toro M, Tamargo Barbeito T, Milian Olivares, Sanchez Bruzon Y. (2020), Anticuerpos anti-proteína P ribosomal: utilidad diagnóstica en el lupus eritematoso sistémico y asociación con nefritis lúpica, Original Research. [Unpublished study]. Spanish.

Submitted: August 19, 2020

Approved for publication: January 6, 2021

Disclosures: None

Correspondence: inmunología@hha.sld.cu 


\title{
Comprehensive Surveillance Needed to Contain COVID-19
}

\author{
Saurabh RamBihariLal Shrivastava MD and Prateek Saurabh Shrivastava MD
}

The coronavirus pandemic has shaken public health authorities around the world and raised questions about health sector preparedness in responding to infectious disease outbreaks. As of December 7, 2020, more than 66 million cases had been reported globally, and more than 1.5 million people have died from the infection in 219 nations and territories.[1,2] The hard lesson is that preparedness must be urgently improved, including case detection through better surveillance; improved laboratory diagnostic facilities; more and better-equipped isolation wards and treatment facilities; increased supply and better distribution of personal protective equipment; more effective risk communication; and adoption of community engagement action plans. [1,3]

\section{Preparedness must be urgently improved, including case detection through better surveillance}

Surveillance is key. Strengthening surveillance in China and elsewhere has been acknowledged as a prime component for effective response to minimize the number of cases and prevent further loss of life.[4] This has proven true in other scenarios as well, such as the 2014 Ebola outbreak in West Africa, where stronger surveillance proved to be a main factor for effective containment.[5]

Case detection and confirmation testing, as well as contact tracing, must include effective surveillance at all international points of entry-airports, border crossings and maritime ports.

Turning for a moment to our own country, India: we can assume significant under-reporting of cases, given the country's population density and other sociodemographic factors that, taken together, favor rapid COVID-19 transmission. We believe this may be due to deficient surveillance compounded by insufficient availability of testing facilities. In particular, comprehensive surveillance is hobbled by lack of diagnostic kits in laboratories and community settings. This precludes more realistic caseload estimates and thus hinders more precise forecasts of logistic requirements. It is paramount at this stage to increase laboratory capacities and to include private facilities in the panel of approved laboratories where this has not already been done.[6]

Returning to the global community: a worldwide surveillance system is already in a place capable of collecting and organizing data on disease magnitude and distribution.[3] Many countries have surveillance systems and/or electronic data collection mechanisms which transmit information daily from WHO regional offices to its Geneva headquarters. [3,4] This requires countries to adhere to established case definitions-suspect, probable and confirmed-for reporting COVID-19 infections,[3] providing data in a prescribed format in order to align global estimates. According to WHO surveillance guidelines, these data would ideally include details on the number of cases, deaths, laboratory tests performed, positive results and number of contacts being monitored. Further, it is recommended that each nation provide clinical-epidemiological travel histories of any new cases within two days of confirmation. Member states should use WHO-established categories for classifying transmission status-no cases, sporadic cases, clusters or community transmission-in order to strengthen global surveillance, enable risk assessment at various levels, assist in monitoring disease caseloads and provide evidence for national health authorities to mount a better public health response.[4]

However, it is important to acknowledge that such comprehensive surveillance is only efficient and effective in those nations that had viable health systems prior to the outbreak. Both WHO recommendations and our own would prove impractical for strengthening surveillance in nations facing system-wide challenges such as fragmented healthcare delivery; access disparities; scarcity of trained personnel; and financial or technological constraints. These systemic issues make it extremely difficult to perform risk assessments, provide timely detection and monitor overall caseload.

In those countries with weaker surveillance systems, strategies should be implemented to: ensure the general population is at least informed about COVID-19 and how it is transmitted; encourage selfquarantine; and improve health-seeking behavior by symptomatic individuals. If the need arises based on caseload, active surveillance can be adopted with the help of outreach workers, trained as part of a community engagement action plan. In order to gain extra leverage and time to improve readiness and reduce transmission, many nations have imposed lockdowns, but these are passive interventions: once lockdown is over, cases will rise once again-as is happening currently in many countries. Lockdowns can be used effectively to actively search for cases in the community, while managing suspect or confirmed cases according to established protocols.

In essence, complacency is not an option for any country and surveillance has proven integral to preparedness, prevention and control of the COVID-19 pandemic. As nations review their health systems' viability, ample attention should be paid to implementing effective surveillance activities, with sufficient support for public health authorities. Our preparedness now-and in the face of future infectious threats-depends on it. -1 -

\section{References}

1. World Health Organization. Statement on the second meeting of the International Health Regulations (2005) Emergency Committee regarding the outbreak of novel coronavirus (2019-nCoV) [Internet]. Geneva: World Health Organization; 2020 Jan 30 [cited 2020 Feb 28]. Available at: https://www.who .int/news-room/detail/30-01-2020-statement-on-the-second-meeting-of-the -international-health-regulations-(2005)-emergency-committee-regarding-the -outbreak-of-novel-coronavirus-(2019-ncov)

2. World Health Organization. Coronavirus (COVID-19) Dashboard [Internet]. Geneva: World Health Organization; 2020 Dec 7 [cited 2020 Dec 7]. Available at: https://covid19.who.int

3. World Health Organization. 2019 Novel Coronavirus (2019-nCoV): Strategic preparedness and response plan. Geneva: World Health Organization Press; 2020. p. 1-8

4. World Health Organization. Global Surveillance for human infection with novel coronavirus (2019-nCoV) - Interim guidance. Geneva: World Health Organization Press; 2020. p. 1-3.

5. Shrivastava SR, Shrivastava PS, Ramasamy J. Lessons learnt from the 2014 Ebola outbreak in West Africa. J Res Med Sci. 2015 Jan;20(1):107-8.

6. Indian Council of Medical Research [Internet]. New Delhi: Indian Council of Medical Research; c2020. COVID-19. Information for Testing Laboratories; [cited 2020 Oct 12]; [about 3 p.]. Available at: https://www.icmr.gov.in/ctestlab.html

Submitted: February 28, 2020

Approved for publication: November 12, 2020

Disclosures: None

Correspondence: drshrishri2008@gmail.com

https://doi.org/10.37757/MR2021.V23.N1.1 


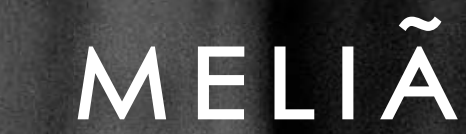

HAB A A

CUBA

THE LEVEL

Havana as a world-class international destination is further enhanced with The Level, a service that boasts attention to detail for business meetings, scientific events and successful negotiations.

The Meliá Habana shows its best colours, promising an unforgettable experience.
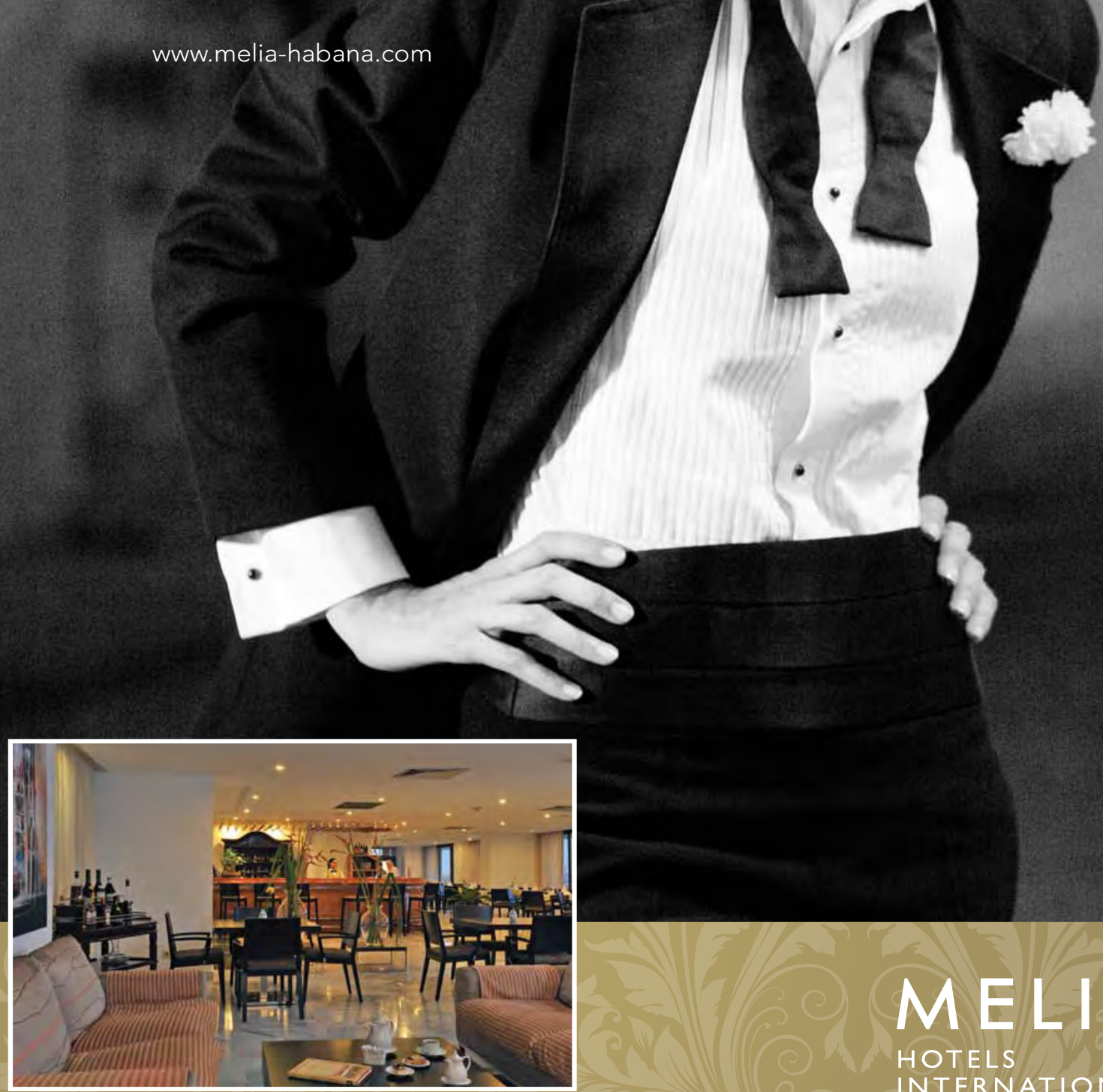

E X C E P T I O NA L

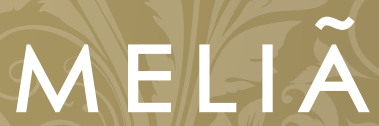

HOTELS

INTERNATIONAL CUBA 
1714 Franklin Street, Suite 100-282 Oakland, CA 94612 USA www.mediccreview.org

$$
\begin{array}{ccc}
\sqrt{\mathcal{T}}_{\text {Paper from }} \\
\text { FSC }
\end{array}
$$

